\title{
Reacciones en fase líquida para la obtención de hidrógeno y biopropilenglicol a partir de glicerol
}

\author{
Tesis de Doctorado \\ María Laura Barbelli \\ Presentada ante la Facultad de Ingeniería de la \\ Universidad Nacional de La Plata \\ como requisito para la obtención del grado académico de
}

\section{DOCTOR EN INGENIERÍA}

Dirección de tesis:

Dra. Nora Nancy Nichio, Dr. Gerardo Fabian Santori

Jurado de Tesis:

Dr. John Múnera, Dra. María Cristina Abello, Dra. Norma Elvira Amadeo

Fecha de la defensa oral: 08 de Septiembre de 2016 


\section{Agradecimientos}

En primer lugar quiero agradecer a mis seres queridos, mi familia, mi compañero de camino Sebastián y mis amigos, me siento bendecida por tenerlos en mi vida.

Quiero agradecer a mis directores Nora y Gerardo y a mi grupo de trabajo, Francisco, Ivana y Martín, por toda la ayuda y apoyo que me brindaron.

A todo el personal del CINDECA, por la ayuda recibida.

A la Agencia Nacional de Promoción científica y técnica ANPCyTy a la UNLP por el apoyo recibido a través de la beca PRH que me ha sido otorgada para la realización de esta Tesis.

Al Centro de Investigación y Desarrollo en Procesos Cataliticos (CINDECA), donde pude desarrollar las experiencias de laboratorio necesarias para la elaboración de este trabajo.

Al Departamento de Ingeniería Química de la Facultad de Ingeniería de la UNLP.

Al Laboratorio Nacional de Luz Sincrotrón (LNLS) de Campinas Brasil por el financiamiento parcial de los experimentos EXAFS realizados en la línea XAS del $L N L S$. 


\section{ÍNDICE}

Página

Índice

Resumen

Capítulo I. Introducción, antecedentes y objetivos

I.1. Introducción

I.2. Aprovechamiento de biomasa

I.2.1. Materias primas provenientes de la biomasa

I.2.2. Biomasa de primera generación

I.2.3. Biomasa de segunda generación 5

I.2.4. Biomasa de tercera generación 5

$\begin{array}{ll}\text { I.2.5. Preocupaciones ambientales del uso de biomasa } & 6\end{array}$

I.3. Valorización del glicerol como producto de biomasa 7

I.4. Principales vías de valorización del glicerol. Antecedentes 9

$\begin{array}{ll}\text { I.4.1. Oxidación selectiva } & 10\end{array}$

$\begin{array}{ll}\text { I.4.2. Deshidratación } & 11\end{array}$

$\begin{array}{ll}\text { I.4.3. Esterificación } & 12\end{array}$

I.4.4. Hidrogenólisis $\quad 12$

$\begin{array}{ll}\text { I.4.5. Obtención de hidrógeno y/o gas de síntesis } & 15\end{array}$

$\begin{array}{ll}\text { Reformado con agua en fase líquida } & 16\end{array}$

$\begin{array}{ll}\text { I.4.5.1. Estudios con catalizadores monometálicos } & 16\end{array}$

$\begin{array}{ll}\text { I.4.5.2. Estudios con catalizadores bimetálicos } & 27\end{array}$

I.5. Conclusiones del capítulo y objetivos planteados 32

$\begin{array}{ll}\text { I.6. Referencias } & 34\end{array}$ 
II.1 Introducción $\quad 40$

$\begin{array}{ll}\text { II.2. Técnicas de preparación } & 40\end{array}$

II.2.1. Método de impregnación a humedad incipiente 41

II.2.2. Preparación de catalizadores por el método de impregnación a humedad 42 incipiente

II.2.3. Método de impregnación por Intercambio Iónico 43

II.2.4. Preparación de Catalizadores por el método de intercambio iónico 46

II.2.5. Método de la Química Organometálica de Superficies sobre Metales 47 (QOMS/M)

II.2.6. Preparación de sistemas bimetálicos por el método QOMS/M 48

II.3. Técnicas de Caracterización $\quad 49$

II.3.1. Determinación de la superficie específica de los soportes (BET) 49

II.3.2. Quimisorción dinámica de $\mathrm{H}_{2}$

II.3.3. Microscopía Electrónica de Transmisión (TEM) 53

II.3.4. Difracción de rayos X (DRX) 54

II.3.5. Reducción a Temperatura Programada (TPR) 57

II.3.6. Reacción de descomposición del alcohol isopropílico (IPA) 58

$\begin{array}{ll}\text { II.3.7. Espectroscopía RAMAN } & 60\end{array}$

II.3.8. Espectroscopía Fotoelectrónica de Rayos X (XPS) 61

II.3.9. Espectroscopía de Absorción de Rayos X (EXAFS) 63

$\begin{array}{ll}\text { II.4. Evaluación catalítica } & 68\end{array}$

$\begin{array}{ll}\text { II.4.1. Esquema y descripción del equipo } & 68\end{array}$

$\begin{array}{ll}\text { II.4.2. Procedimiento del test de reacción } & 70\end{array}$

$\begin{array}{ll}\text { II.4.3. Análisis de los productos de reacción } & 71\end{array}$

II.4.4. Cálculos de conversión y selectividad 71

$\begin{array}{ll}\text { II.4.5. Repetibilidad de resultados } & 72\end{array}$

$\begin{array}{ll}\text { II.5. Referencias } & 73\end{array}$ 
$\begin{array}{ll}\text { III.1. Introducción } & 76\end{array}$

III.2. Determinación de condiciones experimentales 77

III.2.1. Verificación de la ausencia de control difusional 77

III.2.2. Efecto de la temperatura $\quad 78$

Calculo de Energía de Activación $\quad 80$

III.2.3. Efecto de la presión $\quad 82$

III.2.4. Efecto del tiempo de reacción $\quad 84$

III.3. Resultados del reformado de metanol, etanol, etilenglicol, propilenglicol, 86 acetol y glicerol

$\begin{array}{ll}\text { III.3.1. Reformado en fase líquida de metanol } & 87\end{array}$

III.3.2. Reformado en fase líquida de etanol 88

III.3.3. Reformado en fase líquida de Etilenglicol (EG) 89

III.3.4. Reformado en fase líquida de propilenglicol (PG) 94

III.3.5. Reformado en fase líquida de Acetol (AC) 98

III.3.6. Esquema de reacciones del glicerol 102

III.4. Conclusiones del capítulo 105

III.5. Referencias 106

Capítulo IV. Reformado en fase líquida de glicerol sobre catalizadores de Pt 108 soportados

IV.1. Resumen 109

$\begin{array}{ll}\text { IV.2. Introducción } & 109\end{array}$

IV.3. Efecto del tamaño de partícula

IV.3.1. Preparación y caracterización de catalizadores 111

IV.3.2. Resultados del APR de glicerol con catalizadores $\mathrm{Pt} / \mathrm{SiO}_{2} \quad 112$

IV.3.3. Resultados del APR de glicerol con catalizadores $\mathrm{Pt} / \gamma-\mathrm{Al}_{2} \mathrm{O}_{3} \quad 114$

IV.4. Efecto del soporte $\quad 115$

IV.4.1. Preparación y caracterización de catalizadores 115 
IV.4.2. Resultados del APR de glicerol sobre catalizadores de Pt sobre distintos soportes

IV.5. Estudio de la estabilidad

IV.6. Conclusiones del capítulo

IV.7. Referencias

Capitulo V. Hidrogenólisis de glicerol en fase líquida con catalizadores de $\mathrm{PtSn} / \mathrm{SiO}_{2}$

V.1. Resumen del capítulo 135

V.2. Introducción

V.3. Preparación y caracterización de los catalizadores bimetálicos Pt-Sn 137

V.4. Resultados catalíticos en la hidrogenólisis del glicerol

V.4.1. Ensayos bajo presión de $\mathrm{N}_{2}$ 143

V.4.2. Ensayos bajo presión de $\mathrm{H}_{2}$ 144

$\begin{array}{ll}\text { V.5. Conclusiones del capítulo } & 144\end{array}$

$\begin{array}{ll}\text { V.6. Referencias } & 145\end{array}$

Capítulo VI. Hidrogenólisis de glicerol en fase liquida con un catalizador de PtNi/CZA

VI.1. Resumen del capítulo

VI.2. Introducción

VI.3. Preparación de catalizadores

VI.4. Resultados de caracterización de catalizadores 148

VI.5. Resultados catalíticos 155

VI.6. Análisis de la estabilidad 158

VI.7. Conclusiones del capítulo 165

VI.8. Referencias 166 
$\begin{array}{ll}\text { VII.1. Conclusiones generales } & 169\end{array}$

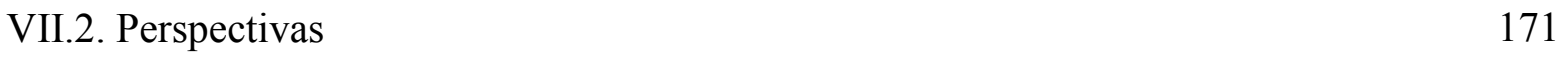

Anexo I. Protocolo operativo de la preparación de catalizadores bimetálicos

PtSn

Anexo II. Calibraciones cromatográficas

Anexo III. Resultados TEM y XPS

190 


\section{Resumen}

En los últimos años se han dictado a nivel nacional una serie de leyes y normativas (algunas de ellas: Ley 26.093/06, Ley $\mathrm{N}^{0} 26.190 / 06$ y Ley $\mathrm{N}^{\circ} 26334 / 08$ ) tendientes a lograr el afianzamiento y crecimiento de los biocombustibles. Este marco legal ha dado un fuerte impulso a la producción de biodiesel y bioetanol. Los procesos involucrados producen cantidades importantes de subproductos, los cuales pueden constituir materias primas de excelente calidad para su transformación en productos de mayor valor agregado. Entre ellos se encuentra el glicerol, principal subproducto del biodiesel.

Por otra parte, el hidrógeno se considera un combustible limpio y eficiente, que produce un mínimo de emisiones cuando se quema. El beneficio de generar hidrógeno se plantea cuando se utilizan fuentes renovables y con un requerimiento energético bajo.

Sin embargo, la conversión de biomasa a hidrógeno representa un desafío debido a la menor velocidad de producción de $\mathrm{H}_{2}$ y a la complejidad del proceso si se lo compara con el reformador de gas natural. El rendimiento a $\mathrm{H}_{2}$, la presencia de $\mathrm{CO}_{2}$ o $\mathrm{CO}$ en la corriente, y la formación de $\mathrm{CH}_{4} \mathrm{u}$ otros alcanos, dependerá fundamentalmente de cómo se conduce la reacción de reformado y del catalizador utilizado. El desarrollo de un eficiente proceso de reformación es imperativo para que el proceso global sea factible.

Los productos derivados de la biomasa, como glicerol, también pueden ser transformados, en productos de mayor valor agregado, por reacciones como hidrogenólisis, oxidación, deshidratación, esterificación, etc. En particular la reacción de hidrogenólisis de glicerol conduce a la obtención de bio-glicoles, tales como etilenglicol y propilenglicol, que son utilizados por la industria, principalmente como anticongelantes.

Este trabajo de Tesis se refiere al estudio de las reacciones en fase líquida del glicerol para obtener hidrógeno y productos de mayor valor agregado como el propilenglicol, poniendo especial énfasis en el desarrollo de catalizadores metálicos soportados.

El Capítulo I presenta un análisis bibliográfico sobre los procesos de reformación e hidrogenólisis en fase líquida. Se incluye un análisis del estado del conocimiento, en lo que respecta al desarrollo y funcionamiento de catalizadores para la obtención de hidrógeno y propilenglicol. De este análisis surge que el estudio de catalizadores de Pt es interesante para obtener hidrógeno, debido a su excelente actividad para el reformado en fase líquida. Sin embargo, para obtener propilenglicol por hidrogenólisis del glicerol 
es necesario modificar los catalizadores de Pt. Para esto se plantearon dos estrategias en la formulación de la fase metálica. En la primera, se propone el agregado de pequeñas cantidades de $\mathrm{Sn}$ como promotor del $\mathrm{Pt}$ utilizando técnicas de la Química Organometálica de Superficies sobre Metales. En la segunda, se plantea desarrollar un catalizador bimetálico PtNi a partir de técnicas convencionales.

El Capítulo II trata sobre la preparación de los catalizadores. Se detallan además las técnicas experimentales utilizadas para la caracterización y la evaluación de propiedades catalíticas, explicando la selección de las variables operativas para los diferentes ensayos.

El Capítulo III presenta los primeros resultados de los ensayos experimentales de la reacción del glicerol en fase líquida (APR) para obtener hidrógeno. Empleando un catalizador de $\mathrm{Pt} / \gamma-\mathrm{Al}_{2} \mathrm{O}_{3}$ se logró estudiar el efecto de las principales variables operativas (temperatura, presión, masa de catalizador y tiempo de reacción) sobre los productos de reacción. Para identificar los principales compuestos intermediarios y laterales de reacción, se realizaron en ensayos de APR con etilenglicol, propilenglicol, acetol, metanol y etanol para determinar la diferente reactividad de estos compuestos a las reacciones de ruptura $\mathrm{C}-\mathrm{C}$ y $\mathrm{C}-\mathrm{O}$.

En la primera parte del Capítulo IV, se analiza el efecto del tamaño de partícula y el rol del soporte sobre la actividad y selectividad a productos gaseosos y líquidos en el APR del glicerol. Para analizar el efecto del tamaño de partícula metálica, se prepararon catalizadores de $\mathrm{Pt} / \mathrm{SiO}_{2}$ y $\mathrm{Pt} / \gamma-\mathrm{Al}_{2} \mathrm{O}_{3}$ empleando diferentes métodos que permitan obtener diferentes tamaños de partícula metálica. Para estudiar el efecto del soporte se utilizaron óxidos con diferentes propiedades acidas superficiales y propiedades redox como: $\mathrm{SiO}_{2}, \gamma-\mathrm{Al}_{2} \mathrm{O}_{3}, \alpha-\mathrm{Al}_{2} \mathrm{O}_{3}$ y $\alpha-\mathrm{Al}_{2} \mathrm{O}_{3}$ modificada con Ce y Zr. Finalmente, con el catalizador Pt soportado sobre $\alpha-\mathrm{Al}_{2} \mathrm{O}_{3}$ modificada con Ce y $\mathrm{Zr}$, que resultó más activo y selectivo para la producción de hidrógeno, fue estudiada la estabilidad.

El Capítulo V está dirigido al estudio de la hidrogenólisis de glicerol utilizando catalizadores de $\mathrm{Pt}$ y $\mathrm{PtSn}$ soportados sobre $\mathrm{SiO}_{2}$ preparados mediante técnicas controladas de preparación derivadas de la Química Organometálica de Superficies sobre Metales (QOMS/M). Se analiza el efecto de la presión inicial de $\mathrm{H}_{2}$ y la influencia del contenido de $\mathrm{Sn}$. Los resultados demuestran que el $\mathrm{Sn}$, en una concentración muy baja del $0,12 \%$ en peso, es capaz de mejorar las propiedades catalíticas del Pt en la hidrogenólisis del glicerol. 
Con el objetivo de mejorar la selectividad a propilenglicol se utiliza otra estrategia en el diseño del catalizador que consiste en el estudio del efecto de una fase bimetálica PtNi, presentado en el Capítulo VI. Además, los resultados de la caracterización estructural realizada por Espectroscopia de Absorción Extendida de Estructura Fina (EXAFS), TEM, DRX y XPS de los catalizadores frescos y usados se utilizan para correlacionar la estructura con la perfomance catalítica y la estabilidad.

Finalmente, en el Capítulo VII, se presentan las conclusiones consideradas más importantes, discutidas y señaladas a lo largo de esta presentación. 
Capítulo I

Introducción, antecedentes y

objetivos 


\section{Capítulo I. Introducción, antecedentes y objetivos}

\section{I.1. Introducción}

En esta última década se ha propuesto el uso de fuentes de energías renovables como una alternativa más viable para solucionar los problemas asociados a la creciente demanda de energía, la necesidad de proteger el medio ambiente y el requerimiento de una mejor calidad de vida.

El carbono es el elemento básico de las moléculas orgánicas ya que todos los seres vivos están compuestos por el mismo. Las plantas, mediante el proceso fotosintético transforman el $\mathrm{CO}_{2}$ atmosférico en materia viva compuesta por carbono. El $\mathrm{CO}_{2}$ es necesario para el mantenimiento de la vida del planeta puesto que junto con otros gases mantiene una adecuada temperatura de la superficie terrestre, sin embargo, una concentración excesiva de dicho gas en la atmósfera está ocasionando un serio problema. El sector energético es el principal responsable de las emisiones a la atmósfera de $\mathrm{CO}_{2} \mathrm{y}$ otros gases de efecto invernadero y, por lo tanto, se los señala como responsables del calentamiento global del planeta que acelera el cambio climático. Actualmente, la mayor parte de la energía que se consume mundialmente proviene de la combustión térmica de combustibles fósiles (petróleo, carbón, gas natural). En Argentina se consume el combustible fósil principalmente para la producción de electricidad en usinas térmicas y en el transporte vehicular. En nuestro país además se utiliza la energía hidráulica en una alta proporción en la matriz energética. Los problemas medioambientales causados por la dependencia de combustibles fósiles combinados con la disminución de las reservas de petróleo, impulsan la búsqueda de nuevas fuentes renovables de energía.

Los impactos ambientales directos de la industria del petróleo son muy variados. Impactos en las zonas de extracción, debido al transporte del petróleo y también los impactos en las refinerías donde se procesa el petróleo o donde se consumen los derivados del mismo, siendo el tráfico la principal causa de la contaminación de las aglomeraciones urbanas. Todos ellos contribuyen además al agravamiento del cambio climático. Pese a esto, el petróleo es la principal fuente energética global. 
Reducir el consumo de energía y aumentar nuestra capacidad de producción a partir de fuentes de energía renovable puede ser el primer paso para abandonar nuestra dependencia al petróleo crudo.

En los últimos tiempos se ha impulsado la búsqueda de posibles fuentes alternativas de energía, así como materia prima para químicos de alto valor agregado. Entre las energías alternativas más estudiadas se encuentra la energía solar, energía eólica, energía geotérmica, energía mareomotriz, energía proveniente de la biomasa, etc. Dejando el tipo de energía nuclear a un lado, aunque ésta no sea de la forma tradicional de energía petróleo-dependiente, la energía nuclear es limpia a nivel de emisiones, pero presenta un grave problema de residuos, además de su dependencia con un recurso no renovable como lo es el uranio. La dificultad más importante de estos tipos de energía surge en el almacenamiento y el trasporte al lugar de consumo. Para reducir los impactos ambientales, una buena solución sería la descentralización y producción de energía donde fuera consumida, y para ello es necesario pequeñas infraestructuras con bajo impacto ambiental y alta eficiencia.

\section{I.2. Aprovechamiento de Biomasa}

\section{I.2.1. Materias primas provenientes de la biomasa}

En la actualidad, la energía derivada de la biomasa suplanta un 6\% de la energía mundial total anual de consumo primaria y $\sim 75 \%$ de la energía derivada de fuentes alternativas $[\mathbf{1}, \mathbf{2}]$. 


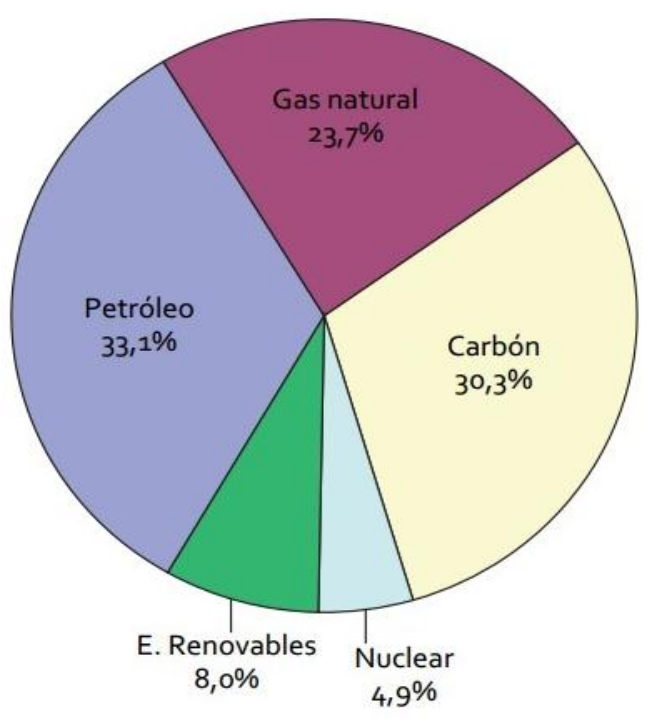

Figura I-01. Matriz de consumo energético mundial Fuente: BP Statistical Review of World Energy Junio 2016

Actualmente, solo el $2 \%$ de la energía obtenida a partir de biomasa es utilizada en el sector de transporte mientras que el resto es en general para uso doméstico [3, 4]. Los combustibles para transporte derivados de biomasa (por ejemplo: biofuels) se producen utilizando materias primas de cultivos agrícolas convencionales (primera-generación), cultivos lignocelulósicos y desechos agrícolas (segunda-generación) u organismos microscópicos (tercera-generación) [5]. Las materias primas de biomasa se clasifican de acuerdo al tipo de materiales utilizados para su obtención como también de acuerdo a los procesos de transformación.

\section{I.2.2. Biomasa de primera generación}

La biomasa de primera generación consiste en una materia prima alimenticia proveniente del sector agricultor como por ejemplo maíz, trigo, caña de azúcar y semillas oleaginosas. Esta materia prima básica generalmente se cosecha con un alto contenido de carbohidratos y/o aceite, y se transforman en combustibles como el biodiesel (bio-ésteres), alcoholes y biogás (mezclas de $\mathrm{CH}_{4}$ y $\mathrm{CO}_{2}$ ). Los cultivos convencionales se encuentran disponibles en grandes cantidades ya que se producen en gran escala para el consumo humano y animal. Actualmente, los cultivos comestibles más populares explotados para la producción de biocombustibles son: caña de azúcar 
(en Brasil para bioetanol), maíz (en Estados Unidos para bioetanol), colza (en varias naciones Europeas para biodiesel) y soja (en Argentina y Brasil para biodiesel) [6].

\section{I.2.3. Biomasa de segunda generación}

A medida que la demanda de energía renovable se incrementa exponencialmente, la producción de materia prima de primera generación se vuelve limitada ya que se necesitan grandes superficies en zonas tropicales y templadas para su cultivo o más bien monocultivo, con el consecuente desmonte de cultivos herbáceos de estas regiones. Por otra parte, la directa competencia de los biocombustibles con el alimento humano y animal resulta en un aumento significativo de los precios de estos cultivos (o más bien de los alimentos provenientes de ellos). Los "feedstock" de segunda generación son no comestibles comprendiendo materias primas derivadas de biomasa lingocelulósica y desechos o desperdicios de cultivos de procesos agrícolas y forestales [7]. Estas materias primas son más convenientes para la producción de combustibles ya que su utilización no impacta en la industria alimenticia. En concordancia, la biomasa de segunda generación puede ser cultivada en gran escala con el único propósito de producir energía. Sin embargo, los procesos de conversión (por ejemplo: conversión termoquímica y conversión bioquímica) son mucho más complejos y sofisticados debido a la naturaleza de la biomasa celulósica, asociada a su composición con complejos polisacáridos, como lo es la celulosa, hemicelulosa y lignina.

En conclusión, debido a este cuello de botella en el esquema productivo, los feedstock de segunda generación no poseen un costo competitivo con los combustibles fósiles existentes. Hasta la fecha, los cultivos energéticos de mayor interés son: las hierbas perennes (como el pasto varilla y Miscanthus) y los cultivos energéticos leñosos (como polares, sauces y eucaliptos) $[8,9]$.

\section{I.2.4. Biomasa de tercera generación}

Mientras que actualmente se estudia una alta variedad de colonias de bacterias fermentativas y fotosintéticas y de algas como biocatalizadores, también son reconocidos como excelentes feedstock, constituyendo los feedstock de tercera generación, principalmente por su alto contenido en aceite/lípidos, hidratos de carbono o proteínas. En comparación con los feedstock de primera y segunda generación, estas 
células microbianas se pueden obtener con altos rendimientos en bioreactores sin el requerimiento de tierras de cultivo e insumos agrícolas (por ejemplo, fertilizantes, agua y pesticidas) $[10,11]$. Se estima que en un futuro las microalgas pueden producir 10300 veces más aceite (usado para la producción de biodiesel) que los cultivos convencionales y dedicados a la producción de energía [10].

\section{I.2.5. Preocupaciones ambientales del uso de biomasa}

Aunque la aplicación de biocombustibles, en principio, puede mitigar el impacto ambiental asociado al uso de combustibles fósiles, varios estudios indican que el cultivo a gran escala para abastecer la demanda de combustibles puede producir daños irreparables al medio ambiente.

De manera que si se quisiera abarcar la demanda total con biocombustibles, la estrategia sería la de implementar un aumento significativo en la producción de la agricultura, lo que acarrearía, por ejemplo, los siguientes impactos ambientales:

- pérdida de biodiversidad

- introducción de semillas transgénicas las cuales son altamente invasivas

- liberación de agro-contaminantes (pesticidas, herbicidas y fertilizantes) en sistemas acuáticos

- incremento en las emisiones globales de NOx [12-17]

En primer lugar y ante todo, la demanda de tierras para producir cultivos con fines energéticos no puede desplazar el cultivo para fines alimenticios. Por otra parte, la introducción de monocultivos puede afectar el eco-equilibrio existente de ciertas regiones, especialmente si esas semillas con fines energéticos son invasivas y/o transgénicas. Sumado a que, sin una gestión adecuada de nutrientes, los monocultivos pueden agotar en el lapso de pocos años los nutrientes esenciales del suelo [12-17]. Algunos de los problemas asociados con el monocultivo pueden ser mitigados a través de innovaciones agrotécnicas para la mejora de prácticas agrícolas. Por ejemplo, la competencia con los cultivos alimentarios se pueden evitar con la producción de ciertos cultivos energéticos de segunda generación con bajas demandas de agroquímicos en tierras marginales [17]. Otra estrategia que carece de competencia por la tierra es el cultivo a gran escala de microalgas en estanques abiertos y canales. Además, las 
microalgas pueden cultivarse en aguas residuales contaminadas para eliminar los contaminantes ambientales $[18, \mathbf{1 9}]$. Los biocombustibles son cuestionados ya que no quedan claros sus reales beneficios para el medio ambiente. Existen estudios [20] que sugieren que el uso de bioetanol producido a partir de cultivos de biomasa de primera generación puede generar la misma cantidad de emisiones gaseosas de efecto invernadero o hasta mayor que el uso de gasolina. Sin embargo, el bioetanol y otros biocombustibles derivados de materias primas celulósicas de segunda generación pueden reducir potencialmente las emisiones de gases de efecto invernadero en un 85 $\%$. Por ejemplo, el uso de residuos de cultivos podría reducir las emisiones gaseosas de efecto invernadero en un $50 \%$ [21]. Según estudios recientes [15], el uso de biodiesel puede disminuir las emisiones de $\mathrm{NOx}$ en un $10 \%$, las de $\mathrm{CO}_{2}$ en un $45 \%$, las de hidrocarburos en un $65 \%$, y óxidos de sulfuro en un $100 \%$.

A pesar de esta situación preocupante desde el punto de vista ambiental, no deberían considerarse a los biocombustibles como el fin en sí mismo, sino como un escalón fundamental para avanzar hacia la próxima generación en donde la energía renovable sea predominante en la matriz energética mundial.

\section{I.3. Valorización del glicerol como producto de biomasa}

Dentro de las materias primas provenientes de biomasa de primera generación se encuentra el glicerol. La principal fuente de obtención es de la corriente de residuos procedente de la transesterificación de aceites vegetales y grasas animales para la producción de biodiesel. Estos residuos contienen glicerol en agua en altas concentraciones (por ejemplo, $80 \% \mathrm{p} / \mathrm{p}$ ), y de esta manera la venta de soluciones de residuos de biodiesel puede reducir los costos de producción del mismo. El glicerol también puede ser producido a partir de biomasa de segunda generación: por fermentación de azúcares como la glucosa, ya sea directamente o como un subproducto de la conversión industrial de la lignocelulosa en etanol. Aunque la fermentación de la glucosa produzca etanol en concentraciones de alrededor del 5\% en peso en agua, puede llevarse a cabo para producir glicerol en concentraciones de al menos $25 \%$ en peso [22]. Otra fuente de obtención del glicerol natural deriva de la reacción de saponificación e hidrólisis de plantas oleoquímicas en la manufactura de jabones, mientras que el glicerol sintético deriva de la oxidación y cloración del propileno [23]. Además el glicerol 
también se puede obtener a partir de la fermentación microbiana [24] aunque su escala de producción es muy pequeña.

El glicerol se utiliza directamente en grado puro en varios mercados debido a sus extraordinarias cualidades, lo que da lugar a una gran cantidad de aplicaciones, con más de 1500 usos en distintos sectores, tales como:

1. Sector alimentario, que es el que más lo consume (con casi un $24 \%$ ) y que además continúa presentando un crecimiento constante año tras año (cercano al 4\%). En este sector se utiliza principalmente como conservante de productos, dada su habilidad para absorber la humedad del ambiente, y también tiene uso como aditivo (fuente de carbohidratos) o endulzante. Además, y debido a que es inocuo para el ser humano, se suele utilizar en la industria alimenticia como lubricante en los equipos de la línea de fabricación

2. Sector farmacéutico, a la par que el alimentario (con un porcentaje próximo al $24 \%$ ), en este sector se utiliza principalmente como agente edulcorante y aditivo, mayoritariamente en productos como pastas de dientes (sector que consume prácticamente el $80 \%$ ), o como lubricante o plastificante en diversos productos

3. Sector de la industria cosmética, con un consumo también muy elevado (próximo al 23\%) donde el glicerol se utiliza dadas sus propiedades emolientes y su capacidad de absorber el agua

4. Sector tabaquero, con un consumo sobre el total del $11 \%$, donde se utiliza como humectante en el propio proceso de tratamiento de las hojas, como aditivo del tabaco o incluso como tratamiento del papel de lijar, al que proporciona plasticidad para su manejo

El glicerol además se emplea como materia prima en otros procesos como en la fabricación de espumas de poliuretano, resinas, plásticos, pinturas, explosivos, curtiembre, y más recientemente como sustituto de glicoles en anticongelantes, etc.

Respecto al glicerol crudo, éste posee un precio más estable y es menos del tercio del costo del glicerol puro [25]. Se han desarrollado técnicas de purificación como filtración, microfiltración y ultrafiltración utilizando membranas de polímeros orgánicos, destilación simple, destilación al vacío, tratamientos físicos y químicos, $\mathrm{y}$ técnicas de adsorción por intercambio iónico. Finalmente es posible conseguir el glicerol altamente purificado combinando dos o más de estas técnicas [26]. Sin 
embargo, los tratamientos "downstream" como la destilación para refinar el crudo de glicerol son caros, especialmente para plantas de biodiesel de baja escala.

Respecto a su utilización como combustible, el glicerol no puede ser quemado directamente ya que polimeriza a altas temperaturas y produce por combustión incompleta acroleína, la cual es altamente tóxica. Por esto las aplicaciones directas del glicerol crudo son escasas, por lo que actualmente es común eliminar o almacenar el exceso de glicerol crudo en los procesos de obtención de biodiesel [25]. La acumulación del glicerol crudo no solo frena el desarrollo de la industria del biodiesel, sino que además crea problemas económicos y ambientales. Con el aumento de la producción de biodiesel, el glicerol se enfrenta a un reto de investigación y desarrollo. Por ello, se deben buscar nuevas salidas y aplicaciones al producto final o bien encontrar nuevas aplicaciones en las que se utilice glicerol como materia prima química [27].

\section{I.4. Principales vías de valorización del glicerol. Antecedentes}

El glicerol se utiliza como materia prima para obtener productos de mayor valor agregado. Las posibilidades de transformación química del glicerol son múltiples por reacciones como la carboxilación, la oxidación o la deshidratación de este compuesto.

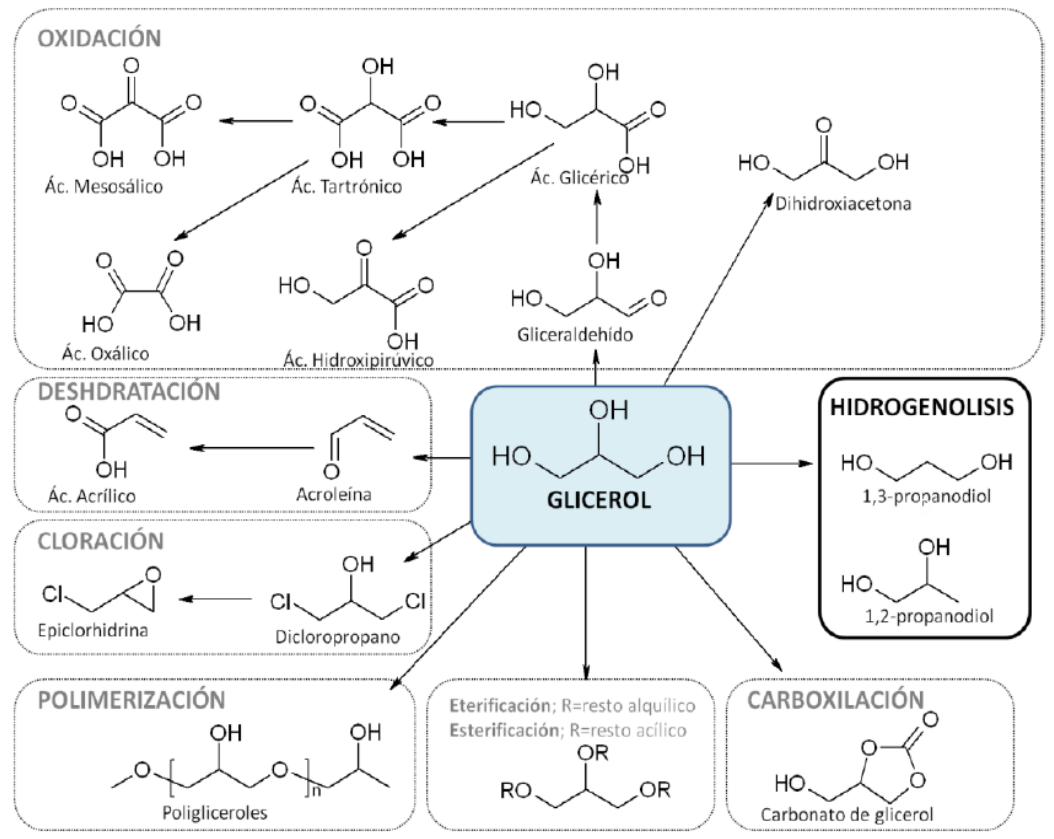

Figura I-02. Vías de valorización del glicerol 
De esta forma ya existen procesos, con sus correspondientes patentes, para producir entre otros:

- Metanol a partir de la hidrogenólisis catalítica del glicerol, con aplicaciones prácticas en multitud de operaciones en la industria química y petroquímica

- Ácido oxálico mediante la oxidación del glicerol con ácido nítrico, usado principalmente como agente quelante

- Ácido acrílico mediante oxidación catalítica, muy utilizado para pinturas, adhesivos y recubrimientos

- Propanol mediante reducción por hidrogenación catalítica del glicerol, que podría utilizarse tanto en la industria química o incluso recircularse al propio proceso de obtención de biodiesel

- Aditivos oxigenados (GTBE) para combustibles diesel, mediante procesos de eterificación

También existen procesos de transformación biológica del glicerol (conocidos como bioprocesos) que, al igual que ocurre en el caso de la generación del biogás, podrían utilizar el glicerol como sustrato o co-sustrato para generar, mediante digestión, ácidos grasos esenciales, propilenglicol, etanol, etc.

El glicerol está convirtiéndose poco a poco en una plataforma para la generación de nuevos compuestos e incluso nuevas soluciones energéticas, como las que se mencionan a continuación:

\section{I.4.1. Oxidación selectiva}

De la oxidación del glicerol se puede obtener un gran número de productos tales como la dihidroxiacetona, ácido glicérico, ácido hidroxipirúvico, ácido tartrónico y ácido láctico [28-32]. Estos productos son de valioso interés ya que se pueden utilizar como compuestos intermedios en la síntesis de productos de química fina y de nuevos polímeros [33], además de su uso como agentes quelantes.

En la oxidación del glicerol, la distribución de los productos depende de la selectividad que posea el catalizador para activar el grupo hidroxi primario o secundario de la molécula y de las condiciones de reacción. Al oxidarse el grupo secundario hidroxi del glicerol, se forma la di-hidroxiacetona. Este producto, además de su utilización en 
cosméticos, también tiene otras aplicaciones como monómero principal en la producción de biomateriales poliméricos. Al oxidarse el grupo hidroxi primario del glicerol se forma gliceraldehído. La oxidación adicional de este producto produce ácidos carboxílicos empleados como polímeros o emulsionantes biodegradables [34]. Carrettin y col. [35] obtuvieron 100\% de selectividad a ácido glicérico de la oxidación del $56 \%$ de conversión de glicerol empleando catalizadores de $\mathrm{Au} / \mathrm{C}$ a $50{ }^{\circ} \mathrm{C}, 30 \mathrm{bar}$ presión de $\mathrm{O}_{2}$ y una relación molar de glicerol/ $\mathrm{NaOH}$ igual a 1. Bajo las mismas condiciones, Chinchilla y col. [36] reportaron que el glicerol se oxida a ácido glicérico con un rendimiento del $76 \%$, con $100 \%$ de conversión para catalizadores de Ru$\mathrm{Au} / \mathrm{Ce}-\mathrm{Zr}-\mathrm{O}$.

\section{I.4.2. Deshidratación}

De la deshidratación del glicerol se puede obtener acroleína o bien hidroxiacetona (acetol) dependiendo del proceso utilizado. Los catalizadores ácidos son eficaces en la producción de acroleína $[37,38]$ mientras que el cobre cataliza selectivamente la deshidratación del glicerol en hidroxiacetona [39]. El acetol forma parte del principio activo básico del que se componen todas las cremas solares bronceadoras. La acroleína obtenida por este medio puede reemplazar la producción a partir de la vía no renovable de oxidación del propileno (derivado del petróleo). Para obtener acroleína a partir de la deshidratación del glicerol, en fase líquida o en fase gas, se emplean catalizadores heterogéneos como zeolitas y alúminas. La acroleína también es un intermediario importante en la producción del ácido acrílico y sus ésteres, y en la obtención de polímeros superabsorbentes o detergentes [33].

Tsukuda y col. [40] investigaron la producción de acroleína a partir de la deshidratación en fase vapor del glicerol sobre catalizadores heteropoliácidos soportados en sílice. En su estudio lograron alcanzar una selectividad a acroleína del $85 \%$ a $275^{\circ} \mathrm{C}$ y a 1 bar de presión. Corma y col. [37] obtuvieron acroleína como producto principal mediante reacción en fase gaseosa del glicerol, con zeolitas como catalizadores, en un reactor de lecho fluidizado. En el trabajo realizado por Sato y col. [39] el reformado en fase vapor de trioles y dioles sobre catalizadores de cobre impregnados en diferentes soportes mostró que el cobre es un metal eficaz en la deshidratación del glicerol para producir hidroxiacetona a $250{ }^{\circ} \mathrm{C}$ y presión atmosférica. 


\section{I.4.3. Esterificación}

La esterificación del glicerol produce poligliceroles y ésteres de poligliceroles. En la actualidad estos productos se utilizan como tensioactivos biodegradables, lubricantes, cosméticos y aditivos en los alimentos, además forman parte del metacrilato $\mathrm{y}$ se utilizan para tratamientos en la madera para mejorar su estabilidad. Los poligliceroles y los ésteres de poligliceroles se obtienen a partir de la oligomerización del glicerol y la esterificación o transesterificación de los oligómeros con ácidos grasos o ésteres de metilo, en el cual las unidades de glicerol se van uniendo a través de sus grupos hidroxi primarios. Las reacciones se realizan en presencia de catalizadores, los catalizadores homogéneos pueden producir oligómeros principalmente lineales, mientras que con los catalizadores heterogéneos predominan los oligómeros ramificados [33, 41].

\section{I.4.4. Hidrogenólisis}

Se ha demostrado que por hidrogenólisis selectiva del glicerol en presencia de catalizadores metálicos y de hidrógeno se obtiene 1,2-propanodiol y/o 1,3-propanodiol, productos de partida para la fabricación de polímeros, o etilenglicol. El 1,3-propanodiol es un producto químico de alto valor que se utiliza principalmente en fibras de poliéster, policarbonatos, poliuretanos y recubrimientos. El 1,2-propanodiol se usa en la fabricación de resinas de poliéster, detergentes líquidos, productos farmacéuticos, aditivo en cosméticos, sabores y fragancias, pinturas, como fluido hidráulico, lubricante o agente anticongelante, como producto de partida para disolventes, emulsionantes y plastificantes.

Desde un punto de vista netamente comercial, la conversión de glicerol a 1,2propanodiol o propilenglicol (PG) resulta un descubrimiento de suma importancia para la nueva química del glicerol. El propilenglicol es un commodity químico tradicionalmente obtenido a partir del óxido de propileno. Por lo que la fuerte dependencia con el petróleo crudo ha causado inestabilidad en su precio y en la oferta. La disponibilidad y abundancia de bioglicerol de menor costo podría solucionar este inconveniente.

La hidrogenólisis de glicerol a propilenglicol ha sido reportada utilizando varios catalizadores a base de metales de transición, tales como $\mathrm{Ru}, \mathrm{Pt}, \mathrm{Cu}$, Ni [42-48], y sistemas bimetálicos de Pt-Ru, Ru-Re, etc [49-51]. Se ha reportado que la actividad del 
$\mathrm{Ru}$ es mayor pero con menor selectividad que el Pt. En el caso de catalizadores bimetálicos de Ru-Re se encontró un efecto promotor del Re sobre la actividad del catalizador, si bien la selectividad fue similar al catalizador monometálico de Ru.

Existen diferentes vías para efectuar el proceso de hidrogenólisis del glicerol hacia el producto 1,2-propanodiol. Montassier y col. [52] lo estudiaron bajo flujo de $\mathrm{H}_{2}$, a 260 ${ }^{\circ} \mathrm{C}$, empleando catalizadores $\mathrm{Cu}-\mathrm{Raney}, \mathrm{Ru}, \mathrm{Rh}$ e Ir. Observaron que en presencia del catalizador Cu-Raney el principal producto de reacción es el 1,2-propanodiol, mostrando una actividad hidrogenolítica pobre hacia los enlaces $\mathrm{C}-\mathrm{C}$, pero siendo un catalizador eficaz para la hidrogenación y deshidrogenación de los enlaces C-O.

Por otro lado, la hidrogenólisis del glicerol sobre catalizadores heterogéneos en flujo de $\mathrm{H}_{2}$ a $180{ }^{\circ} \mathrm{C}$ fue investigada por Chaminad y col. [53]. Estos autores emplearon catalizadores basados en $\mathrm{Cu}, \mathrm{Pd}$ y $\mathrm{Rh}$ soportados en $\mathrm{ZnO}$, carbono y alúmina utilizando diferentes disolventes (agua, sulfolano y dioxanos). Además, añadieron un aditivo (ácido túngstico, $\mathrm{H}_{2} \mathrm{WO}_{4}$ ) que modifica y mejora la selectividad. Obtuvieron como resultado el $100 \%$ de selectividad a 1,2-propanodiol usando como disolvente agua en presencia del catalizador $\mathrm{CuO} / \mathrm{ZnO}$. También, Dasari y col. [54] emplearon el proceso de hidrogenólisis a partir de una disolución concentrada de glicerol. El catalizador más eficaz fue el cromito de cobre, produciendo un 73\% de 1,2-propanodiol en condiciones moderadas de reacción (flujo de $\mathrm{H}_{2}$ a 14 bar de presión y $200{ }^{\circ} \mathrm{C}$ de temperatura). Los autores propusieron un mecanismo de reacción en dos etapas. La primera etapa implica la formación de la hidroxiacetona por deshidratación del glicerol llevada a cabo a presión atmosférica, mientras que en la segunda etapa ocurre la hidrogenación de la hidroxiacetona, la cual requiere de una presión parcial de hidrógeno.

Debdut y col. [55] reportaron, en 2010, la hidrogenólisis en fase acuosa del glicerol a 1,2-propanodiol empleando un catalizador mezcla $5 \% \mathrm{p} / \mathrm{p} \mathrm{Ru} / \mathrm{Al}_{2} \mathrm{O}_{3}$ y $5 \% \mathrm{p} / \mathrm{p} \mathrm{Pt} / \mathrm{Al}_{2} \mathrm{O}_{3}$ en cantidades variables, sin agregado externo de hidrógeno, debido a que se utiliza el hidrógeno generado in-situ por reformado en fase líquida del glicerol. Luego de 6 horas de reacción en modo batch, se observó que la mezcla de catalizadores de $\mathrm{Ru}$ y Pt, a 220 ${ }^{\circ} \mathrm{C}$, permitió obtener mejor rendimiento a 1,2-propanodiol que con los catalizadores individuales de Pt y Ru. En idénticas condiciones de funcionamiento, una experiencia de hidrogenólisis de glicerol en presencia de $\mathrm{H}_{2}$ (41 bar), mostró una menor selectividad a 1,2-propanodiol (31,9\%) que sin el agregado de $\mathrm{H}_{2}$ (47,2\%). Con la adición externa de hidrógeno, la disponibilidad de hidrógeno en exceso promueve la transformación de CO 
y $\mathrm{CO}_{2}$ en metano y otros alcanos, lo que afectan negativamente a la selectividad a 1,2propanodiol.

Guo y col. [56] sintetizaron catalizadores de $\mathrm{Cu}$ soportados para la obtención de propanodioles. Entre los catalizadores de $\mathrm{Cu}$ soportados sobre $\gamma-\mathrm{Al}_{2} \mathrm{O}_{3}$, zeolita $\mathrm{HY}$, zeolita $13 \mathrm{X}$, zeolita HZSM-5 y zeolita $\mathrm{Hb}$, el de mejor performance fue el $\mathrm{Cu} / \gamma-\mathrm{Al}_{2} \mathrm{O}_{3}$. A diferencia que la mayoría de los metales preciosos, se suprimió completamente el anclaje y ruptura de enlaces $\mathrm{C}-\mathrm{C}$ sobre los catalizadores $\mathrm{Cu} / \gamma-\mathrm{Al}_{2} \mathrm{O}_{3}$ sin sacrificar la conversión del glicerol. Las condiciones moderadas de reacción fueron: $220^{\circ} \mathrm{C}, 15$ bar de presión inicial de $\mathrm{H}_{2}, 10 \mathrm{~h}$ de reacción y una relación molar $\mathrm{Cu} /$ glicerol=3:100.

Dasari y col. [57] estudiaron la hidrogenólisis del glicerol utilizando catalizadores de níquel, paladio, platino, cobre o cromito de cobre soportados sobre $\mathrm{C}$, alúmina y sílicealúmina, evaluando el efecto de la temperatura, presión de hidrógeno, contenido inicial de agua, tipo de catalizador, temperatura de reducción de catalizador y cantidad del mismo. A temperatura por encima de $\operatorname{los} 200^{\circ} \mathrm{C}$ y presiones de hidrógeno de 13,8 bar, observaron una disminución en la selectividad a propilenglicol debido a la hidrogenólisis del mismo. Mientras que obtuvieron una alta selectividad y buenas conversiones a temperaturas de $200{ }^{\circ} \mathrm{C}$ y presiones de $\mathrm{H}_{2}$ de 13,8 bar, observaron que con la disminución del contenido de agua en la alimentación aumentó el rendimiento de PG. Propusieron y validaron el camino de reacción a través del intermediario acetol. Entre todos los catalizadores estudiados el más efectivo fue el catalizador de cromito de cobre. La selectividad a PG obtenida en condiciones medias de reacción fue mayor al $73 \%$.

Sin embargo, en la obtención del 1,3-propanodiol los catalizadores heterogéneos no son muy selectivos. Los sistemas más notorios para convertir el glicerol a 1,3-propanodiol son los catalizadores homogéneos como el complejo $\left[\mathrm{Rh}(\mathrm{CO})_{2}\right.$ (acuo.)] que conduce a una conversión selectiva del 21\% a 1,3-propanodiol a temperatura ambiente y presión atmosférica, así como algunos biocatalizadores. Algunas enzimas y microorganismos pueden convertir el glicerol en 3-hidroxipropanal mediante una reacción enzimática en un solo paso, a temperatura ambiente y presión atmosférica, con rendimientos del 85\% de manera altamente selectiva [58]. 


\section{I.4.5. Obtención de hidrógeno y/o gas de síntesis}

El hidrógeno se considera un combustible limpio y eficiente, que produce un mínimo de emisiones cuando se quema directamente o en combinación con combustibles de hidrocarburos. Éste, además, puede ser utilizado en celdas de combustible de manera de generar energía con $\mathrm{H}_{2} \mathrm{O}$ como principal subproducto. Mientras el uso del hidrógeno en celdas de combustible tiene bajo impacto ambiental, no ocurre lo mismo con los procesos de generación de hidrógeno, en especial cuando se utilizan procesos de reformado con vapor o "steam reforming" de hidrocarburos fósiles. El beneficio de generar hidrógeno se plantea cuando se utilizan fuentes renovables y con un requerimiento energético bajo. En el caso de esta tesis se estudiará la obtención de $\mathrm{H}_{2}$ a partir de glicerol como fuente renovable.

Aunque existen experiencias ya realizadas de cogeneración de combustible mediante combustión directa de glicerol, este tipo de prácticas están siendo actualmente abandonadas debido a los problemas técnicos que supone su combustión, que debe realizarse con temperaturas de llama de unos $1000{ }^{\circ} \mathrm{C}$ y tiempos de residencia de unos 5 segundos para evitar la generación de acroleína. Como alternativa más rentable está surgiendo, en los últimos años, los procesos termoquímicos utilizados para la oxidación del glicerol a altas temperaturas generando así combustibles que pueden utilizarse en la generación energética (ya sea mediante gasificación o pirólisis). En concreto, la gasificación del glicerol parece ser una alternativa bastante viable para su valorización energética, especialmente cuando se produce con vapor de agua o agua supercrítica, aunque estos procesos actualmente están todavía en fase de estudio y desarrollo.

También ha sido reportado en la literatura el tratamiento hidrotérmico de biomasa y compuestos relacionados, como una posible tecnología para la producción de hidrógeno. Sin embargo, la conversión de biomasa a hidrógeno representa un desafío debido a la menor velocidad de producción de $\mathrm{H}_{2}$ y a la complejidad del proceso si se lo compara con el reformador de gas natural. La conversión de biomasa a hidrógeno es un proceso que requiere de varias etapas. Primero resultan necesarias etapas de extracción y obtención de una corriente acuosa de compuestos oxigenados o carbohidratos a partir de la biomasa. Posteriormente, esta corriente constituirá la alimentación para la reformación que permitirá producir $\mathrm{H}_{2}, \mathrm{CO}_{2}, \mathrm{CO}$ y/o alcanos. El rendimiento a $\mathrm{H}_{2}$, la presencia de $\mathrm{CO}_{2}$ o $\mathrm{CO}$ en la corriente, y la formación de $\mathrm{CH}_{4} \mathrm{u}$ otros alcanos, dependerá fundamentalmente de cómo se conduce la reacción de reformado y del 
catalizador utilizado. El desarrollo de un proceso eficiente de reformación es indispensable si se pretende que el proceso global sea factible.

Los carbohidratos y los polioles (como glicerol, etilenglicol, sorbitol, etc.) pueden convertirse en $\mathrm{H}_{2}, \mathrm{CO}_{2}$ y/o alcanos, en el proceso de reformado con agua, utilizando catalizadores metálicos heterogéneos a temperaturas próximas a $250{ }^{\circ} \mathrm{C}$ para la reacción en fase líquida, mientras que las reacciones en fase vapor requieren temperaturas mayores a $350{ }^{\circ} \mathrm{C}$. Aun así, estos niveles térmicos son notablemente inferiores a las temperaturas cercanas a $800{ }^{\circ} \mathrm{C}$ requeridas por los reformadores convencionales de gas natural.

En 2002, el grupo de investigación del profesor Dumesic (Cortright y col. [59]) informó por primera vez el reformado en fase líquida (APR) de compuestos oxigenados que fueron elegidos como modelo de biomasa, demostrando la capacidad de producción de hidrógeno en un reactor de flujo a temperaturas $\left(\sim 225^{\circ} \mathrm{C}\right)$ muy inferiores a las requeridas para la pirólisis o gasificación.

\section{Reformado con agua en fase líquida}

\section{I.4.5.1. Estudios con catalizadores monometálicos}

El proceso de reformado en fase líquida de compuestos oxigenados fue estudiado, como se mencionó, en un comienzo por Cortright y col. [59]. Estos autores emplearon catalizadores $3 \% \mathrm{p} / \mathrm{p} \quad \mathrm{Pt} / \mathrm{Al}_{2} \mathrm{O}_{3}$ a 225 y $265{ }^{\circ} \mathrm{C}$ y presiones de 29 y 53 bar, respectivamente, utilizando varias moléculas modelo como reactivo. Los autores encontraron que este catalizador fue activo en la reacción de reformado en fase líquida con una selectividad a $\mathrm{H}_{2}$ en el orden: Metanol > Etilenglicol > Glicerol > Sorbitol > Glucosa. Menores temperaturas de operación resultaron en mayores selectividades a $\mathrm{H}_{2}$, a costa de menores conversiones. La selectividad para la producción de alcanos siguió una tendencia opuesta a la selectividad de producción de $\mathrm{H}_{2}$. Obtuvieron una baja concentración de $\mathrm{CO}$, en el orden de las ppm.

En el 2003, Davda y col. [60] testearon el grupo VIII de metales sobre sílice como soporte. La reacción de reformado se llevó a cabo con etilenglicol a 22 bar, $210^{\circ} \mathrm{C}$ y $225^{\circ} \mathrm{C}$. Ni, Pd, Pt, Ru y $\mathrm{Rh}$ exhibieron actividad catalítica. Ir presentó muy baja selectividad en las condiciones de trabajo. $\mathrm{Ni}$ y $\mathrm{Ru}$ presentaron altas velocidades de producción de $\mathrm{CO}_{2}$, sin embargo la selectividad a $\mathrm{H}_{2}$ fue baja y exhibieron 
desactivación con el tiempo de operación. Pt presentó una buena estabilidad en las experiencias a temperaturas más altas, pero $\mathrm{Rh}$ y $\mathrm{Pd}$ exhibieron las mejores estabilidades. Además, indicaron que $\mathrm{Rh}$ presentó bajas selectividad a $\mathrm{H}_{2}$ y baja actividad. Pt y Pd presentaron selectividades mayores, pero el Pt mostró una mayor actividad catalítica que el Pd. Por otra parte, los autores destacaron que el Ni experimentó la mayor desactivación.

En otro de sus trabajos [61] realizaron el reformado en fase líquida de metanol y etilenglicol sobre catalizadores de $\mathrm{Pt} / \mathrm{Al}_{2} \mathrm{O}_{3}$ a 210 y $225{ }^{\circ} \mathrm{C}$. Obtuvieron una mayor producción de hidrógeno a partir del metanol en comparación con el etilenglicol, debido a que los productos líquidos producidos a partir del etilenglicol cubren la superficie y desactivan los catalizadores.

En el 2003, Shabaker y col. [62] realizaron un estudio con catalizadores de Pt sobre distintos soportes, en condiciones de $210{ }^{\circ} \mathrm{C}$ y $225{ }^{\circ} \mathrm{C}$, presiones de 22,4 y 29,3 bar, respectivamente, y $10 \% \mathrm{p} / \mathrm{p}$ de etilenglicol. Los autores observaron una buena estabilidad, excepto para $\mathrm{SiO}_{2}$ y $\mathrm{CeO}_{2}$. El orden de los catalizadores soportados respecto a la producción de hidrógeno fue: $\mathrm{PtTiO}_{2}>\mathrm{PtAl}_{2} \mathrm{O}_{3}$, Ptcarbón, Pt-black $>$ $\mathrm{PtSiO}_{2}-\mathrm{Al}_{2} \mathrm{O}_{3}, \mathrm{PtZrO}_{2}>\mathrm{PtCeO}_{2}, \mathrm{PtZnO}, \mathrm{PtSiO}_{2}$. Los catalizadores de Pt con soportes $\mathrm{Al}_{2} \mathrm{O}_{3}$ y $\mathrm{ZrO}_{2}$ fueron activos para el reformado y selectivos para la producción de hidrógeno, mientras que Pt/carbón, $\mathrm{Pt} / \mathrm{TiO}_{2}, \mathrm{Pt} / \mathrm{SiO}_{2}-\mathrm{Al}_{2} \mathrm{O}_{3}$ y Pt-black fueron activos en la producción de alcanos y otros subproductos líquidos, siendo el soporte carbonoso el que presentó la mayor selectividad a alcanos gaseosos.

Posteriormente el grupo de Dumesic [63] realizó experiencias de reformado en fase líquida, empleando soluciones acuosas al $10 \% \mathrm{p} / \mathrm{p}$ de sorbitol y glucosa, a $265{ }^{\circ} \mathrm{C}$ y 52,4 bar sobre catalizadores de $\mathrm{Pt} / \mathrm{Al}_{2} \mathrm{O}_{3}$. Los ensayos permitieron obtener alta conversión de productos gaseosos. Para la glucosa, la selectividad a $\mathrm{H}_{2}$ fue de $10-13 \%$, mientras para el sorbitol la selectividad a $\mathrm{H}_{2}$ fue mucho mayor, aproximadamente $60 \%$. Tanksale y col. [64] estudiaron el reformado en fase líquida de productos directos de la biomasa (azúcares), analizando el efecto de la variación en la alimentación, temperatura y tipo de catalizador. Además, los autores discutieron el efecto del coque depositado durante el reformado. Para el estudio utilizaron catalizadores preparados por impregnación húmeda y por el método de co-síntesis: $\mathrm{Pt} / \gamma-\mathrm{Al}_{2} \mathrm{O}_{3}, \mathrm{Pt} / \mathrm{ZrO}_{2}, \mathrm{Pt} / \mathrm{CeAl}$, $\mathrm{Pt} / \gamma-\mathrm{Al}_{2} \mathrm{O}_{3}$ (comercial), $\mathrm{Ni} / \mathrm{g}-\mathrm{Al}_{2} \mathrm{O}_{3}, \mathrm{Ni} / \mathrm{ZrO}_{2}, \mathrm{Ni} / \mathrm{CeAl}$ (soporte obtenido por la técnica de sol gel (relación molar Ce:Al de 1:500)). La alimentación que utilizaron fue etilenglicol, glucosa, fructuosa, sacarosa y una mezcla de glucosa y fructuosa. Todas las 
soluciones fueron al $20 \% \mathrm{p} / \mathrm{p}$ de carbohidratos en agua. El reactor fue un reactor discontinuo. La reacción se llevó a cabo a 185, 200 y $220^{\circ} \mathrm{C}$ a 27,6 bar. El tiempo de reacción fue de 8 a 10 h. Los autores encontraron que la velocidad de formación de hidrógeno dependió del metal utilizado como catalizador encontrándose un orden en la actividad de $\mathrm{Pt}>\mathrm{Pd}>\mathrm{Ni}$. Respecto a los soportes utilizados el orden de actividad encontrado fue: $\mathrm{Pt} / \gamma-\mathrm{Al}_{2} \mathrm{O}_{3}>\mathrm{Pt} / \mathrm{ZrO}_{2},>\mathrm{Pt} / \mathrm{CeAl}$. Esto pudo deberse al orden de su acidez bronsted: $\gamma-\mathrm{Al}_{2} \mathrm{O}_{3}>\mathrm{ZrO}_{2}>\mathrm{CeAl}$. A temperaturas de $220^{\circ} \mathrm{C}$ el reformado de glucosa mostró desactivación luego de 3 horas (disminución de velocidad de formación de hidrógeno), lo que pudo deberse a la formación de intermediarios tales como éteres aromáticos y éteres que no toman parte en las reacciones de reformado por la presencia de enlaces $\mathrm{C}-\mathrm{O}$ en sus moléculas. Menores temperaturas en el reformado de glucosa produjeron alcoholes y ácidos (C1-C4) como intermediarios que son mucho más selectivos para la formación de hidrógeno. La naturaleza del coque depositado fue de tipo amorfo y también levemente cristalino. Identificando la fuente de los diferentes tipos de carbones, les fue posible minimizar la deposición, inhibiendo las reacciones de formación de carbón. Un resultado interesante fue que para el catalizador preparado por co-síntesis, antes de la reacción el soporte no presenta la fase $\gamma-\mathrm{Al}_{2} \mathrm{O}_{3}$, mientras que el catalizador post reacción si la evidencia. Este cambio en la fase de la alúmina pudo deberse al efecto del agua a altas temperaturas y presiones. Los autores vieron por imágenes SEM de los catalizadores $\mathrm{Pd} / \gamma-\mathrm{Al}_{2} \mathrm{O}_{3}$ impregnado que el carbón depositado luego de la reacción con glucosa o etilenglicol es de distinta morfología.

Luo y col. [65] estudiaron el efecto de la carga de Pt. Compararon cuatro porcentajes diferentes de Pt en el APR de glicerol en condiciones $220{ }^{\circ} \mathrm{C}, 25$ bar de presión y $5 \%$ $\mathrm{p} / \mathrm{p}$ de glicerol. El rendimiento a $\mathrm{H}_{2}$ y conversión de $\mathrm{C}$ a gas, para distintas cargas metálicas, fue en el orden: $0,9 \% \mathrm{p} / \mathrm{p}>0,6 \% \mathrm{p} / \mathrm{p} \sim 1,2 \% \mathrm{p} / \mathrm{p}>0,3 \% \mathrm{p} / \mathrm{p}$ de Pt. Sin embargo, todos los catalizadores mostraron similar selectividad a $\mathrm{H}_{2} \mathrm{y} \mathrm{CH}_{4}$, de $70 \%$ y $30 \%$ respectivamente, así como también similar relación $\mathrm{H}_{2} / \mathrm{CO}_{2}$. La producción de metano es acompañada por una disminución de la producción de $\mathrm{H}_{2}$. De los análisis termodinámicos, estos autores concluyeron que cuanto más cerca sea la presión de trabajo a la presión de saturación del agua, menor es el nivel de CO producido. Las condiciones de $220^{\circ} \mathrm{C}$ y 25 bar fueron las más adecuadas para el reformado en fase liquida. Con una concentración mayor de glicerol en la alimentación, se puede producir un menor rendimiento a hidrógeno pero una mayor selectividad. Cambiando el LHSV 
no se modificó la desactivación del catalizador significativamente, pero menores valores pueden facilitar la conversión de glicerol a hidrógeno. Con menores LHSV, la relación $\mathrm{H}_{2} / \mathrm{CO}_{2}$ es más cercana al valor teórico de 2,33.

Lehnert y Claus [66] estudiaron diferentes propiedades de los catalizadores de Pt, así como el tamaño de la partícula del metal o soporte. La reacción se llevó a cabo en un reactor de flujo utilizando una concentración $10 \% \mathrm{p} / \mathrm{p}$ de glicerol. El reactor se presurizó con Argón a 20 bar y la temperatura se fijó en $250{ }^{\circ} \mathrm{C}$. Los catalizadores preparados a partir de distintos precursores mostraron actividades y selectividades a hidrógeno similares. La conversión del glicerol fue de un $45 \%$, la selectividad a hidrógeno fue de $85 \%$ mientras que la composición molar fue de CO (0,2 \%molar), $\mathrm{CO}_{2}$ (32\%molar) y metano (3,2\%molar). En todos los experimentos con catalizadores de distintos tamaños de partículas (1,6-3,2 nm) observaron una conversión a gas de $20 \%$. Con el aumento del tamaño de partículas de Pt notaron un aumento en la selectividad a hidrógeno. Los autores compararon los soportes: Catapal B, Puralox ${ }^{\circledR}$, una mezcla de fases $\gamma$-, $\delta$ - y $\theta-\mathrm{Al}_{2} \mathrm{O}_{3}$ y $\gamma-\mathrm{Al}_{2} \mathrm{O}_{3}$. El catalizador soportado en Puralox ${ }^{\circledR}$ dió la mayor actividad catalítica. La selectividad se mantuvo constante en $85 \%$ en todas las experiencias. Se compararon catalizadores 1, 3, 5 y $10 \%$ p/p de Pt. La mayor velocidad de producción de hidrógeno fue observada para el catalizador con $10 \% \mathrm{de} \mathrm{Pt}$, debido a que los tamaños de partículas se incrementan con los porcentajes más altos de metal.

Murata y col. [67] estudiaron catalizadores $5 \% \mathrm{p} / \mathrm{p}$ Pt sobre soportes ácidos tales como $\mathrm{H}-Z \mathrm{SM}$, $\mathrm{H}$-Mordenite, $\gamma-\mathrm{Al}_{2} \mathrm{O}_{3}$, USY y Beta, para producir alcanos en presencia de $\mathrm{H}_{2}$. Las reacciones se llevaron a cabo en un reactor batch por $12 \mathrm{~h}$ a $270{ }^{\circ} \mathrm{C}$ y 20 bar de presión inicial de $\mathrm{H}_{2} / \mathrm{N}_{2}=90: 10$. Los resultados indicaron que el catalizador Pt/H-ZSM5 $\left(\mathrm{Si} / \mathrm{Al}_{2}=29\right)$ resultó muy activo para el reformado del glicerol. La conversión a productos gaseosos fue $80,2 \%$ con una selectividad a propano de $35,4 \%$. Otros productos fueron etano y $\mathrm{CO}_{2}$ y en menor cantidades $\mathrm{CH}_{4}$, hidrocarburos $\mathrm{C}_{4}-\mathrm{C}_{7}$ y $\mathrm{CO}$. El orden de producción de propano fue: $\mathrm{H}-\mathrm{ZSM} 5>\mathrm{H}-\mathrm{MOR}>\gamma-\mathrm{Al}_{2} \mathrm{O}_{3}>\mathrm{USY}>$ Beta $>$ $\mathrm{SiO}_{2}$.

Cruz y col. [68] estudiaron el reformado en fase líquida de etanol en un reactor Parr, utilizando $200 \mathrm{~mL}$ de solución $1 \%$ de etanol, $100 \mathrm{mg}$. de catalizador y condiciones de temperatura entre $200{ }^{\circ} \mathrm{C}$ y $250^{\circ} \mathrm{C}$ con presiones entre 15 bar y 39 bar. Los catalizadores estudiados fueron a base de $\mathrm{Ni}$ con contenidos de 10, 20 y $30 \%$ sobre hidrotalcitas modificadas con Mg-Al (HTLC). A $200{ }^{\circ} \mathrm{C}$, el catalizador 10NiHTC exhibió la mejor 
performance. Para todos los catalizadores, la selectividad a $\mathrm{H}_{2}$ varió entre 60 y $75 \%$, y la selectividad a $\mathrm{CO}_{2}$ entre $10-15 \%$. El catalizador $20 \mathrm{NiHTC}$ presentó la mayor selectividad a $\mathrm{H}_{2}, 78 \%$ luego de 25 h de tiempo de reacción a $230^{\circ} \mathrm{C}$. La selectividad a $\mathrm{CH}_{4}$ es cercana a $12 \%$. La mayor selectividad a hidrogeno y la baja actividad para la metanación de los catalizadores a base de hidrotalcitas comparados a un catalizador impregnado pudo deberse a diferencias en la dispersión. Este efecto es similar a la adicción de Sn al Ni reportado por Shabaker y col. [69].

Wen y col. [70] analizaron el efecto del metal (Pt, Ni, Co y $\mathrm{Cu}$ ) así también como el efecto del soporte $\left(\mathrm{Al}_{2} \mathrm{O}_{3}, \mathrm{SiO}_{2}, \mathrm{AC}, \mathrm{MgO}\right.$, HUSY y SAPO-11), sobre la actividad y estabilidad en la reacción de APR de glicerol. El reformado en fase líquida de $10 \% \mathrm{p} / \mathrm{p}$ de glicerol se realizó en un reactor continuo a $230{ }^{\circ} \mathrm{C}$ y 32 bar por $4 \mathrm{~h}$. Se observó que el rendimiento a hidrógeno decreció en el orden: $\mathrm{Pt}>\mathrm{Cu}>\mathrm{Ni}>\mathrm{Co}$. El catalizador $\mathrm{Pt} / \mathrm{Al}_{2} \mathrm{O}_{3}$ no solo dio un alto rendimiento inicial a $\mathrm{H}_{2}$ sino que también fue estable con el tiempo de reacción. Por el contrario, los catalizadores de Ni y Co mostraron una baja actividad inicial, y también exhibieron una importante desactivación con el tiempo. Se observó grandes cantidades de carbón en el catalizador de Ni y Co. Respecto de los diferentes soportes, se determinó que la actividad total se incrementa en el siguiente orden: SAPO$11<\mathrm{AC}<\mathrm{HUSY}<\mathrm{SiO}_{2}<\mathrm{MgO}<\mathrm{Al}_{2} \mathrm{O}_{3}$. Se obtuvieron altas concentraciones molares de hidrógeno y bajas de alcanos sobre soportes básicos como el $\mathrm{MgO}$, y altas concentraciones molares de alcanos sobre los soportes ácidos como HUSY y $\mathrm{Al}_{2} \mathrm{O}_{3}$ neutra. Los catalizadores soportados sobre $\mathrm{Al}_{2} \mathrm{O}_{3}, \mathrm{SiO}_{2}, \mathrm{AC}$, y HUSY fueron estables con el tiempo de reacción, sin embargo $\mathrm{MgO}$ y SAPO-11 mostraron una notable desactivación. Se encontraron altas concentraciones molares de alcanos sobre el soporte $\mathrm{Al}_{2} \mathrm{O}_{3}$, que fue atribuido a los sitios ácidos. Se observó la formación de una fase de $\mathrm{MgCO}_{3}$ sobre el $\mathrm{Pt} / \mathrm{MgO}$ durante la reacción, indicando la severa adsorción de $\mathrm{CO}_{2}$ en las condiciones de reacción. Se encontraron trazas de carbón depositado sobre los soportes de todos los catalizadores excepto los soportados sobre $\mathrm{MgO}$.

Wawrzetz y col. [71] estudiaron el APR del glicerol en agua con catalizadores bifuncionales de $\mathrm{Pt} / \mathrm{Al}_{2} \mathrm{O}_{3}$. Los niveles de conversión fueron mantenidos entre 7 a $10 \%$. La Influencia del tamaño de partícula se estudió con una solución $20 \%$ p/p de glicerol, $225^{\circ} \mathrm{C}$ y 29 bar. Los productos gaseosos formados principales fueron hidrógeno y dióxido de carbono con una baja concentración de alcanos $\left(\mathrm{C}_{1}-\mathrm{C}_{3}\right)$ y $\mathrm{CO}$. Los productos líquidos principales fueron: 1,2-propilenglicol, hidroxiacetona, 1,2-etilenglicol y etanol. La conversión del glicerol varió muy poco con el tamaño de partícula, en cambio la 
distribución de los productos se vio más afectada. La selectividad a reformado (manifestado por el $\mathrm{H}_{2}$ y $\mathrm{CO}_{2}$ ) disminuyo con el aumento de tamaño de partícula desde $35 \%$ a $21 \%$. El CO se incrementó con el aumento del tamaño de partícula en paralelo con la formación de alcanos livianos. Los autores estudiaron la influencia de la concentración de glicerol, la presión total y conversión con $3 \% \mathrm{p} / \mathrm{p} \mathrm{Pt} / \mathrm{Al}_{2} \mathrm{O}_{3}$ a $225^{\circ} \mathrm{C} \mathrm{y}$ 29 bar de presión. Los valores de TOF $\left(\mathrm{mol} /\left(\mathrm{mol}^{\mathrm{Pt}} * \mathrm{~min}\right)\right)$ del glicerol y de los productos principales se incrementó con el aumento en la concentración de alimentación de glicerol. Respecto a la presión total del sistema, la conversión total del glicerol no se vio afectada, sin embargo la selectividad lo hizo drásticamente. La fracción de moléculas convertidas a $\mathrm{H}_{2}$ y $\mathrm{CO}_{2}$ disminuyó de $43 \%$ a 26 bar a $12 \%$ a 45 bar.

Menezes y col. publicaron en el 2010 [72] un trabajo que muestra el comportamiento de catalizadores de Pt (con 1,13 y 1,49\% p/p), en el reformado de glicerol evaluado con un reactor batch a $225^{\circ} \mathrm{C}$ y presión autógena de 23 bar, con $100 \mathrm{~mL}$ de solución al $1 \% \mathrm{p} / \mathrm{p}$ de glicerol y 3 horas de reacción. Utilizaron distintos soportes en base de óxidos como $\mathrm{Al}_{2} \mathrm{O}_{3}, \mathrm{ZrO}_{2}, \mathrm{MgO}$ y $\mathrm{CeO}_{2}$. Todos los catalizadores permiten obtener una fase de gas rica en hidrógeno. Sin embargo, una alta producción de hidrógeno y una baja concentración de hidrocarburos se logró sobre los catalizadores soportados en $\mathrm{MgO}$ y $\mathrm{ZrO}_{2}$. El alto carácter de donación de electrones del $\mathrm{MgO}$ indicó la influencia de la naturaleza del soporte en el rendimiento para el reformado de glicerol.

Tokarev y col. [73] estudiaron el reformado en fase acuosa sobre catalizadores $5 \% \mathrm{p} / \mathrm{p}$ $\mathrm{Pt} / \mathrm{Al}_{2} \mathrm{O}_{3}$ a $225^{\circ} \mathrm{C}$, utilizando un reactor de flujo. El caudal de solución de alimentación fue de $0,1 \mathrm{~mL} / \mathrm{min}$. La presión interna fue mantenida a 29,3 bar, y el caudal de nitrógeno fue de $30 \mathrm{~mL} / \mathrm{min}$. Se utilizaron soluciones de sorbitol, etanol, glicerol, y mezclas de sorbitol-etanol y glicerol-etanol. El incremento en la formación de productos en fase líquida fue indicativo de la desactivación del catalizador. La razón principal de desactivación en el caso del sorbitol fue la formación de carbón. En el APR del etanol, observaron un $98,3 \%$ de conversión, con la siguiente distribución de productos expresada en fracción molar: $\mathrm{H}_{2}=0,44 ; \mathrm{CO}_{2}=0,22 ; \mathrm{CH}_{4}=0,19 ; \mathrm{CO}=0,10$. En la fase líquida analizada por HPLC, se observó solo etanol y ácido acético. En el APR del glicerol observaron una conversión casi completa $(96,4 \%)$. Experimentalmente se obtuvo un menor contenido de $\mathrm{H}_{2}$ respecto a lo esperado por estequiometría. En los productos líquidos se observaron ácido acético, hidroxiacetona, acetaldehído y etanol. En el APR del sorbitol se observó mayor cantidad de subproductos líquidos y una 
relación $\mathrm{H}_{2} / \mathrm{CO}_{2}$ muy lejana a la esperada por estequiometría. Por el agregado de etanol al APR de glicerol y sorbitol no se ha observado la formación de ácido acético y acetaldehído. La explicación probable es que el etanol actúa como una trampa de aldehídos convirtiéndolos a hemiacetales y acetales, evitando la condensación de aldehídos a subproductos más pesados. Por este motivo, los autores recomiendan al etanol como un posible solvente para el proceso de APR de compuestos de fuentes renovables.

Wen y col. [74] estudiaron los siguientes catalizadores: $5 \% \mathrm{p} / \mathrm{p} \mathrm{Pt} / \mathrm{C}, 5 \% \mathrm{p} / \mathrm{p} \mathrm{Pd} / \mathrm{C}, 5$ $\% \mathrm{Ir} / \mathrm{C}, 20 \% \mathrm{Ni} / \mathrm{C} 20 \% \mathrm{Co} / \mathrm{C}$ preparados por el método de reducción-precipitación con formaldehído. Utilizaron como materias primas algunos derivados de celulosa como algodón desgrasado, papel de filtro y celulosa microcristalina, además de glucosa y sorbitol. Los autores informaron que la selectividad y la producción de hidrógeno para el reformado de celulosa fue significantemente mayor que el reformado de la glucosa y comparable con el reformado de sorbitol. También se demostró que este proceso involucra la hidrólisis lenta de la celulosa a glucosa y el posterior reformado de la glucosa a $\mathrm{H}_{2}$ (reacción rápida). La alta eficiencia para la producción de $\mathrm{H}_{2}$ se atribuyó a la baja velocidad de hidrólisis de la celulosa, la que fue catalizada por la presencia de $\mathrm{H}^{+}$reversibles formados en el agua durante la reacción.

Manfro y col. [75] prepararon catalizadores de níquel soportados en $\mathrm{CeO}_{2}$ y los evaluaron en el APR de glicerol en fase líquida. Se utilizaron tres metodologías diferentes de síntesis: impregnación húmeda, co-precipitación y combustión. La reacción se llevó a cabo en un reactor tipo Batch con soluciones de 1 y $10 \%$ p/p de glicerol, a temperaturas de 250 y $270^{\circ} \mathrm{C}$. Se alcanzó una conversión máxima de glicerol de $30 \%$ utilizando el catalizador preparado por combustión, operando a $270{ }^{\circ} \mathrm{C}$ con solución $1 \%$ de concentración de glicerol. En la fase gaseosa, la fracción molar de $\mathrm{H}_{2}$ fue siempre mayor a $70 \%$ y la formación de $\mathrm{CH}_{4}$ fue pequeña (aprox. $1 \%$ ). El incremento de la concentración del glicerol produjo una disminución en la conversión y en la formación de $\mathrm{H}_{2}$. El catalizador preparado por combustión tiene la menor superficie específica, sin embargo, los cristalitos de Ni formados en la reducción son los más pequeños, indicando una buena dispersión metálica. El catalizador de $\mathrm{Ni} / \mathrm{CeO}_{2}$ mostró un gran potencial para ser utilizado en el reformado en fase líquida de glicerol, con una buena actividad y una alta producción de hidrógeno, lo que puede ser relacionado con los pequeños tamaños de partícula de Ni. Se alcanzó una conversión máxima de glicerol utilizando una solución $1 \%$ a $270{ }^{\circ} \mathrm{C}$ de reacción con una fracción 
molar de $\mathrm{H}_{2}$ mayor a $70 \%$. Este catalizador preparado sobre soporte de cerio presentó menor formación de metano que los catalizadores de bibliografía soportados sobre alúmina. Los catalizadores mostraron baja conversión de glicerol a $250{ }^{\circ} \mathrm{C}$ debido a la oxidación de los sitios activos de Ni y los depósitos de carbón.

Ozgur y Uysal [76] estudiaron catalizadores $1 \% \mathrm{p} / \mathrm{p} \mathrm{Pt} / \mathrm{Al}_{2} \mathrm{O}_{3}$ en un reactor batch para investigar el efecto de la temperatura, y en un reactor continuo estudiaron el efecto de la relación del caudal de alimentación y la concentración de glicerol sobre el rendimiento a hidrógeno. De manera de estudiar el efecto de la temperatura utilizaron una concentración del $80 \% \mathrm{p} / \mathrm{p}$ de glicerol (para simular la corriente de salida de glicerol del proceso de biodiesel), y temperaturas entre 160 y $280^{\circ} \mathrm{C}$. Observaron que a medida que aumenta la temperatura también aumentan los productos de reacción. Cuando se pasa de $160{ }^{\circ} \mathrm{C}$ a $280^{\circ} \mathrm{C}$ el hidrógeno decrece de $71 \%$ a $44 \%$, mientras que la concentración de $\mathrm{CO}_{2}$ y otros hidrocarburos aumentan. Por encima de $230{ }^{\circ} \mathrm{C}$ se observan muchos productos de hidrocraqueo. La temperatura óptima para la producción de hidrógeno por APR fue de $230{ }^{\circ} \mathrm{C}$. Para el estudio del efecto del caudal y la concentración de alimentación se utilizaron caudales de 0,01-0,5 $\mathrm{mL} / \mathrm{min}$ y concentraciones entre 5 y $80 \%$ p/p de glicerol. La mayor producción de gases se obtuvo con el menor caudal a todas las concentraciones. La producción de gases a un caudal fijo se incrementa con la disminución de concentración. Esto lo explican mediante la estequiometria de la reacción donde el exceso de agua beneficia la formación de productos. La composición de los gases se modifica con la concentración de glicerol de la alimentación. El contenido de metano y etano decrece con el aumento de la concentración de glicerol. Los hidrocarburos de mayor peso molecular fluctúan pero se ve un aumento a mayores concentraciones de glicerol. La velocidad máxima de producción de hidrógeno se obtuvo con caudales de $0,1 \mathrm{~mL} / \mathrm{min}$ en la alimentación, lo que corresponde a un LHSV de $0,73 \mathrm{~h}^{-1}$. Analizando diferentes concentraciones de glicerol se encontró que cuando la concentración es menor a $45 \% \mathrm{p} / \mathrm{p}$, es posible alcanzar una concentración de hidrógeno de $67 \%$ en los productos gaseosos.

Ciftci y col. [77] estudiaron el APR de glicerol en un reactor continuo a $225^{\circ} \mathrm{C}$, presión total mantenida por flujo de $\mathrm{N}_{2}$ de 29 bar, $20 \% \mathrm{p} / \mathrm{p}$ de glicerol. WHSV=4,2 $\mathrm{h}^{-1}$. Los resultados se registraron a las $3,5,11$ y $23 \mathrm{~h}$. Los catalizadores utilizados fueron $1 \% \mathrm{p} / \mathrm{p}$ Pt sobre soportes $\mathrm{Pt} / \mathrm{SiO}_{2}, \mathrm{Pt} / \mathrm{ASA}, \mathrm{Pt} / \gamma-\mathrm{Al}_{2} \mathrm{O}_{3}$, donde $\mathrm{ASA}$ : alúmina-sílice amorfa, $\operatorname{ASA}(y): \% \mathrm{p} / \mathrm{p}$ de $\mathrm{Al}_{2} \mathrm{O}_{3}$ (concentración determinada por análisis ICP). Además, ASA(55) es un soporte comercial mientras que todos los demás fueron sintetizados por 
deposición-precipitación homogénea de $\mathrm{Al}^{+3}$ sobre sílice, seguida de una calcinación a $800{ }^{\circ} \mathrm{C}$. Los autores informaron que los productos principales en la fase gaseosa fueron $\mathrm{H}_{2}, \mathrm{CO}_{2}$, alcanos $\mathrm{C} 1-\mathrm{C} 3$. En los productos líquidos se identificaron 1,2-propilenglicol, hidroxiacetona y alcoholes monofuncionales C1-C3. La evolución encontrada de la conversión y selectividades con el tiempo de reacción sugiere que el contenido de Al en el soporte produce cambios considerables. Las medidas de DRX y 27Al NMR evidenciaron la formación de bohemita a partir de la fase alúmina. Su formación es más pronunciada para muestras que contienen $\gamma-\mathrm{Al}_{2} \mathrm{O}_{3}$ libre y pura, pero la bohemita también se forma en silico-aluminatos amorfos con bajo contenido en Al que contienen predominantemente pequeños dominios de alúmina. Al mismo tiempo, se produce un lixiviado de silica del catalizador, el cual es más pronunciado para los ASA más ricos en sílice. La bohemita formada cataliza la deshidratación del glicerol a hidroxiacetona, la que posteriormente es hidrogenada a 1,2-propilenglicol sobre las partículas de Pt. Por lo que los resultados de actividad indican que el Pt en interacción con la bohemita resulta más activo para las reacciones de hidrogenación de la hidroxiacetona (1,2propilenglicol) y deshidrogenación del glicerol (gliceraldehido), comparado con el Pt en interacción con la $\gamma-\mathrm{Al}_{2} \mathrm{O}_{3}$ y sílice. La mayor acidez superficial como resultado de la formación de bohemita conlleva a una mayor cantidad de hidroxiacetona y 1,2propilenglicol comparado con los productos de reformado. Para soportes ASA con bajo contenido en Al, se observa que parte del Pt termina ubicándose sobre sectores ricos en sílice luego de una aglomeración de la alúmina, lo que provoca la desactivación de la función metal. Los autores indican que los pocos sitios ácidos tipo Brønsted encontrados en los soportes ASA no juegan un rol significante en el proceso de APR del glicerol.

Guo y col. [78] estudiaron catalizadores preparados a partir de coloides de Pt presintetizados sobre soportes: $\mathrm{MgO}, \mathrm{Al}_{2} \mathrm{O}_{3}, \mathrm{CeO}_{2}, \mathrm{TiO}_{2} \mathrm{SiO}_{2}\left(\mathrm{Al}_{2} \mathrm{O}_{3}\right.$ lo prepararon por calcinación de una pseudo bohemita comercial a $550{ }^{\circ} \mathrm{C}$ ), con un porcentaje de Pt entre 0,72-0,79 \% p/p. Como los catalizadores poseen la misma carga de Pt y la misma morfología de nanopartículas, las diferentes actividades fueron atribuidas a las propiedades de los soportes. Estudiaron el APR de glicerol en un reactor de lecho fijo, con solución $5 \% \mathrm{p} / \mathrm{p}$ de glicerol en agua a 3,6 mL/h de caudal, temperatura de $225^{\circ} \mathrm{y}$ presiones de 27,6 bar. Además, estudiaron la reacción de gas de agua o "WGS" en un reactor de lecho fijo a $225^{\circ} \mathrm{C}$ y presión atmosférica. La alimentación fue de una mezcla de $\mathrm{CO} / \mathrm{N}_{2}$ con un $5,2 \% \mathrm{p} / \mathrm{p}$ de $\mathrm{CO}$ a $4,2 \mathrm{~mL} / \mathrm{min}$ y agua desionizada vaporizada a 150 
${ }^{\circ} \mathrm{C}$. Encontraron que resulta más interesante promover la capacidad de la WGS, que la capacidad de ruptura C-C. Determinaron la basicidad de los soportes por $\mathrm{CO}_{2}-\mathrm{TPD}$, encontrando que decrecen en el orden: $\mathrm{MgO}>\mathrm{Al}_{2} \mathrm{O}_{3}>\mathrm{CeO}_{2}>\mathrm{TiO}_{2}>\mathrm{SiO}_{2}$. Los resultados de APR mostraron un orden de actividad catalítica de: $\mathrm{Pt} / \mathrm{MgO}>\mathrm{Pt} / \mathrm{Al}_{2} \mathrm{O}_{3}>$ $\mathrm{Pt} / \mathrm{CeO}_{2}>\mathrm{Pt} / \mathrm{TiO}_{2}>\mathrm{Pt} / \mathrm{SiO}_{2}$. Esto demuestra que el APR del glicerol es más favorable sobre catalizadores con soportes fuertemente básicos. La conversión a gases fue la más alta y con muy bajo contenido de $\mathrm{CO}$, sobre sólidos de $\mathrm{MgO}$. Los datos de actividad empleando el catalizador $\mathrm{Pt} / \mathrm{MgO}$ se tomaron luego de $25 \mathrm{~h}$, mientras que para los otros catalizadores los tiempos de corrida fueron de $40 \mathrm{~h}$. Esto se debió a que el $\mathrm{MgO}$ bloquea el reactor por su poca estabilidad hidrotérmica y la formación de carbonatos (detectado por DRX), que hace que aumente la caída de presión del lecho, bloqueando finalmente al reactor. El rendimiento a $\mathrm{H}_{2}$ para el $\mathrm{MgO}$ fue de 28,4\%, con un 48\% de conversión de carbón a gases, mientras que para el $\mathrm{Al}_{2} \mathrm{O}_{3}$, tuvo menor conversión (38\%), pero con una selectividad a hidrógeno mayor, por lo que el rendimiento fue similar. $\mathrm{Pt} / \mathrm{SiO}_{2}$ presentó conversiones considerablemente menores. Estos autores plantean que la basicidad promueve la reacción de WGS y aumenta la producción de hidrógeno gracias a la polarización del agua, lo que induce su disociación formando un grupo hidroxilo propenso a la adsorción sobre el catalizador, un paso cinéticamente significativo en la reacción WGS. Además los aniones de baja coordinación se pueden transformar en grupo $\mathrm{OH}^{-}$por la interacción con agua. En los soportes fuertemente básicos, existen muchos aniones de baja coordinación $\mathrm{O}_{2}{ }^{-}$presentes en esquinas y bordes, los que son responsables de la formación de sitios fuertemente básicos. Debido a esta disociación del agua se promueve la reacción de WGS. En las experiencias de reacción de WGS se observó la misma tendencia que para APR. Para el catalizador $\mathrm{Pt} / \mathrm{SiO}_{2}$ se detectó mayor cantidad de $\mathrm{CO}$, lo que demuestra que el * $\mathrm{CO}$ adsorbido no es convertido por la WGS y se desorbe. Existe una correlación entre la habilidad para la WGS y la actividad de APR. El catalizador que mostró una mayor promoción para la WGS mostró también una mayor actividad a APR. A pesar que los soportes básicos son buenos para el proceso APR su baja estabilidad en condiciones hidrotérmicas limitan sus aplicaciones.

Van Haasterecht y col. [79] evaluaron la estabilidad, actividad catalítica y selectividad en el reformado de etilenglicol en fase acuosa de nanopartículas de $\mathrm{Ni}, \mathrm{Co}, \mathrm{Cu}$ y $\mathrm{Pt}$ soportadas sobre nanofibras de carbono, en un reactor discontinuo a $230{ }^{\circ} \mathrm{C}$ y presión autógena. Las actividades específicas encontradas para los catalizadores siguen el orden de: $\operatorname{Pt}\left(15,5 \mathrm{~h}^{-1}\right)>\operatorname{Co}\left(13,0 \mathrm{~h}^{-1}\right)>\mathrm{Ni}\left(5,2 \mathrm{~h}^{-1}\right)$ mientras que el catalizador $\mathrm{Cu}$ sólo mostró 
baja actividad de deshidrogenación. La selectividad molar a hidrógeno disminuyó en el orden: $\mathrm{Pt}(53 \%)>\mathrm{Co}(21 \%)>\mathrm{Ni}(15 \%)$ como resultado de la producción de metano en Co y Ni. Para el catalizador de Co se formaron en la fase líquida compuestos ácidos, mientras que sobre Pt y Ni predomina la formación de alcoholes. También, observaron una rápida desactivación del catalizador de Co, lo que puede deberse a la significativa lixiviación del mismo en la solución, debido al bajo $\mathrm{pH}$ de la mezcla de reacción como resultado de los ácidos formados. Mediante estudios de caracterización por DRX y quimisorción de $\mathrm{H}_{2}$ determinaron que el crecimiento de las partículas metálicas fue responsable de la desactivación de los catalizadores de Pt y Ni. Además, se observó formación de carbón en el catalizador de $\mathrm{Ni}$, lo cual también contribuye a la desactivación del mismo. El reformado de etilenglicol a $\mathrm{H}_{2}$ es acompañado por la formación de productos líquidos con diferentes selectividades para los diversos catalizadores. Esto indicó que existen diferentes vías de reacción disponibles para los distintos metales. Con el Co, el ácido glicólico y el ácido acético son los productos primarios mientras que el Ni y el Pt producen principalmente metanol y etanol.

Copeland y col. [80] estudiaron por espectroscopia ATR-IR la activación del glicerol sobre el catalizador $\mathrm{Pt} / \gamma-\mathrm{Al}_{2} \mathrm{O}_{3}$ en medio acuoso a temperatura ambiente. Los resultados indicaron que la velocidad de formación y conversión de diferentes especies de CO dependen del pre-tratamiento superficial de los catalizadores. La exposición del catalizador al agua saturada con hidrógeno indujo a la formación de hidrógeno adsorbido y a dos especies de CO linealmente unidas a las partículas de Pt. Una de estas especies de CO interactuó principalmente con hidrógeno co-adsorbido, la otra interactuó principalmente con moléculas de $\mathrm{H}_{2} \mathrm{O}$ adsorbidas. Todas estas especies inhibieron la formación posterior de $\mathrm{CO}$ a partir de glicerol. El sitio preferido de unión para el hidrógeno adsorbido pareció ser los sitios de Pt que preferentemente formaron $\mathrm{CO}$ en forma de puente. Cuando los autores utilizaron agua saturada de oxígeno para el tratamiento previo en la superficie del catalizador, el oxígeno residual adsorbido en el Pt convirtió inicialmente el $\mathrm{CO}$ formado a partir de glicerol a $\mathrm{CO}_{2}$ resultando en una leve reducción de las tasas de formación aparente de $\mathrm{CO}$. El pre-tratamiento del catalizador alternando flujo de agua saturada con hidrógeno y oxígeno fue procedimiento más eficaz. Las tasas más rápidas de formación de $\mathrm{CO}$ las observaron después de este tratamiento previo, debido a la mayor concentración de sitios de Pt accesibles y a la disponibilidad de algunos sitios de Pt particularmente reactivos. Estos sitios reactivos preferentemente generaron hidrógeno adsorbido y especies $\mathrm{CO}$ tipo puente adsorbidas a 
partir del glicerol, además que fueron activos para la remoción de especies CO tipo puente a través de la conversión de gas de agua. El procedimiento de pre-tratamiento utilizado para la estabilización y limpieza del catalizador $\mathrm{Pt} / \gamma-\mathrm{Al}_{2} \mathrm{O}_{3}$ tiene un fuerte impacto en la cinética del APR de glicerol. El tratamiento constó de hacer pasar un flujo de $\mathrm{H}_{2} \mathrm{O}$ para estabilizar el lecho catalítico. La cantidad de sitios Pt ligados a especies CO limitó el número de sitios activos para la activación de glicerol. La eliminación lenta de la especie $\mathrm{CO}$ puente durante la exposición al glicerol y $\mathrm{H}_{2} \mathrm{O}$ indicó que estos mismos sitios también fueron los más activos para WGS con actividad notable a temperatura ambiente. La velocidad de formación de $\mathrm{CO}$ proveniente de la deshidrogenación del glicerol estuvo limitada por la baja cantidad de sitios activos Pt disponibles debido a la coberturas de especies adsorbidas de $\mathrm{CO}$ e $\mathrm{H}^{*}$ (hidrógeno disociado).

\section{I.4.5.2. Estudios con catalizadores bimetálicos}

Huber y col. [81] reportaron resultados de reformado en fase acuosa sobre $\mathrm{Pt} / \mathrm{Al}_{2} \mathrm{O}_{3}$, $\mathrm{Ni} / \mathrm{Al}_{2} \mathrm{O}_{3}$, Ni-Raney y NiSn-Raney, encontrando que los rangos de producción de $\mathrm{H}_{2}$ con catalizadores Ni:Sn igual a 14:1 son similares a los obtenidos para $\mathrm{Pt} / \mathrm{Al}_{2} \mathrm{O}_{3}$. Las soluciones de alimentación utilizadas fueron entre 1 y $5 \% \mathrm{p} / \mathrm{p}$ de compuestos oxigenados, las condiciones se fijaron en $225{ }^{\circ} \mathrm{C}$ y $265{ }^{\circ} \mathrm{C}$ y 25,8 y 51,3 bar, respectivamente. Cada corrida experimental fue mantenida por 6 h. El reformado de sorbitol, glicerol y etilenglicol produjo una corriente gaseosa compuesta por 50-70 \%molar $\mathrm{H}_{2}, 30-40 \%$ molar $\mathrm{CO}_{2}$ y 2-11 \%molar de alcanos a altas conversiones, con muy baja concentración de CO. Las selectividades de $\mathrm{H}_{2}$ y alcanos fueron similares para el Ni14Sn y el $3 \% \mathrm{Pt} / \mathrm{Al}_{2} \mathrm{O}_{3}$. Sobre ambos catalizadores las selectividades a $\mathrm{H}_{2}$ decrecen a medida que la molécula de alimentación se vuelve más grande mientras que la selectividad de alcanos se incrementa.

Posteriormente, Shabaker y col. [82] reportaron que la adición del estaño al níquel disminuye la velocidad de formación de $\mathrm{CH}_{4}$ proveniente de las reacciones de rupturas de enlaces $\mathrm{C}-\mathrm{O}$, mientras que mantiene una alta velocidad de reacciones de ruptura de enlaces $\mathrm{C}-\mathrm{C}$ requerida para la formación de $\mathrm{H}_{2}$. El catalizador óptimo Ni-Raney promovido con Sn fue obtenido por descomposición de acetato de tributilestaño con una relación atómica $\mathrm{Sn} / \mathrm{Ni}$ de 0,075 . Los productos líquidos contienen bajas cantidades de alcoholes, ácidos orgánicos y aldehídos ( $<50 \mathrm{ppm}$ a conversiones $>90 \%)$. El 
catalizador NiSn-Raney exhibió mayor producción de $\mathrm{H}_{2}$ y menores selectividades a alcanos que el catalizador $3 \% \mathrm{p} / \mathrm{p} \mathrm{Pt} / \mathrm{Al}_{2} \mathrm{O}_{3}$ en el reformado de glicerol y etilenglicol, en especial a mayores temperaturas. Cuando se utiliza sorbitol como molécula de alimentación se observaron selectividades comparables. El efecto benéfico de la adición de $\mathrm{Sn}$ sobre la selectividad a la producción de $\mathrm{H}_{2}$ puede estar causado por la presencia de $\mathrm{Sn}$ en sitios defectuosos del $\mathrm{Ni}$ y por la formación de aleaciones $\mathrm{Ni}-\mathrm{Sn}$ en la superficie, como por ejemplo $\mathrm{Ni}_{3} \mathrm{Sn}$.

Huber y col. [83] también estudiaron catalizadores bimetálicos de PtNi, PtCo, PtFe y PdFe en el APR de etilenglicol en un reactor de lecho fijo. Los catalizadores bimetálicos poseen una actividad significativamente mayor que los monometálicos de $\mathrm{Pt}$ y $\mathrm{Pd}$. Se encontró que los catalizadores $\mathrm{PtNi} / \mathrm{Al}_{2} \mathrm{O}_{3}$ y $\mathrm{PtCo} / \mathrm{Al}_{2} \mathrm{O}_{3}$ a $210{ }^{\circ} \mathrm{C}$ fueron 2,1-3,5 veces más activos que el catalizador de Pt. El catalizador Pt1Fe9/ $\mathrm{Al}_{2} \mathrm{O}_{3}$ mostró un TOF $\mathrm{H}_{2}$ de $0,3-4,3 \min ^{-1}$ a 180 y $210{ }^{\circ} \mathrm{C}$, lo que es tres veces mayor que el encontrado para $\mathrm{Pt} / \mathrm{Al}_{2} \mathrm{O}_{3}$. El catalizador $\mathrm{Pd} 1 \mathrm{Fe} 9 / \mathrm{Al}_{2} \mathrm{O}_{3}$ mostró TOF $\mathrm{H}_{2}$ igual a 1,4 y $4,3 \min ^{-1}$ a 180 y $210{ }^{\circ} \mathrm{C}$, los que son valores $39-46$ veces más grandes que el encontrado para $\mathrm{Pd} / \mathrm{Al}_{2} \mathrm{O}_{3}$ en las mismas condiciones. El catalizador que mostró la mayor actividad intrínseca fue el de $\mathrm{Pd}$ soportado en $\mathrm{Fe}_{2} \mathrm{O}_{3}$ (Nanocat) con $\mathrm{TOF} \mathrm{H}_{2}$ : 14,6; 39,1 y 60,1 $\min ^{-1}$ a temperaturas de 180,210 y $225{ }^{\circ} \mathrm{C}$, respectivamente. Los autores sugieren que las aleaciones de Pt con Ni, Co o Fe mejoran la actividad para la producción de $\mathrm{H}_{2}$ por un mecanismo de disminución de banda d, lo que causa un descenso en los calores de adsorción del $\mathrm{CO}$ e $\mathrm{H}_{2}$, y así un incremento en los sitios superficiales disponibles para la reacción del etilenglicol. Además en este estudio se puso en evidencia que el paso limitante para el APR del etilenglicol sobre catalizadores a base de Pd es la reacción de WGS, por lo que adicionando un promotor para esta reacción, como el $\mathrm{Fe}_{2} \mathrm{O}_{3}$, puede mejorar la actividad catalítica para el reformado.

Miyao y col. [84] estudiaron catalizadores de Pt-Ru preparados por impregnación sobre $\mathrm{SiO}_{2}, \mathrm{MgO}, \mathrm{TiO}_{2}, \mathrm{ZrO}_{2}$ y $\mathrm{CeO}_{2}$ con cargas de $\mathrm{Pt} 5 \% \mathrm{p} / \mathrm{p}, \mathrm{Pt} / \mathrm{Ru}=1$. Las medidas de actividad del reformado en fase líquida del metanol se realizaron en un reactor tipo batch, con circulación de gases, la alimentación consistió en una solución acuosa de 10 $\%$ metanol. Los experimentos se realizaron entre 77 y $84{ }^{\circ} \mathrm{C}$. Los autores encontraron que el catalizador más activo fue $\mathrm{Pt}-\mathrm{Ru} / \mathrm{TiO}_{2}$. Los soportes básicos mejoraron la selectividad a $\mathrm{CO}_{2}$ y los soportes ácidos suprimieron la actividad y la selectividad. La interacción del Pt con el $\mathrm{TiO}_{2}$ reducido parcialmente, es responsable del mejoramiento en la selectividad sobre este catalizador. Mayores temperaturas de reducción del Pt- 
$\mathrm{Ru} / \mathrm{TiO}_{2}$ mejoraron su actividad catalítica y selectividad gracias a la formación de una aleación PtRu.

Xie y col. [85] estudiaron en el año 2006 catalizadores de Skeletal Ni (RQ Ni) preparados por lixiviación alcalina de una aleación Ni50A150, y luego modificado mediante impregnación con $\mathrm{SnCl}_{4}$, seguido de un tratamiento térmico en atmósfera inerte, obteniéndose un catalizador homogéneo de Sn-modificado sobre Ni (RQ Ni-Sn). Encontraron que el tratamiento térmico induce la formación de aleaciones metálicas Sn con $\mathrm{Ni}$, formando una aleación $\mathrm{Ni}_{3} \mathrm{Sn}$ que se encuentra segregada en la superficie del catalizador. Se midió la actividad de este catalizador en APR de etilenglicol, y se encontró que el catalizador RQ Ni fue menos selectivo en la producción de $\mathrm{H}_{2}$ pero más selectivo en la producción de alcanos que el catalizador Ni-Raney. Investigaron los productos líquidos y gaseosos obtenidos empleando el catalizador RQ Ni y observaron que las diferencias estructurales influyen en los caminos de reacción del etilenglicol con agua, suprimiendo completamente el camino indeseado de reacciones de ruptura de enlace $\mathrm{C}-\mathrm{O}$. La modificación de RQ Ni con Sn mejoró drásticamente la selectividad a $\mathrm{H}_{2}$. Sobre catalizadores RQ Ni80Sn20, se observó que se retarda la producción de alcanos, obteniéndose una selectividad a $\mathrm{H}_{2}$ del $98 \%$ a altas conversiones. Basados en la caracterización, los autores sugieren que el Sn puede estar bloqueando sitios activos en la adsorción y/o disociación de CO, por lo que se suprime la reacción indeseada de metanación. Por otro lado, se pueden estar formando ensambles bifuncionales entre Ni$\mathrm{Sn}$, en donde el $\mathrm{Sn}$ facilita la disociación del $\mathrm{H}_{2} \mathrm{O}$ mientras que los átomos vecinos de Ni adsorben al CO, promoviendo la reacción de WGS altamente deseada para el proceso de APR.

Kunkes y col. [86] realizaron medidas de APR de glicerol (30 y $80 \%$ p/p) sobre catalizadores de Pt y Pt-Re soportados sobre carbón en un rango de temperaturas entre 210 a $250{ }^{\circ} \mathrm{C}$. Los catalizadores Pt-Re/C son más activos que el monometálico Pt/C. El resultado de estos estudios mostraron que los TOF para la producción de $\mathrm{H}_{2}, \mathrm{CO}, \mathrm{CO}_{2}$, y alcanos livianos (metano principalmente) se incrementaron gracias a la adición de Re a los catalizadores $\mathrm{Pt} / \mathrm{C}$. La fracción molar $\mathrm{H}_{2} / \mathrm{CO}$ aumentó, mientras que la relación $\mathrm{CO} / \mathrm{CO}_{2}$ disminuyó con la adición de $\mathrm{Re}$, indicando un aumento en la velocidad de la reacción de WGS. Con el catalizador con una relación Pt:Re 1:1, incrementando la presión o disminuyendo la temperatura se obtuvo un incremento en la producción de alcanos e hidrocarburos oxigenados livianos (etanol, metanol, propanodioles y acetona) a expensas de la producción de $\mathrm{CO}$ y $\mathrm{CO}_{2}$. Estudios de desorción a temperatura 
programada y medidas microcalorimétricas indicaron que la adición de $\mathrm{Re}$ al $\mathrm{Pt}$ modifica la interacción del CO con los sitios superficiales. Por DRX y TEM se evidenció que el catalizador $\mathrm{Pt}-\mathrm{Re} / \mathrm{C}$ consiste principalmente de nano partículas bimetálicas con tamaños por debajo de los $2 \mathrm{~nm}$, y que el Re inhibe la sinterización de esas nano partículas bajo las condiciones de reacción. En particular, los resultados de TPD de CO demostraron que la energía de desorción de CO sobre Pt-Re/C disminuyó en relación a las muestras monometálicas, luego de haber sido expuestas a un pretratamiento de oxidación selectivo. Esta oxidación selectiva del Re puede ocurrir bajo las condiciones de reacción, y es potencialmente responsable de la formación de sitios activos superficiales. Como conclusión se observó que la buena performance encontrada para el catalizador $\mathrm{Pt}-\mathrm{Re} / \mathrm{C}$ se relaciona a la formación de nanopartículas de Pt-Re, en las cuales el Re promueve la velocidad global del reformado de glicerol debilitando la energía de enlace del $\mathrm{CO}$ en partículas de Pt vecinas, y de esta manera incrementando la velocidad de WGS, y facilitando la hidrogenólisis de los enlaces C-O a elevadas presiones. Este efecto lo explican en términos de que los sitios activos consisten en átomos de Pt superficiales adyacentes a átomos de Re superficiales que se enlazan preferentemente a especies oxigenadas, como por ejemplo grupos hidróxidos.

En 2010, King y col. [87] encontraron que la adición del Re incrementa la ruptura de enlaces C-C, dado el aumento significativo de la conversión de glicerol y producción de hidrógeno. La producción de $\mathrm{H}_{2}$ requiere dos pasos claves, ambos catalizados por metal: la deshidrogenación para formar intermediarios aldehídicos (gliceraldehído), y la posterior ruptura de enlaces $\mathrm{C}-\mathrm{C}$ del gliceraldehído para generar $\mathrm{CO}$ e $\mathrm{H}_{2}$. Además, se forma $\mathrm{H}_{2}$ adicional por la reacción de WGS. La producción de otros productos, como por ejemplo el propilenglicol (PG), aparentemente se debe a la competitividad de las reacciones que involucran la deshidratación y la subsiguiente hidrogenación. El paso de deshidratación es probable que sea catalizado por medio ácido. La acidez del catalizador $\mathrm{Pt} / \mathrm{C}$ puede derivar de sitios ácidos del soporte de $\mathrm{C}$ o del metal en sí mismo. Con el catalizador $\mathrm{Pt}-\mathrm{Re} / \mathrm{C}$, parece probable que especies de $\mathrm{ReOx}$ se encuentren presentes sobre la superficie del catalizador, lo cual puede proveer acidez para facilitar los caminos de deshidratación. A menores velocidades espaciales (mayores conversiones de glicerol), mayor $\mathrm{H}_{2}$ y menos productos líquidos son formados con el catalizador PtRe/C, lo que sugiere que proporcionando un mayor tiempo de residencia, la vía de deshidrogenación y ruptura C-C puede competir más favorablemente con la ruta basada en la deshidratación. Se estudió también la adición de $\mathrm{KOH}$ al 1\% para disminuir las 
vías de la deshidratación catalizada por ácido que conducen a productos oxigenados. Para $\mathrm{Pt} / \mathrm{C}$, la adición de $\mathrm{KOH}$ incrementa la conversión a productos oxigenados en fase líquida, sobre todo a PG y en menor medida a EG, pero no aumentó significativamente la producción de $\mathrm{H}_{2}$. La mayor productividad a hidrógeno con la adición de $\mathrm{KOH}$ sobre $\mathrm{Pt}-\mathrm{Re} / \mathrm{C}$ (comparado sin adición de $\mathrm{KOH}$ ) parece ser principalmente el resultado de una disminución en la producción de alcanos $\mathrm{C} 2+$, pero se incrementó la fracción de productos líquidos, siendo especialmente pronunciado el incremento en PG.

Zhang y col. [88] realizaron ensayos de APR del glicerol sobre catalizadores de Pt-Re/C preparados por secuencias de impregnación a humedad incipiente. Las reacciones de APR se realizaron en un microreactor de canal simple, con un intercambiador de calor para mantener el sistema isotérmico. Además, estudiaron la estructura de los catalizadores $\mathrm{Pt}-\mathrm{Re} / \mathrm{C}$ con distintas cargas de Re, luego de su reducción y exposición a un ambiente hidrotérmico simulado. Vieron que cuando se expone a vapor a elevadas temperaturas, el catalizador $\mathrm{Pt}-\mathrm{Re}$ se oxida. Estos resultados sugieren que los sitios activos durante la reacción de APR no son los sitios de aleación Pt-Re sino los sitios oxidados Pt-Re. La interacción Pt-Re bajo condiciones hidrotérmicas resultó en una superficie local ácida. El número de sitios ácidos es proporcional a la cantidad de Re en el catalizador Pt-Re. La superficie ácida facilita los caminos de deshidratación. Los resultados muestran la importancia de los sitios ácidos superficiales en el control de los caminos de reacción durante el proceso de APR.

Iriondo y col. [88] estudiaron el APR de glicerol a 225 y $240{ }^{\circ} \mathrm{C}$ utilizando catalizadores de Pt y $\mathrm{Ni}$ mono y bimetálicos soportados sobre $\gamma-\mathrm{Al}_{2} \mathrm{O}_{3}$ y $\gamma-\mathrm{Al}_{2} \mathrm{O}_{3}$ modificada con $\mathrm{La}_{2} \mathrm{O}_{3}$. Se obtuvieron conversiones totales entre 13 y $27 \%$, sin embargo fueron bajas las conversiones a gases, siendo la conversión total principalmente a intermediarios oxigenados. Este comportamiento fue atribuido a la baja dispersión metálica, posiblemente obtenida por la presencia de aleaciones Pt-Ni, y por el "spill-over" de $\mathrm{H}_{2}$, el que parece ser adecuado para el proceso de hidrogenólisis. Se reportó además que la presencia de $\mathrm{La}_{2} \mathrm{O}_{3}$ en los catalizadores bimetálicos mejoró la conversión del glicerol y aumentó la cantidad de $\mathrm{H}_{2}$ producido. A $240{ }^{\circ} \mathrm{C}$, el orden de actividad fue de: $\mathrm{PtNi} / \gamma-$ $\mathrm{Al}_{2} \mathrm{O}_{3}-\mathrm{La}_{2} \mathrm{O}_{3}>\mathrm{PtNi} / \gamma-\mathrm{Al}_{2} \mathrm{O}_{3}>\mathrm{Pt} / \gamma-\mathrm{Al}_{2} \mathrm{O}_{3}>\mathrm{Pt} / \gamma-\mathrm{Al}_{2} \mathrm{O}_{3}-\mathrm{La}_{2} \mathrm{O}_{3}>\mathrm{Ni} / \gamma-\mathrm{Al}_{2} \mathrm{O}_{3}>\mathrm{Ni} / \gamma-$ $\mathrm{Al}_{2} \mathrm{O}_{3}-\mathrm{La}_{2} \mathrm{O}_{3}$.

Tuza y col. [90] prepararon catalizadores de $\mathrm{Ni}-\mathrm{Cu}$ derivados de compuestos de hidrotalcita y fueron ensayados en el APR de glicerol. La reacción se llevó a cabo en un reactor discontinuo con una solución $10 \% \mathrm{p} / \mathrm{p}$ de glicerol, a 250 y $270{ }^{\circ} \mathrm{C}$. Los 
catalizadores de $\mathrm{Ni}-\mathrm{Cu}$ mostraron buena actividad y alta selectividad a hidrógeno. Se obtuvo una conversión máxima de glicerol del $60 \%$ a $270{ }^{\circ} \mathrm{C}$. En la fase gas, la selectividad a $\mathrm{H}_{2}$ fue siempre mayor que $80 \%$ y la formación de $\mathrm{CO}$ fue muy baja $(<3 \%)$ a $250^{\circ} \mathrm{C}$. El catalizador $\mathrm{Ni} 5 \mathrm{Cu}$ presentó la mayor selectividad a $\mathrm{H}_{2}$ a $250{ }^{\circ} \mathrm{C}$, con la menor cantidad de $\mathrm{CO} \mathrm{y} \mathrm{CH}_{4}$ producido. Sin embargo, este catalizador proporciona un muy bajo rendimiento a $270{ }^{\circ} \mathrm{C}$ debido al consumo casi total de hidrógeno. El consumo de $\mathrm{H}_{2}$ está relacionado con la hidrogenación de la acetona (formada por deshidratación de glicerol) para formar propilenglicol. Ácido láctico y el acetaldehído también se formaron en fase líquida, además de pequeñas trazas de subproductos más pesados.

\section{I.5. Conclusiones del capítulo y objetivos planteados}

Debido a que en el año 2006 fue promulgada en nuestro país la ley nacional $N^{\circ} 26.123$ "Régimen para el desarrollo de la tecnología, producción, uso y aplicaciones del hidrógeno como combustible y vector de energía", y que aún se está trabajando en la reglamentación de esta ley; el avance en la temática de hidrógeno representa la generación de conocimiento y la formación de recursos humanos que posibilitará a la Argentina insertarse en el grupo de países que desarrollen tecnología propia.

Tal como ha sido mencionado en este capítulo, en los últimos años ha crecido notablemente el interés y las contribuciones científicas dirigidas a la producción de hidrógeno a partir de materias primas renovables (biomasa).

Sin embargo, aún no se ha alcanzado el nivel de conocimiento que permita una aplicación tecnológica industrial, lo que indica que hay que continuar estudiando esta temática.

La biomasa también permite obtener una amplia gama de productos y debido a que Argentina es un país de fuerte carácter agrícola-forestal, el aprovechamiento de la biomasa le permitiría generar un desarrollo industrial estratégico.

El concepto del aprovechamiento de la biomasa no es nuevo, pero con la disminución de la reservas de petróleo esta concepción se renovó para reorientar su utilización en biocombustibles y químicos.

La sustitución de derivados del petróleo por derivados de biomasa requiere un considerable esfuerzo de investigación fundamentalmente por la naturaleza de esta 
materia prima. Mientras que los catalizadores que convierten el petróleo en productos químicos apuntan a la funcionalización de hidrocarburos en forma selectiva, la biomasa ya es una materia prima altamente funcionalizada. Por lo tanto, los catalizadores que se han desarrollado durante los últimos 100 años no son directamente aplicables a materias primas de biomasa. Los catalizadores deberán eliminar selectivamente algunas de las funcionalidades y aprovechar los grupos funcionales existentes.

Las posibilidades futuras de investigar sobre catalizadores para aplicaciones que permitan el aprovechamiento de la biomasa es muy amplia, y resulta un gran desafío científico-tecnológico. De esta manera, la conversión selectiva de los polioles, compuestos altamente oxigenados, permitirán transformarlos en una gran cantidad de productos químicos útiles.

En este contexto, esta tesis plantea como objetivo general desarrollar catalizadores metálicos soportados que permitan obtener, de forma sustentable, hidrógeno y/o productos de alto valor comercial a partir de glicerol.

Como objetivos específicos fueron planteados:

Diseñar y preparar, empleando diferentes métodos, catalizadores metálicos basados en Pt que sean potencialmente aptos para la obtención de hidrógeno por APR del glicerol

$\checkmark$ Diseñar y preparar, empleando diferentes métodos, catalizadores bimetálicos basados en $\mathrm{Pt}(\mathrm{Sn}-\mathrm{Pt}, \mathrm{Ni}-\mathrm{Pt})$ que sean potencialmente aptos en la reacción de hidrogenólisis del glicerol para obtención de biopropilenglicol

$\checkmark$ Determinar las propiedades fisicoquímicas, empleando diferentes técnicas de caracterización de los catalizadores tales como DRX, TEM, XPS, EXAFS

$\checkmark$ Evaluar la actividad catalítica de los materiales preparados en las reacciones conducidas en fase líquida: reformado e hidrogenólisis del glicerol

$\checkmark$ Correlacionar las propiedades fisicoquímicas con la actividad y selectividad de cada catalizador 


\section{I.6. Referencias}

[1] Kajan Srirangan, Lamees Akawi, Murray Moo-Young, C. Perry Chou. Applied Energy 100 (2012) 172-186

[2] Helmut Haberl, Tim Beringer, Sribas C Bhattacharya, Karl-Heinz Erb, Monique Hoogwijk. Current Opinion in Environmental Sustainability 2, 5-6, (2010) 394403

[3] Brentan R. Alexander, Reginald E. Mitchell, and Turgut M. Gür. Journal of The Electrochemical Society 159(12) (2012) 810-818

[4] Berndes G., Hoogwijk M., van den Broek R. Biomass and Bioenergy 25 (2003) 128

[5] Worldwatch-Institute. Biofuels for transport: global potential and implications for sustainable energy and agriculture. London: Earthscan (2007)

[6] Cherubini F. Energy Convers Manage 51 (2010) 1412-1421

[7] Margeot A., Hahn-Hagerdal B., Edlund M., Slade R., Monot F. Current Opinion in Biotechnology 20(3) (2009) 372-380

[8] Klass D.L. San Diego: Academic Press; 1998

[9] Bassam N. Handbook of bioenergy crops. London: Earthscan; 2010

[10] Poonam Singh Nigam, Anoop Singh. Progress in Energy and Combustion Science 37 (2011) 52-68

[11] Carlo R. Carere, Richard Sparling, Nazim Cicek, David B. Levin. International Journal of Molecular Sciences 9(7) (2008) 1342-1360

[12] Barry D. Solomon. Annals of the New York Academy of Sciences 1185 (2010) $119-134$

[13] Prem S. Bindraban, Erwin H. Bulte, Sjaak G. Conijn. Agricultural Systems 101(3) (2009) 197-199

[14] Ayhan Demirbas. Applied Energy 86(Supplement 1) (2009) S108-S117

[15] Ambuj D. Sagar, Sivan Kartha. Annual Review of Environment and Resources 32 (2007) 131-167

[16] Ben Phalan. Applied Energy 86(Supplement 1) (2009) S21-S29

[17] Adrian Zhou, Elspeth Thomson. Applied Energy 86(Supplement 1) (2009) S11S20

[18] M. Fatih Demirbas. Applied Energy 88 (2011) 3473-3480 
[19] I. Rawat, R. Ranjith Kumar, T. Mutanda, F. Bux. Applied Energy 88 (2011) 34113424

[20] Farrell AE, Plevin RJ, Turner BT, Jones AD, O'Hare M, Kammen DM. Science 311(5760) (2006) 506-508

[21] Francesco Cherubini, Sergio Ulgiati. Applied Energy 87(1) (2010) 47-57

[22] Yu-Chuan Lin. International Journal of Hydrogen Energy 38 (2013) 2678-2700

[23] Ueoka H., Katayama T. United States Patent 6288287 (2001)

[24] Ooi T.L, Yong K.C., Hazimah A.H., Dzulkefty K. , Wan-Yunus W.M.Z. Journal of Oil Palm Research 13 (2001) 16-22

[25] Donkin Shawn S. Revista Brasileira de Zootecnia 37 (2008) 280-286

[26] Isahak W.N.R.W., Ismail M, Yarmo M.A., Jahim J.M., Salimon J. Journal of Applied Sciences 10 (2010) 2590-2595

[27] Mohammad Fauzi A.H., Amin N.A.S. Renewable \& Sustainable Energy Reviews 16(8) (2012) 5770-5786.

[28] Ketchie WC, Murayama M, Davis RJ. Topics in Catalysis 44 (2007) 307

[29] Shu-Sen Liu, Ke-Qiang Sun, and Bo-Qing Xu. ACS Catalysis 4(7) (2014) 22262230

[30] Zope BN, Davis RJ. Topics in Catalysis 52 (2009) 269

[31] Demirel S, Lucas M, Wärnå J, Salmi T., Murzin D, Claus P. Topics in Catalysis 44 (2007) 299

[32] Dimitratos N, Villa A, Bianchi CL, Prati L, Makkee M. Applied Catalysis A: General 311 (2006) 185

[33] Zhou CH, Beltramini JN, Fan YX, Lu GQ. Chemical Society Reviews 37 (2008) $527-549$

[34] Behr A, Eilting J, Irawadi K, Leschinski J, Linder F. Green Chemistry 10 (2008) $13-30$

[35] Carrettin S, McMorn P, Johnston P, Griffin K, Hutchings GJ. Chemical Communications 7 (2002) 696

[36] Chinchilla LE, Olmos CM, Villa A, Carlsson A, Prati L, Chen X, Blanco G, Calvino JJ, Hungria AB. Catalysis Today 253 (2015) 178

[37] Corma A, Huber GW, Sauvanaud L, O'Connor PJ. Catalysis 257 (2008) 163-171

[38] Ott L, Bicker M, Vogel H. Green Chemistry 8 (2006) 214-220

[39] Sato S, Akiyama M, Takahashi R, Hara T, Inui K, Yokota M. Applied Catalysis A: General 347 (2008) 186-191 
[40] Tsukuda E, Sato S, Takahashi R, Sodesawa T. Catalysis Communications 8 (2007) $1349-1353$

[41] Zheng Y, Chen X, Shen Y. Chemical Reviews 108 (2008) 5253-5277.

[42] Alhanash A, Kozhevnikova EF, Kozhevnikov IV. Catalysis Letters 120 (2008) $307-311$

[43] Wang J, Shen S, Li B, Lin H, Yuan Y. Chemistry Letters 38 (2009) 572-573

[44] D’Hondt E, Vyver SVd, Sels BF, Jacobs PA. Chemical Communications (2008) $6011-6012$

[45] Gandarias I, Arias PL, Requies J, Güemez MB, Fierro JLG. Applied Catalysis B: Environmental 97 (2010) 248-256

[46] Huang L, Zhu YL, Zheng HY, Li YW, Zeng ZY. Journal of Chemical Technology and Biotechnology 83 (2008) 1670-1675

[47] Yuan ZL, Wang JH, Wang LN, Xie WH, Chen P, Hou ZY, Zheng XM. Bioresource Technology 101 (2010) 7088-7092

[48] Perosa A, Tundo P. 2005. Industrial \& Engineering Chemistry Research 44 (2005) $8535-8537$

[49] Daniel OM, DeLaRiva A, Kunkes EL, Datye AK, Dumesic JA, Davis RJ. ChemCatChem 2 (2010) 1107-1114

[50] Xia S, Yuan Z, Wang L, Chen P, Hou Z. Bioresource Technology 104 (2012) 814817

[51] Gandarias I, Arias PL, Requies J, El Doukkali, M, Güemez MB. Journal of Catalysis 282 (2011) 237-247

[52] Montassier C, Giraud D, Barbier J. Heterogeneous Catalysis and Fine Chemicals, Elsevier, Amsterdam, 1988

[53] Chaminand J, Djakovitch 1, Gallezot P, Marion P, Pinel C, Rosier C. Green Chemistry 6 (2004) 359-361

[54] Dasari MA, Kiatsimkul PP, Sutterlin WR, Suppes GJ. Applied Catalysis A: General 281 (2005) 225-231

[55] Debdut Roy, Bala Subramaniam, Raghunath V. Chaudhari. Catalysis Today 156 (2010) 31-37

[56] Guo L, Zhou J, Mao J, Guo X, Zhang S. Applied Catalysis A: General 367 (2009) 93-98

[57] Dasari MA, Kiatsimkul PP, Sutterlin WR, Suppes GJ. Applied Catalysis A: General 281 (2005) 225-231 
[58] Behr A, Eilting J, Irawadi K, Leschinski J, Linder F. Green Chemistry 10 (2008) $13-30$

[59] Cortright RD, Davda RR, Dumesic JA. Nature 418 (2002) 964-967

[60] Davda RR, Shabaker JW, Huber GW, Cortright RD, Dumesic JA. Applied Catalysis B: Environmental 43 (2003) 13-26

[61] Shabaker JW, Davda RR, Huber GW, Cortright RD, Dumesic JA. Journal of Catalysis 215 (2003) 344-352

[62] Shabaker JW, Huber GW, Davda RR, Cortright RD, Dumesic JA. Catalysis Letters 88 (2003) 1-2

[63] Davda RR y Dumesic JA. Chemical Communications (2004) 36-37

[64] Tanksale A, Wong Y, Beltramini JN, Lu GQ. International Journal of Hydrogen Energy 32 (2007) 717-724

[65] Luo N, Fu X, Cao F, Xiao T, Edwards PP. Fuel 87 (2008) 3483-348

[66] Lehnert K, Claus P. Catalysis Communications 9 (2008) 2543-2546

[67] Murata K, Takahara I, Inaba M. Reaction Kinetics and Catalysis Letters 93(1) (2008) 59-66

[68] Cruz IO, Ribeiro N, Aranda D, Souza M. Catalysis Communications 9 (2008) 2606-2611

[69] Shabaker J, Huber GW, Dumesic J. Journal of Catalysis 222 (2004) 180-191

[70] Wen G, Xu Y, Ma H, Zhusheng Xu Z, Tian Z. International journal of hydrogen energy 33 (2008) $6657-6666$

[71] Wawrzetz A, Peng B, Hrabar A, Jentys A, Lemonidou AA, Lercher JA. Journal of Catalysis 269 (2010) 411-420

[72] Menezes AO, Rodrigues MT, Zimmaro A, Borges LEP, Fraga MA. Renewable Energy 36 (2011) 595-599

[73] Tokarev AV, Kirilin AV, Murzina EV, Eränen K, Kustov LM, Murzin DYu, Mikkola J-P. International journal of hydrogen energy 35 (2010) 12642-12649

[74] Wen G, Xu Y, Xu Z, Tian Z. Catalysis Communications 11 (2010) 522-526

[75] Manfro R, da Costa A, Ribeiro N, Souza M. Fuel Processing Technology 92 (2011) $330-335$

[76] Derya Oncel Ozgur, Bekir Zuhtu Uysal. Biomass and bioenergy 35 (2011) 822-826

[77] Ciftci A, Peng B, Jentys A, Lercher J, Hensen E. Applied Catalysis A: General $431-432$ (2012) 113- 119.

[78] Guo Y, Azmat M, Liu X, Wang Y, Lu G. Applied Energy 92 (2012) 218-223 
[79] T. van Haasterecht, C. C. I. Ludding, K. P. de Jong, J. H. Bitter. Journal of Energy Chemistry 22 (2013) 257-269

[80] Copeland J, Foo G, Harrison L, Sievers C. Catalysis Today 205 (2013) 49-59

[81] Huber G, Shabaker J, Dumesic J. Science 300 (2003) 2075-2077

[82] Shabaker J, Huber GW, Dumesic J. Journal of Catalysis 222 (2004) 180-191

[83] Huber G, Shabaker J, Evans S, Dumesic J. Applied Catalysis B: Environmental 62 (2006) 226-235

[84] Miyao T, Yamauchi M, Narita H, Naito S. Applied Catalysis A: General 299 (2006) 285-291

[85] Xie F, Chu X, Hu H, Qiao M, Yan S, Zhu Y, He H, Fan K, Li H, Zong B, Zhang X. Journal of Catalysis 241 (2006) 211-220

[86] Kunkes EL, Simonetti DA, Dumesic JA, Pyrz WD, Murillo LE, Chen JG, Buttrey DJ. Journal of Catalysis 260 (2008) 164-177

[87] King D, Zhang L, Xi G, Kari AM, Heldebrant DJ, Wang X, Peterson T, Wang Y. Applied Catalysis B: Environmental 99 (2010) 206-213

[88] Zhang L, Karim A, Engelhard M, Wei Z, King D, Wang Y. Journal of Catalysis 287 (2012) 37-43

[89] Iriondo A, Cambra J, Barrio V, Guemez M, Arias P, Sanchez-Sanchez M, Navarro R, Fierro J. Applied Catalysis B: Environmental 106 (2011) 83-93

[90] Tuza P, Manfro R, Ribeiro N, Souza M. Renewable Energy 50 (2013) 408-414 
Capítulo II

Sección Experimental 


\section{Capítulo II. Sección Experimental}

\section{II.1. Introducción}

En este capítulo se describen los métodos utilizados en la preparación de los sistemas catalíticos. Se detalla tanto la metodología para la preparación de los soportes como así también los métodos de incorporación de las fases activas.

Posteriormente, se presentan las técnicas de caracterización empleadas, con una breve descripción de las mismas y una breve fundamentación de su utilidad: isotermas de adsorción de $\mathrm{N}_{2}$ (BET), quimisorción de $\mathrm{H}_{2}$, Microscopía Electrónica de Transmisión (TEM), difracción de rayos X (DRX), Reducción a Temperatura Programada (TPR), determinación de propiedades ácido-base por descomposición de isopropanol (IPA), Espectroscopia Fotoelectrónica de Rayos X (XPS) y Espectroscopia de absorción de Rayos X (EXAFS).

Finalmente, se describen las técnicas de evaluación catalítica, los equipos experimentales y las condiciones operativas utilizadas.

\section{II.2. Técnicas de preparación}

La preparación y formulación de catalizadores comprende, diferentes etapas: impregnación del soporte con los precursores metálicos, agregado de aditivos o promotores, secado y tratamientos para la transformación de las fases activas (ya sea para obtener catalizadores a base de óxidos o de metales reducidos). La etapa de impregnación consiste en poner en contacto el soporte sólido con la solución que contiene los precursores de la fase activa. La manera en que esto se lleva a cabo juega un papel determinante en la distribución macroscópica y microscópica de los componentes y la concentración final de los metales depositados.

Se pueden distinguir dos tipos principales de impregnación: con interacción y sin interacción. La impregnación con interacción involucra la aparición de una fuerte relación entre el precursor y el soporte desde la puesta en contacto entre ambos (intercambio iónico). En la impregnación sin interacción se da la situación inversa, la 
cohesión entre el precursor y el soporte es débil; siendo las fuerzas puestas en juego del tipo Van der Waals [1, 2].

En esta Tesis se han utilizado ambas técnicas: impregnación con interacción (intercambio iónico) así como también la impregnación sin interacción (impregnación a humedad incipiente) para la preparación de los catalizadores.

Se utilizaron soportes comerciales y soportes modificados por óxidos a partir del método de impregnación:

- $\gamma-\mathrm{Al}_{2} \mathrm{O}_{3}$ Dycat International, Dytech Corporation LTD, $205 \mathrm{~m}^{2} / \mathrm{g}$

- $\alpha-\mathrm{Al}_{2} \mathrm{O}_{3}$ Rhone Poulenc Spheralite $512 ; 10 \mathrm{~m}^{2} / \mathrm{g}$

- $\mathrm{SiO}_{2}$ Aerosil 200-Degussa, $200 \mathrm{~m}^{2} / \mathrm{g}$, no porosa

- $\mathrm{CeZr} \alpha-\mathrm{Al}_{2} \mathrm{O}_{3}: \alpha-\mathrm{Al}_{2} \mathrm{O}_{3}$ Rhone Poulenc Spheralite 512 modificada con $4 \%$ de $\mathrm{CeO}_{2}$ y $1 \%$ de $\mathrm{ZrO}_{2}$

\section{II.2.1. Método de impregnación a humedad incipiente}

Es el método más simple y utilizado para dispersar un componente activo sobre un soporte poroso. Se realiza la impregnación del soporte seco a humedad incipiente con una solución acuosa que contiene la sal (precursor) del elemento activo. La sal precursora se disuelve en un volumen de solución igual al volumen de poros del soporte, luego esta solución es agregada lentamente al soporte, el cual se transporta a través de los poros gracias a la fuerza capilar que tiene lugar. Este agregado de solución se realiza hasta que los poros del soporte se encuentren saturados. De esta manera se asegura la cantidad precisa de fase activa sobre el soporte. Luego al secar el soporte en aire, gas inerte o vacío (generalmente entre $80{ }^{\circ} \mathrm{C}$ y $150{ }^{\circ} \mathrm{C}$ ) se depositan cristales del precursor en los poros. La velocidad del secado determinada por el flujo de gas y la temperatura, afecta la deposición del material. Bajas velocidades de secado producen a la evaporación de la solución en los meniscos del poro lo que hace que la mayoría del precursor se deposite en el fondo del poro. Si el secado es demasiado rápido se establece un gradiente de temperatura que produce la evaporación del solvente en el fondo del poro, creando la deposición del precursor en la entrada del mismo.

Una desventaja de este método es su dificultad para lograr distribuciones uniformes de la fase activa sobre los soportes, ya que un soporte posee un rango de distribución de tamaños de poros por lo que es difícil optimizar la velocidad de secado. Sin embargo, 
posee ventajas como su simplicidad, rapidez y capacidad para depositar altos contenidos metálicos.

\section{II.2.2. Preparación de catalizadores por el método de impregnación a humedad incipiente}

- $\mathbf{P t} / \mathrm{SiO}_{2}\left(\mathbf{P t S i}{ }^{\mathrm{IMP}}\right)$ : Como soporte se utilizó $\mathrm{SiO}_{2}$ de las características citadas anteriormente. Previo a la impregnación, la sílice fue calcinada durante $2 \mathrm{~h} \mathrm{a}$ $500^{\circ} \mathrm{C}$ para eliminar impurezas. La impregnación de este soporte se realizó con una solución de $\left[\mathrm{Pt}\left(\mathrm{NH}_{3}\right)_{4}\right] \mathrm{Cl}_{2}$, de modo tal de obtener de 1 a $2 \%$ p/p de Pt en el sólido. El sólido, luego de la impregnación, se secó a $100^{\circ} \mathrm{C}$ en estufa, se calcinó en aire a $500^{\circ} \mathrm{C}$ y se redujo en $\mathrm{H}_{2}$ a la misma temperatura. El contenido de $\mathrm{Pt}$ fijado en el sólido se analizó por Absorción Atómica.

- $\mathbf{P t} / \gamma-\mathrm{Al}_{2} \mathrm{O}_{3}\left(\mathbf{P t A l}{ }^{\mathrm{IMP}}\right)$ : Como soporte se utilizó $\gamma-\mathrm{Al}_{2} \mathrm{O}_{3}$ de las características citadas anteriormente. Previo a la impregnación, la alúmina fue calcinada durante $2 \mathrm{~h}$ a $500{ }^{\circ} \mathrm{C}$ para eliminar impurezas. La impregnación de este soporte se realizó con una solución de $\mathrm{H}_{2} \mathrm{PtCl}_{6}$, de modo tal de obtener de 1 a $2 \%$ p/p de Pt en el sólido. El sólido, luego de la impregnación, se secó a $100{ }^{\circ} \mathrm{C}$ en estufa, se calcinó en aire a $500{ }^{\circ} \mathrm{C}$ y se redujo en $\mathrm{H}_{2}$ a la misma temperatura. El contenido de Pt fijado en el sólido se analizó por Absorción Atómica.

- $\mathbf{P t} / \boldsymbol{\alpha}-\mathrm{Al}_{2} \mathrm{O}_{3}$ (PtaAl): Como soporte se utilizó $\alpha-\mathrm{Al}_{2} \mathrm{O}_{3}$ de las características citadas anteriormente. Fue calcinada previamente durante $2 \mathrm{~h}$ a $500{ }^{\circ} \mathrm{C}$ para eliminar impurezas. La impregnación de este soporte se realizó con una solución de $\mathrm{H}_{2} \mathrm{PtCl}_{6}$, de modo tal de obtener $1 \% \mathrm{p} / \mathrm{p}$ de Pt en el sólido. El sólido luego de la impregnación se secó a $100{ }^{\circ} \mathrm{C}$ en estufa, se calcinó en aire a $500{ }^{\circ} \mathrm{C}$ y se redujo en $\mathrm{H}_{2}$ a la misma temperatura. El contenido de Pt fijado en el sólido se analizó por Absorción Atómica.

- Soporte CeZra- $\mathrm{Al}_{2} \mathrm{O}_{3}$ (CZA): Este soporte se obtuvo por impregnación con $\mathrm{ZrO}\left(\mathrm{NO}_{3}\right)_{2} \mathrm{xH}_{2} \mathrm{O}$ (Aldrich) y posterior impregnación con $\mathrm{Ce}\left(\mathrm{NO}_{3}\right)_{3} 6 \mathrm{H}_{2} \mathrm{O}$ (Alfa) sobre el soporte $\alpha-\mathrm{Al}_{2} \mathrm{O}_{3}$ de Rhone Poulenc. La composición de las soluciones 
de impregnación fueron tales que condujeron a una concentración $4 \% \mathrm{p} / \mathrm{p}$ de $\mathrm{CeO}_{2}$ y $1 \%$ p/p de $\mathrm{ZrO}_{2}$ en el soporte. Luego de la impregnación, se procedió al secado a $120{ }^{\circ} \mathrm{C}$ durante 12 horas y a su calcinación en aire durante 4 horas a $600^{\circ} \mathrm{C}$.

- $\mathrm{Pt} / \mathrm{CeO}_{2} \mathrm{ZrO}_{2} \alpha-\mathrm{Al}_{2} \mathrm{O}_{3}$ (PtCZA): La preparación se realizó por impregnación del soporte CZA con una solución de $\mathrm{H}_{2} \mathrm{PtCl}_{6}$, de modo tal de obtener $1 \% \mathrm{p} / \mathrm{p}$ de Pt en el sólido. El sólido, luego de la impregnación, se secó a $100^{\circ} \mathrm{C}$ en estufa, se calcinó en aire a $500^{\circ} \mathrm{C}$ y se redujo en $\mathrm{H}_{2}$ a la misma temperatura. El contenido de Pt fijado en el sólido se analizó por Absorción Atómica.

- $\mathrm{Ni} / \mathrm{CeO}_{2} \mathrm{ZrO}_{2} \alpha-\mathrm{Al}_{2} \mathrm{O}_{3}$ (NiCZA): La preparación se realizó por impregnación del soporte CZA con una solución de $\mathrm{Ni}\left(\mathrm{NO}_{3}\right)_{2} 6 \mathrm{H}_{2} \mathrm{O}$ (Aldrich), de modo tal de obtener 5\% p/p de Ni en el sólido. El sólido, luego de la impregnación, se secó a $100{ }^{\circ} \mathrm{C}$ en estufa, se calcinó en aire a $750{ }^{\circ} \mathrm{C}$ y se redujo en $\mathrm{H}_{2}$ a la misma temperatura. El contenido de Ni fijado en el sólido se analizó por Absorción Atómica.

- Catalizador bimetálico PtNi/CeO $\mathrm{ZrO}_{2} \alpha-\mathrm{Al}_{2} \mathrm{O}_{3}$ (PtNi/CZA): El catalizador de $\mathrm{Ni} / \mathrm{CeO}_{2} \mathrm{ZrO}_{2} \alpha-\mathrm{Al}_{2} \mathrm{O}_{3}$ (descrito anteriormente), fue impregnado con una solución de $\mathrm{H}_{2} \mathrm{PtCl}_{6}$, de modo tal de obtener $1 \% \mathrm{p} / \mathrm{p}$ de Pt en el sólido. El sólido, luego de la impregnación, se secó a $100{ }^{\circ} \mathrm{C}$ en estufa, se calcinó en aire a $500{ }^{\circ} \mathrm{C}$ y se redujo en $\mathrm{H}_{2}$ a la misma temperatura. El contenido de Pt fijado en el sólido se analizó por Absorción Atómica.

\section{II.2.3. Método de impregnación por Intercambio Iónico}

El método de intercambio iónico consiste en intercambiar un ión ligado al soporte con otro ión, que contiene al precursor de la fase catalítica, presente en la solución de contacto. Muchos sólidos se comportan como intercambiadores naturales (zeolitas, resinas de intercambio), otros presentan un carácter anfótero, como ocurre con algunos soportes cuya superficie es portadora de grupos $\mathrm{OH}^{-}$.

La variación en la carga de la superficie, Z-OH, puede describirse por la siguiente ecuación: 
Esto significa que si se agrega un ácido en el medio, la reacción (Ecuación II-01) se desplaza hacia la derecha, dando como resultado un sólido cuya superficie está formada por especies $\mathrm{Z}^{+}$, lo que convierte al sólido en un intercambiador aniónico. Por el contrario, si se agrega una base, la reacción se desplaza hacia la izquierda, la superficie del sólido se encuentra como Z-O-, y en este caso actúa como intercambiador catiónico. Estos grupos superficiales cargados (debido a la protonación o deprotonación de los grupos Z-OH) son los sitios de adsorción del ión activo en el intercambio y su concentración determina la cantidad de especies positivas o negativas que pueden ser adsorbidas sobre la superficie del sólido. Existe un $\mathrm{pH}$ para el cual la resultante de cargas sobre la superficie es nula; esto es, la cantidad de grupos superficiales cargados positivamente, del tipo $\mathrm{Z}^{+}$es igual a la cantidad de grupos cargados negativamente, $\mathrm{Z}-\mathrm{O}^{-}$. A este valor de $\mathrm{pH}$ se lo conoce como punto isoeléctrico (pI). En la Tabla II-01, se presentan una serie de valores de pI, para algunos sólidos de interés catalítico.

Tabla II-01. Puntos isoeléctricos (pI) para sólidos de interés en catálisis

Fuente: George A. Parks, [3]

\begin{tabular}{|c|c|c|}
\hline Sólido & pI & Tipo de intercambio \\
\hline $\mathrm{Sb}_{2} \mathrm{O}_{5}$ & $<0,4$ & Catiónico \\
\hline $\mathrm{WO}_{3}$ & $<0,3$ & “ \\
\hline $\mathrm{SiO}_{2}$ & $1-2$ & “ \\
\hline $\mathrm{MnO}_{2}$ & $3,9-4,5$ & Aniónico o Catiónico \\
\hline $\mathrm{SnO}_{2}$ & 5,5 & " \\
\hline $\mathrm{TiO}_{2}$ & 6 & “ \\
\hline$\tau-\mathrm{Fe}_{2} \mathrm{O}_{3}$ & $6,5-6,9$ & “ \\
\hline $\mathrm{ZrO}_{2}$ & 6,7 & “ \\
\hline $\mathrm{CeO}_{2}$ & 6,8 & “ \\
\hline $\mathrm{Cr}_{2} \mathrm{O}_{3}$ & $6,5-7,5$ & “niónico \\
\hline $\mathrm{Al}_{2} \mathrm{O}_{3}$ & $7,0-9,0$ & “ \\
\hline$\alpha-\mathrm{Fe}_{2} \mathrm{O}_{3}$ & $8,4-9,0$ & “ \\
\hline $\mathrm{ZnO}$ & $8,7-9,7$ & “ \\
\hline $\mathrm{La}_{2} \mathrm{O}_{3}$ & 10,5 & \\
\hline $\mathrm{MgO}$ & $12,1-12,7$ & \\
\hline
\end{tabular}


La técnica más utilizada para determinar el pI de un material es la electroforesis. Esta técnica se basa en la migración diferencial (en sentido y velocidad) de partículas cargadas en un campo eléctrico establecido al efecto, es decir, en un gradiente de potencial. La velocidad electroforética es proporcional a la diferencia de potencial entre áreas opuestas de la doble capa eléctrica (potencial Z). De esta manera se puede determinar una relación entre la carga superficial y el $\mathrm{pH}$. Variación del potencial zeta para la sílica y alúmina, se muestran en la siguiente figura:

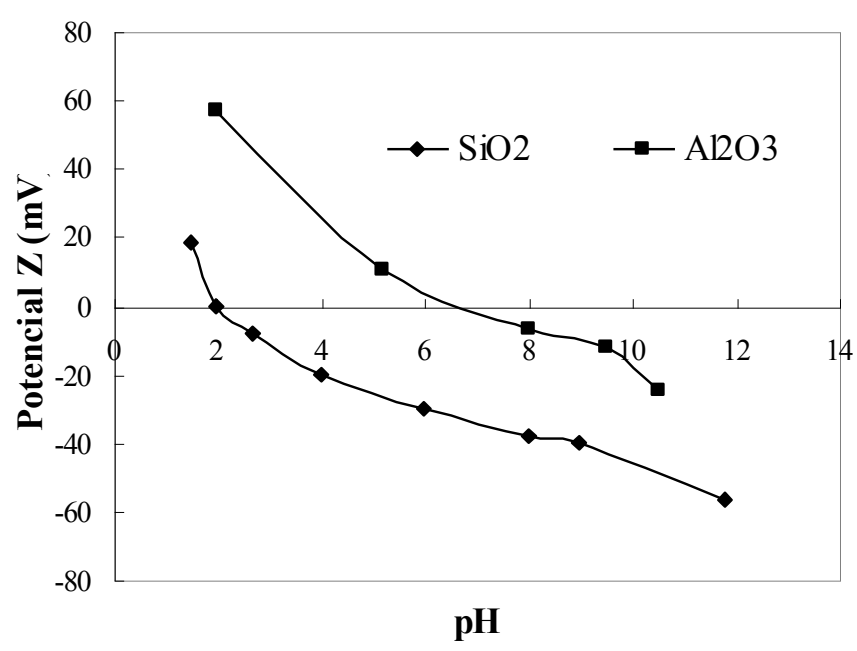

Figura II-01. Potencial $\mathrm{Z}$ como función del pH para $\mathrm{SiO}_{2}$ y $\mathrm{Al}_{2} \mathrm{O}_{3}$

Fuente: Tesis Doctoral G. Santori, [4]

Para un valor de $\mathrm{pH}>\mathrm{pI}$, el soporte se comporta como intercambiador catiónico ( ${\left.\mathrm{Z}-\mathrm{O}^{-}\right)}^{-}$ y si el $\mathrm{pH}<\mathrm{pI}$, se comporta como intercambiador aniónico $\left(\mathrm{Z}^{+}\right)$. El punto isoeléctrico de la $\mathrm{SiO}_{2}$ es aproximadamente 2 (Figura II-01), corresponde al valor de $\mathrm{pH}$ para el cual el potencial $\mathrm{Z}$ es cero. Este valor nos indica la naturaleza ácida de este sólido. Una polarización negativa de su superficie ocurre a valores de $\mathrm{pH}$ mayores que 2 , pero llega a ser significativo solamente a valores de $\mathrm{pH}$ por encima de 5 . A partir de un $\mathrm{pH}=11$, la $\mathrm{SiO}_{2}$ comienza a disolverse. De esta manera la $\mathrm{SiO}_{2}$ es un excelente intercambiador catiónico para valores de $\mathrm{pH}$ entre 9 y 11. La $\gamma-\mathrm{Al}_{2} \mathrm{O}_{3}$, cuyo pI se encuentra entre 6-7, es intercambiador aniónico a valores de $\mathrm{pH}$ entre 1 y 2 [2, 5].

El valor de saturación de la concentración metálica es un factor muy importante y queda determinada por el número de sitios disponibles para la adsorción en el soporte, la concentración de los iones en la solución, el pH y la constante de equilibrio de adsorción. En general, mediante este método se obtienen cantidades entre 2-3\%p/p de 
metal depositado. A pesar de esta limitación en la carga metálica, el intercambio iónico es un método sumamente eficiente para obtener catalizadores con alta dispersión metálica y homogeneidad en la distribución de tamaños de partículas. En este trabajo se eligieron valores de concentración del metal entre 1 y $2 \%$ p/p de Pt.

La capacidad máxima de intercambio de $\mathrm{Pt}$ sobre los soportes $\mathrm{SiO}_{2}$ y $\mathrm{Al}_{2} \mathrm{O}_{3}$ fue determinada en trabajos previos del grupo de trabajo [4]. Estos valores son de 2,53 $\% \mathrm{p} / \mathrm{p} \mathrm{Pt} / \gamma-\mathrm{Al}_{2} \mathrm{O}_{3}$ y $2,05 \% \mathrm{p} / \mathrm{p} \mathrm{Pt} / \mathrm{SiO}_{2}$.

\section{II.2.4. Preparación de Catalizadores por el método de intercambio iónico}

- Preparación del catalizador de $\mathbf{P t} / \mathrm{SiO}_{2}$ (PtSi): A la $\mathrm{SiO}_{2}$ descripta anteriormente se adicionó una solución de $\mathrm{NH}_{4} \mathrm{OH}$ de $\mathrm{pH}=10,6$. Se agitó y se mantuvo el sistema a una temperatura de $25^{\circ} \mathrm{C}$, en un baño termostatizado. La reacción que ocurre en esta etapa puede escribirse en la forma siguiente:

$$
[\mathrm{Si}-\mathrm{OH}]+\mathrm{NH}_{4}^{+} \leftrightarrow\left\lfloor\left(\mathrm{NH}_{4}^{+}\right)(\equiv \mathrm{Si}-\mathrm{O})^{-}\right\rfloor+H^{+}
$$

Ecuación II-02

Luego de este paso, los sólidos se separaron de la solución por filtración, y se impregnaron con una solución de $\left[\mathrm{Pt}\left(\mathrm{NH}_{3}\right)_{4}\right] \mathrm{Cl}_{2}$. La concentración de la solución de intercambio utilizada fue la necesaria para obtener $1 \% \mathrm{p} / \mathrm{p}$ y $2 \% \mathrm{p} / \mathrm{p}$ de Pt en el sólido. La reacción que representa el intercambio es la siguiente:

$$
\left[\mathrm{Pt}\left(\mathrm{NH}_{3}\right)_{4}\right]^{++}+2\left[\left(\mathrm{NH}_{4}\right)^{+}(\equiv \mathrm{Si}-\mathrm{O})^{-}\right] \leftrightarrow\left[\mathrm{Pt}\left(\mathrm{NH}_{3}\right)_{4}\right]^{++}(\equiv \mathrm{Si}-\mathrm{O})_{2}^{-}+2 \mathrm{NH}_{4}^{+}
$$

Ecuación II-03

Se mantuvo el sistema durante $24 \mathrm{~h}$ en agitación y a una temperatura de $25^{\circ} \mathrm{C}$, con el fin de obtener una distribución uniforme de Pt sobre la superficie del soporte, tal como fue reportado por Goguet y col. [6].

Los sólidos luego del intercambio se separaron de las aguas madres por filtración, se lavaron, se secaron a $100^{\circ} \mathrm{C}$ en estufa. Posteriormente se calcinaron en mufla a $500^{\circ} \mathrm{C}$ y se redujeron ex situ en flujo de $\mathrm{H}_{2}$ durante $2 \mathrm{~h}$ a $500{ }^{\circ} \mathrm{C}$. 
- Preparación del catalizador de $\mathrm{Pt} / \mathrm{SiO}_{2}$ sinterizado (PtSi ${ }^{\mathrm{SINT}}$ ): El catalizador denominado $\mathrm{PtSi}^{\mathrm{SINT}}$ fue preparado por sinterizado del catalizador $2 \mathrm{PtSi}$ por tratamiento a $800^{\circ} \mathrm{C}$ en flujo de hidrógeno saturado con vapor de agua durante 24 horas.

- Preparación de $\mathbf{P t} / \gamma-\mathrm{Al}_{2} \mathrm{O}_{3}$ (PtAl): Como soporte se utilizó $\gamma-\mathrm{Al}_{2} \mathrm{O}_{3}$, de las características citadas anteriormente. La impregnación de este soporte se realizó por intercambio aniónico con una solución de $\mathrm{H}_{2} \mathrm{PtCl}_{6}$, de modo tal de obtener $1 \% \mathrm{p} / \mathrm{p}$ y $2 \% \mathrm{p} / \mathrm{p}$ de Pt en el sólido.

La reacción que representa el intercambio es la siguiente:

$\mathrm{H}_{2} \mathrm{PtCl}_{6}+2(=\mathrm{Al}-\mathrm{OH}) \leftrightarrow\left[\left(\mathrm{PtCl}_{6}\right)^{=}(=\mathrm{Al}-)_{2}^{+}\right\rfloor+2 \mathrm{H}_{2} \mathrm{O}$ Ecuación II-04

Luego de mantener el sistema en agitación durante $24 \mathrm{~h}$ a una temperatura de $25^{\circ} \mathrm{C}$, se separaron los sólidos de la solución sobrenadante por filtración, se secaron en estufa a $100^{\circ} \mathrm{C}$. Posteriormente se calcinaron en mufla a $500^{\circ} \mathrm{C}$ y se redujeron exsitu en flujo de $\mathrm{H}_{2}$ durante $2 \mathrm{~h}$ a $500^{\circ} \mathrm{C}$.

Luego de la etapa de reducción, los catalizadores se lavaron varias veces con $\mathrm{NH}_{4} \mathrm{OH}(\mathrm{pH}=10,6)$, de modo de obtener una concentración de cloro por debajo de $0,1 \%$ en el sólido resultante. Luego de este lavado, se procedió a secar en estufa a $100^{\circ} \mathrm{C}$.

El contenido de Pt fijado en el sólido se analizó por Absorción Atómica.

\section{II.2.5. Método de la química organometálica de superficies sobre metales (QOMS/M)}

Los métodos clásicos de preparación de sistemas bimetálicos involucran coimpregnaciones o impregnaciones sucesivas de los precursores metálicos (usualmente sales inorgánicas), sobre soportes sólidos. Estas técnicas son ampliamente utilizadas porque, además de su simplicidad, permiten arribar a materiales catalíticos que pueden ser preparados en gran escala y utilizados en aplicaciones industriales. Sin embargo, estas metodologías simples de preparación generalmente llevan a la formación de fases bimetálicas bastante heterogéneas, debido a que coexisten varias composiciones 
metálicas en dichas fases. La obtención de fases activas homogéneas en su composición y naturaleza conduce a sistemas con mejores propiedades globales, razón por la que el estudio y la comprensión de técnicas de preparación controlada de catalizadores sólidos es de interés permanente. La QOMS/M es una técnica de preparación controlada de sistemas bimetálicos que consiste en la reacción de compuestos organometálicos (principalmente alquilmetales del Grupo 14) con metales de transición soportados (en estado reducido u oxidado) [7-10]. Sistemas catalíticos preparados vía QOMS/M muestran un remarcable comportamiento en lo que respecta a la selectividad bajo determinadas condiciones operativas en numerosas reacciones de hidrogenación y deshidrogenación. Por ejemplo, en reacciones de hidrogenación de ésteres a alcoholes (RhSn, RuSn, NiSn), hidrogenación de compuestos carbonílicos insaturados a alcoholes insaturados (RhSn, RhSnBux), hidrogenación de diolefinas y alquinos a monoolefinas $(\mathrm{PdPb})$, deshidrogenación de isobutano a isobuteno ( $\mathrm{RhSn}, \mathrm{PtSn})$, hidrogenación de acrilonitrilo a propionitrilo $(\mathrm{NiPb})$ [11-14]. En trabajos previos realizados por Santori y col. se han estudiado catalizadores de $\mathrm{PtSn} / \mathrm{SiO}_{2}$ preparados vía QOMS/M con excelentes resultados en hidrogenación selectiva de aldehídos $\alpha, \beta$-insaturados y cetonas $[15,16]$.

\section{II.2.6. Preparación de sistemas bimetálicos por el método QOMS/M}

- Preparación de sistemas $\mathrm{PtSn} / \mathrm{SiO}_{2}$ : En esta Tesis se prepararon catalizadores bimetálicos de $\mathrm{PtSn} / \mathrm{SiO}_{2}$ siguiendo el protocolo que se detalla en el ANEXO I. La preparación consistió en la reacción entre el catalizador $\mathrm{Pt} / \mathrm{SiO}_{2}$ reducido y $\mathrm{SnBu}_{4}$, disuelto en n-heptano $\left(90^{\circ} \mathrm{C}\right)$ o n-decano $\left(120\right.$ y $\left.150^{\circ} \mathrm{C}\right)$, en atmósfera de $\mathrm{H}_{2}$ (Ecuación II-05). Luego de seis horas de reacción, el sólido obtenido se lavó con varias porciones de n-heptano y se secó en $\mathrm{Ar}$ a $90^{\circ} \mathrm{C}$.

$$
\mathrm{Pt} / \mathrm{SiO}_{2}+y \mathrm{SnBu} u_{4}+x y / 2 \mathrm{H}_{2} \rightarrow \mathrm{Pt}\left(\mathrm{SnBu} u_{4-x}\right)_{y} / \mathrm{SiO}_{2}+x y \mathrm{BuH}
$$

Ecuación II-05

$$
\mathrm{Pt}\left(\mathrm{SnBu}_{4-x}\right)_{y} / \mathrm{SiO}_{2}+(4-x) y / 2 \mathrm{H}_{2} \rightarrow \mathrm{PtSn}_{y} / \mathrm{SiO}_{2}+(4-x) y \mathrm{BuH}
$$

Ecuación II-06 
Luego de esta primera etapa de reacción se realizó la activación de la fase organobimetálica soportada $\left.\mathrm{Pt}(\mathrm{SnBu})_{4-\mathrm{x}}\right)_{\mathrm{y}} / \mathrm{SiO}_{2}$ en $\mathrm{H}_{2}$ a $500^{\circ} \mathrm{C}$ durante $2 \mathrm{~h}$ (Ecuación II-06).

La cantidad de Sn se varió entre 0,1 a $0,5 \%$ p/p de Sn. La variación de la concentración de $\mathrm{SnBu}_{4}$ y la de los gases desprendidos en la reacción (principalmente butano) fue analizada utilizando un cromatógrafo gaseoso Varian 3400, equipado con un detector FID y una columna 10\% OV-101 (1/8 od y $0,5 \mathrm{~m}$ de longitud). El contenido de Pt y Sn en los catalizadores se determinó por Absorción Atómica (AA) utilizando un espectrómetro IL-457. El contenido de $\mathrm{Sn}$ en los catalizadores determinado por AA estuvo en concordancia con los valores calculados a partir del balance de materia.

\section{3. Técnicas de Caracterización}

\section{III.3.1. Determinación de la superficie específica de los soportes (BET)}

Los átomos que se encuentran en la superficie de un sólido utilizado como soporte, no tienen las fuerzas de cohesión compensadas, como ocurre en los átomos situados en el seno del sólido, siendo en definitiva esta descompensación, la responsable de las propiedades de adsorción de los sólidos. Existen dos tipos de adsorción: fisisorción y quimisorción. La diferencia fundamental entre ambas es que en el caso de la fisisorción la especie adsorbida (fisisorbida) conserva su naturaleza química, mientras que durante la quimisorción la especie adsorbida (quimisorbida) sufre una transformación para dar una especie distinta.

En el caso de los sólidos porosos, la adsorción ocurre fundamentalmente en los poros. La IUPAC reconoce tres tipos de poros según su tamaño. Si son mayores de $50 \mathrm{~nm}$ se los denomina macroporos, si su diámetro está comprendido entre 3 y $50 \mathrm{~nm}$ se trata de mesoporos y si son menores de $3 \mathrm{~nm}$ se denominan microporos.

La adsorción característica en sólidos con macroporos, es del tipo de condensación capilar (el adsorbato se ordena en capas sucesivas: llenado en multicapas). Este tipo de adsorción se encuentra descripta por la ecuación de Kelvin (Ecuación II-07), que en el caso de los poros cilíndricos, puede escribirse de la forma: 
$\ln (P / P o)=2 V \gamma / R \operatorname{Tr} \cos (\varphi)$

Ecuación II-07

donde $\mathrm{V}$ y $\gamma$ son, respectivamente, el volumen molar y la tensión superficial del adsorbato, $\mathrm{r}$ el tamaño de poro del adsorbente y $\varphi$ el ángulo de contacto entre el adsorbato y el adsorbente, que en general se supone igual a cero. Po es la presión de saturación del adsorbato.

Cuando el tamaño del poro disminuye se produce un incremento significativo del potencial de adsorción, ocasionado por el solapamiento de los potenciales de las paredes del poro. Así para un mismo adsorbato, la interacción con las paredes del poro es mayor cuanto menor es el tamaño del poro, y por lo tanto, mejor el confinamiento de la molécula adsorbida.

La cantidad de gas adsorbido a una temperatura dada para distintas presiones relativas de gas se conoce como isoterma de adsorción. Las isotermas de adsorción son muy útiles para la caracterización de sólidos porosos. La IUPAC reconoce seis tipos de isotermas de adsorción. La forma de la isoterma nos puede dar alguna indicación del tipo de porosidad del sólido. Se han desarrollado numerosos métodos con el objetivo de estimar algunas de las propiedades relacionadas con la porosidad de los sólidos tales como la superficie específica, el volumen de poros y la distribución del tamaño de poros.

El método BET propuesto por Brunauer, Emmett y Teller en 1938 es el más usado para el análisis de los datos de adsorción, el cual introduce un número de simplificaciones para su aplicación. La idea central del método BET consiste en determinar el área superficial de un sólido, conocida la cantidad de gas adsorbido necesario para formar una monocapa y el área que ocupa una de estas moléculas adsorbidas [17].

$$
\frac{p}{n\left(p_{0}-p\right)}=\frac{1}{n_{m} C}+\frac{(C-1)}{n_{m} C} \times \frac{p}{p_{0}}
$$

Ecuación II-08

$\mathrm{n}$ : es la cantidad de gas adsorbida en equilibrio con la presión $\mathrm{p}$

$\mathrm{n}_{\mathrm{m}}$ : es la cantidad de gas adsorbida por una monocapa

$\mathrm{p}_{0}$ : es la presión de vapor del adsorbato en el estado condensado a la temperatura de adsorción

$\mathrm{C}$ : es una constante que relaciona el calor de adsorción en la primera capa y el calor de condensación del adsorbato. Esta constante determina en parte la forma de la isoterma 
Esta ecuación (Ecuación II-08) permite obtener una relación lineal entre $p / n\left(p_{0}-p\right)$ y $\mathrm{p} / \mathrm{p}_{0}$. La linealidad y por lo tanto el rango de aplicación del método BET está restringido a valores de $\mathrm{p} / \mathrm{p}_{0}$ entre $0,05-0,30$.

A pesar de la simplicidad del modelo BET y de las simplificaciones hechas para derivar esta ecuación, el área específica BET es un valor reproducible y correcto para la mayoría de los materiales catalíticos.

El área superficial BET presentada en este trabajo de tesis fue medida usando un equipo de adsorción de Nitrógeno Micromeritics Accursorb $2100 \mathrm{E}$, a $-196^{\circ} \mathrm{C}$ sobre $200 \mathrm{mg}$ de muestra previamente desgasificada a $200{ }^{\circ} \mathrm{C}$ bajo una atmósfera de alto vacío durante 2 horas.

\section{II.3.2. Quimisorción dinámica de $\mathrm{H}_{2}$}

La quimisorción de moléculas sonda $\left(\mathrm{H}_{2}, \mathrm{CO}, \mathrm{O}_{2}\right)$ es una técnica simple que brinda información muy valiosa para la caracterización de metales. Involucra la medida de la cantidad de gas requerido para formar una monocapa adsorbida sobre la superficie metálica. El gas es selectivamente quimisorbido sobre la superficie del metal. De esta manera la quimisorción puede usarse para medir la dispersión, que es la relación entre los átomos metálicos superficiales y la cantidad total de átomos metálicos que posee la muestra.

El éxito del método de quimisorción depende del conocimiento de la estequiometría de adsorción de los gases sobre metales. La estequiometría de adsorción se determina directamente por medida de la adsorción sobre un metal puro no soportado con área superficial conocida. Es comúnmente observado que la relación adsorbato-metal es cercana a la unidad para catalizadores en los cuales el tamaño de partícula es de $1 \mathrm{~nm}$ o menores, en cuyo caso todos los átomos metálicos están en la superficie.

En este trabajo de Tesis se estudió la adsorción de $\mathrm{H}_{2}$ como molécula sonda mediante el método de quimisorción dinámica por pulsos. A partir del conocimiento de la estequiometría de adsorción $\left(\mathrm{H} / \mathrm{Pt}^{\mathrm{s}}\right)$ resulta muy sencillo llegar a la dispersión.

Las medidas se realizaron cuantificando el número de pulsos requeridos para alcanzar un plateau. El ensayo comienza con la reducción de la muestra y posterior barrido con gas inerte $(\mathrm{Ar}$ o $\mathrm{He})$ a niveles térmicos suficientes $\left(500^{\circ} \mathrm{C}\right)$ para que se produzca la desorción del hidrógeno. Luego se enfría a temperatura ambiente y se inyectan pulsos de $\mathrm{H}_{2}$, mientras se analiza la composición de salida del reactor con un detector de 
conductividad térmica. La inyección de pulsos finaliza con la saturación de la superficie (la composición de salida es igual a la de entrada). El resultado de la quimisorción se obtiene integrando la cantidad de $\mathrm{H}_{2}$ que quimisorbió la muestra al cabo de la serie completa de pulsos. Para los cálculos de superficie metálica y dispersión se asume el modelo de que cada átomo de $\mathrm{H}_{2}$ es adsorbido por un átomo metálico. Conociendo el volumen de $\mathrm{H}_{2}$ adsorbido se calculan los moles $\left(\mathrm{mH}_{2}\right)$ y átomos de hidrógeno $(\mathrm{atH})$, correspondientes a ese volumen.

Los ensayos se realizaron en un equipo de quimisorción dinámico del grupo de trabajo (Figura II-02). Dicho equipo está equipado con una línea de $\mathrm{Ar}$, una línea de $\mathrm{H}_{2}$ para reducción del catalizador, válvulas de cuatro vías, detector TCD, horno calefactor con control de temperatura y válvula inyectora para los pulsos de $\mathrm{H}_{2}$.

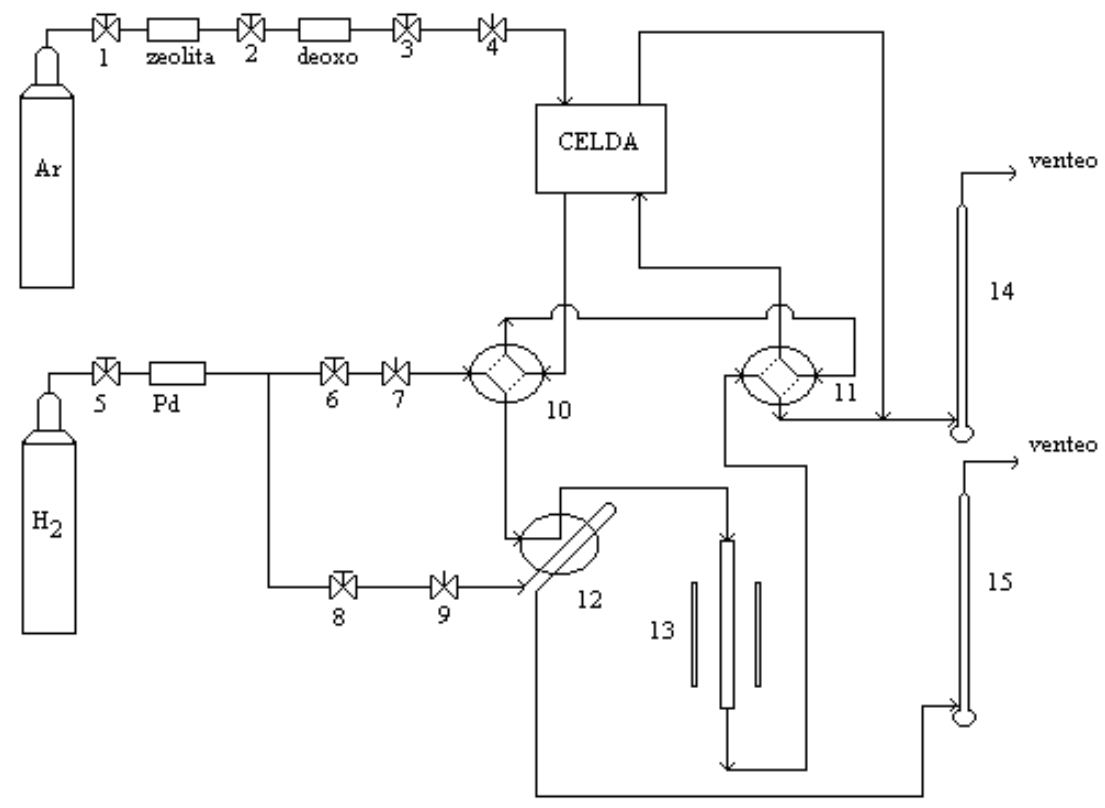

Figura II-02. Esquema del equipo de Quimisorción dinámico

Referencias:

\subsection{8.- Válvulas ON-OFF}

4.7.9.- Válvulas aguja

10.11.- Válvulas de cuatro vías

12.- Válvula inyectora

13.- Reactor

14.15.- Caudalímetros 


\section{II.3.3. Microscopía Electrónica de Transmisión (TEM)}

La microscopía electrónica de transmisión es una técnica directa, que no necesita hacer suposiciones físicas o matemáticas. El principio de funcionamiento del método es idéntico al del microscopio óptico. La fuente es un haz de electrones generados por efecto termoiónico y acelerados en un campo eléctrico (100 keV). Un sistema de lentes electromagnéticas (condensador) da una imagen reducida y focalizada de la fuente sobre la muestra. Esta debe ser muy fina (espesor del orden de $100 \mathrm{~nm}$ ) para que permita a los electrones atravesar el objeto sin ser detenidos. Luego mediante otro sistema de lentes electromagnéticas se obtiene una imagen agrandada del objeto del orden de $10^{6}$ veces. La experiencia se lleva a cabo en vacío ( $10^{-6}$ torr) para no perturbar el haz de electrones. La formación de la imagen puede realizarse con el sistema de imagen del campo claro o del campo oscuro. En el primer caso el diafragma está centrado sobre el haz central, sólo los electrones transmitidos sin difracción forman la imagen; aquéllos que se desviaron pueden ser detenidos. La partícula que difracta aparece entonces oscura sobre un fondo claro. Cuando la imagen se forma, por el contrario, con un rayo difractado y no con el principal, la partícula se ilumina en un campo oscuro. El uso de uno u otro depende de las características del material a observar.

Aunque con los microscopios modernos se pueden alcanzar resoluciones de 0,3 $\mathrm{nm}$ o mejores, en la práctica esto no debe esperarse por varias razones. Por ejemplo, una de ellas es que el soporte normalmente tiene gases adsorbidos que son desorbidos durante la irradiación, conduciendo a una disminución en el vacío del instrumento. Otro problema posible es que el soporte del catalizador es muchas veces aislante y puede hacer que la muestra se cargue eléctricamente, actuando así como una lente extra y degradando de esta manera la calidad de la imagen. También se debe tener en cuenta que la interacción entre el catalizador y la alta energía del haz electrónico puede hacer que los cristales aumenten sensiblemente la temperatura causando el sinterizado, fusión o evaporación del metal. Puede inducir incluso a cambios en la cristalinidad de las partículas.

En este trabajo de tesis se presenta la distribución de los tamaños de partícula, en forma de histogramas para cada una de las muestras analizadas, obtenidas a partir de las fotos tomadas de la pantalla utilizando el sistema de imagen del campo claro. 
El diámetro medio de las partículas se obtuvo a partir del segundo momento de la distribución, denominado diámetro volumen-área, ya que éste se relaciona directamente con las medidas de quimisorción.

Para estimar el tamaño de partícula promedio, las partículas fueron consideradas esféricas y el diámetro volumen-área fue calculado usando la siguiente expresión (Ecuación II-09).

$d_{v a}=\frac{\sum n i \cdot l i^{3}}{\sum n i \cdot l i^{2}}$

Ecuación II-09

Donde li = d(TEM)/ac.u.; siendo d(TEM) el tamaño de las partículas obtenidos por TEM y ac.u. la arista de la celda unidad (cúbica centrada en las caras) para el metal estudiado (ni representa el número de partículas que tienen un diámetro li).

Los resultados de microscopia TEM presentados fueron adquiridos en un microscopio de transmisión electrónica JEOL $100 \mathrm{CX}$, con resolución nominal de $6 \AA$, operado con un voltaje de aceleración de $100 \mathrm{kV}$ y usando una magnificación de 100000x. Cada histograma fue trazado a partir de datos sobre muestras contando un mínimo de 200 partículas.

\section{II.3.4. Difracción de rayos X (DRX)}

La difracción de rayos X es una técnica utilizada para el análisis estructural de cristales. La técnica se basa en una "sonda" electromagnética con una longitud de onda $(\lambda=1,542$ Å) de magnitud muy similar al espaciado interplanar de los sólidos (típicamente de unos $\AA$ ). Por ser los fotones partículas de masa en reposo nula y libre de carga, interactúan con la materia de forma "suave" lo que produce que la DRX sea una técnica de caracterización no destructiva.

Los experimentos de difracción de rayos-X generalmente se realizan bombardeando un blanco metálico, generalmente $\mathrm{Mo} \mathrm{o} \mathrm{Cu}$ con electrones que provienen de un filamento incandescente y son acelerados por un campo eléctrico muy fuerte $30-40 \mathrm{Kv}$. El haz de electrones ioniza electrones de la capa $\mathrm{K}$ (1s) de los átomos metálicos y los rayos-X se emiten como consecuencia de la relajación del sistema mediante el llenado de esos orbitales vacíos con electrones que provienen de capas de mayor energía L (2p) o M 
(3p). Esto da lugar a las líneas de emisión características, $\mathrm{K} \alpha$ y $\mathrm{K} \beta$, que corresponden a las relajaciones, $\mathrm{L} \rightarrow \mathrm{K}: \mathrm{K} \alpha 1$ y $\mathrm{K} \alpha 2$ y $\mathrm{M} \rightarrow \mathrm{K}: \mathrm{K} \beta 1$ y $\mathrm{K} \beta 2$; respectivamente.

Al aumentar el número atómico, la energía de los rayos-X característicos aumenta siendo $1,542 \AA(8,04 \mathrm{keV})$ la $\mathrm{K} \alpha \operatorname{del~Cu~y~} 0,711 \AA(17,44 \mathrm{keV})$ la Ka del Mo.

Se puede seleccionar un haz monocromático, es decir con solo una longitud de onda, de la salida del tubo de rayos-X, mediante el uso de monocromadores o filtros apropiados. Así se dispone de la radiación monocromática que es uno de los elementos principales de un experimento de difracción de rayos-X.

En los difractómetros, los rayos $\mathrm{X}$ provienen de un tubo sellado convencional con anticátodo de cobre. El haz es colimado por un juego de rendijas antes y después de incidir sobre la muestra. El barrido se realiza sincronizadamente entre $\theta-2 \theta$, es decir mientras la muestra avanza un ángulo $\theta$ el detector avanza un ángulo $2 \theta$. De esta forma en todo momento se mantiene la geometría $\theta-2 \theta$ y el haz difractado es recogido por el detector cuando se alcanza la condición de Bragg.

Al impactar un haz de rayos $\mathrm{X}$ sobre un grupo de átomos que constituyen un plano cristalográfico, el mismo es dispersado en dos direcciones con propiedades especiales. Las direcciones corresponden a la continuación del haz en la dirección original y a la reflexión del haz por el plano sobre el cual están los átomos. En ambos casos la distancia entre el frente de onda incidente y un átomo, y el nuevo frente de onda es la misma para todos los átomos localizados sobre el plano. La transmisión a través del plano llevada a cabo por los átomos es entonces equivalente a la reflexión por el plano. Si se mide la intensidad del haz que ha sido difractado, la ley de Bragg permite obtener valores de distancias interplanares de la red cristalina: $\mathrm{n} \lambda=2 \mathrm{~d} \operatorname{sen} \theta$ donde $\mathrm{n}$ es el orden de reflexión, $\lambda$ es la longitud de onda, $\mathrm{d}$ es la distancia entre los planos y $2 \theta$ es el ángulo formado entre el haz incidente y el haz reflejado.

Las experiencias de rayos $\mathrm{X}$ presentados en éste trabajo de tesis se llevaron a cabo en un Goniómetro Philips 3020 con un controlador PW 3710, empleando radiación $\mathrm{Cu}-\mathrm{K} \alpha$, filtro de Ni, $35 \mathrm{kV}-40 \mathrm{~mA}$. No se utilizó monocromador. El barrido fue realizado entre $20^{\circ}$ y $70^{\circ}$ con paso de $0,02^{\circ}$ y $2 \mathrm{~s} /$ paso.

Para determinar los parámetros estructurales y microestructurales de las fases cristalinas identificadas, los difractogramas fueron analizados con el programa FULLPROF, que es un paquete basado en el método de Rietveld. Dicho método de refinamiento estructural se basa en un procedimiento matemático para ajustar un difractograma experimental con uno teórico realizado en base a un modelo 
cristalográfico y a parámetros experimentales. Se trata de lograr minimizar la diferencia matemática entre las intensidades observadas y las calculadas, punto a punto sobre todo el espectro. Para la determinación de parámetros de celda de las fases presentes, se utilizó alúmina como patrón interno para corregir el desplazamiento vertical de la muestra.

La determinación de tamaños cristalinos $\mathrm{D}$ se realizó utilizando la relación de Scherrer donde $\theta$ es el ángulo de reflexión y $\mathrm{B}$ es el ancho de pico:

$D=\frac{0.94 \lambda}{B \cos \theta}$

Ecuación II-11

Para el ajuste de los parámetros instrumentales correspondientes, ancho de los picos de difracción, se utilizó una muestra altamente cristalina de cuarcita natural, como patrón. A partir de los parámetros de celda refinados, se aplicó la Ley de Vegard (Relación lineal entre los parámetros de red y la composición de una solución sólida/aleación expresada en función de la fracción molar) para determinar la composición tanto de la fases $\mathrm{CeO}_{2}-\mathrm{ZrO}_{2}$, como de la aleación PtNi.

Ley de Vegard: $\quad a_{s s}=a_{2} x_{2}+\left(1-x_{2}\right) a_{1}$

Ecuación II-12

Despejando, $x_{2}=\left(a_{s s}-a_{1}\right) /\left(a_{2}-a_{1}\right)$

Donde $\mathrm{a}_{1}$ y $\mathrm{a}_{2}$ son los parámetros de celda cúbicos de las fases puras, $\mathrm{y} \mathrm{a}_{\mathrm{ss}}$ es el parámetro de celda de la solución sólida y $\mathrm{x}_{2}$ es la fracción molar de la fase de mayor $\mathrm{a}_{\mathrm{o}}$ Los parámetros de celda de las sustancias puras utilizados son:

ao $\left(\mathrm{CeO}_{2}\right)=5,4113 \AA$ (PDF: 00-034-0394)

ao $\left(\mathrm{ZrO}_{2}\right)=5,090 \AA$ (PDF 00-027-0997)

ao $(\mathrm{Pt})=3,9231 \AA$ (PDF 00-004-0802)

ao $(\mathrm{Ni})=3,5238 \AA$ (PDF 00-004-0850 ) 


\section{II.3.5. Reducción a Temperatura Programada (TPR)}

La técnica de reducción a temperatura programada (TPR) es utilizada para la caracterización química de sólidos. Es altamente sensible y no depende de ninguna propiedad específica del sólido, sino solamente de su reducibilidad. Esta técnica se basa en la reducción de un sólido por un gas, al mismo tiempo que la temperatura del sistema varía de manera predeterminada. De esta forma puede obtenerse un diagrama de reducción en función de la temperatura, que presenta una serie de picos. Cada uno de ellos representa el proceso de reducción de una especie química particular del sólido. La posición del pico en el diagrama es determinada por la naturaleza química y el entorno de la especie química [18].

Durante la experiencia de TPR, la corriente de gas $\left(\mathrm{H}_{2}-\mathrm{N}_{2}\right)$ que ingresa al sistema, pasa a través de dos trampas, una de retención de oxígeno y la otra para retener agua. Luego esta corriente es dirigida a través de una de las ramas de la celda de conductividad térmica. Una vez que deja la celda, fluye a través del reactor que contiene una cantidad conocida de muestra a reducir (lecho fijo). El reactor se calienta siguiendo una programación lineal de temperatura (usualmente $10^{\circ} \mathrm{C} \min ^{-1}$ ). Los gases que salen del mismo se hacen pasar por una trampa conteniendo un tamiz molecular para retener el agua formada durante el proceso de reducción; y finalmente son conducidos a la otra rama de la celda de conductividad, la que detecta los cambios producidos en la concentración de $\mathrm{H}_{2}$. Dado que el flujo de gas es constante, el cambio en la concentración de $\mathrm{H}_{2}$ es proporcional a la velocidad de reducción. La señal de la celda es adquirida y procesada por un equipo convencional.

En el presente estudio, los diagramas de TPR se obtuvieron trabajando con una mezcla de $10 \%$ de $\mathrm{H}_{2}$ y $90 \%$ de $\mathrm{N}_{2}$, a un caudal de $20 \mathrm{~mL} / \mathrm{min}$, con una velocidad de calentamiento de $10^{\circ} \mathrm{C} \min ^{-1}$. Se utilizó el equipo existente en el CINDECA que se muestra en el siguiente esquema (Figura II-03): 


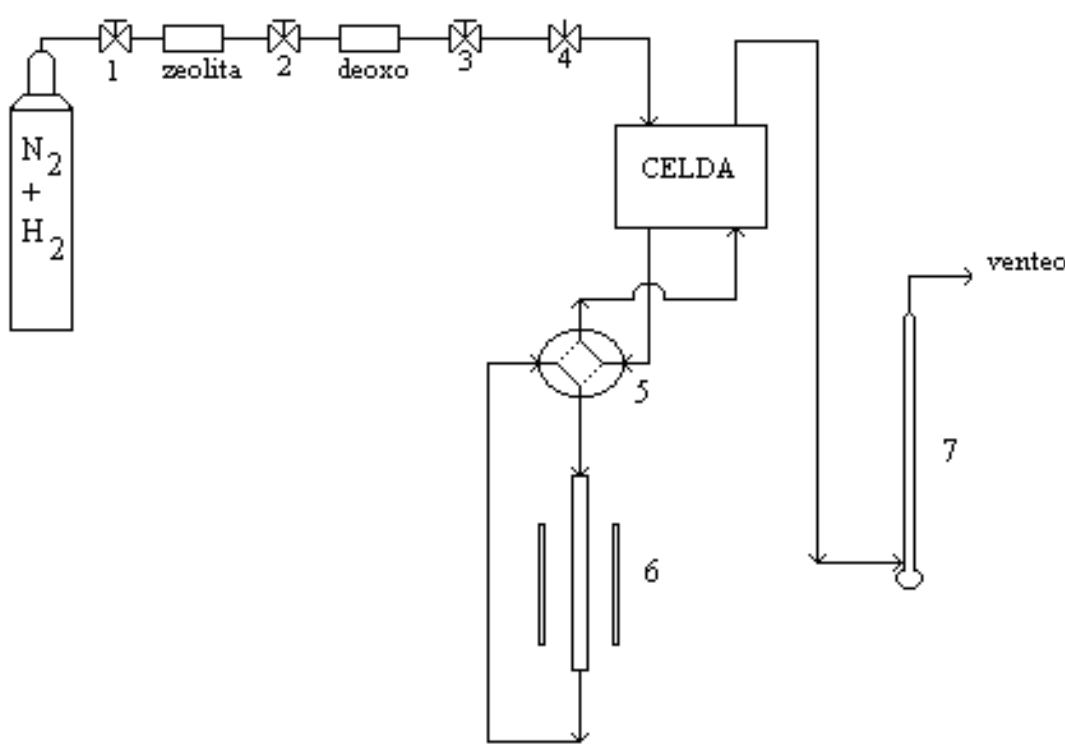

Figura II-03. Esquema del equipo de Reducción a Temperatura Programada

\section{Referencias:}

1.2.3.- Válvulas ON-OFF de la línea de mezcla $\mathrm{N}_{2}-\mathrm{H}_{2}$

4.- Válvula aguja de la línea de mezcla $\mathrm{N}_{2}-\mathrm{H}_{2}$

5.- Válvula de cuatro vías

6.- Reactor

7.- Caudalímetro de línea de mezcla

\section{II.3.6. Reacción de descomposición del alcohol isopropílico (IPA)}

Las propiedades finales de un catalizador dependen marcadamente de la naturaleza de la interacción precursor-soporte generada durante la etapa de preparación. Para determinar las propiedades ácido-base de los soportes se llevó a cabo una caracterización de la acidez superficial.

La reacción de descomposición catalítica de isopropanol es extremadamente sensible a la distribución y fuerza de los sitios ácidos y básicos presentes en los sistemas catalíticos, lo que la hace adecuada como reacción de caracterización. Cuando se produce la descomposición de isopropanol (IPA) por medio de un sólido puede ocurrir una reacción de deshidrogenación, obteniéndose acetona (A) e hidrógeno como productos, o reacciones de deshidratación que originan propileno $(\mathrm{P})$ y agua o diisopropil éter y agua (DIE) (Figura II-04). 


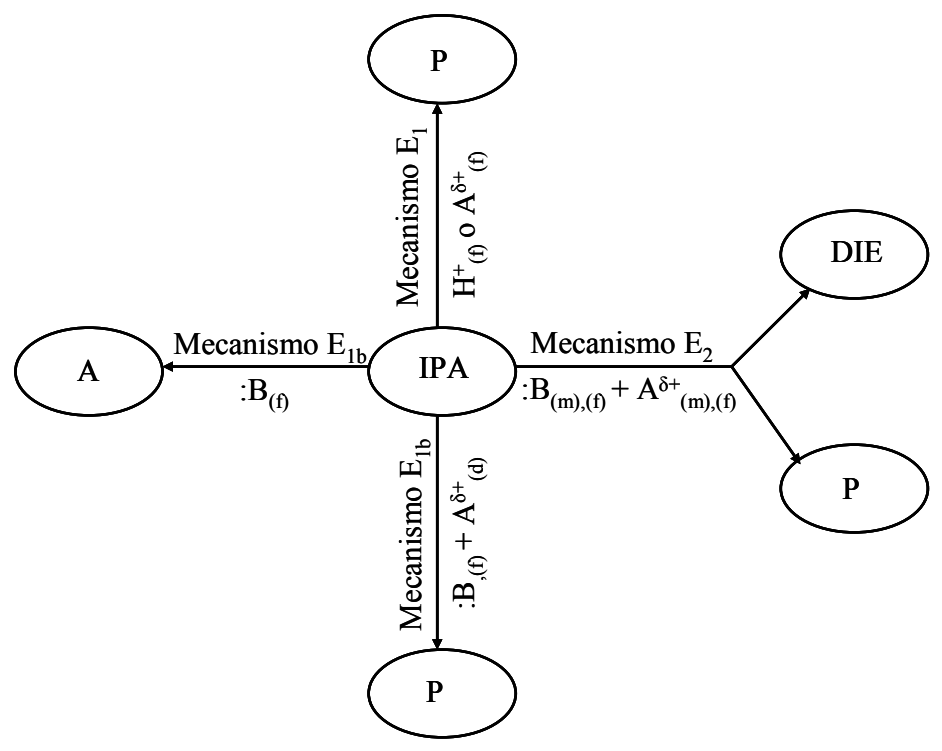

Figura II-04. Mecanismos de reacción para la descomposición del IPA sobre soportes ácidos o básicos. :B indica sitio básico; $\mathrm{d}, \mathrm{m}$, f indican débil, medio y fuerte respectivamente. $\mathrm{A} \delta+$ sitio ácido de Lewis

La deshidratación de isopropanol es catalizada por sitios ácidos mientras que la deshidrogenación, en ausencia de metales, es catalizada por sitios ácidos y básicos a través de un mecanismo concertado. Como consecuencia, la velocidad de deshidratación se interpreta como una medida de la acidez mientras que la relación entre la velocidad de deshidrogenación y la velocidad de deshidratación, como una medida de la basicidad de los materiales analizados. La fuerza ácida de una gran variedad de óxidos ha sido evaluada por Gervasini y col. [19], empleando la descomposición de isopropanol como reacción test. Si se modifican las propiedades ácido-base superficiales, se modifica la selectividad, lo que constituye el motivo principal por el que se utiliza esta reacción para evaluar los centros activos ácidos y básicos.

Para determinar cualitativamente si hay diferencias en las propiedades ácido-base superficial de los soportes utilizados en este estudio, se evaluó la conversión de isopropanol (IPA) y distribución de productos en la reacción de descomposición de isopropanol en el rango de 150 a $300{ }^{\circ} \mathrm{C}$, a presión atmosférica y en ausencia de oxígeno. La alimentación consiste de $4,5 \%$ de isopropanol en helio, con un flujo de 40 $\mathrm{mL} / \mathrm{min}$. Los productos de reacción fueron analizados por cromatografía gaseosa usando una columna de Carbowax $20 \mathrm{M}$ sobre Chromosorb W, empleando detector de conductividad térmica. 


\section{II.3.7. Espectroscopia RAMAN}

La espectroscopia Raman se basa en hacer incidir un haz de luz monocromático de frecuencia vo sobre una muestra cuyas características moleculares se desean determinar, y examinar la luz dispersada por dicha muestra. La mayor parte de la luz dispersada presenta la misma frecuencia que la luz incidente pero una fracción muy pequeña presenta un cambio en la frecuencia como resultado de la interacción de la luz con la materia. La luz que mantiene la misma frecuencia que la luz incidente (vo) se conoce como dispersión Rayleigh y no aporta ninguna información sobre la composición de la muestra analizada. La luz dispersada que presenta frecuencias distintas a la de la radiación incidente, es la que proporciona información sobre la composición molecular de la muestra y es la que se conoce como dispersión Raman. Las nuevas frecuencias $+v r$ y - vr son las frecuencias Raman, características de la naturaleza química y del estado físico de la muestra e independientes de la radiación incidente.

Si el resultado de la interacción fotón-molécula es un fotón dispersado a la misma frecuencia que el fotón incidente, se dice que el choque es elástico ya que ni el fotón ni la molécula sufren variaciones en su estado energético. La molécula vuelve a su estado energético inicial y el fotón dispersado tiene una frecuencia vo igual a la incidente, dando lugar a la denominada dispersión Rayleigh.

Si el resultado de la interacción fotón-molécula es un fotón dispersado a una frecuencia diferente que el fotón incidente, se dice que el choque es inelástico (existe transferencia de energía entre el fotón y la molécula); en este caso se pueden dar dos fenómenos: si el fotón dispersado tiene una energía menor al incidente se produce una transferencia de energía del fotón a la molécula (vo- vr) a este tipo de dispersión se la conoce como dispersión Raman Stokes. Si el fotón dispersado tiene una energía mayor al incidente se produce una transferencia de energía de la molécula al fotón a $(v o+v r)$ a este tipo de dispersión se la conoce como dispersión Raman anti-Stokes.

Cada material tendrá un conjunto de valores vr característicos de su estructura poliatómica y de la naturaleza de los enlaces químicos que la forman.

Los ensayos por espectroscopia Raman presentados en esta tesis fueron realizados en un equipo Jovin Yvon-Horiba Labram 800 equipado con un detector CCD y con una fuente de excitación Láser cuya longitud de onda es de $532 \mathrm{~nm}(\mathrm{He}-\mathrm{Ne})$. 


\section{II.3.8. Espectroscopia Fotoelectrónica de Rayos X (XPS)}

La espectroscopia fotoelectrónica XPS es una técnica de sumo interés en catálisis ya que permite aportar respuestas a dos cuestiones fundamentales: las concentraciones relativas de los diferentes componentes de un catalizador en las primeras capas superficiales (15-50 Å) y el estado de oxidación de los diferentes elementos y/o el carácter covalente de los enlaces metal-ligando. Además, es una técnica que permite la determinación de todos los elementos excepto el hidrógeno y el deuterio.

La espectroscopia fotoelectrónica se basa en un proceso de entrada de un fotón/salida de un electrón. La energía del fotón incidente viene dada por la ecuación:

$E=h v$

Ecuación II-13

donde $\mathrm{h}$ es la constante de Planck $\left(6,62 \times 10^{34} \mathrm{~J} \mathrm{~s}\right)$ y $v$ la frecuencia $(\mathrm{Hz})$ de la radiación. La espectroscopia fotoelectrónica utiliza fuentes de radiación monocromática (ésto es, fotones de energía fija). Como fuentes de excitación se usa las líneas $\mathrm{K} \alpha_{1,2}$ de $\mathrm{Mg}$ o $\mathrm{Al}$ que tienen energías de 1253,6 y $1486 \mathrm{eV}$, respectivamente. En XPS, el fotón es absorbido por un átomo en una molécula o sólido, conduciendo a la ionización y la emisión de un electrón de las capas internas del átomo.

La distribución de energía cinética de los fotoelectrones emitidos (es decir, el número de fotoelectrones emitidos en función de su energía cinética) puede medirse utilizando un analizador de energía electrónica apropiado, y de ese modo registrar el espectro fotoelectrónico. El proceso de fotoionización puede ser considerado de diversas maneras, una de ellas es considerar el proceso global como sigue:

$A+h v \rightarrow A^{+}+e^{-}$

Ecuación II-14

El principio de conservación de energía requiere que:

$E(A)+h v=E\left(A^{+}\right)+E\left(e^{-}\right)$

Ecuación II-15

Dado que la energía del electrón sólo aparecerá como energía cinética $(\mathrm{KE})$, esta ecuación puede reacomodarse para dar la energía cinética del fotoelectrón emitido: 
$K E=h v-\left(E\left(A^{+}\right)-E(A)\right)$

Ecuación II-16

El término entre paréntesis representa la diferencia de energía entre el átomo ionizado y el átomo neutro, y se lo denomina la "energía de enlace" o "binding energy" (BE) del electrón. Si introducimos esta definición, encontramos la conocida relación:

$K E=h v-B E$

Ecuación II-17

La energía de enlace se define como la diferencia entre la energía del estado fundamental inicial (Ei) y el estado final (Ef) con la vacancia electrónica creada por la partida del electrón eyectado:

$B E=E_{f}^{N-1}-E_{i}^{N}$

Ecuación II-18

Las aplicaciones más importantes de la técnica XPS se basan en el hecho de que la interacción de los electrones con la materia es muy fuerte y las energías de los electrones emitidos son relativamente bajas $(\leq 1,5 \mathrm{keV})$ por lo que son detenidos muy fácilmente. Solo electrones emitidos o que han interaccionando en la superficie de la muestra pueden alcanzar el detector para ser analizados. Por esto, la técnica XPS es superficial (informa sobre tres o cuatro capas de átomos en la superficie de la muestra). La preparación de la muestra es fundamental para que lo que se mida sea representativo de la muestra bajo estudio. Por esto, la preparación y manipulación de la muestra es cada vez más importante en los estudios por XPS. Hay que mencionar que al emitir los electrones, la muestra queda cargada positivamente. Puesto que el voltaje que se desarrolla depende de la conductividad de la muestra (y otros factores) las energías que se detectan están sujetas a una desviación que hay que calibrar. Este paso se conoce como calibración del cero de energía y es un problema muy difícil de corregir con exactitud.

La composición superficial puede determinarse por la relación área/pico utilizando: los valores de fotoionización transversal reportados por Scofield [20] (Ecuación II-19), o los factores de sensitividad atómica derivados de los factores respuesta empíricos reportados por Wagner y col. [21] (Ecuación II-20). 
$\frac{(n A)}{(n B)}=\frac{\left(I_{A} / \sigma_{A}\right)}{\left(I_{B} / \sigma_{B}\right)}$

Ecuación II-19

$\sigma_{A}$ y $\sigma_{B}$ : valores de fotoionización transversal determinados a partir de los espectros.

$I_{A}$ y $I_{B}$ : intensidades de la señal XPS

$\frac{(n A)}{(n B)}=\frac{\left(I_{A} / S_{A}\right)}{\left(I_{B} / S_{B}\right)}$

Ecuación II-20

$S_{A}$ y $S_{B}$ son valores determinados a partir de los factores de respuesta empíricos

En general los dos métodos de análisis presentan buena concordancia en los resultados reportados. El error en el análisis superficial cuantitativo por XPS es del orden del 10\%. Los espectros XPS fueron realizados en un equipo Leybold Heraeus LHS10, operado en modo FAT, con radiación Al Ka (1486,6 eV).

El comportamiento espectroscópico del Ce es muy complejo debido a los multipletes de la señal. Para el ajuste de los datos experimentales se empleó la técnica denominada "multiplet splitting”, para ello fueron fijadas las separaciones entre los picos de $\mathrm{Ce}^{+3} \mathrm{y}$ $\mathrm{Ce}^{+4}$ y las intensidades de dichas señales. Los análisis de datos incluyen smoothing, remoción de las bandas satelitales, substracción de línea de base del tipo Shirley y ajuste de las curvas utilizando una mezcla de funciones Gaussiana-Lorentziana por ajuste de mínimos cuadrados (CASA XPS software). Los valores de energía de enlace (BE) fueron referenciados al C1s a 285,0 eV y medidos con una precisión de $\pm 0,2 \mathrm{eV}$.

\section{II.3.9. Espectroscopia de Absorción de Rayos X (EXAFS)}

La espectroscopia de absorción de rayos X (XAS) comprende a la espectroscopia de absorción extendida de estructura fina (EXAFS) y la espectroscopia de absorción de la estructura cerca del borde (XANES). En particular, EXAFS se refiere a la variación sinusoidal del coeficiente de absorción de rayos $\mathrm{X}$ en función de la energía del fotón de 
rayos $\mathrm{X}$, que ocurre luego de cada borde de absorción de un elemento, típicamente entre los 50 y los $1000 \mathrm{eV}$; mientras que la región XANES se extiende en $50 \mathrm{eV}$ antes y después de dicho borde. En esta zona se registra la absorción asociada con las transiciones electrónicas de los fotoelectrones entre los diferentes niveles de energía accesibles.

Estas técnicas analíticas brindan información estructural de una muestra a partir del análisis del espectro de absorción de rayos X. Esto permite determinar el entorno químico de un elemento, en términos de número y tipo de vecinos, distancias interatómicas y desórdenes estructurales. Esta determinación está restringida a una distancia entre los 2 y los $8 \AA$ del radio del elemento analizado.

Los rayos $\mathrm{X}$ pueden ser absorbidos por los átomos de una molécula. Generalmente, la proporción de rayos $\mathrm{X}$ absorbidos (el coeficiente de absorción $\mu \mathrm{x}$ ) decrece a medida que la energía se incrementa, pero a ciertos valores de energía, específica para cada elemento, se observa un incremento repentino en la cantidad de energía absorbida. Estas energías corresponden a la expulsión de un electrón del átomo en cuestión (ionización). El electrón expulsado puede ser analizado como una onda, viajando hacia el exterior del átomo absorbente, con una energía cinética dada por:

$$
E=E_{x}-E_{o}
$$

Ecuación II-21

Donde: $\mathrm{E}_{\mathrm{x}}$ es la energía del fotón y $\mathrm{E}_{0}$ es la energía de unión del electrón.

El incremento en la absorción en el borde ocurre cuando la energía del rayo X incidente iguala al umbral de energía necesario para expulsar un electrón [22]. A efectos de ilustrar este fenómeno la Figura II-05 muestra el comportamiento típico de átomos de un elemento de transición, donde es posible reconocer cuatro bordes debido a electrones K y L. 


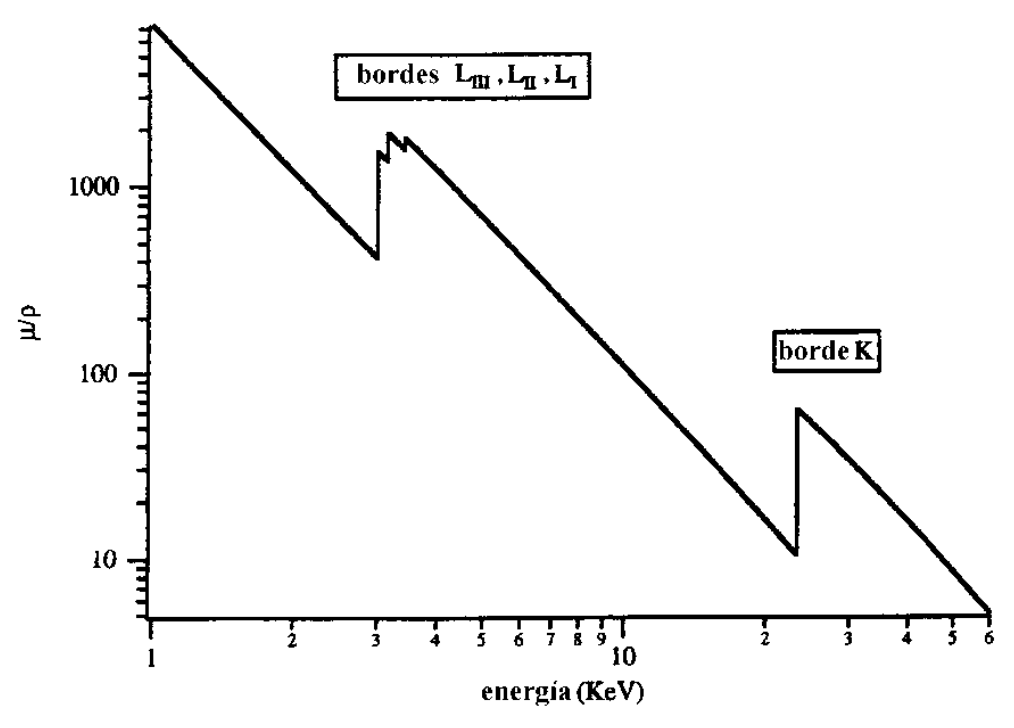

Figura II-05. Espectro de absorción de átomos metálicos

Fuente: Vlaic G. y col. [23]

Donde $\mu / \rho$ es el coeficiente de absorción másico de Rayos X.

La energía del borde es característica en átomos aislados, de esta forma el espectro de absorción de una muestra exhibe muchos bordes en los que la energía umbral iguala a la de los elementos contenidos en ella. Esta afirmación constituye una aproximación dado que estrictamente los niveles de energía de los elementos se desplazan ligeramente (en energía) de acuerdo a las características de su entorno.

Modelos simples de absorción de rayos X predicen un descenso gradual monótono del coeficiente de absorción con el incremento en la energía más allá del borde de absorción. Tal comportamiento se observa en el caso de un átomo aislado, en el que el fotoelectrón se propaga como una onda isotrópica no perturbada. En cambio la presencia de otros átomos alrededor del átomo absorbente genera oscilaciones en el coeficiente de absorción cerca del borde. Estas oscilaciones provienen de la dispersión de los electrones emitidos por los átomos vecinos y de esta manera el espectro de absorción de la estructura en la región posterior al borde se refiere a la distribución radial de los átomos en la muestra. En consecuencia, por el análisis de esta estructura (frecuencia y amplitud de las oscilaciones) se puede obtener información acerca del entorno del elemento absorbente.

La oscilación EXAFS está estrictamente relacionada al fenómeno de interferencia. La amplitud de dispersión total depende del tipo y número de vecinos. El tipo de 
interferencia, para una dada energía del fotoelectrón, depende de la distancia entre el átomo emisor y el átomo dispersor y de su naturaleza, de esta manera la señal EXAFS contiene también información de las distancias interatómicas.

La señal EXAFS $\chi(k)$ se define matemáticamente de acuerdo a:

$\chi(k)=\frac{\mu x-\mu_{1} x}{\mu_{1} x}=\frac{\mu x}{\mu_{1} x}-1$

Ecuación II-22

donde $\mu \mathrm{x}$ es el coeficiente de absorción experimental $\mathrm{y} \mu_{1} \mathrm{x}$ es el coeficiente de absorción atómico intrínseco. La señal se divide por $\mu_{1} \mathrm{x}$ a los efectos de su normalización [24].

La técnica EXAFS requiere una fuente de rayos X policromática de alta intensidad, en un rango de energía desde $100 \mathrm{eV}$ hasta $30 \mathrm{keV}$, como por ejemplo, la luz sincrotrón. Esta produce radiación de rayos $\mathrm{X}$ por aceleración de pulsos de electrones a una velocidad aproximada a la de la luz, en un camino circular de alrededor de 20 metros de radio. La Figura II-06 muestra una típica línea de EXAFS trabajando en modo transmisión.

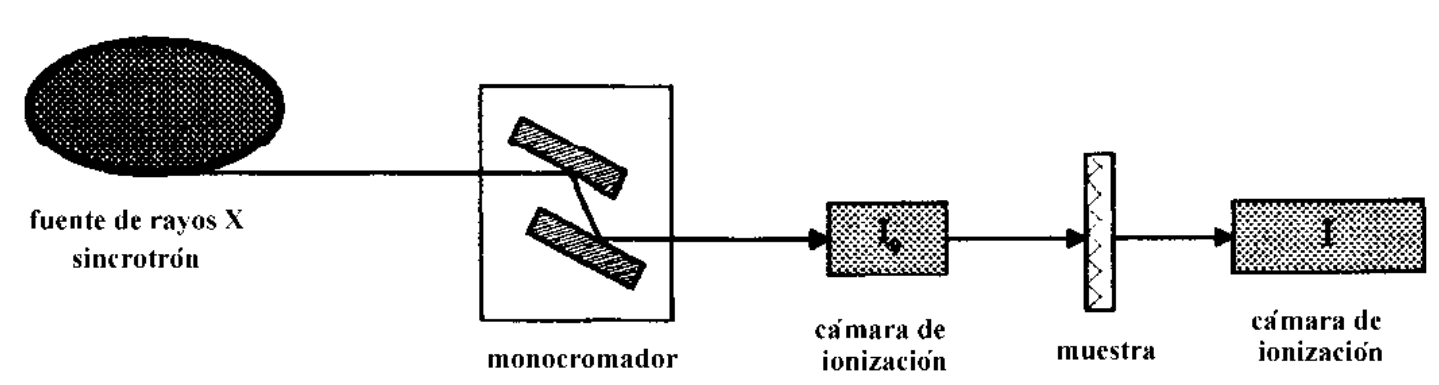

Figura II-06. Esquema de la línea EXAFS

El monocromador permite obtener fotones con una energía fija o hacer un barrido de energía por debajo y por encima del borde de absorción de interés; el mismo está compuesto de dos monocristales paralelos del mismo índice de Miller. Los espectros experimentales se registran variando la energía desde aproximadamente $100 \mathrm{eV}$ por debajo del borde hasta $1000 \mathrm{eV}$ por encima de éste. 
Como es bien conocido, la ley de Lambert-Beer relaciona las intensidades $\mathrm{I}_{0}$ del rayo incidente e I del rayo transmitido con el coeficiente de absorción, de acuerdo a:

$\ln \frac{I_{0}}{I}=\mu x$

Ecuación II-23

Existen dos maneras de medir el coeficiente de absorción $\mu$ de una muestra. El método más utilizado es el de transmisión, el cual mide la intensidad del flujo de fotones antes y después de atravesar la muestra, con dos cámaras de ionización. Si $\mathrm{I}_{0}$ e I son las intensidades medidas, el coeficiente de absorción $\mu$ de la muestra puede obtenerse a partir de la Ecuación II-23.

En el caso de muestras muy diluidas (catalizadores conteniendo menos del 1\% de metal soportado) es recomendable utilizar el método de fluorescencia.

La señal EXAFS cruda está formada por muchas ondas sinusoidales. La transformada de Fourier (FT) es la herramienta estándar utilizada para la separación de frecuencias. Esta operación transforma cada componente sinusoidal en un pico en la FT. La función resultante puede ser interpretada como la distribución radial de centros dispersores.

Una vez que diferentes valores de distancia $\mathrm{R}$ han sido separados, se lleva a cabo la transformada de Fourier inversa. Cada pico es transformado individualmente y el resultado de esta operación es una función $\chi_{i}(k)$. A partir de esta función se pueden obtener los parámetros estructurales por medio de un procedimiento de ajuste utilizando funciones de fase y amplitud, los que deben ser introducidos a través de una referencia experimental o calculados a partir de simulaciones teóricas del proceso de dispersión. De esta manera EXAFS permite obtener números de coordinación, distancias interatómicas y estimar desórdenes alrededor del átomo central.

Los experimentos EXAFS en esta Tesis fueron realizados en la línea XAFS2 del Laboratorio Nacional de Luz Sincrotrón (LNLS, Campinas, Brasil). Los espectros fueron medidos en los bordes K-Ni (8333 eV) y L3-Pt (11564 eV) empleando un cristal monocromador de Si (111). Todas las medidas fueron realizadas a temperatura ambiente y en modo de transmisión. Las muestras fueron montadas en un porta muestra con ventanas de kapton y selladas en atmósfera de Ar para evitar el contacto con el aire. La información EXAFS fue extraída del espectro de absorción utilizando métodos convencionales, empleando el software Athena y el análisis posterior fue realizado usando el software Arthemis [25]. La información de fase y amplitud fueron calculadas 
haciendo uso de la rutina FEFF [26]. Para la calibración de cada espectro se midió simultáneamente con la muestra un film del metal de referencia.

\section{II.4. Evaluación catalítica}

\section{II.4.1. Esquema y descripción del equipo de reacción}

Para la realización de los ensayos de las reacciones en fase líquida (APR) se utilizó un reactor tipo Batch de acero inoxidable de $100 \mathrm{~mL}$ de capacidad (HIP) (Figura II-07 y Figura II-08). El reactor puede operar a altas presiones, y se encuentra calefaccionado por medio de un horno eléctrico y provisto de agitación magnética. El equipo tiene conectado un manómetro de aguja para el rango entre 0 a 100 bar y un manómetro digital que permite registrar la presión durante el transcurso de la reacción mediante un software de adquisición de datos.

El sistema de reacción posee válvulas que permiten el ingreso de $\mathrm{N}_{2} \mathrm{o}_{2} \mathrm{H}_{2}$ para la presurización inicial del reactor y también para la toma de muestra de gases o líquidos. La línea de toma de muestra se compone de un tramo relleno de sílica gel con el objetivo de retener humedad y posteriormente se encuentra un septum que permite la toma de muestra gaseosa.

La temperatura de reacción se controla utilizando una termocupla tipo $\mathrm{K}$, que se encuentra alojada en una vaina de acero inoxidable en el interior del reactor. Esta termocupla se encuentra conectada al controlador de temperatura permitiendo registrar la temperatura del reactor mediante un software de adquisición de datos.

El reactor se calefacciona mediante una resistencia eléctrica provista de un controlador de temperaturas. 


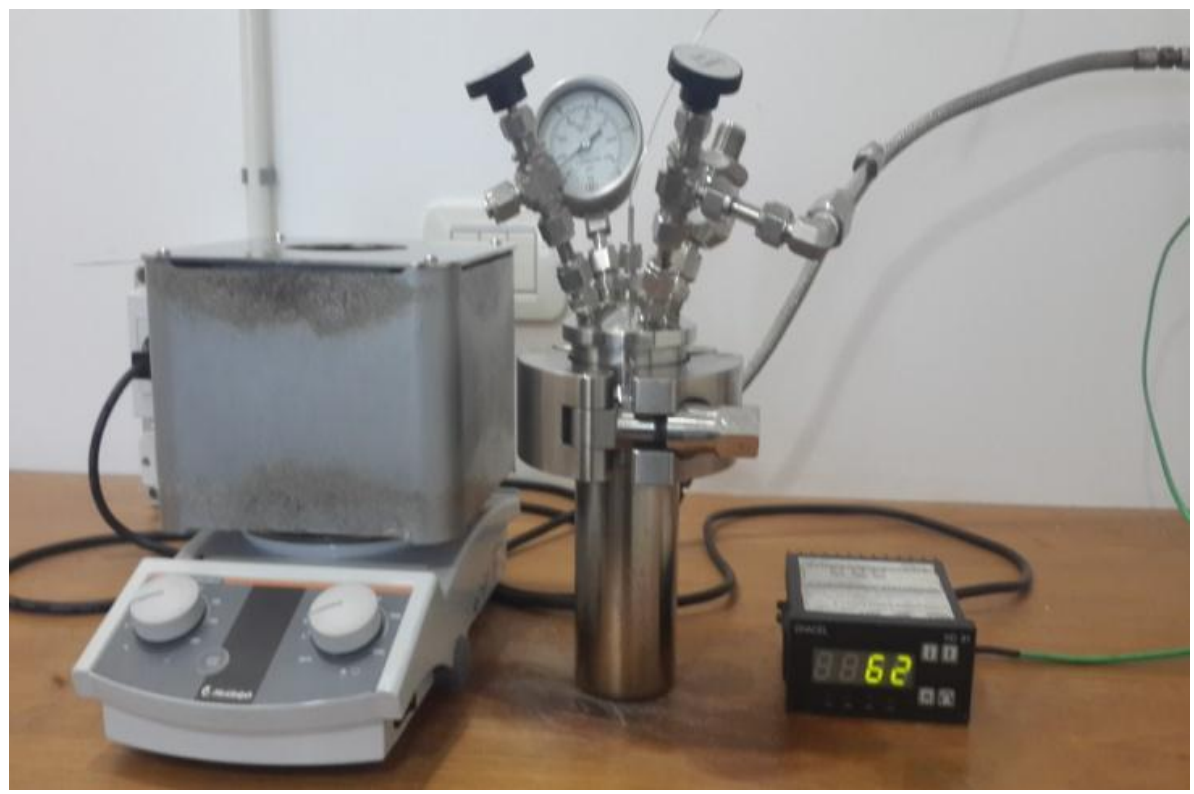

Figura II-07. Sistema de reacción

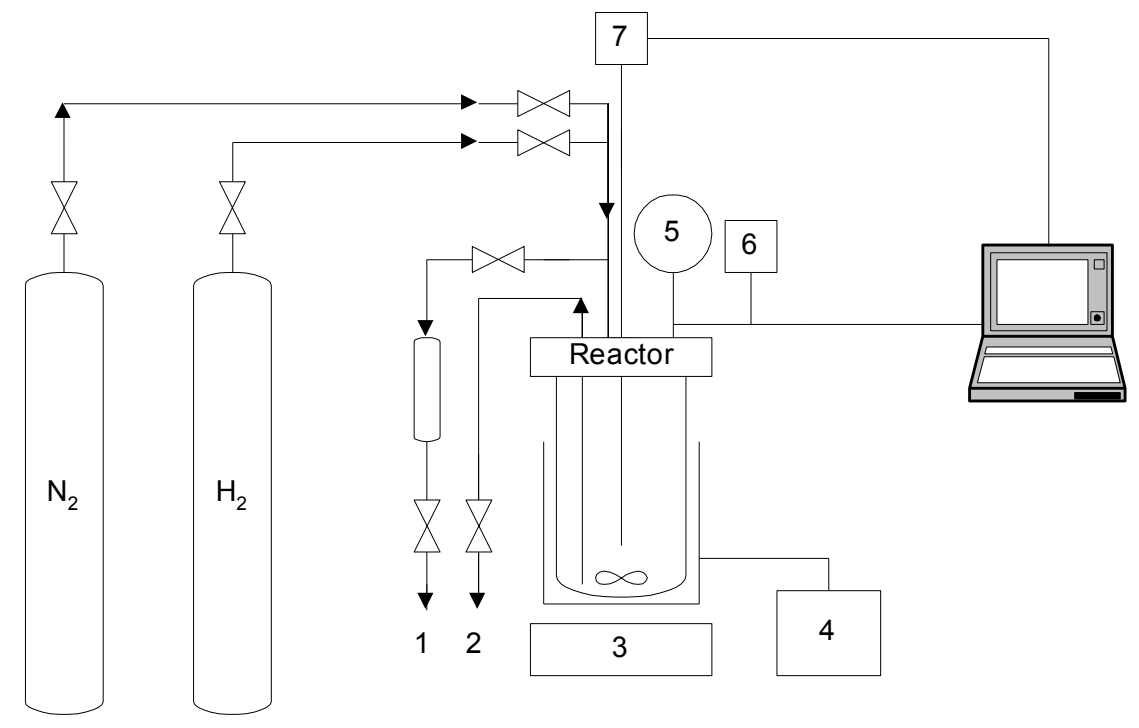

Figura II-08. Esquema del sistema de reacción

\section{Referencias:}

1- sistema toma muestra de gases

2- sistema toma muestra de líquidos

3- agitador magnético

4- controlador de temperatura

5- manómetro de aguja

6- lector de presión digital

7- lector de temperatura 
El equipo de reducción ex situ consiste en un tubo de cuarzo de $8 \mathrm{~mm}$ de diámetro interno. Este tubo de cuarzo se encuentra calefaccionado por un horno eléctrico provisto de un controlador de temperatura que permite la programación de rampas de temperatura controladas. La temperatura se mide a través de una termocupla tipo $\mathrm{K}$ alojada entre el reactor y el horno, y conectada a un lector digital de temperaturas. En el ingreso al reactor se encuentra una válvula reguladora de caudal. Las líneas de ingreso al reactor permiten la alimentación de flujo de nitrógeno puro o hidrógeno puro.

\section{II.4.2. Procedimiento del test de reacción}

El reactor se carga con la solución líquida de glicerol en agua y se incorpora luego el catalizador pre-reducido. Una vez que se cierra el reactor, se purga con inerte y se presuriza en la atmósfera deseada $\left(\mathrm{N}_{2}\right.$ puro, o $\mathrm{H}_{2}$ puro).

La presión inicial fue elegida teniendo en cuanta la temperatura de reacción, de manera de evitar que ocurra una vaporización mayor al 10\%. En la Tabla II-02 se muestran algunos ejemplos.

Tabla II-02. Equivalencia entre Presión inicial a temperatura ambiente y la Presión alcanzada a la temperatura de reacción

\begin{tabular}{cccc}
\hline $\mathbf{P}_{\text {inicial }}(\mathbf{b a r})$ & $\mathbf{T}_{\text {reacción }}\left({ }^{\mathbf{o}} \mathbf{C}\right)$ & $\mathbf{P}_{\text {Treacción }}(\mathbf{b a r})$ & \% vaporización \\
\hline 1 & 225 & 25 & 10 \\
4 & 200 & 16 & 2 \\
4 & 225 & 22 & 5 \\
12 & 200 & 26 & 5 \\
12 & 225 & 35 & 6,5 \\
12 & 250 & 44 & 9 \\
\hline
\end{tabular}

El tiempo de reacción se considera a partir del momento en que la temperatura del reactor alcanza el valor deseado. Para proceder a la toma de muestras, el reactor es rápidamente enfriado y una vez alcanzada la temperatura ambiente se toma muestra de los productos gaseosos en primer lugar. Posteriormente se abre el reactor y se toma la muestra líquida. Finalmente se procede a extraer y separar por filtración el catalizador. 


\section{II.4.3. Análisis de los productos de reacción}

Los productos gaseosos, tales como $\mathrm{H}_{2}, \mathrm{~N}_{2}, \mathrm{CH}_{4}, \mathrm{CO}$ y $\mathrm{CO}_{2}$, se identificaron y cuantificaron por cromatografía gaseosa con detector de conductividad térmica (CG/TCD) en un cromatógrafo Shimazdu equipado con columna Hayesep D 100-120 de $10 \mathrm{~m}$ de longitud y un diámetro de $1 / 8$ ".

La identificación de los productos líquidos se realizó mediante espectrometría de masas, mientras que su cuantificación se llevó a cabo por cromatografía gaseosa con detector de ionización de llama (CG/FID/MS) en un cromatógrafo Shimadzu GCMS-QP5050A. Este equipo, con detector de ionización de llama (FID) está conectado a un bus modulador de comunicaciones Shimazu CBM-102 y software procesador e integrador de datos cromatográficos, modelo CLASS GC-10 C. Para la separación de los distintos productos se utilizó una columna 19091S-001 HP PONA 50 m, 0,2 mm, 0,5 $\mu \mathrm{m}$. Las condiciones cromatográficas utilizadas así como también las calibraciones de los reactivos y productos de reacción se detallan en el ANEXO II.

\section{II.4.4. Cálculos de conversión y selectividad}

La actividad catalítica se expresa como conversión a productos gaseosos $\mathrm{X}^{\mathrm{G}}$, conversión a productos líquidos $\mathrm{X}^{\mathrm{L}}$, y conversión total de reactivo.

$$
\mathrm{X}^{\mathrm{G}}=\frac{\mathrm{N}_{\mathrm{CO}}+\mathrm{N}_{\mathrm{CO}_{2}}+\mathrm{N}_{\mathrm{CH}_{4}}}{\mathrm{n} \times \mathrm{N}_{\mathrm{i}}^{\mathrm{o}}} \times 100
$$

Donde: $\mathrm{N}_{\mathrm{CO}}, \mathrm{N}_{\mathrm{CO} 2}, \mathrm{~N}_{\mathrm{CH} 4}=$ moles de $\mathrm{CO}, \mathrm{CO}_{2}$ y $\mathrm{CH}_{4}$ en los productos gaseosos $\mathrm{y} \mathrm{N}_{\mathrm{i}}^{\mathrm{o}}=$ moles iniciales de reactivo, $\mathrm{n}=$ número de átomos de carbono en la molécula de reactivo $(\mathrm{n}=3$, para glicerol $)$.

$$
\mathrm{X}^{\mathrm{T}}=\frac{\mathrm{N}^{\mathrm{o}}-\mathrm{N}^{\mathrm{f}}}{\mathrm{N}^{\mathrm{o}}} \mathrm{x} 100
$$

$$
\mathrm{X}^{\mathrm{L}}=\mathrm{X}^{\mathrm{T}}-\mathrm{X}^{\mathrm{G}}
$$

donde, 
$\mathrm{N}^{\mathrm{o}}=$ moles iniciales de glicerol

$\mathrm{N}^{\mathrm{f}}=$ moles finales de glicerol

La selectividad a productos carbonados $\left(\mathrm{SCO}_{2}, \mathrm{SCO}, \mathrm{SCH}_{4}, \mathrm{SC}_{1}, \mathrm{SC}_{2}\right.$ y $\left.\mathrm{SC}_{3}\right)$ y la selectividad a $\mathrm{H}_{2}\left(\mathrm{SH}_{2}\right)$, fueron definidas según:

$\mathrm{SC}_{\mathrm{n}} \%=\frac{(\text { moles de producto } " \mathrm{n} ") \times(\text { numero de átomos de } \mathrm{C} \text { en el producto } " \mathrm{n} ")}{\text { moles de glicerol consumido } \times 3} \times 100$

Ecuación II-27

$\mathrm{SH}_{2} \%=\frac{\text { moléculas de } \mathrm{H}_{2} \text { producido }}{\text { átomos de } \mathrm{C} \text { en los productos gaseosos }} \times \frac{1}{\mathrm{R}} \times 100$

Ecuación II-28

Donde $\mathrm{R}$ es la relación $\mathrm{H}_{2} / \mathrm{CO}_{2}$ de 7/3 para el reformado de glicerol.

Por último se presenta el rendimiento a $\mathrm{H}_{2}$, el cual se calcula según la ecuación:

$\mathrm{RH}_{2} \%=\frac{\text { moles de } \mathrm{H}_{2} \text { producido }}{\text { moles de glicerol inicial } * 7} \times 100$

Ecuación II-29

\section{II.4.5. Repetibilidad de resultados}

A continuación se presentan resultados en el reformado en fase líquida (APR) de glicerol empleando el catalizador $1 \mathrm{PtAl}$, a $225^{\circ} \mathrm{C}$ y 1 atm de presión de $\mathrm{N}_{2}$ inicial. 
Tabla II-03. Resultados de APR de glicerol

\begin{tabular}{|c|c|c|c|c|c|c|c|}
\hline APR de glicerol & Test 1 & Test 2 & Test 3 & Test 4 & Valores medios & Varianza & Desv. Est. \\
\hline$\overline{X^{G}(\%)}$ & 15 & 20 & 16 & 14 & 16,3 & 6,9 & 2,6 \\
\hline$X^{L}(\%)$ & 12 & 14 & 9 & 10 & 11,3 & 4,9 & 2,2 \\
\hline$X^{T}(\%)$ & 27 & 34 & 25 & 24 & 27,5 & 20,3 & 4,5 \\
\hline $\mathrm{SH}_{2}(\%)$ & 72 & 69 & 84 & 83 & 77 & 58 & 7,6 \\
\hline SCO $(\%)$ & 0,0 & 0,0 & 0,6 & 0,0 & 0,1 & 0,1 & 0,3 \\
\hline $\mathrm{SCH}_{4}(\%)$ & 4,9 & 5,1 & 7,2 & 5,3 & 5,6 & 1,1 & 1,1 \\
\hline $\mathrm{SCO}_{2}(\%)$ & 51,5 & 52,8 & 57,2 & 51,7 & 53,3 & 7,1 & 2,7 \\
\hline Smetanol (\%) & 1,8 & 1,5 & 1,4 & 1,4 & 1,5 & 0,0 & 0,2 \\
\hline Setanol (\%) & 7,2 & 5,3 & 7,1 & 6,1 & 6,4 & 0,9 & 0,9 \\
\hline S1-propanol (\%) & 0,5 & 2,0 & 0,8 & 1,6 & 1,2 & 0,5 & 0,7 \\
\hline Sacetol(\%) & 1,4 & 3,4 & 1,2 & 2,2 & 2,1 & 0,9 & 1,0 \\
\hline Setilenglicol (\%) & 2,8 & 1,9 & 3,4 & 3,3 & 2,8 & 0,4 & 0,7 \\
\hline Spropilenlgicol (\%) & 21,1 & 20,5 & 12,9 & 20,2 & 18,7 & 15,2 & 3,9 \\
\hline
\end{tabular}

En la Tabla II-03 se puede observar los valores medios para las medidas catalíticas, la varianza y la desviación estándar de los datos extraídos. Los valores de varianza y desviación estándar indican que se obtuvo buena repetibilidad en los ensayos de APR en el reactor de estudio.

\section{II.5. Referencias}

[1] Maatman R, Prater C. Industrial and Engineering Chemistry 49 (1957) 253

[2] Le Page JF. “Catalyse de contact” cap V, p 144, IFP, Ed. Technip. (1978)

[3] George A. Parks Chemical Reviews 65(2) (1965) 177-198

[4] Santori GF, Tesis Doctoral, Facultad de Ingeniería, Universidad Nacional de La Plata, Argentina, (2000)

[5] Gonzalez RD, Miura H. Catalysis Reviews 36(1) (1994) 145

[6] Goguet A, Aouine M, Cadete Santos Aires FJ, De Mallmann A, Schweich D, Candy JP. Journal of Catalysis 209 (2002) 135-144

[7] U.S.Patent 4456775 (1986).

[8] Travers Ch, Bournonville JP, Martino G. Proceedings of the 8th International Congress on Catalysis, Berlin,Verlag-Chemie 4 (1984) 891

[9] Margitfalvi J, Szabo S, Nagy F. Studies in Surface Science and Catalysis 27 (1986) 373 
[10] Basset JM, Candy JP, Choplin A, Dufour P, Louessard P, Santini C. "Heterogeneous Catalysis and Fine Chemicals" (Eds. M. Guisnet y col.,), Elsevier, 1 (1988)

[11] Aduriz HR, Bodnariuk P, Coq B, Figueras F. Journal of Catalysis 119 (1989) 97

[12] Ferretti OA, Lucas C, Candy JP, Basset JM, Didillon B, Lepeltier F. Journal of Molecular Catalysis 103 (1995) 125

[13] Didillon B, Candy JP, Lepeltier F, Ferretti OA, Basset JM. Studies in Surface Science and Catalysis 78 (1994) 203

[14] Reyes P, Aguirre MC, Fierro JLG, Santori G, Ferretti O. Journal of Molecular Catalysis A: Chemical 184 (2002) 431-441.

[15] Santori Gerardo F, Casella Mónica L, Siri Guillermo J, Adúriz Hugo R, Ferretti Osmar A. Applied Catalysis A: General 197 (2000) 141-149

[16] Santori Gerardo F, Moglioni Albertina G, Vetere Virginia, Moltrasio Iglesias Graciela Y, Casella Mónica L, Ferretti Osmar A. Applied Catalysis A: General 269 (2004) 215-223

[17] Brunauer S Emmett P, Teller E. Journal of the American Chemical Society 60 (1938) 309

[18] Jones A, McNicol B. "Temperature Programmed Reduction for Solid materials Characterization". New York, (1986)

[19] Gervasini A, Fenyvesi J, Auroux A. Catalysis Letters, 43 (1997) 228

[20] Scofield JH. Journal of Electron Spectroscopy and Related Phenomenon 8 (1976) 129

[21] Wagner CD, Riggs WM, Davis LE, Moulder JF. "Handbook of X-Ray Photoelectron Spectroscopy”.G. E. Muilenberg Ed. Minnesota (1978)

[22] McMaster W.H., del Grande N.K., Mallet J.H., Hubbel J.H. “Compilation of X-ray cross sections" UCPL-50174 sec. II rev. 1 (1969)

[23] Vlaic G, Andreatta D, Colavita PE. Catalysis Today 41 (1998) 261

[24] Teo BK. "EXAFS: Basic Principles and Data Analysis”, Springer Berlin (1986)

[25] Ravel B, Newville M. Journal of Synchrotron Radiation 12 (2005) 537-541

[26] Zabinsky SI, Rehr JJ, Ankudinov A, Albers RC, EllerMJ. Physical Review B 52 (1995) 2995 


\section{Capítulo III}

\section{Determinación de}

\section{condiciones experimentales \\ y esquema de reacciones}


Capítulo III. Determinación de condiciones experimentales y esquema de reacciones

\section{Capítulo III. Determinación de condiciones experimentales y esquema de reacciones}

\section{III.1. Introducción}

En este capítulo se presentan los primeros resultados de los ensayos experimentales de la reacción de reformado del glicerol en fase líquida (APR).

Las reacciones globales que han sido reportadas en el reformado del glicerol son:

$\mathrm{C}_{3} \mathrm{H}_{8} \mathrm{O}_{3} \leftrightarrow 4 \mathrm{H}_{2}+3 \mathrm{CO}$ (Descomposición del glicerol)

Ecuación III-01

$\mathrm{CO}+\mathrm{H}_{2} \mathrm{O} \leftrightarrow \mathrm{H}_{2}+\mathrm{CO}_{2}$ (Reacción de WGS)

Ecuación III-02

$\mathrm{C}_{3} \mathrm{H}_{8} \mathrm{O}_{3}+3 \mathrm{H}_{2} \mathrm{O} \leftrightarrow 7 \mathrm{H}_{2}+3 \mathrm{CO}_{2}$ (Reacción de reformado)

Ecuación III-03

$\mathrm{CO}+3 \mathrm{H}_{2} \leftrightarrow \mathrm{CH}_{4}+\mathrm{H}_{2} \mathrm{O}$ (Reacción de metanación)

Ecuación III-04

Sin embargo, hay otras reacciones laterales que producen principalmente alcoholes que se encuentran en la fase líquida.

Empleando un catalizador $2 \% \mathrm{p} / \mathrm{p} \mathrm{Pt} / \gamma-\mathrm{Al}_{2} \mathrm{O}_{3}$ obtenido por intercambio iónico (2PtAl) se logró estudiar el efecto de las principales variables operativas (temperatura, presión, masa de catalizador y tiempo de reacción) sobre los productos de reacción.

El objetivo del reformado en fase líquida es el de producir hidrógeno, sin embargo la selectividad a $\mathrm{H}_{2}$ se encuentra amenazada a causa de la reacciones posteriores en la fase gaseosa y a reacciones paralelas en la fase líquida.

De manera de identificar los principales compuestos intermediarios y laterales de reacción, se realizaron ensayos de APR sobre 2PtAl con etilenglicol, propilenglicol, acetol, metanol y etanol para determinar la diferente reactividad de estos compuestos a las reacciones de ruptura $\mathrm{C}-\mathrm{C}$ y $\mathrm{C}-\mathrm{O}$. 


\section{III.2. Determinación de condiciones experimentales}

\section{III.2.1. Verificación de la ausencia de control difusional}

El efecto de la variación de la masa de catalizador en el APR del glicerol se estudió analizando el efecto del transporte intraparticular, aplicando el método de MadonBuodart [1]. Se determinó la velocidad de reacción utilizando catalizadores Pt sobre $\gamma-$ $\mathrm{Al}_{2} \mathrm{O}_{3}$ con diferentes cargas metálicas ( 1 y $\left.2 \% \mathrm{p} / \mathrm{p}\right)$ y dispersión metálica similar entre sí ( 0,8 y 0,71 , respectivamente), ambos catalizadores fueron obtenidos por intercambio iónico (1PtAl y 2PtAl).

Elegidas las condiciones de presión y temperatura, se construye el gráfico del logaritmo de la velocidad de reacción en $\mu$ moles producidos de $\mathrm{CO}_{2} \cdot \mathrm{s}^{-1} \cdot \mathrm{g}_{\text {catalizador }}{ }^{-1}$ versus el logaritmo de la concentración superficial de Pt. Según el método de Madon Buodart si la pendiente de la recta es unitaria significa que no hay influencia de las etapas de transporte en la determinación experimental de la velocidad de reacción.

Los soportes fueron molidos en tamices de mesh 120-230 (con tamaños de partícula entre 63 y $125 \mu \mathrm{m})$.

La Figura III-01 muestra los resultados para 2 condiciones de trabajo: $225^{\circ} \mathrm{C}$ y 1 bar de presión de $\mathrm{N}_{2}$ inicial y $250{ }^{\circ} \mathrm{C}$ y 12 bar de presión de $\mathrm{N}_{2}$ inicial con una solución al $10 \%$ p/p de glicerol, tiempo de reacción 2 h, utilizando los catalizadores 1PtAl y $2 \mathrm{PtAl}$. Como se puede observar en la Figura III-01, debido a que la pendiente de la línea de tendencia es aproximadamente igual a la unidad $\left(0,9996\right.$ y 1,0408 para 225 y $250{ }^{\circ} \mathrm{C}$, respectivamente), se puede afirmar que en estas condiciones se satisface el criterio de Madon-Boudart y se asegura la ausencia de limitaciones difusionales. 


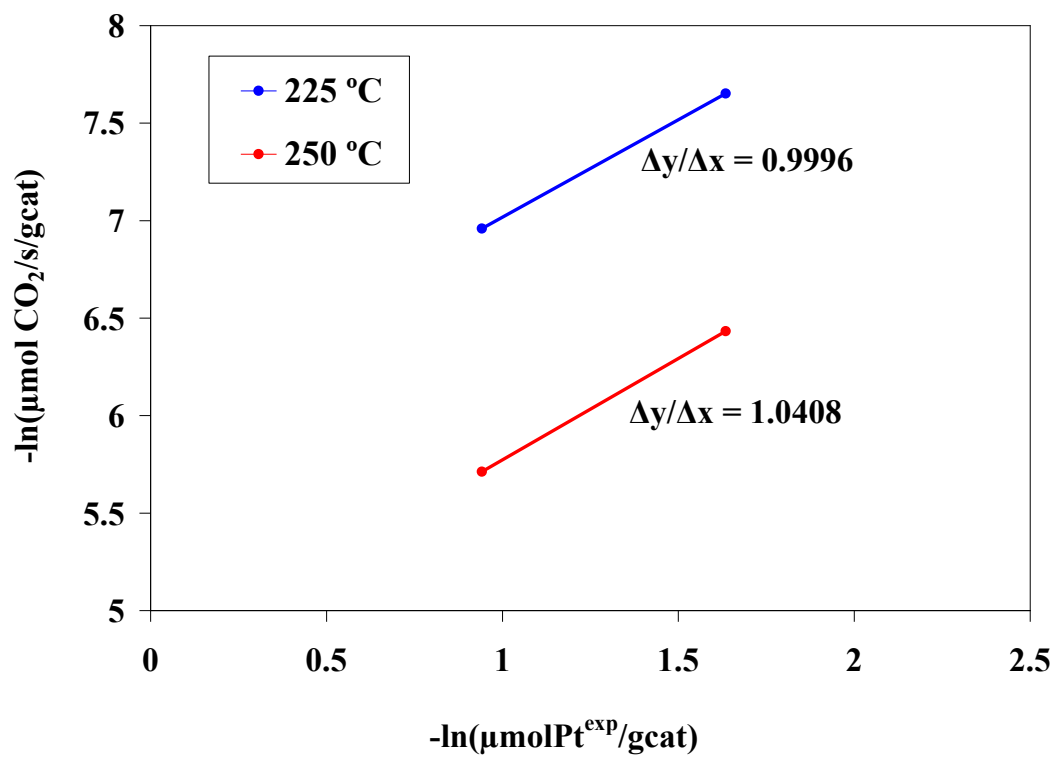

Figura III-01. Velocidad de reacción de APR de glicerol vs. Concentración superficial de Pt. Condiciones de reacción: $225{ }^{\circ} \mathrm{C}$ y 1 bar de presión de $\mathrm{N}_{2}$ inicial, y $250{ }^{\circ} \mathrm{C}$ y 12 bar de presión de $\mathrm{N}_{2}$

\section{III.2.2. Efecto de la temperatura}

Para este conjunto de experiencias se utilizó un catalizador de $\mathrm{Pt} / \gamma-\mathrm{Al}_{2} \mathrm{O}_{3}$, con carga nominal 2\%, 2PtAl. El equipo experimental, el procedimiento y el cálculo de conversión y selectividad fueron detallados en el Capítulo II. La mezcla de reacción consiste en $12 \mathrm{~mL}$ de solución acuosa al $10 \%$ p/p de glicerol. El reactor fue operado a una presión de 12 bar de $\mathrm{N}_{2}$ inicial (medida a temperatura ambiente). Por análisis $\mathrm{CG} / \mathrm{TCD}$ de la fase vapor se identificaron los siguientes productos: $\mathrm{H}_{2}, \mathrm{CO}, \mathrm{CO}_{2} \mathrm{y} \mathrm{CH}_{4}$. Por análisis CG/MS de la fase líquida se identificaron los siguientes subproductos principales: propilenglicol, etanol, metanol, etilenglicol, propanol y acetol. Existen compuestos que no fueron identificados y que representan aproximadamente el $2 \%$ del total de productos líquidos.

El balance de carbón en las experiencias fue de 95 a 98\%. La selectividad de los compuestos carbonados se calcula excluyendo los compuestos carbonados no identificados en la fase líquida.

Las temperaturas estudiadas fueron 200,225 y $250^{\circ} \mathrm{C}$. Los resultados presentados en la Tabla III-01 fueron obtenidos a 2 horas de reacción. Cada experiencia se realizó con 
Capítulo III. Determinación de condiciones experimentales y esquema de reacciones

una muestra de catalizador fresco y fueron llevadas a cabo a una presión inicial de inerte de 12 bar.

Tabla III-01. APR de glicerol con el catalizador 2PtAl. Condiciones de reacción: 200, 225 y $250{ }^{\circ} \mathrm{C}, 12$ bar $\mathrm{N}_{2}$ inicial, 120 min de reacción, masa catalizador: 0,5 g, solución acuosa al 10\% p/p de glicerol, agitación 700 rpm

\begin{tabular}{lccc}
\hline Temperatura $\left({ }^{\mathbf{0}} \mathbf{C}\right)$ & $\mathbf{2 0 0}$ & $\mathbf{2 2 5}$ & $\mathbf{2 5 0}$ \\
\hline $\mathbf{X}^{\mathbf{G}}(\%)$ & 2 & 10 & 34 \\
$\mathbf{X}^{\mathrm{T}}(\%)$ & 4 & 19 & 63 \\
$\mathbf{R H}_{\mathbf{2}}(\%)$ & 2 & 10 & 29 \\
$\mathbf{S H}_{\mathbf{2}}(\%)$ & 93 & 96 & 86 \\
$\mathbf{H}_{\mathbf{2}} / \mathbf{C O}_{\mathbf{2}}$ & 2,3 & 2,4 & 2,2 \\
\hline
\end{tabular}

Los resultados muestran un aumento en la conversión a gases con el aumento de la temperatura, así también como un aumento considerable en el $\mathrm{RH}_{2}$.

Respecto a los productos gaseosos se observa que la relación $\mathrm{H}_{2} / \mathrm{CO}_{2}$ se mantiene muy próxima a 2,33 correspondiente a la relación estequiométrica de la reacción de reformado del glicerol (Ecuación III-03). La selectividad a CO (SCO) es en todos los casos del orden de los $1000 \mathrm{ppm}$. La selectividad a $\mathrm{CO}_{2}\left(\mathrm{SCO}_{2}\right)$ es representativa de la contribución de la reacción de reformado (Reacción III-03), mientras que la selectividad a CO lo es de la reacción de descomposición del glicerol (Reacción III01). Con el aumento de 200 a $250{ }^{\circ} \mathrm{C}$ se observa que la conversión total de glicerol aumenta de $4 \%$ a $63 \%$ (Tabla III-01).

Respecto a la selectividad a $\mathrm{H}_{2}$, se observa un leve descenso de la misma para la temperatura más alta.

Respecto a la selectividad de los productos líquidos, los compuestos identificados fueron metanol, etanol, 1-propanol, acetol, etilenglicol y propilenglicol.

La selectividad fue agrupada por número de átomos de carbono:

- SC1: selectividad a productos que poseen un átomo de carbono en su molécula: metanol

- SC2: selectividad a productos que poseen dos átomos de carbono en su molécula: etanol y etilenglicol 
- SC3: selectividad a productos que poseen tres átomos de carbono en su molécula: 1-propanol, acetol y propilenglicol

Analizando la selectividad de productos carbonados en función de la temperatura (Figura III-02), se observa un leve aumento en la $\mathrm{SCO}_{2}$, y una disminución en $\mathrm{SC}_{3}$, que indicarían la mayor contribución de reacciones de ruptura C-C con la temperatura.

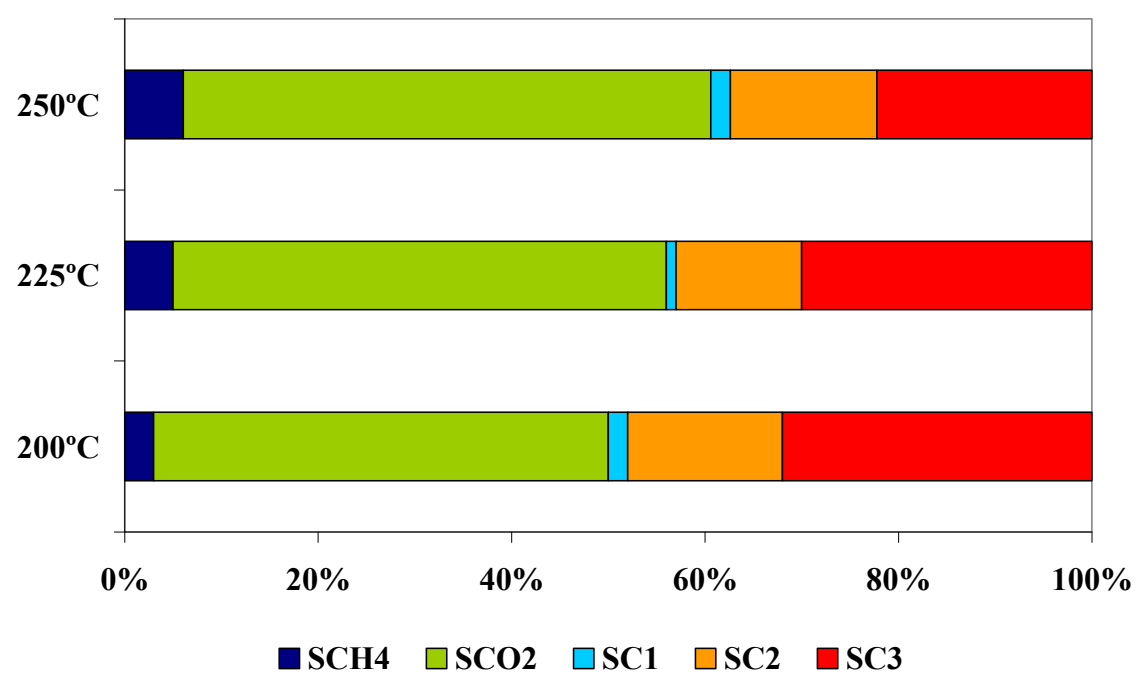

Figura III-02. Selectividad de productos vs. Temperatura de reacción. Condiciones de reacción: 200,225 y $250^{\circ} \mathrm{C}, 12$ bar $\mathrm{N}_{2}$ inicial, 120 min de reacción, masa catalizador: $0,5 \mathrm{~g}$, solución acuosa al 10\% p/p de glicerol, agitación $700 \mathrm{rpm}$

\section{Cálculo de la Energía de Activación}

A partir de los resultados de actividad inicial para estas tres temperaturas, se estimó una energía de activación aparente para la producción de $\mathrm{H}_{2}$ y $\mathrm{CO}_{2}$.

Para poder calcular la energía de activación, se hace uso de la ley de Arrhenius, que establece, la siguiente dependencia de la constante de reacción con la temperatura:

$k=A e^{\left(-\frac{E a}{R T}\right)}$

Ecuación III-05

donde:

$\mathrm{k}$ : Constante de reacción para una condición de temperatura $[\mathrm{K}]$ 
A: Factor pre-exponencial o factor de frecuencia

Ea: Energía de activación aparente

$\mathrm{R}$ : Constante universal de los gases

Aplicando logaritmos a la expresión de Arrhenius:

$$
\ln k=\ln A-\frac{E a}{R}\left(\frac{1}{T}\right)
$$

\section{Ecuación III-06}

Luego, se realizó una regresión de ln k vs 1/T y se determinó la pendiente $\mathrm{Ea} / \mathrm{R}$ :

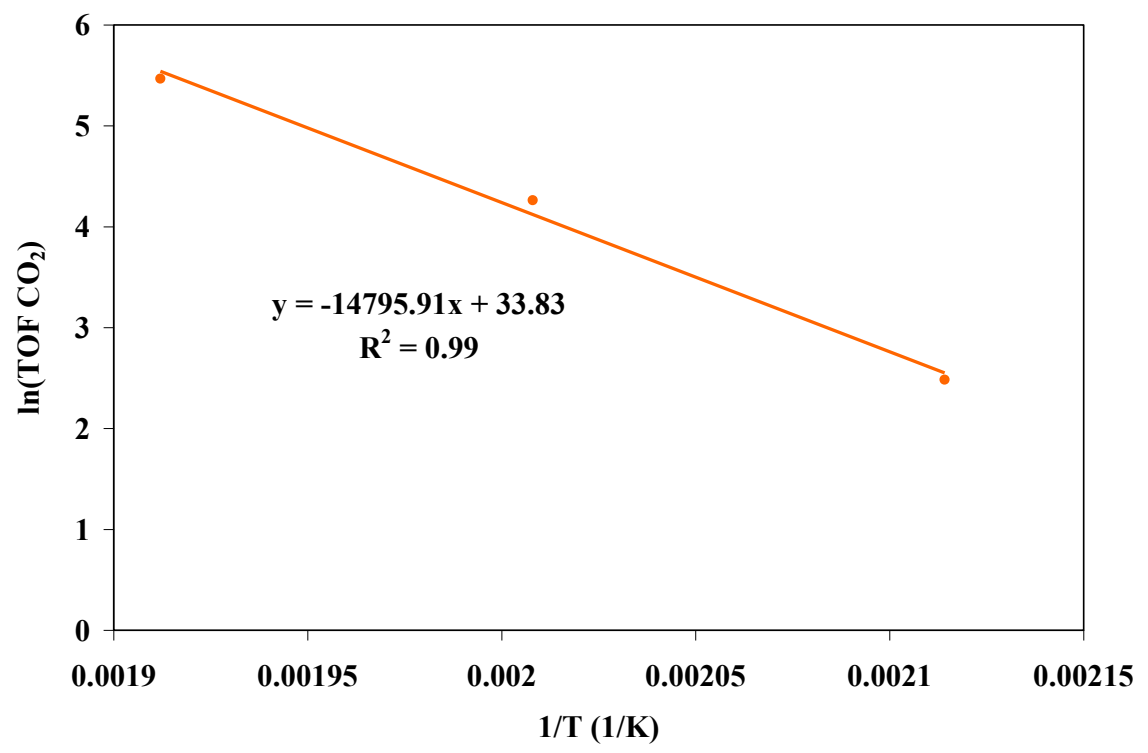

Figura III-03. TOF $\mathrm{CO}_{2}$ vs. 1/T

Donde TOF (Turnover frequencies) $=$ moles producidos $\mathrm{CO}_{2} / \mathrm{h}$ moles de $\mathrm{Pt}$ Donde $(-\mathrm{Ea} / \mathrm{R})=-14795,91 \mathrm{~K}$

$\mathrm{Ea}=14795,91 \mathrm{~K} \times \mathrm{R}=14795,91 \mathrm{~K}$ x 8,314472 J $/ \mathrm{mol} \mathrm{K}=123,02 \mathrm{KJ} / \mathrm{mol}$

\section{$\mathrm{Ea} \mathrm{CO}_{2}=123,02 \mathrm{KJ} / \mathrm{mol}$}




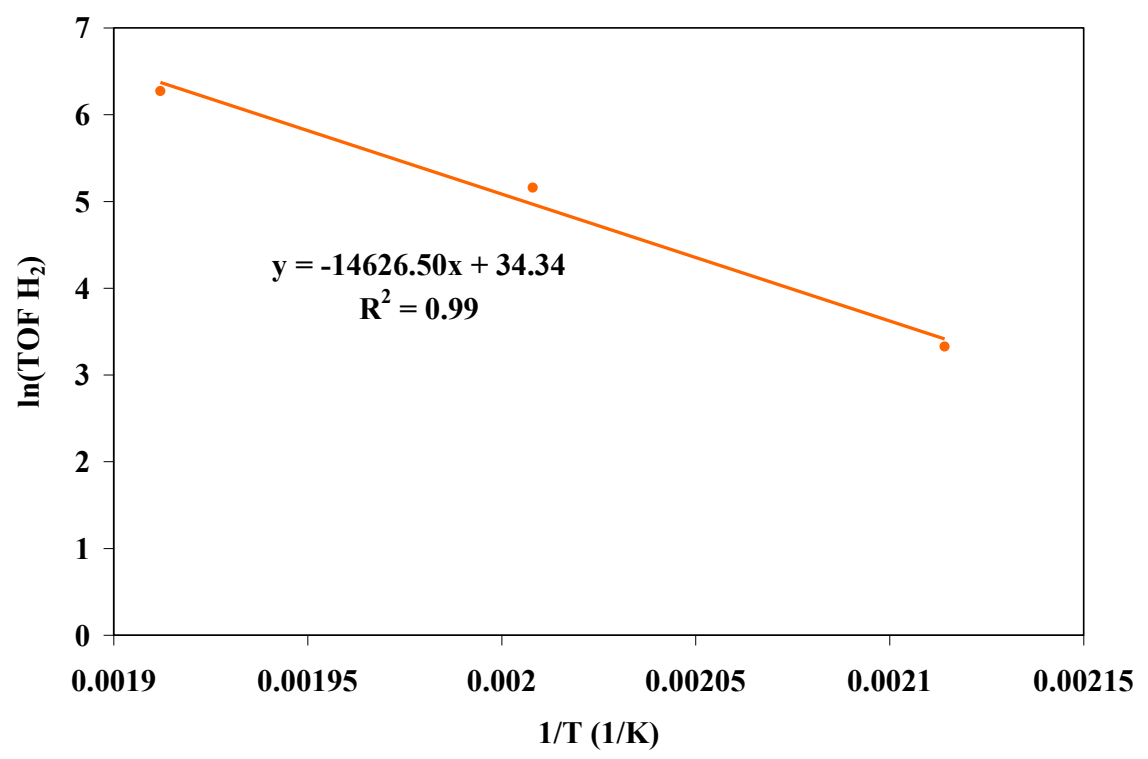

Figura III-04. TOF $\mathrm{H}_{2}$ vs. 1/T

Donde TOF (Turnover frequencies) $=$ moles producidos $\mathrm{H}_{2} / \mathrm{h}$ moles de $\mathrm{Pt}$

Donde $(-\mathrm{Ea} / \mathrm{R})=-14626,50 \mathrm{~K}$

$\mathrm{Ea}=14626,50 \mathrm{~K}$ x R=14626,50 K x 8,314472 J/mol K=121,61 KJ/mol

\section{Ea $\mathrm{H}_{2}=121,61 \mathrm{KJ} / \mathrm{mol}$}

Para la reacción de APR del glicerol sobre catalizadores 2PtAl se determinó una energía de activación aparente de producción de $\mathrm{H}_{2}$ y $\mathrm{CO}_{2}$ de $121,61 \mathrm{KJ} / \mathrm{mol}$ y $123,02 \mathrm{KJ} / \mathrm{mol}$ respectivamente.

Estos valores se encuentran en concordancia con lo encontrado en bibliografía. Shabaker y col. [2] han informado valores de energías de activación entre 140 y 100 $\mathrm{kJ} / \mathrm{mol}$ para el reformado de metanol y de etilenglicol respectivamente. Roy y col. [3] en el APR de $\mathrm{n}-\mathrm{BuOH}$ con catalizadores $\mathrm{Ni} / \mathrm{Al}_{2} \mathrm{O}_{3}$, obtuvieron una energía de activación para la producción de hidrógeno de $169 \mathrm{~kJ} / \mathrm{mol}$ y para la producción de $\mathrm{CO}_{2}$ de 175 $\mathrm{kJ} / \mathrm{mol}$.

\section{III.2.3. Efecto de la presión}

En la Tabla III-02 se presentan los resultados obtenidos en condiciones de $225{ }^{\circ} \mathrm{C}$ y presiones iniciales de 1 y 12 bar de nitrógeno sobre el catalizador 2PtAl. Tal como fue 
indicado en el Capítulo II, las presiones alcanzadas a $225^{\circ} \mathrm{C}$ fueron de 25 y 35 bar respectivamente (Tabla II-02).

Se puede observar que la disminución en la presión provoca un aumento considerable en la conversión total y en particular un aumento en la conversión a productos gaseosos.

Tabla III-02. APR de glicerol con el catalizador 2PtAl. Condiciones de reacción: 225 ${ }^{\circ} \mathrm{C}, 1$ y 12 bar $\mathrm{N}_{2}$ inicial, 120 min de reacción, masa catalizador: $0,5 \mathrm{~g}$, solución acuosa al $10 \%$ p/p de glicerol, agitación 700 rpm

\begin{tabular}{lcc}
\hline Presión inicial de $\mathbf{N}_{\mathbf{2}}$ (bar) & $\mathbf{1}$ & $\mathbf{1 2}$ \\
\hline $\mathbf{X}^{\mathrm{G}}(\%)$ & 24 & 10 \\
$\mathbf{X}^{\mathrm{T}}(\%)$ & 38 & 19 \\
$\mathbf{R H}_{\mathbf{2}}(\%)$ & 17 & 10 \\
$\mathbf{S H}_{\mathbf{2}}(\%)$ & 88 & 96 \\
$\mathbf{H}_{\mathbf{2}} / \mathbf{C O}_{\mathbf{2}}$ & 1,8 & 2,4 \\
\hline
\end{tabular}

Respecto a la selectividad de los productos, se observa en el gráfico (Figura III-03) un aumento en la selectividad al reformado $\left(\mathrm{SCO}_{2}\right)$ al disminuir la presión. Respecto a los productos en la fase líquida se observa un aumento considerable en la $\mathrm{SC}_{3}$ al aumentar la presión.

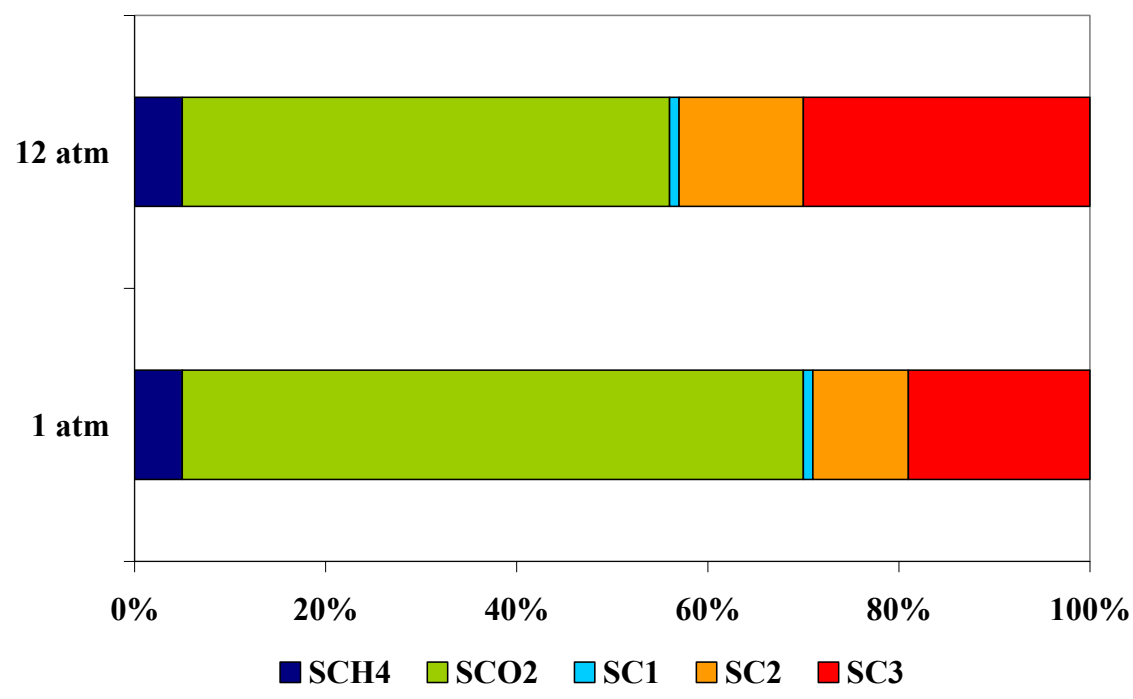

Figura III-03. Selectividad de productos vs. Presión inicial de $\mathrm{N}_{2}$. Condiciones de reacción: $225^{\circ} \mathrm{C}, 1$ y 12 bar $\mathrm{N}_{2}$ inicial, 120 min de reacción, masa catalizador: $0,5 \mathrm{~g}$, solución acuosa al 10\% p/p de glicerol, agitación $700 \mathrm{rpm}$ 
Estos resultados evidencian que la relación de rupturas de enlaces $\mathrm{C}-\mathrm{C} / \mathrm{C}-\mathrm{O}$ es mayor para la condición de menor presión y están en concordancia con lo reportado por Wawrzetz y col. [4] quienes observaron una disminución en la conversión de glicerol a gases de $43 \%$ a 26 bar a $12 \%$ a 45 bar.

\section{III.2.4. Efecto del tiempo de reacción}

En condiciones de $225^{\circ} \mathrm{C}$ y 1 atmósfera de presión de $\mathrm{N}_{2}$ inicial, sobre el catalizador 2PtAl, se puede observar en la Tabla III-03 como aumenta la conversión con el tiempo y como disminuye la selectividad a $\mathrm{H}_{2}$. Cada experiencia se realizó con una muestra de catalizador fresco y se modificó el tiempo de reacción en 30, 120 y 480 minutos.

Tabla III-03. APR de glicerol con el catalizador 2PtAl. Condiciones de reacción: 225 ${ }^{\circ} \mathrm{C}, 1$ bar $\mathrm{N}_{2}$ inicial, 30, 120 y 480 min de reacción, masa catalizador: 0,5 g, solución acuosa al 10\% p/p de glicerol, agitación 700 rpm

\begin{tabular}{lccc}
\hline Tiempo de reacción (min) & $\mathbf{3 0}$ & $\mathbf{1 2 0}$ & $\mathbf{4 8 0}$ \\
\hline $\mathbf{X}^{\mathrm{G}}(\%)$ & 11 & 24 & 36 \\
$\mathbf{X}^{\mathrm{T}}(\%)$ & 16 & 38 & 58 \\
$\mathbf{R} H_{\mathbf{2}}(\%)$ & 10 & 17 & 30 \\
$\mathbf{S H}_{\mathbf{2}}(\%)$ & 90 & 88 & 85 \\
$\mathbf{H}_{\mathbf{2}} / \mathbf{C O}_{\mathbf{2}}$ & 1,8 & 1,8 & 2,2 \\
\hline
\end{tabular}

Al analizar la Figura III-04 se observa como disminuye la selectividad al reformado $\left(\mathrm{SCO}_{2}\right)$ mientras aumenta la selectividad a compuestos carbonados. 


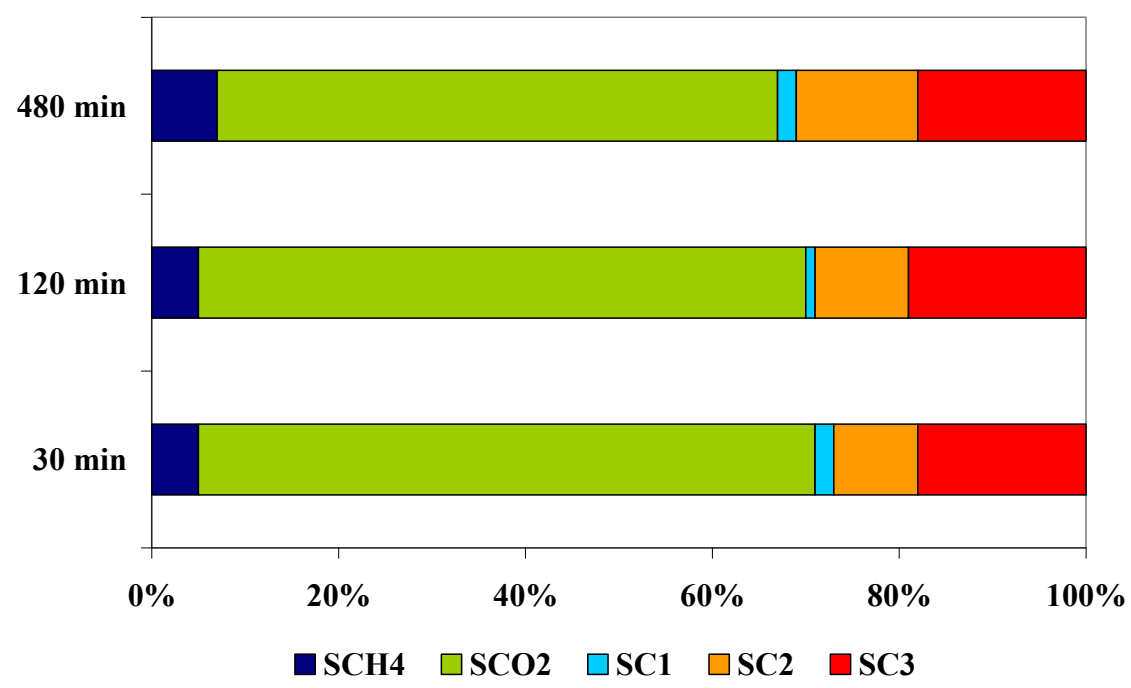

Figura III-04. Selectividad de productos vs. Tiempo de reacción. Condiciones de reacción: $225^{\circ} \mathrm{C}, 1$ bar $\mathrm{N}_{2}$ inicial, 30,120 y 480 min de reacción, masa catalizador: 0,5 g, solución acuosa al 10\% p/p de glicerol, agitación 700 rpm

En la Figura III-05 se esquematiza la evolución de los productos líquidos de manera individual, pudiéndose notar un aumento en la selectividad a etanol y 1-propanol con el tiempo de reacción y también una leve disminución en la selectividad del acetol y propilenglicol.

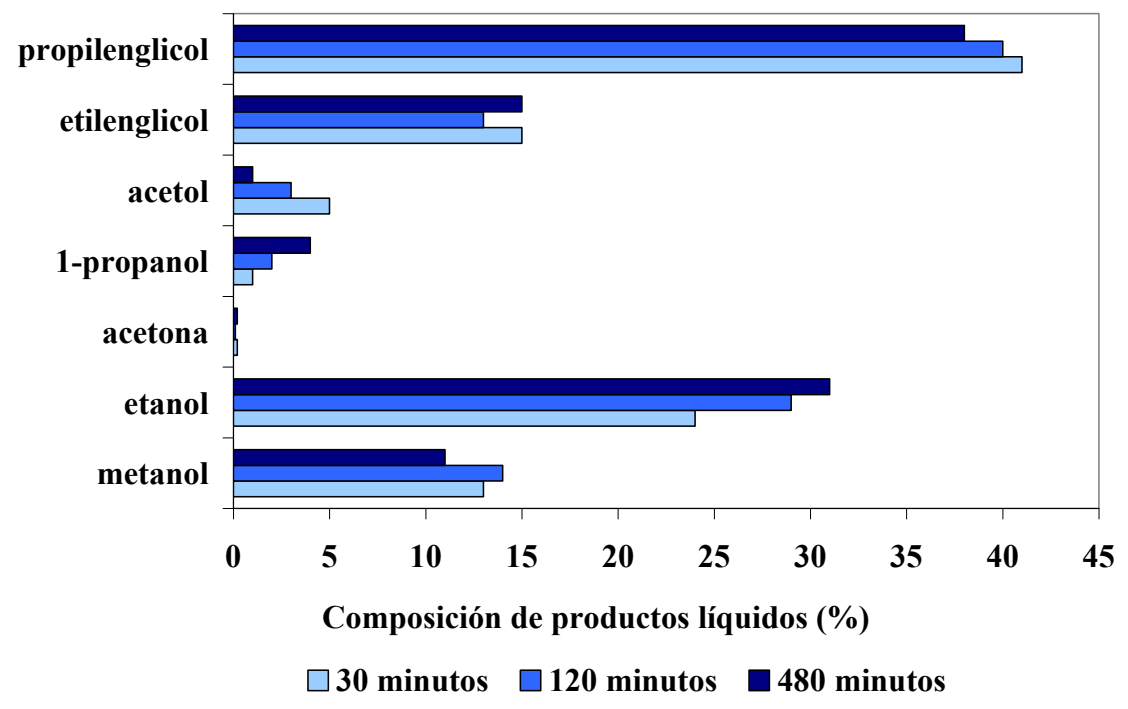

Figura III-05. Composición de productos líquidos vs. Tiempo de reacción. Condiciones de reacción: $225^{\circ} \mathrm{C}, 1$ bar $\mathrm{N}_{2}$ inicial, 30, 120 y 480 min de reacción, masa catalizador: $0,5 \mathrm{~g}$, solución acuosa al 10\% p/p de glicerol, agitación $700 \mathrm{rpm}$ 
De manera de encontrar un posible camino de reacción del APR del glicerol se realizaron ensayos empleando los productos observados (metanol, etanol, etilenglicol, propilenglicol y acetol) en forma aislada.

\section{III.3. Ensayos de APR con otros alcoholes: metanol, etanol, etilenglicol, propilenglicol y acetol}

En esta sección se presentan los resultados del APR de etilenglicol, propilenglicol, acetol, metanol y etanol con el fin de identificar los productos principales y laterales del reformado de glicerol y de esta manera establecer un posible esquema de reacción.

Según lo reportado por el grupo de Dumesic [5], los posibles caminos de reacción en el APR que puede sufrir un poliol son (Esquema III-01):

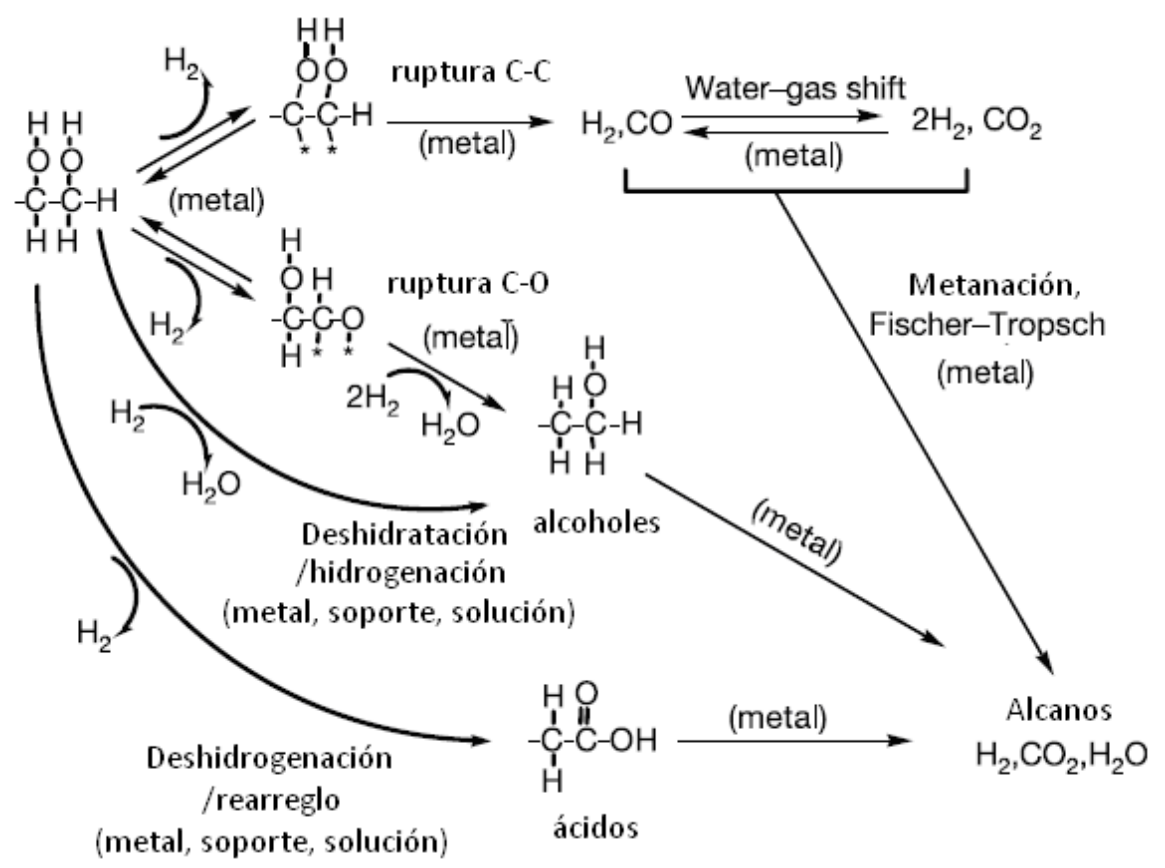

Esquema III-01. Posibles caminos de reacción en el APR de hidrocarburos oxigenados Fuente: Cortright y col. [5]

El reactivo sufre un paso de deshidrogenación sobre la superficie metálica para dar intermediarios adsorbidos antes de la ruptura de los enlaces $\mathrm{C}-\mathrm{C}$ o $\mathrm{C}-\mathrm{O}$. Con catalizadores de $\mathrm{Pt}$, el enlace $\mathrm{Pt}-\mathrm{C}$ es más estable que el $\mathrm{Pt}-\mathrm{O}$, por lo que las especies adsorbidas son probablemente enlazadas a la superficie del metal a través de los enlaces $\mathrm{Pt}-\mathrm{C}$. 
Subsecuentemente, la ruptura de enlaces C-C lleva a la formación de $\mathrm{CO}$ e $\mathrm{H}_{2}$, y el CO formado reacciona con el agua para generar $\mathrm{CO}_{2}$ e $\mathrm{H}_{2}$ a través de la reacción de WGS. La reacción de $\mathrm{CO}$ y/o $\mathrm{CO}_{2}$ con $\mathrm{H}_{2}$ produce alcanos y agua por la reacción de metanación y la de Fischer-Tropsch [6-8].

También, se pueden formar alcanos sobre los sitios metálicos del catalizador a partir de rupturas de enlaces $\mathrm{C}-\mathrm{O}$, seguido de la hidrogenación de la especie adsorbida resultante y de la formación de $\mathrm{H}_{2} \mathrm{O}$. Otro camino paralelo, que también consiste en la ruptura de enlaces C-O, es a través de reacciones de deshidratación catalizadas por sitios ácidos asociados con el soporte del catalizador $[\mathbf{9}, \mathbf{1 0}]$, o bien por protones en la solución acuosa $[11,12]$, seguido de reacciones de hidrogenación sobre el catalizador.

Por otra parte, se pueden formar ácidos orgánicos por reacciones de deshidrogenación catalizadas por el metal seguidas de reacciones de reordenamiento [13] que se producen en solución o bien sobre el catalizador.

Los alcoholes y ácidos orgánicos llevan a la formación de alcanos a partir de los átomos de carbón que no están enlazados a un átomo de oxígeno.

\section{III.3.1. Reformado en fase líquida de metanol}

El metanol se reforma según la siguiente estequiometría:

$\mathrm{CH}_{3} \mathrm{OH} \rightarrow 2 \mathrm{H}_{2}+\mathrm{CO}$

Ecuación III-07

$\mathrm{CO}+\mathrm{H}_{2} \mathrm{O} \leftrightarrow \mathrm{H}_{2}+\mathrm{CO}_{2}$

Ecuación III-08

$\mathrm{CH}_{3} \mathrm{OH}+\mathrm{H}_{2} \mathrm{O} \rightarrow 3 \mathrm{H}_{2}+\mathrm{CO}_{2}$

Ecuación III-09

El catalizador 2PtAl no presentó actividad para el APR del metanol. Las condiciones de reacción fueron de $225^{\circ} \mathrm{C}, 1$ bar de $\mathrm{N}_{2}$ inicial, 2 horas de reacción, 0,5 g de masa de catalizador y $12 \mathrm{~mL}$ de solución acuosa al $10 \%$ p/p de metanol. A $250{ }^{\circ} \mathrm{C}$ y 12 bar de $\mathrm{N}_{2}$ inicial se obtuvo un $9 \%$ de conversión a productos gaseosos con una composición en los gases de: $\mathrm{H}_{2}=75 \%, \mathrm{CH}_{4}=0,92 \%, \mathrm{CO}_{2}=24,1 \%$.

La relación $\mathrm{H}_{2} / \mathrm{CO}_{2}$ obtenida es de 3,11 prácticamente igual a la estequiométrica $\left(\mathrm{H}_{2} / \mathrm{CO}_{2}\right.$ est: 3). El único subproducto encontrado fue $\mathrm{CH}_{4}$. 
Capítulo III. Determinación de condiciones experimentales y esquema de reacciones

Los resultados de composición gaseosa obtenida concuerdan con los estudios de APR de metanol con catalizadores de $\mathrm{Pt} / \gamma-\mathrm{Al}_{2} \mathrm{O}_{3}$ reportados por Cortright y col. [5] y Tang y col. [14].

\section{III.3.2. Reformado en fase líquida de etanol}

En el reformado de etanol, en una primera instancia se produce la descomposición en presencia de agua mediante la reacción:

$\mathrm{C}_{2} \mathrm{H}_{6} \mathrm{O}+\mathrm{H}_{2} \mathrm{O} \rightarrow 4 \mathrm{H}_{2}+2 \mathrm{CO}$

Ecuación III-10

Para luego producirse la transformación del $\mathrm{CO}$ en $\mathrm{CO}_{2}$ a través de la reacción de WGS:

$\mathrm{H}_{2} \mathrm{O}+\mathrm{CO} \leftrightarrow \mathrm{H}_{2}+\mathrm{CO}_{2}$

Ecuación III-11

Los resultados encontrados a $225^{\circ} \mathrm{C}, 1$ bar de $\mathrm{N}_{2}$ inicial, 2 horas de reacción, 0,5 g de masa de catalizador $2 \mathrm{PtAl}$ y $12 \mathrm{~mL}$ de solución acuosa al $10 \% \mathrm{p} / \mathrm{p}$ de etanol, fueron $\mathrm{X}^{\mathrm{G}}=3 \%, \mathrm{X}^{\mathrm{T}}=4 \%, \mathrm{R}_{\mathrm{H} 2}=2 \%$, composición de gases $\mathrm{H}_{2}=72 \%, \mathrm{CH}_{4}=13 \%, \mathrm{CO}_{2}=15 \%$, siendo el metanol el único subproducto líquido encontrado, lo que representa una muy baja actividad.

La composición gaseosa obtenida con un alto contenido a $\mathrm{CH}_{4}$ concuerda con los resultados encontrados por Tokarev y col. [15], quienes observaron que la transformación del etanol resulta en la formación de metano según:

$\mathrm{C}_{2} \mathrm{H}_{6} \mathrm{O}+\mathrm{H}_{2} \mathrm{O} \rightarrow 2 \mathrm{H}_{2}+\mathrm{CO}_{2}+\mathrm{CH}_{4}$

Ecuación III-12

encontrando una distribución de productos gaseosos de $\mathrm{H}_{2}=44 \% \mathrm{CO}_{2}=22 \% \mathrm{CH}_{4}=19 \%$ $\mathrm{CO}=10 \%$ y ácido acético como único subproducto en la fase líquida.

Analizando las posibles reacciones que podría sufrir el etanol vemos en el esquema (Esquema III-02) que en una primera etapa el etanol podría deshidrogenarse para obtener el aldehído etanal, el cual por ruptura $\mathrm{C}-\mathrm{C}$, produce $\mathrm{CO}$ y $\mathrm{CH}_{4}$, o bien produce $\mathrm{CH}_{4}$ y metanol por hidrogenación. 


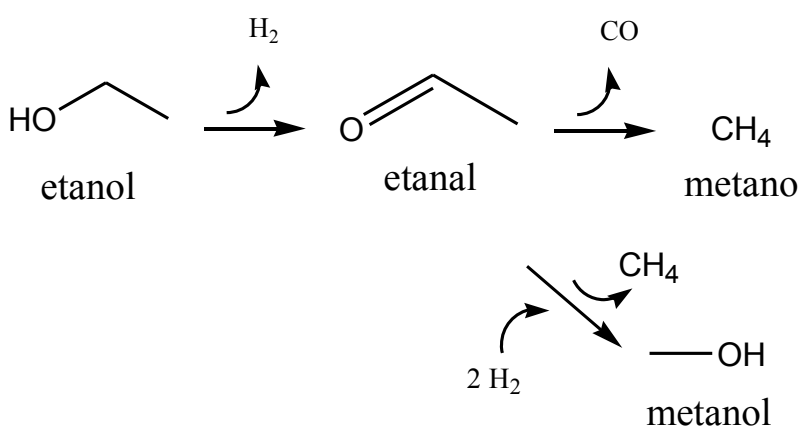

Esquema III-02. Posible camino de reacción en APR de etanol

La formación de $\mathrm{CH}_{4}$ podría provenir de la ruptura $\mathrm{C}-\mathrm{C}$ de la molécula de etanol o bien de la reacción de metanación (Ecuación III-04).

A $250{ }^{\circ} \mathrm{C}$ y 12 bar de $\mathrm{N}_{2}$ inicial los resultados encontrados fueron $X^{\mathrm{G}}=15 \%, X^{\mathrm{T}}=20 \%$, $\mathrm{R}_{\mathrm{H} 2}=7 \%$, composición molar de gases $\mathrm{H}_{2}=57 \%, \mathrm{CH}_{4}=15,5 \%, \mathrm{CO}_{2}=22,3 \%, \mathrm{C}_{2} \mathrm{H}_{6}=5,2 \%$, y nuevamente metanol como único subproducto líquido. A este nivel térmico la relación $\mathrm{H}_{2} / \mathrm{CO}_{2}$ obtenida de 2,55, se aproxima al valor teórico esperado del APR del etanol $=2$ según Ecuación III-12.

\section{III.3.3. Reformado en fase líquida de etilenglicol (EG)}

El reformado del etilenglicol sigue la siguiente estequiometría global:

$\mathrm{C}_{2} \mathrm{H}_{6} \mathrm{O}_{2}+2 \mathrm{H}_{2} \mathrm{O} \rightarrow 5 \mathrm{H}_{2}+2 \mathrm{CO}_{2}$

Ecuación III-13

Esta reacción ocurre vía la formación de $\mathrm{CO}$, él que es convertido a $\mathrm{CO}_{2}$ por la reacción de WGS.

$\mathrm{CO}+\mathrm{H}_{2} \mathrm{O} \leftrightarrow \mathrm{H}_{2}+\mathrm{CO}_{2}$

Ecuación III-14 


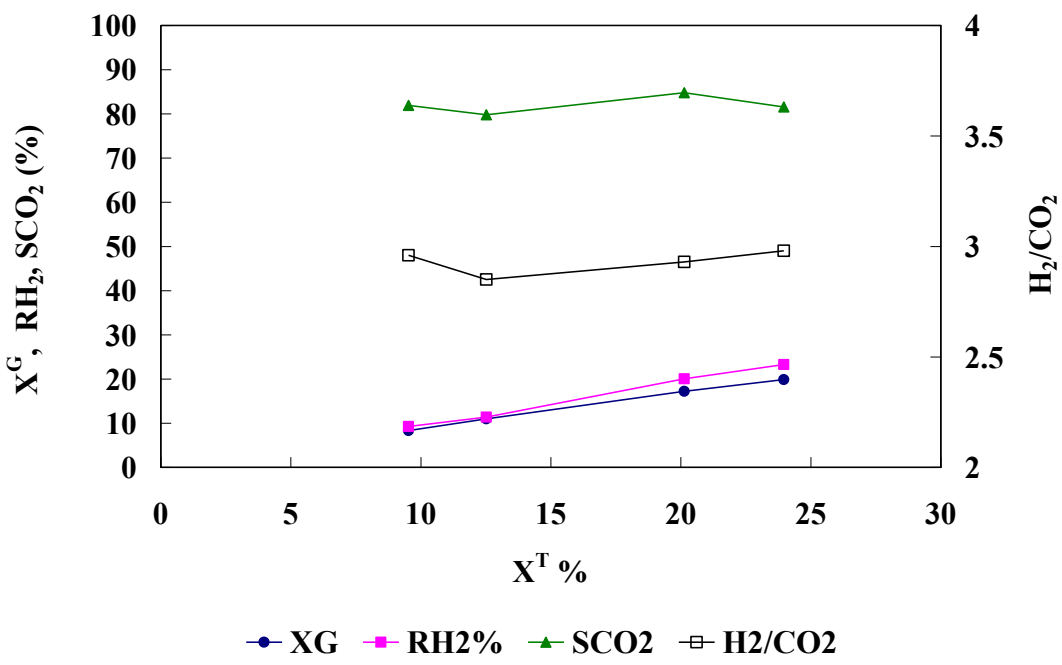

Figura III-06. Resultados de APR de Etilenglicol (EG). Condiciones de reacción: 225

${ }^{\circ} \mathrm{C}, 1$ bar $\mathrm{N}_{2}$ inicial, $2 \mathrm{~h}$ de reacción, solución acuosa al 10\% p/p de etilenglicol, agitación $700 \mathrm{rpm}$

En la Figura III-06 se presentan los resultados a $225^{\circ} \mathrm{C}$ sobre catalizadores $2 \mathrm{PtAl}$ en función de la conversión total de EG. Cada experiencia se realizó con una muestra de catalizador fresco y se modificó la masa de catalizador para alcanzar diferentes conversiones (200-500 mg). La conversión a productos gaseosos $X^{\mathrm{G}}(\%)$ aumenta con el aumento en la conversión total manteniendo prácticamente constante la selectividad al reformado $\left(\mathrm{SCO}_{2}\right)$ en un valor aproximado de $83 \%$ para todo el rango de conversión estudiado.

La relación $\mathrm{H}_{2} / \mathrm{CO}_{2}$ permaneció razonablemente constante con la variación en la conversión total en un valor medio de 2,9, levemente por encima del valor estequiométrico esperado de 2,5 según la Ecuación III-13.

Respecto al rendimiento de hidrógeno observado se ve que el mismo aumenta con el avance en la conversión obteniéndose un rendimiento máximo del $23 \%$ a $24 \%$ de $\mathrm{X}^{\mathrm{T}}$.

Respecto a los subproductos líquidos, se encontró la presencia de metanol y etanol. Analizando la evolución de los subproductos líquidos con la conversión total (Figura III-07), se puede ver que la composición del metanol y etanol permanecen estables con el avance de la conversión, con una composición aproximada de $80 \% \mathrm{~mol} / \mathrm{mol}$ de metanol y $20 \% \mathrm{~mol} / \mathrm{mol}$ de etanol. 


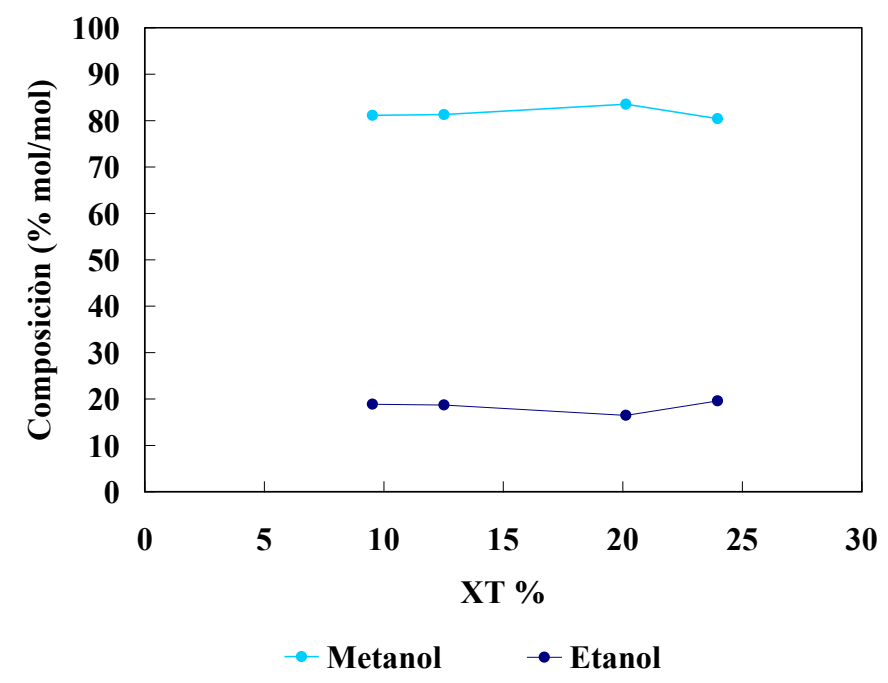

Figura III-07. Composición molar de productos líquidos en el APR de EG.

Condiciones de reacción: $225^{\circ} \mathrm{C}, 1$ bar $\mathrm{N}_{2}$ inicial, 2 h de reacción, solución acuosa al $10 \%$ p/p de etilenglicol, agitación $700 \mathrm{rpm}$

Teniendo en cuenta los resultados encontrados se propone un posible esquema (Esquema III-03) para el APR del etilenglicol. En un primer paso el etilenglicol podría deshidrogenarse sobre la superficie metálica del catalizador mediante el anclaje C-C conduciendo al compuesto 2-hidroxietanal.

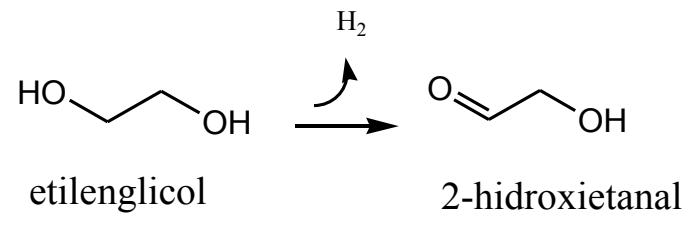

Esquema III-03. Deshidrogenación de etilenglicol a 2-hidroxietanal

El producto de dicha deshidrogenación, el 2-hidroxietanal, resultaría un compuesto inestable ya que no fue detectado en los análisis cromatográficos. Este compuesto a vez podría sufrir una nueva deshidrogenación y posterior ruptura $\mathrm{C}-\mathrm{C}$ conduciendo a la formación de $\mathrm{H}_{2}$ y $\mathrm{CO}$ (Esquema III-04). 


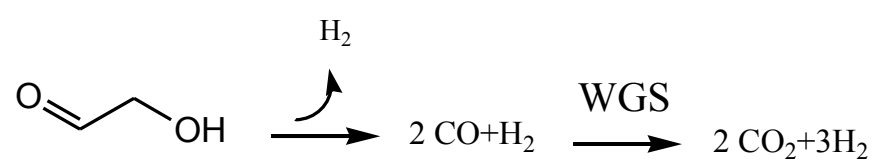

2-hidroxietanal

Esquema III-04. Deshidrogenación y ruptura C-C del 2-hidroxietanal y posterior reacción de WGS

El $\mathrm{CO}$ producido luego se convierte en $\mathrm{CO}_{2}$ a través de la reacción de WGS.

Esta es la ruta principal de reformado del EG, por la que se debiera esperar una relación $\mathrm{H}_{2} / \mathrm{CO}_{2}$ de 2,5 .

La presencia de metanol en los productos líquidos de reacción, estaría evidenciando una posible reacción lateral del 2-hidroxietanal (Esquema III-05), producida por la ruptura del enlace C-C lo que forma metanol y una molécula de CO.

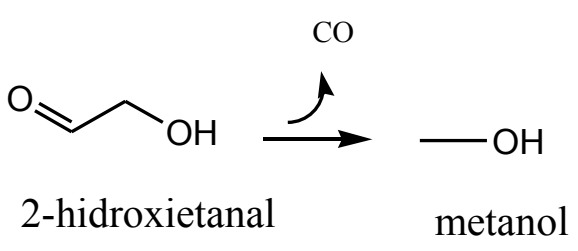

Esquema III-05. Ruptura C-C con formación de CO del 2-hidroxietanal

Respecto a la presencia de etanol en los productos de reacción, este podría provenir del anclaje del enlace C-O del etilenglicol sobre el sitio metálico del catalizador, acompañado de una deshidrogenación, para luego sufrir la ruptura e hidrogenación de la especie adsorbida resultante con desprendimiento de una molécula de $\mathrm{H}_{2} \mathrm{O}$ y etanol (Esquema III-06).

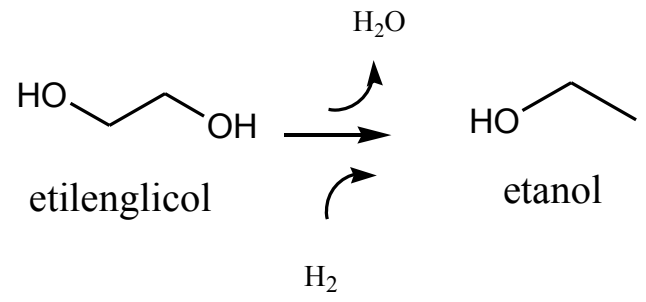

Esquema III-06. Ruptura C-O del etilenglicol

El etanol también podría provenir de un camino paralelo que, al igual que el anterior, involucra la ruptura de enlaces $\mathrm{C}-\mathrm{O}$, pero a través de reacciones de deshidratación 
catalizadas por sitios ácidos, generalmente asociadas con los soportes, seguido de reacciones de hidrogenación sobre el sitio metálico del catalizador.

Estos dos mecanismos de reacción, se sintetizarán de ahora en adelante como el mecanismo ruptura $C-O$, teniendo en cuenta que esta ruptura puede ser generada tanto por el mecanismo de ruptura del enlace sobre sitios metálicos o bien sobre sitios ácidos y metálicos del catalizador. En el Capítulo IV se estudia en profundidad este tema.

Es importante destacar que el etanol se forma a partir de una reacción lateral en el APR del EG, lo que disminuye el rendimiento a $\mathrm{H}_{2}$.

El esquema de reacciones presentes en el APR del etilenglicol quedaría sintetizado de la siguiente manera:

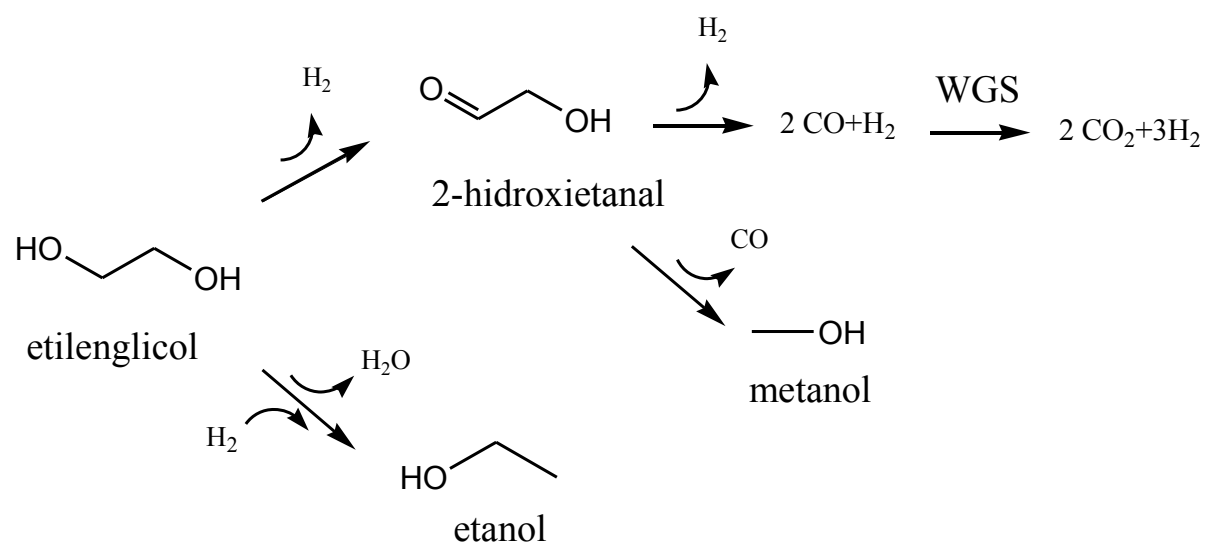

Esquema III-07. Posibles caminos de reacción del APR de etilenglicol

En resumen, existe una ruta de reacción de reformado, la que ocurre por medio de rupturas $\mathrm{C}-\mathrm{C}$, y una ruta paralela que ocurre a partir de ruptura $\mathrm{C}-\mathrm{O}$, con formación de etanol y consecuente disminución del $\mathrm{R}_{\mathrm{H} 2}$. En la ruta de reacciones de reformado existe la posibilidad de producción de metanol, la que también consiste en una disminución del $\mathrm{R}_{\mathrm{H} 2}$.

La alta relación $\mathrm{X}^{\mathrm{G}} / \mathrm{X}^{\mathrm{T}}$ encontrada sumada al menor contenido de etanol respecto al de metanol, indicaría un fuerte aporte de las reacciones de ruptura $\mathrm{C}-\mathrm{C}$ frente a las reacciones de ruptura $\mathrm{C}-\mathrm{O}$ para esta molécula. 


\section{III.3.4. Reformado en fase líquida de propilenglicol (PG)}

El APR del PG sigue la siguiente estequiometría global:

$$
\mathrm{C}_{3} \mathrm{H}_{8} \mathrm{O}_{2}+2 \mathrm{H}_{2} \mathrm{O} \rightarrow 4 \mathrm{H}_{2}+2 \mathrm{CO}_{2}+\mathrm{CH}_{4}
$$

con una relación $\mathrm{H}_{2} / \mathrm{CO}_{2}$ estequiométrica de 2 .

El PG posee un átomo de carbón que no está enlazado a un átomo de oxígeno lo que conduciría a la formación de metano.

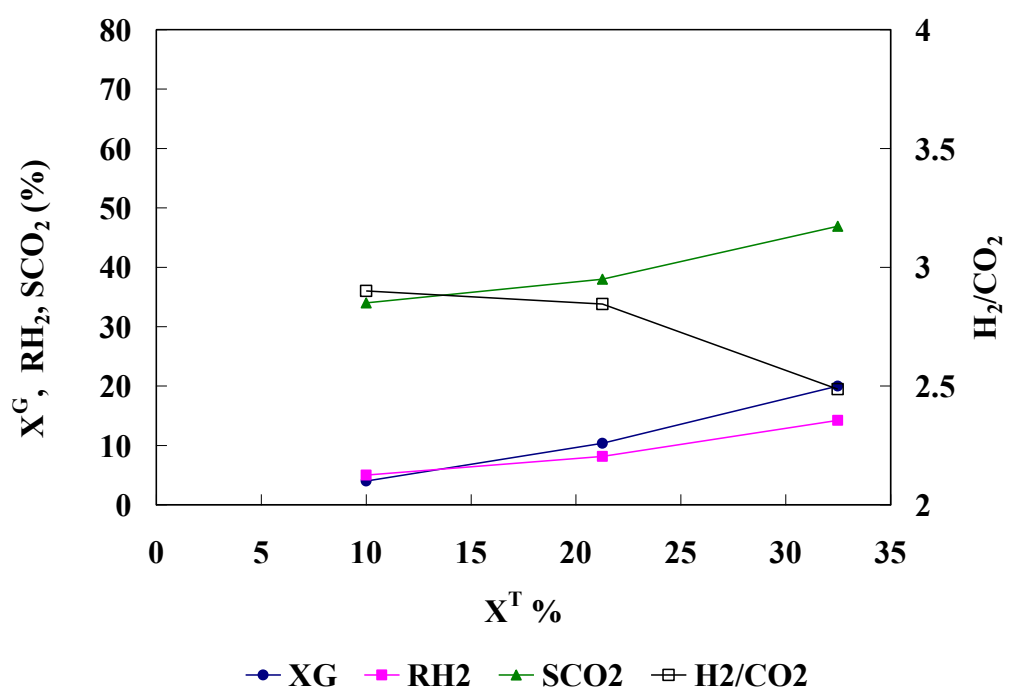

Figura III-08. Resultados del APR de PG. Condiciones de reacción: $225^{\circ} \mathrm{C}, 1$ bar $\mathrm{N}_{2}$ inicial, 2 h de reacción, solución acuosa al 10\% p/p de propilenglicol, agitación $700 \mathrm{rpm}$

La Figura III-08 muestra los resultados a $225^{\circ} \mathrm{C}$ sobre $2 \mathrm{PtAl}$ en función de la conversión total de PG. Cada experiencia se realizó con una muestra de catalizador fresco y se modificó la masa de catalizador para alcanzar diferentes conversiones (200$500 \mathrm{mg}$ ). Los productos gaseosos, si bien se encuentran compuestos principalmente por $\mathrm{H}_{2}$ y $\mathrm{CO}_{2}, \sim 68 \%$ y $\sim 24 \%$ respectivamente, presentan mayor contenido de $\mathrm{CH}_{4}(\sim 7 \%)$ comparado con el contenido que presenta el APR de etilenglicol $\leq 1 \%$, esto se debe a la pérdida del grupo $-\mathrm{CH}_{3}$ del $\mathrm{PG}$.

La relación $\mathrm{H}_{2} / \mathrm{CO}_{2}$ observada está entre 2,5 y 3, valor por encima del valor teórico de la reacción de reformado $=2$. 
Analizando lo que ocurre con el aumento de conversión total del PG, se observa un aumento de $\mathrm{X}^{\mathrm{G}}$ mientras que la selectividad al reformado $\mathrm{SCO}_{2}$ aumenta levemente llegando a un $47 \%$ para un $32 \%$ de conversión total.

El rendimiento a $\mathrm{H}_{2}$ aumenta con la $\mathrm{X}^{\mathrm{T}}$, obteniéndose un valor cercano al $15 \%$ para una conversión total del $32 \%$. Asimismo, se puede observar que éste es menor al encontrado en el APR de etilenglicol.

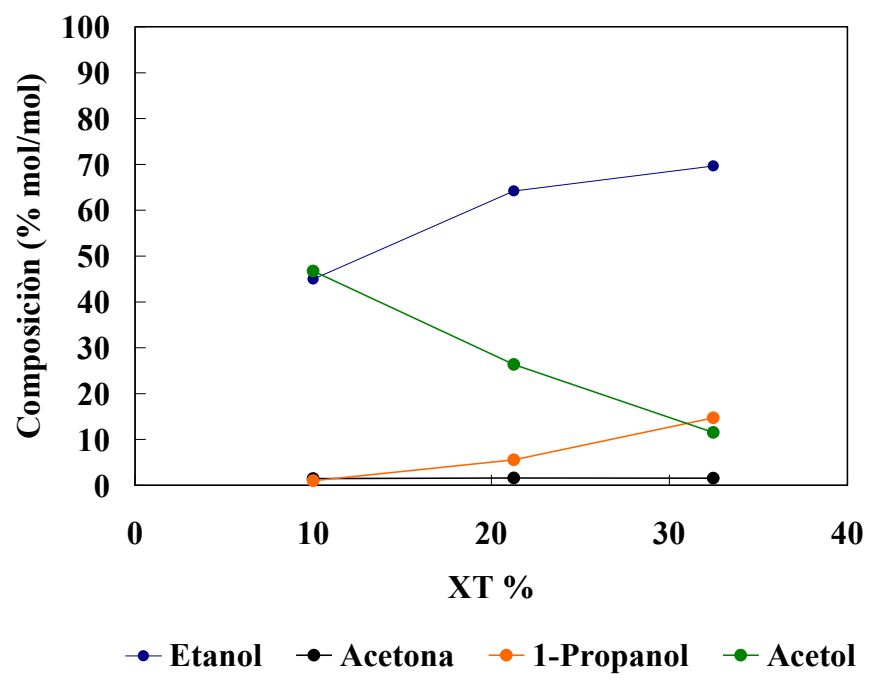

Figura III-09. Composición molar de los productos líquidos del APR de PG.

Condiciones de reacción: $225^{\circ} \mathrm{C}, 1$ bar $\mathrm{N}_{2}$ inicial, 2 h de reacción, solución acuosa al $10 \%$ p/p de propilenglicol, agitación $700 \mathrm{rpm}$

En los productos líquidos se identificaron etanol y acetol como productos mayoritarios y en menor proporción acetona y 1-propanol (Figura III-09).

Respecto a la composición de los productos líquidos se observa que a mayor conversión se produce un descenso en la composición del acetol y un aumento en la composición de etanol. A partir de estos resultados se propone un esquema que represente las posibles reacciones involucradas. El PG en una primera etapa puede sufrir una deshidrogenación del primer o segundo carbono produciendo 2-hidroxipropanal o acetol respectivamente (Esquema III-8). 

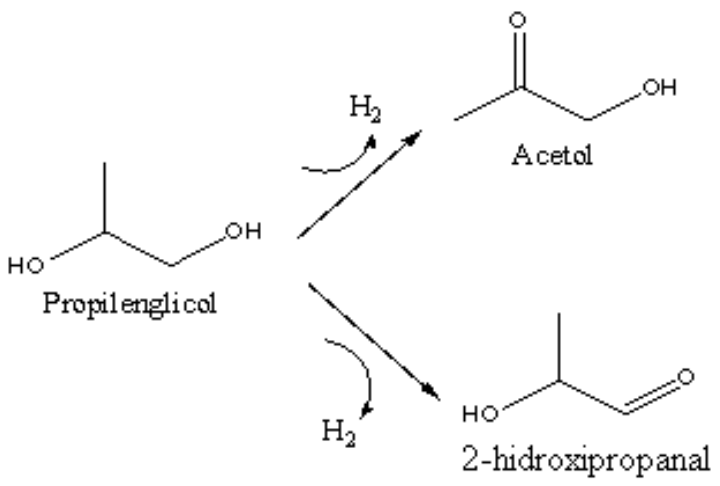

Esquema III-08. Deshidrogenación del propilenglicol

El compuesto 2-hidroxipropanal es el intermediario menos estable, ya que no fue detectado en los productos de reacción.

De esta manera existirían dos rutas principales de conversión a partir de la deshidrogenación del PG, la ruta vía acetol o bien la ruta vía 2-hidroxipropanal.

Ruta vía acetol: Luego de la etapa de deshidrogenación del PG, el compuesto acetol podría sufrir una nueva reacción de deshidrogenación lo que conduciría a la obtención 2-oxopropanal (compuesto inestable y no identificado) el cual sufriría una ruptura C-C, produciendo $\mathrm{CO}$ y etanal, el cual puede sufrir una nueva ruptura $\mathrm{C}-\mathrm{C}$, conduciendo a $\mathrm{CO} \mathrm{y} \mathrm{CH}_{4}$. En este caso el $\mathrm{CH}_{4}$ estaría proviniendo de la función alquilo presente en la molécula de PG y no de la reacción de metanación.

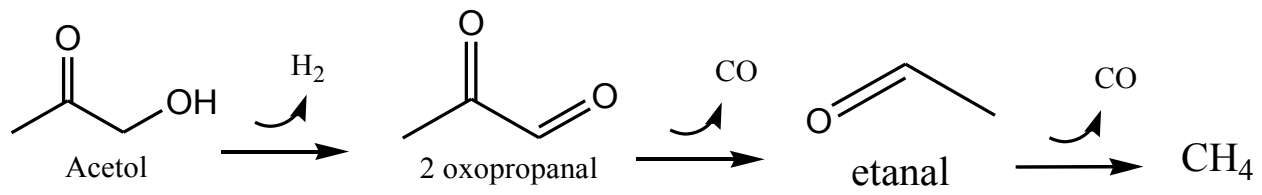

Esquema III-09. Deshidrogenación y rupturas de enlaces C-C a partir de acetol

El CO formado se combina con el $\mathrm{H}_{2} \mathrm{O}$ para la producción de $\mathrm{H}_{2}$ y $\mathrm{CO}_{2}$ mediante la reacción de WGS.

Esta ruta vía el acetol constituye la ruta de reformado del PG propiamente dicho. En esta ruta de reacción, podrían producirse reacciones laterales como la ruptura $\mathrm{C}-\mathrm{O}$ del acetol, para obtener el subproducto acetona. 


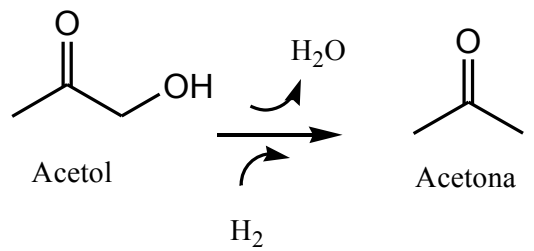

Esquema III-10. Ruptura de enlace C-O del acetol

Como así también la hidrogenación del compuesto etanal a etanol.

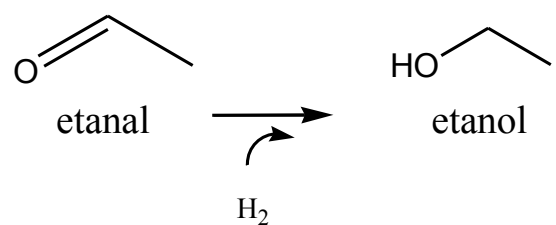

Esquema III-11. Hidrogenacion del etanal a etanol

Ruta vía 2-hidroxipropanal: El compuesto 2-hidroxipropanal podría sufrir una ruptura C-C de manera de obtener CO y etanol.

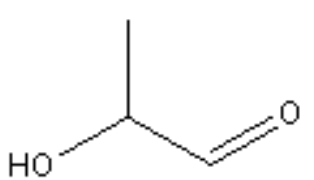

2-hidroxipropanal

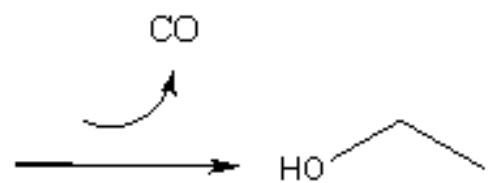

etanol

Esquema III-12. Ruptura de enlace C-C con desprendimiento de CO del 2hidroxipropanal

El PG además de sufrir la deshidrogenación inicial también podría sufrir una ruptura CO del carbono primario y/o secundario, lo que llevaría a la obtención de los alcoholes isopropanol y 1-propanol respectivamente. Esta reacción constituye una reacción lateral indeseada ya que compite con el rendimiento al reformado de la molécula PG.

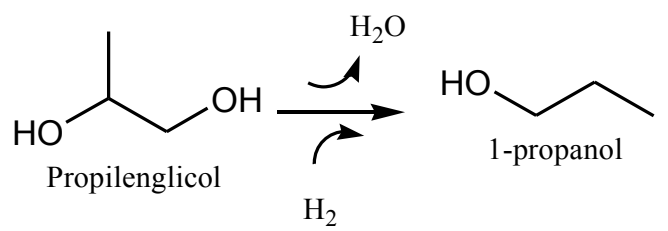

Esquema III-13. Ruptura de enlace C-O del propilenlgicol 
Se descarta la reacción de ruptura C-O del carbón primario debido a que no se identificó el compuesto isopropanol en los productos obtenidos.

El esquema completo del APR del PG quedaría constituido como lo indica el Esquema III-14.

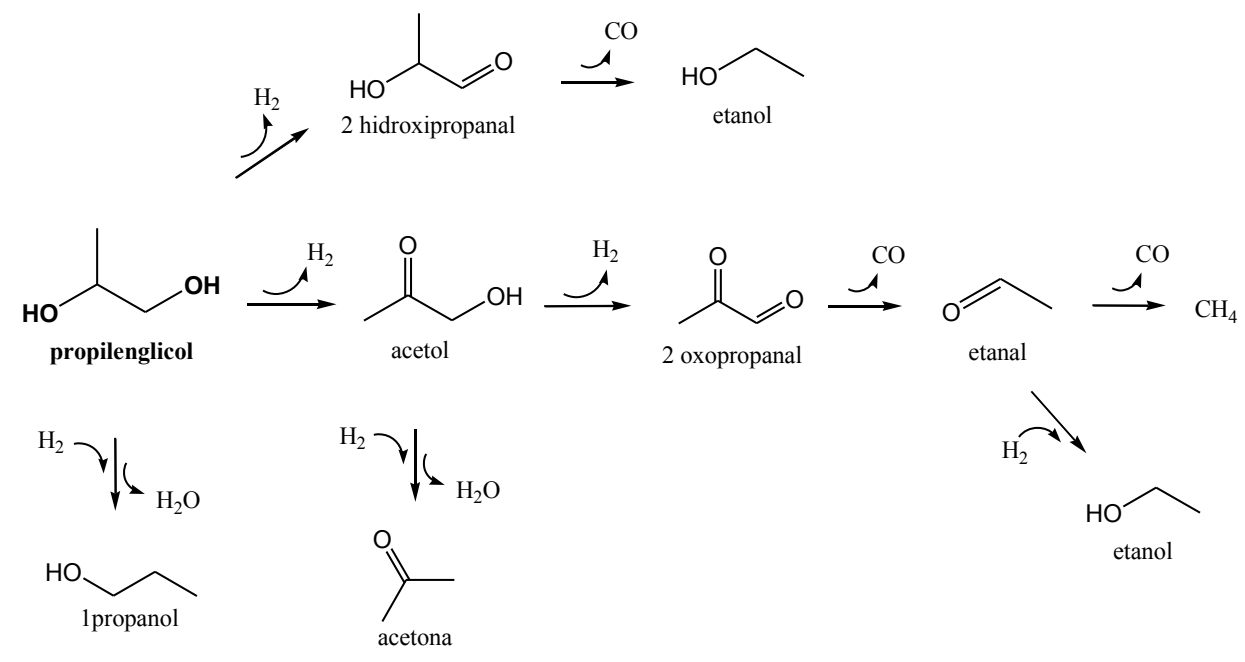

Esquema III-14. Posibles caminos de reacción del APR de propilenglicol

Las bajas selectividades observadas de los compuestos obtenidos por medio de rupturas C-O (1-propanol y acetona) estarían indicando que la contribución de esta ruta es mucho menor comparada con la contribución de las rutas de deshidrogenación/ruptura C-C.

Analizando la distribución de los productos con la conversión (Figura III-09) conjuntamente con el esquema de reacciones propuesto (Esquema III-14), se puede observar cómo al aumentar la conversión total del PG, la ruta de reacción vía el acetol se ve favorecida, generando una disminución en la composición de acetol a expensas de una mayor producción a compuestos gaseosos y de etanol, el cual es el subproducto líquido en esta ruta.

\section{III.3.5. Reformado en fase líquida de Acetol (AC)}

El reformado de acetol puede proceder por la reacción:

$$
\mathrm{C}_{3} \mathrm{H}_{6} \mathrm{O}_{2}+4 \mathrm{H}_{2} \mathrm{O} \rightarrow 7 \mathrm{H}_{2}+3 \mathrm{CO}_{2}
$$


o bien por la reacción:

$\mathrm{C}_{3} \mathrm{H}_{6} \mathrm{O}_{2}+2 \mathrm{H}_{2} \mathrm{O} \rightarrow 3 \mathrm{H}_{2}+2 \mathrm{CO}_{2}+\mathrm{CH}_{4}$

la cual tiene en cuenta el radical $-\mathrm{CH}_{3}$ presente en la molécula, lo que llevaría a la producción de $\mathrm{CH}_{4}$.

En la Figura III-10 se muestran los resultados del APR del AC a $225^{\circ} \mathrm{C}$ con el catalizador 2PtAl. Cada experiencia se realizó con una muestra de catalizador fresco y se modificó la masa de catalizador para alcanzar diferentes conversiones (200-500 mg).

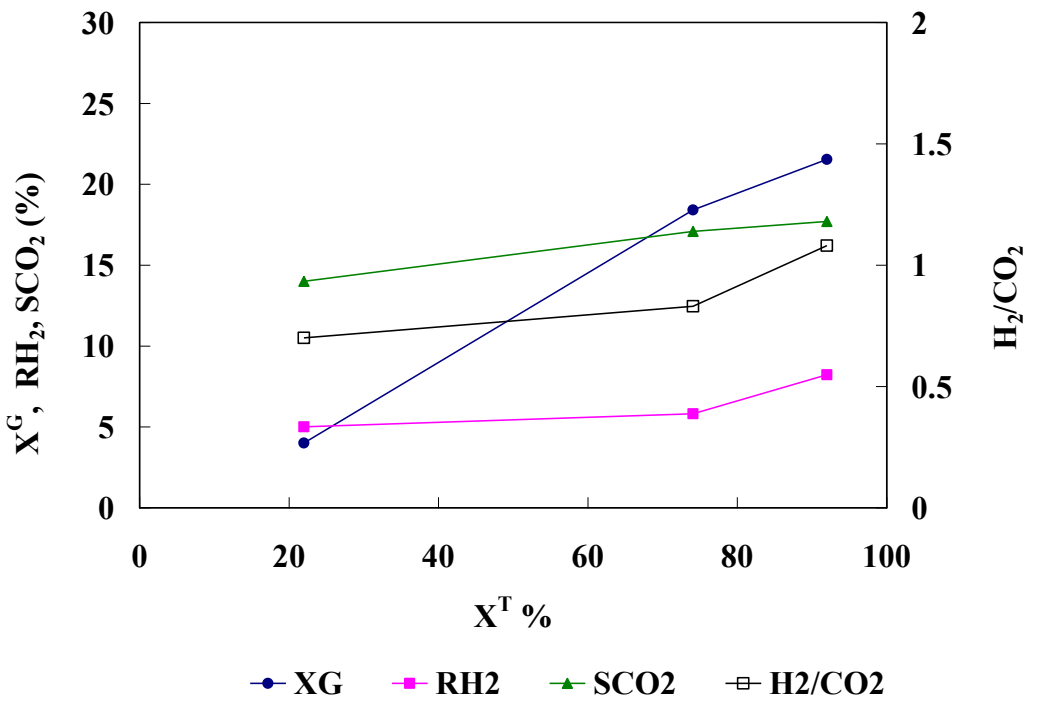

Figura III-10. Resultados del APR del AC. Condiciones de reacción: $225^{\circ} \mathrm{C}, 1$ bar $\mathrm{N}_{2}$ inicial, 2 h de reacción, solución acuosa al 10\% p/p de acetol, agitación 700 rpm

Los resultados del APR del AC muestran alta conversión total y una baja relación a productos de reformado ( $\mathrm{X}^{\mathrm{G}}$ menores a $22 \%$ para un $\mathrm{X}^{\mathrm{T}}$ de $92 \%$ y $\mathrm{SCO}_{2}=15-18 \%$ ), en consecuencia se observa bajo rendimiento a $\mathrm{H}_{2}(6-8 \%)$. 


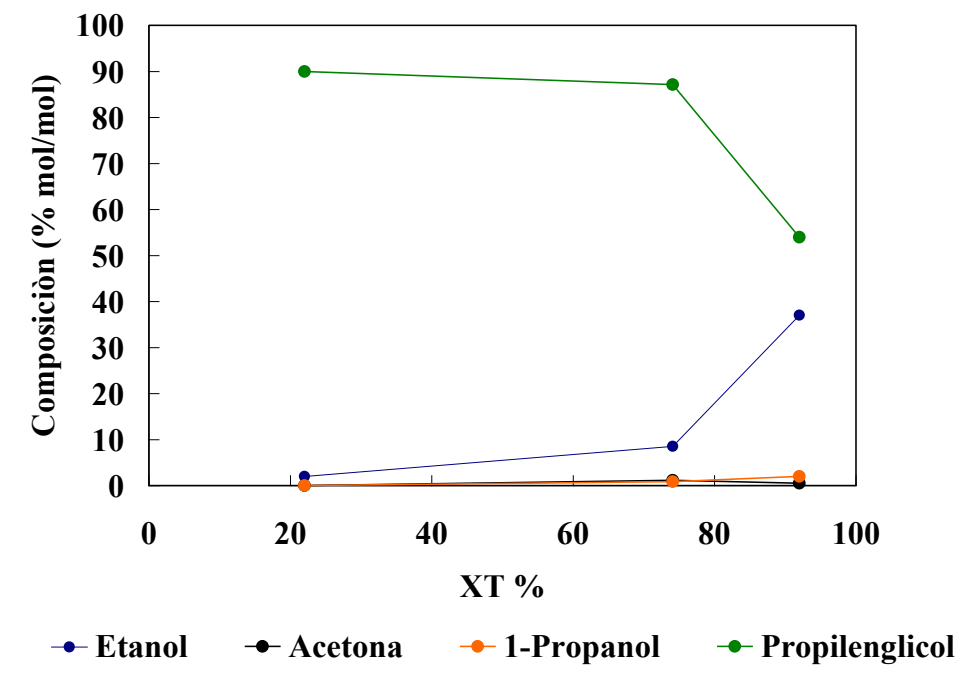

Figura III-11. Composición molar de productos líquidos en el APR del AC.

Condiciones de reacción: $225^{\circ} \mathrm{C}, 1$ bar $\mathrm{N}_{2}$ inicial, $2 \mathrm{~h}$ de reacción, masa catalizador: 0,5 g, solución acuosa al 10\% p/p de acetol, agitación 700 rpm

Respecto a los productos líquidos identificados el PG y etanol fueron los principales, además de acetona y 1-propanol. Se observa que a alta conversión total se produce una disminución en la composición del PG a expensas de un aumento en la composición de etanol.

A partir de estos resultados se propone un esquema de manera de explicar los caminos de reacción de reformado y reacciones laterales presentes en el APR del Acetol.

El acetol puede sufrir una deshidrogenación inicial, una hidrogenación inicial, o bien una ruptura $\mathrm{C}-\mathrm{O}$ del carbono primario de la molécula.

Ruta de deshidrogenación del AC: La deshidrogenación del acetol da como producto el compuesto 2-oxopropanal, el cual por una posterior reacción de ruptura $\mathrm{C}$-C genera etanal, el que puede sufrir una ruptura del enlace $\mathrm{C}-\mathrm{C}$ para generar $\mathrm{CO}$ y $\mathrm{CH}_{4}$. El CO producido reacciona con el $\mathrm{H}_{2} \mathrm{O}$ mediante la reacción de WGS para obtener $\mathrm{H}_{2}$ y $\mathrm{CO}_{2}$. Esta ruta puede dar lugar a una reacción lateral, en donde el etanal podría sufrir una hidrogenación y producir etanol. 


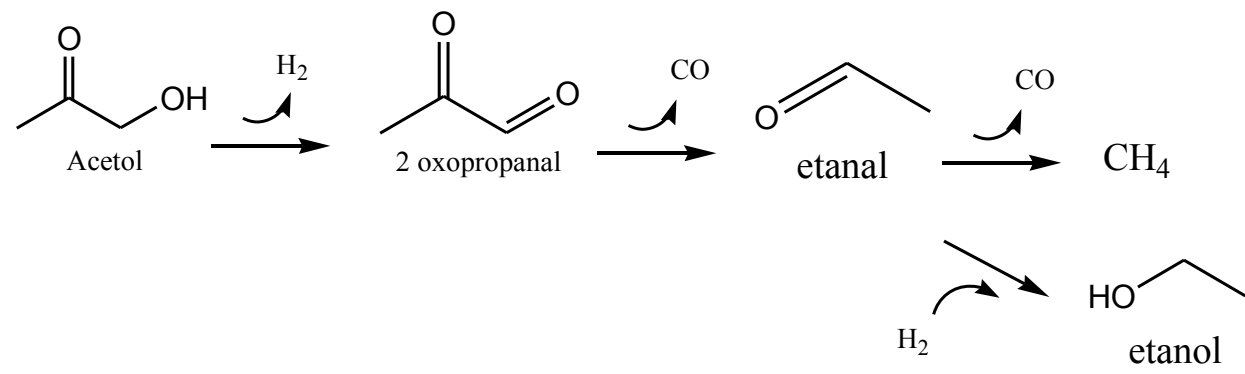

Esquema III-15. Ruta de deshidrogenación del AC

Ruta de hidrogenación del $A C$ : En presencia de $\mathrm{H}_{2}$, el acetol puede sufrir una hidrogenación para obtener PG, además éste puede sufrir una ruptura $\mathrm{C}$-O para dar 1propanol.<smiles>CC(=O)CO</smiles>

Acetol

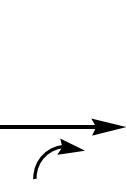

$\mathrm{H}_{2}$<smiles>CC(O)COC1CCCCC1CO</smiles>

$\mathrm{H}_{2}$<smiles>CCCO</smiles>

Esquema III-16. Ruta de hidrogenación del AC

Ruta ruptura $C-O$ del $A C$ : Por último el AC puede sufrir una ruptura del enlace C-O para dar como subproducto acetona.

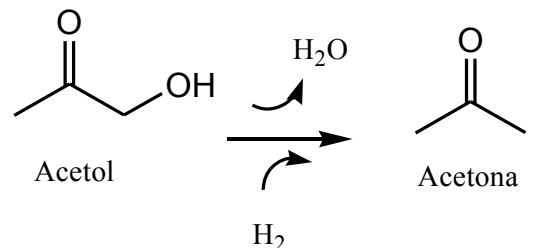

Esquema III-17. Ruta ruptura C-O del AC

Teniendo en cuenta estas tres rutas posibles, el esquema completo del APR con reacciones laterales del $\mathrm{AC}$ es el siguiente: 


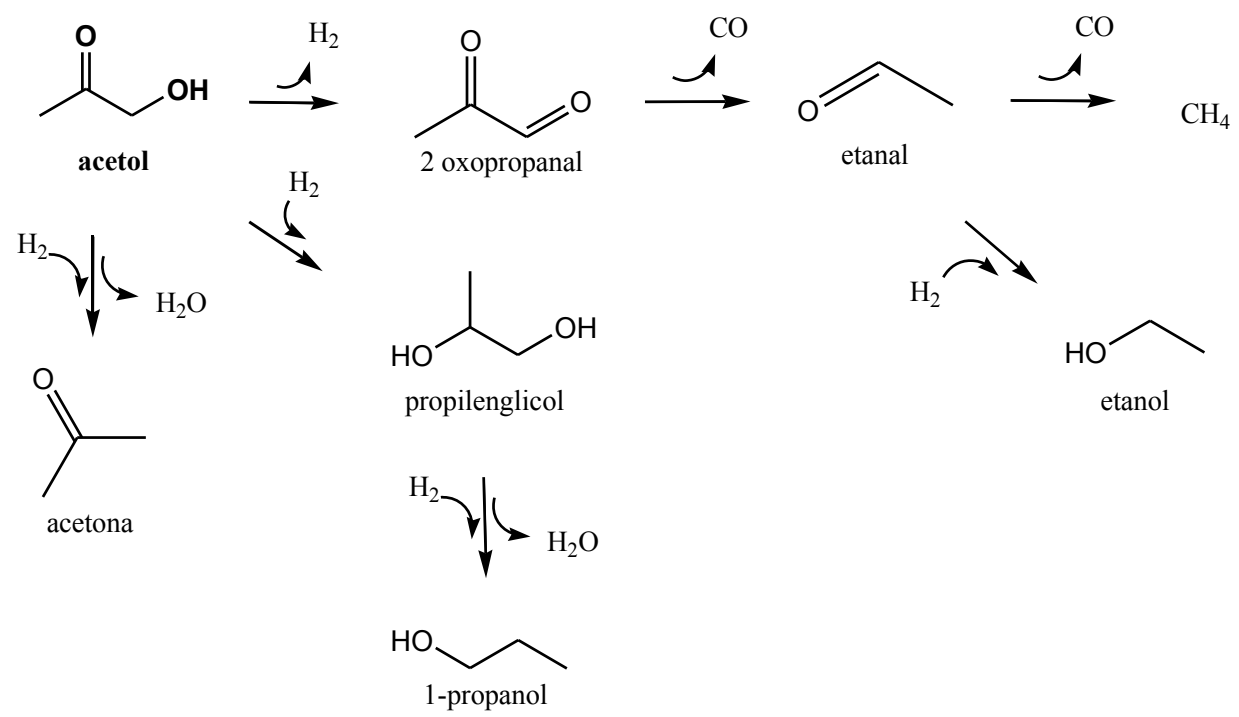

Esquema III-18. Posibles caminos de reacción del APR de AC

Según el esquema de reacciones propuesto, la relación teórica a obtener sería $\mathrm{H}_{2} / \mathrm{CO}_{2}=1$,5. Sin embargo la relación experimental hallada es de un valor de 1 o menor, esta diferencia se atribuye a la fracción de hidrógeno utilizada para la hidrogenación de intermediarios insaturados, en particular el PG, los que se generan en alta proporción $\left(\mathrm{X}^{\mathrm{G}} / \mathrm{X}^{\mathrm{T}} \leq 0,25\right)$.

\section{III.3.6. Esquema de reacciones del glicerol}

Analizando todos los resultados del APR de glicerol a distintas conversiones (Figura III-05) junto con los resultados de los subproductos líquidos de reacción se puede plantear el siguiente esquema de reacción global para el APR del glicerol. 


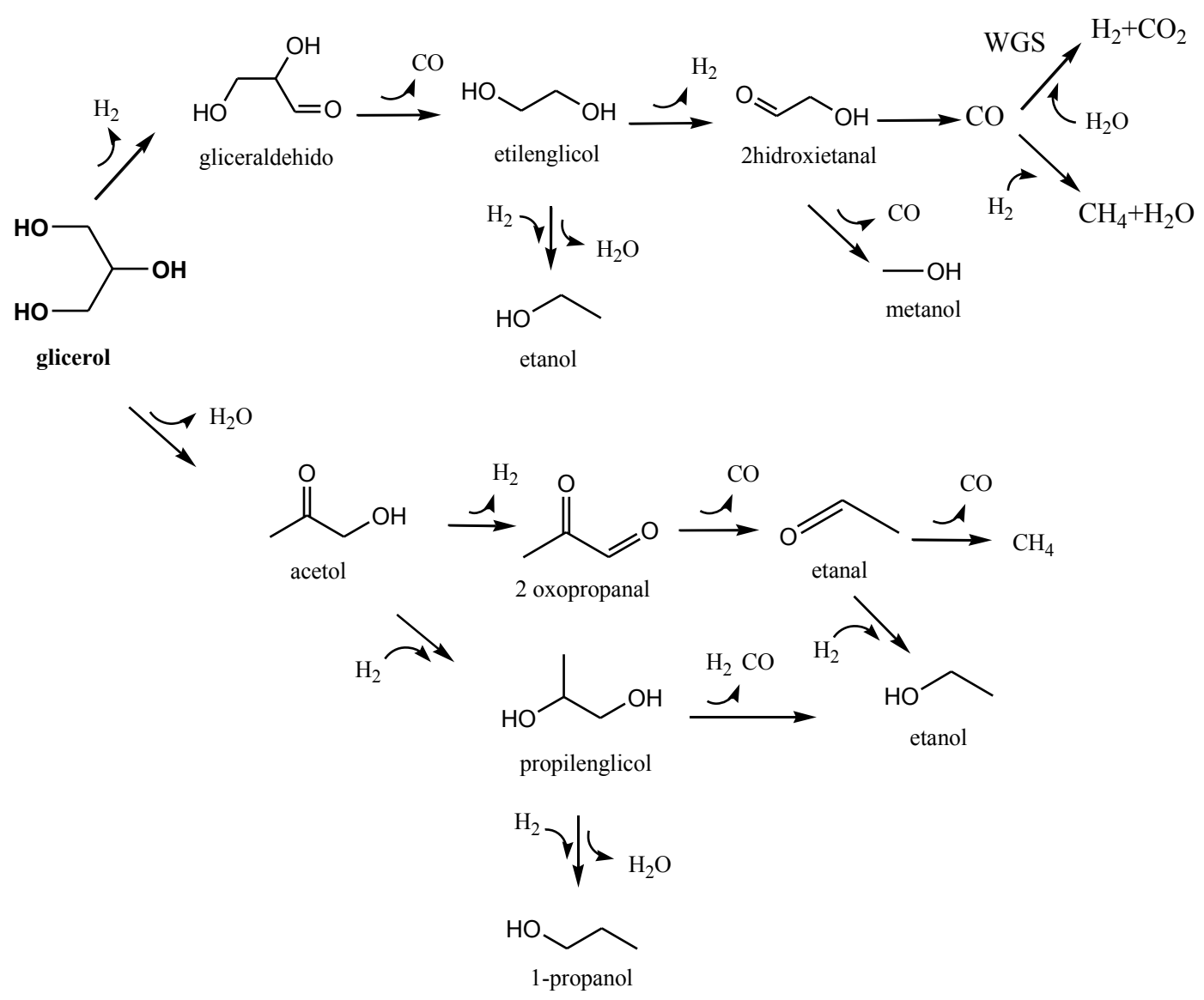

Esquema III-19. Posible caminos de reacción del APR del glicerol

El esquema de reacciones describe la ruta a productos gaseosos y a productos líquidos. Se puede ver que bajo la atmósfera de hidrógeno formada en el sistema de reacción, ambos compuestos, el $\mathrm{CO}$ intermediario como el $\mathrm{CO}_{2}$ formado pueden sufrir la reacción de metanación para producir metano, ya que ésta es termodinámicamente favorable a bajas temperaturas. Por otro lado, la presencia de productos líquidos de reacción indica la ocurrencia de reacciones laterales en el sistema. En el esquema propuesto se observan dos caminos de conversión: el camino o secuencia de reacciones iniciada por la deshidrogenación del carbono primario del glicerol o bien la secuencia de reacciones generadas a partir de la formación del acetol, por deshidratación del glicerol.

\section{Ruta de reacción I: Formación de productos vía gliceraldehído}

La deshidrogenación del carbono primario del glicerol sobre los sitios metálicos del catalizador, conduce al aldehído 2,3-dihidroxi1-propanal, el que es rápidamente decarbonilado (ruptura C-C) para dar CO y etilenglicol. La velocidad de esta reacción pareciera ser tan rápida que el gliceraldehído no es identificado en la fase líquida [16, 
17]. Esta secuencia de etapas de deshidrogenación-ruptura $\mathrm{C}-\mathrm{C}$ se repite hasta que se obtiene $\mathrm{CO}$ e $\mathrm{H}_{2}$. Pudiendo ocurrir reacciones laterales que producen etanol y metanol. La producción de etanol por esta vía de reacción no debiera ser importante, ya que se forma a través de reacciones de ruptura C-O del EG y se determinó que estas reacciones no poseen gran peso en el APR del EG. Mientras que la formación de metanol proviene de la ruptura C-C del 2-hidroxietanal.

\section{Ruta de reacción II: Formación de productos vía acetol}

En esta ruta la primera etapa involucra la deshidrogenación del carbono secundario del glicerol obteniéndose el compuesto 1,3-dihidroxi2-propanona. Esta hidroxicetona es estable frente a la ruptura $\mathrm{C}-\mathrm{C}$ y permitiría la ruptura $\mathrm{C}-\mathrm{O}$ del carbono primario, lo que conduce al acetol. El acetol puede seguir deshidrogenándose hasta obtener $\mathrm{CO}$ y $\mathrm{CH}_{4}$. En presencia de $\mathrm{H}_{2}$, el acetol puede conducir a propilenglicol, lo que explicaría el elevado contenido de propilenglicol en los productos. Además este puede sufrir una ruptura del enlace C-O y así formar 1-propanol.

También se puede obtener etanol en esta ruta mediante la hidrogenación del etanal formado.

Como se observa, la secuencia de reacciones propuestas se resume en la combinación de reacciones de hidrogenación, deshidrogenación, ruptura de enlaces C-C y C-O.

La ruta más selectiva para la producción de $\mathrm{H}_{2} \mathrm{y} \mathrm{CO}_{2}$ es la que posee al gliceraldehído como producto inicial, pasando por la formación del etilenglicol, y comprende reacciones del tipo ruptura de enlaces C-C. En contraposición, la secuencia de reacciones a partir de la formación de acetol por ruptura de enlaces $\mathrm{C}-\mathrm{O}$ del glicerol, conducen principalmente a compuestos intermediarios que resultan menos reactivos a la reformación, conduciendo principalmente a subproductos líquidos.

Observando los productos de reacciones de ruptura C-O para todos los reactivos estudiados, vemos que en el caso del APR del glicerol la producción del AC es importante, teniendo en cuenta que también el PG se obtiene a partir de éste. Mientras que en los casos del EG, PG y AC, los subproductos de reacciones de tipo ruptura $\mathrm{C}-\mathrm{O}$ (etanol para EG, acetona y 1-propanol para PG y AC) no se producen en cantidades significativas comparándolos con los subproductos obtenidos a partir de otros mecanismos. Esto se explica ya que el glicerol sería más propenso a sufrir reacciones de 
ruptura $C$ - $O$, comparado a los demás reactivos estudiados, debido a que la mayor concentración de grupos hidroxilos en la molécula debilita el enlace C-O [18].

Se observa que el glicerol sufre deshidrogenaciones para producir intermediarios adsorbidos, antes de anclarse por medio de los enlaces C-C o C-O. Las especies adsorbidas se pueden formar sobre la superficie metálica por medio de un enlace metalcarbón o metal-oxígeno [19]. En el caso estudiado con catalizadores de Pt, es más probable y estable que se formen enlaces metal-carbono [20]. Obviamente la degradación de glicerol para formar productos líquidos decrece la producción de $\mathrm{H}_{2}$, lo que ocurre a partir de rupturas $\mathrm{C}-\mathrm{O}$ por sobre rupturas $\mathrm{C}-\mathrm{C}$.

\section{III.4. Conclusiones parciales del capítulo}

El reformado de glicerol es activo para las condiciones estudiadas con el sistema catalítico $\mathrm{Pt} / \gamma-\mathrm{Al}_{2} \mathrm{O}_{3}$. Las condiciones usadas fueron: temperaturas de 200 a $250{ }^{\circ} \mathrm{C}$ y presiones iniciales de 1 a 12 bar de inerte $\left(\mathrm{N}_{2}\right)$. Bajo estas condiciones se verificó la ausencia de limitaciones difusionales.

Analizando la variación con la temperatura se encontró una energía de activación aparente de producción de $\mathrm{H}_{2}$ y $\mathrm{CO}_{2}$ de $121,61 \mathrm{KJ} / \mathrm{mol}$ y $123,02 \mathrm{KJ} / \mathrm{mol}$, respectivamente.

Los productos líquidos encontrados en el APR del glicerol fueron metanol, etanol, acetona, 1-propanol, acetol, etilenglicol y propilenglicol.

Respecto a los resultados del APR de los alcoholes estudiados, vemos que el metanol y etanol serían alcoholes estables para el APR y no reactivos en el rango de temperaturas de 200 a $250^{\circ} \mathrm{C}$, mientras que el EG, AC y PG presentaron mayor reactividad. La siguiente tabla (Tabla III-05) permite comparar la selectividad al reformado y el rendimiento a $\mathrm{H}_{2}$ del glicerol, etilenglicol, acetol y propilenglicol a valores de conversión a gases similares. 
Capítulo III. Determinación de condiciones experimentales y esquema de reacciones

Tabla III-05. Resultados del APR de Glicerol, EG, AC y PG para valores de conversión a gases similares. Condiciones de reacción: $225^{\circ} \mathrm{C}, 1$ bar $\mathrm{N}_{2}$ inicial, $2 \mathrm{~h}$ reacción, solución acuosa al 10\% p/p de alcohol, agitación 700 rpm

\begin{tabular}{lcccc}
\hline Catalizador & Glicerol & Etilenglicol & Acetol & Propilenglicol \\
\hline $\mathbf{X}^{\mathbf{G}}(\%)$ & 24 & 20 & 22 & 20 \\
$\mathbf{S C O}_{\mathbf{2}}(\%)$ & 53 & 85 & 18 & 38 \\
$\mathbf{R H}_{\mathbf{2}}(\%)$ & 17 & 23 & 8 & 14 \\
$\mathbf{H}_{\mathbf{2}} / \mathbf{C O}_{\mathbf{2}}$ & 1,8 & 3,0 & 1,1 & 2,5 \\
\hline
\end{tabular}

El APR de EG mostró la mayor selectividad a las reacciones de ruptura C-C y en consecuencia mayor selectividad al reformado $\left(\mathrm{SCO}_{2}=85 \%\right)$. Por otra parte el APR del $\mathrm{AC}$ presentó la menor selectividad a las reacciones de ruptura $\mathrm{C}-\mathrm{C}\left(\mathrm{SCO}_{2}=18 \%\right)$. El APR del PG mostró mayor selectividad al reformado que AC pero menor que glicerol.

Estos resultados nos permiten concluir que la ruta para la producción de $\mathrm{H}_{2}$ y $\mathrm{CO}_{2}$ en el APR del glicerol es la que posee al EG como producto intermediario, mientras que el $\mathrm{AC}$ es un producto lateral derivado de reacciones de ruptura $\mathrm{C}-\mathrm{O}$. El alto contenido de PG en los productos líquidos del APR de glicerol puede ser explicado por la hidrogenación del AC.

De esta manera se observa que el proceso de reformado presenta una clara competencia entre los caminos de producción de $\mathrm{H}_{2}$ y $\mathrm{CO}_{2}$ y los caminos laterales para formar productos líquidos.

\section{III.5. Referencias}

[1] Madon RJ, Boudart M. Industrial and Engineering Chemistry Fundamentals 21 (1982) 438

[2] Shabaker JW, Davda RR, Huber GW, Cortright RD, Dumesic JA. Journal of Catalysis 215 (2003) 344-352

[3] Roy B, Sullivan H, Leclerc CA. Journal of Power Sources 196 (2011) 10652-10657

[4] Wawrzetz A, Peng B, Hrabar A, Jentys A, Lemonidou AA, Lercher JA. Journal of Catalysis 269 (2010) 411-420

[5] Cortright RD, Davda RR, Dumesic JA. Letters to nature 418 (2002) 964-967

[6] Iglesia E, Soled SL, Fiato RA. Journal of Catalysis 137 (1992) 212-224 
[7] Kellner CS, Bell AT. Journal of Catalysis 70 (1981) 418-432

[8] Vannice MA. Journal of Catalysis 50 (1977) 228-236

[9] Bates SP, Van Santen RA. Advances in Catalysis 42 (1998) 1-114

[10] Gates B. Catalytic Chemistry (Wiley, New York, 1992)

[11] Eggleston G, Vercellotti JR. Journal of Carbohydrate Chemistry 19 (2000) 13051318

[12] Kabyemela BM, Adschiri T, Malaluan RM, Arai K. Industrial and Engineering Chemistry Research 38 (1999) 2888-2895

[13] Collins P, Ferrier R. Monosaccharides: Their Chemistry and Their Roles in Natural Products (Wiley, West Sussex, England, 1995)

[14] Zhong Tang, Justin Monroe, Junhang Dong, Tina Nenoff, Donald Weinkauf. Industrial and Engineering Chemistry Research 48 (2009) 2728-2733

[15] Tokarev AV, Kirilin AV, Murzina EV, Eränen K, Kustov LM, Yu. Murzin D, Mikkola J-P. International journal of hydrogen energy 35 (2010) 12642-12649

[16] Gandarias PL, Arias J, Requies MB, Güemez JL, Fierro G. Applied Catalysis B: Environmental 97 (2010) 248-256

[17] Séverine Noe Delgado, David Yap, Laurence Vivier, Catherine Especel. Journal of Molecular Catalysis A: Chemical 367 (2013) 89- 98

[18] Peng Baoxiang, Zhao Chen, Mejía-Centeno Isidro, Fuentes Gustavo A, Jentys Andreas, Lercher Johannes A. Catalysis Today 183 (2012) 3-9

[19] Maria T, Giovanni B, Claudia C, Pasquale S, Umberto C, Michele S. Applied Catalysis B: Environmental 77 (2007) 46-57

[20] Greeley Jeff, Mavrikakis Manos. Journal of the American Chemical Society 124 (2002) 7193-7201 


\section{Capítulo IV}

Reformado en fase líquida de glicerol sobre catalizadores de Pt soportados 
Capítulo IV. Reformado en fase líquida de glicerol sobre catalizadores de Pt soportados

Capítulo IV. Reformado en fase líquida de glicerol sobre catalizadores de Pt soportados

\section{IV.1. Resumen del capítulo}

El objetivo de este capítulo es desarrollar un catalizador de Pt soportado apto para la obtención de hidrógeno por APR de glicerol. En la primera parte del capítulo se analiza el efecto del tamaño de partícula y el rol del soporte sobre la actividad y selectividad a productos gaseosos y líquidos en el APR de glicerol. Para analizar el efecto del tamaño de partícula metálica, se prepararon catalizadores de $\mathrm{Pt} / \mathrm{SiO}_{2}$ y $\mathrm{Pt} / \gamma-\mathrm{Al}_{2} \mathrm{O}_{3}$ empleando distintos métodos que permitan obtener diferentes tamaños de partícula metálica.

Para estudiar el efecto del soporte se utilizaron óxidos con diferentes propiedades ácidas superficiales y propiedades redox como: $\mathrm{SiO}_{2}, \gamma-\mathrm{Al}_{2} \mathrm{O}_{3}, \alpha-\mathrm{Al}_{2} \mathrm{O}_{3}$ y $\alpha-\mathrm{Al}_{2} \mathrm{O}_{3}$ modificada con Ce y Zr.

Finalmente con el catalizador que resultó más activo y selectivo fue estudiada la estabilidad sometiendo a las muestras a tres ciclos de reacción y analizando los catalizadores pos-reacción por XPS, TEM y Raman.

\section{IV.2. Introducción}

Como se ha mencionado en el Capítulo I, los sistemas catalíticos basados en metales del grupo VIII son citados en bibliografía para el APR de hidrocarburos oxigenados [17]. La actividad, estabilidad y la composición de productos gaseosos podría ser afectada significativamente por la naturaleza del metal, acidez o basicidad y la estabilidad hidrotérmica del soporte. Es esperable que las propiedades redox de los soportes puedan influir en la hidrogenación de CO [8, 9] y en la reacción de WGS $[\mathbf{1 0}, \mathbf{1 1}$ (Esquema III-19 Ruta de reacción I: Formación de productos vía gliceraldehído), mientras que la deshidratación de compuestos oxigenados (Esquema III-19 Ruta de reacción II: Formación de productos vía acetol) se espera que sea catalizada por sitios ácidos [12-14].

Con respecto al estudio de diferentes soportes, el APR del etilenglicol fue estudiado sobre catalizadores de $\mathrm{Pt}$ soportados en $\mathrm{TiO}_{2}, \mathrm{Al}_{2} \mathrm{O}_{3}$, carbón, $\mathrm{SiO}_{2}, \mathrm{SiO}_{2}-\mathrm{Al}_{2} \mathrm{O}_{3}, \mathrm{ZrO}_{2}$, 
$\mathrm{CeO}_{2}$ y $\mathrm{ZnO}$ [15]. Los autores demuestran que Pt soportado en $\mathrm{Al}_{2} \mathrm{O}_{3}, \mathrm{TiO}_{2}$ y carbón exhibieron la mayor actividad expresada como TOF de $\mathrm{H}_{2}$. Por el contrario, $\mathrm{Pt}$ soportado sobre carbón, $\mathrm{TiO}_{2}, \mathrm{SiO}_{2}-\mathrm{Al}_{2} \mathrm{O}_{3}$ produjeron mayores cantidades de compuestos en fase líquida, como por ejemplo: etanol, ácido acético y acetaldehído, que podrían conducir a alcanos a altas conversiones.

Manfro y col. [16], estudiaron catalizadores de $\mathrm{Ni} / \mathrm{CeO}_{2}$ en el APR del glicerol a 250$270{ }^{\circ} \mathrm{C}$. Estos sistemas soportados en $\mathrm{CeO}_{2}$ mostraron menor formación de metano que los de Ni soportados en alúmina.

Menezes y col. [17], estudiaron catalizadores de Pt soportados en $\mathrm{Al}_{2} \mathrm{O}_{3}, \mathrm{ZrO}_{2}, \mathrm{MgO}$ y $\mathrm{CeO}_{2}$ en la misma reacción estudiada por Manfro y col. Todos los catalizadores conducen a una fase gaseosa rica en hidrógeno. Con los catalizadores soportados en $\mathrm{MgO}$ y $\mathrm{ZrO}_{2}$ obtuvieron una buena actividad y alta producción de hidrógeno con baja concentración de hidrocarburos no deseados.

Iriondo y col. [18] también estudiaron el APR de glicerol usando un reactor de flujo con catalizadores de $\mathrm{Ni}$ y $\mathrm{Pt}$ monometálicos y bimetálicos soportados en $\gamma-\mathrm{Al}_{2} \mathrm{O}_{3}$ y $\gamma-\mathrm{Al}_{2} \mathrm{O}_{3}$ modificada con $\mathrm{La}_{2} \mathrm{O}_{3}$. Los catalizadores bimetálicos $\mathrm{PtNi}$ fueron los más activos, mientras que los catalizadores monometálicos de $\mathrm{Ni}$ han mostrado desactivación a medida que la temperatura se incrementa. La presencia de $\mathrm{La}_{2} \mathrm{O}_{3}$ mejora el comportamiento catalítico hacia productos gaseosos livianos.

Con respecto a los antecedentes bibliográficos referidos al estudio del efecto de tamaño de partícula sobre la actividad catalítica, Wawrzetz y col. [19] indicaron que la mayor concentración de bordes y esquinas presentes en la superficie de pequeñas partículas metálicas favorece el anclaje y ruptura de los enlaces C-H y C-C. Roy y col. [20, 21] también obtuvieron resultados similares al estudiar catalizadores de $\mathrm{Ni} / \mathrm{Al}_{2} \mathrm{O}_{3}$ en el APR de etanol. Manfro y col. [22] estudiaron catalizadores de níquel soportados sobre ceria en el APR del glicerol, observando que el catalizador con menor tamaño de partícula presentó mayor conversión de glicerol y mayor producción de hidrógeno.

En oposición, Lehnert y col. [23] postularon que la selectividad a $\mathrm{H}_{2}$ se incrementó con el incremento de tamaño de partícula metálica. En concordancia con estos resultados Jiang y col. [24] obtuvieron resultados similares estudiando la reacción en fase líquida de xilitol para la obtención de pentano. Además encontraron que las partículas de Ni son más estables en las condiciones de APR que las partículas de Pt.

Por otra parte, también ha sido reportado que el tamaño de partícula de los catalizadores no posee incidencia en el grado de actividad en el APR. Wen y col. [25] indicaron que a 
Capítulo IV. Reformado en fase líquida de glicerol sobre catalizadores de Pt soportados

pesar de observar la sinterización de partículas de Pt, no encontraron gran desactivación del Pt soportado sobre $\mathrm{Al}_{2} \mathrm{O}_{3}, \mathrm{SiO}_{2}$ y $\mathrm{HUSY}$, indicando que el efecto del tamaño de partícula del catalizador no es dominante.

\section{IV.3. Efecto del tamaño de partícula}

\section{IV.3.1. Preparación y caracterización de catalizadores}

De manera de obtener sólidos con diferente dispersión metálica se prepararon catalizadores de Pt ( $\sim 1$ y $2 \%$ p/p) sobre $\mathrm{SiO}_{2}$ (Aerosil 200) y $\gamma-\mathrm{Al}_{2} \mathrm{O}_{3}$ (Dycat internacional) utilizando dos métodos diferentes: impregnación a humedad incipiente $\left(\mathrm{PtSi}^{\mathrm{IMP}}, \mathrm{PtAl}^{\mathrm{IMP}}\right)$ e intercambio iónico (PtSi, PtAl). Para la preparación por intercambio catiónico la $\mathrm{SiO}_{2}$ fue suspendida en solución acuosa de $\mathrm{NH}_{4} \mathrm{OH}$ bajo agitación previa a la adición de la solución de $\mathrm{Pt}\left(\mathrm{NH}_{3}\right)_{4} \mathrm{Cl}_{2}$ en una concentración tal que permite obtener 1 y $2 \%$ de Pt. Para la preparación por intercambio aniónico se utilizó una solución acuosa de $\mathrm{H}_{2} \mathrm{PtCl}_{6}$. Los detalles de la preparación han sido descriptos en el Capítulo II.

Con el objetivo de obtener un catalizador con baja dispersión metálica se preparó una muestra de PtSi tratada con una corriente de $\mathrm{H}_{2}$ saturado con vapor a $800{ }^{\circ} \mathrm{C}\left(\mathrm{PtSi}^{\mathrm{SINT}}\right)$.

En la Tabla IV-01 se resumen los resultados de la caracterización de las muestras por AA, quimisorción de $\mathrm{H}_{2}$, TEM y TPR. En la nomenclatura de los catalizadores, el número indica el contenido metálico.

Tabla IV-01. Resultados de caracterización de catalizadores de Pt

\begin{tabular}{|c|c|c|c|c|c|}
\hline \multirow{2}{*}{ Catalizador } & \multirow{2}{*}{$\begin{array}{c}\text { Contenido de Pt } \\
(\% \text { p/p) }\end{array}$} & \multirow{2}{*}{$\begin{array}{l}\text { Dispersión } \\
\text { (H/Pt) }\end{array}$} & \multirow{2}{*}{$\begin{array}{c}d_{\mathrm{va}} \\
(\mathrm{nm})\end{array}$} & \multicolumn{2}{|c|}{ TPR } \\
\hline & & & & LT & HT \\
\hline $2 \mathrm{PtSi}{ }^{\text {IMP }}$ & 2,3 & 0,20 & 5,5 & 147 & 400 \\
\hline $2 P t S i$ & 2,0 & 0,60 & 2,2 & 155 & 410 \\
\hline 2PtSi ${ }^{\text {SINT }}$ & 2,0 & 0,20 & 6,2 & 130 & 400 \\
\hline 1PtSi & 0,93 & 0,60 & 2,4 & 110 & 450 \\
\hline $2 P t A I^{\text {IMP }}$ & 2,3 & 0,54 & 2,0 & 130 & 350 \\
\hline 2PtAl & 1,8 & 0,71 & 1,5 & 115 & 405 \\
\hline 1PtAl & 0,96 & 0,80 & 1,4 & 75 & 367 \\
\hline
\end{tabular}


De la Tabla IV-01 se observa que las muestras impregnadas presentan menor dispersión metálica que las muestras preparadas por intercambio iónico. El catalizador $2 \mathrm{PtAl}^{\mathrm{IMP}}$ presenta un tamaño promedio de partícula de $2,0 \mathrm{~nm}$ mientras que $2 \mathrm{PtSi}^{\mathrm{IMP}}$ de $5,5 \mathrm{~nm}$. El catalizador $2 \mathrm{PtSi}^{\mathrm{SINT}}$ mostró una baja dispersión metálica y el mayor diámetro de partícula $(6,2 \mathrm{~nm})$.

El incremento del contenido de Pt de 1 a $2 \% \mathrm{p} / \mathrm{p}$ no tiene grandes efectos en las propiedades de los catalizadores PtSi y PtAl, tal como se observa en la Tabla IV-01. Los perfiles de reducción obtenidos por TPR muestran la presencia de dos picos, el primero alrededor de los $107-155^{\circ} \mathrm{C}$ y el segundo entre los 390 y $430{ }^{\circ} \mathrm{C}$ (denominados como LT y HT, respectivamente en la Tabla IV-01). De acuerdo a la literatura, los picos de baja temperatura (LT) se pueden asignar a la reducción de las especies oxidadas de Pt con interacción débil con el soporte [26, 27]. Respecto a los de alta temperatura (HT), Ho y col. [26] reportaron que para $\mathrm{Pt} / \mathrm{SiO}_{2}$, las especies con mayor interacción Pt- $(\mathrm{O}-\mathrm{Si})^{\mathrm{n}-\mathrm{y}}(\mathrm{n}=+2 \mathrm{o}+4)$ son reducidas a temperaturas por encima de los $400{ }^{\circ} \mathrm{C}$. Varios autores reportaron que para $\mathrm{Pt} / \mathrm{Al}_{2} \mathrm{O}_{3}$, la segunda banda de menor importancia es asignada a la reducción de especies oxicloradas de Pt (PtOxCly) de mayor interacción con el soporte [27-29].

\section{IV.3.2. Resultados del APR de glicerol con catalizadores $\mathrm{Pt} / \mathrm{SiO}_{2}$}

Los resultados obtenidos en el APR del glicerol se muestran en la Tabla IV-02 y

Figura IV-01. Los valores de actividad catalítica reportados son los obtenidos luego de 2 horas de reacción.

Tabla IV-02. APR de glicerol con catalizadores $\mathrm{Pt} / \mathrm{SiO}_{2}$. Condiciones de reacción: 225

${ }^{\circ} \mathrm{C}, 1$ bar $\mathrm{N}_{2}$ inicial, 2 horas de reacción, masa catalizador: 0,5 g, solución acuosa al $10 \% \mathrm{p} / \mathrm{p}$ de glicerol, agitación $700 \mathrm{rpm}$

\begin{tabular}{lccc}
\hline Catalizador & 2PtSi $^{\text {IMP }}$ & 2PtSi & 2PtSi $^{\text {SINT }}$ \\
\hline $\mathbf{X}^{\mathbf{G}}(\%)$ & 5 & 9 & 4 \\
$\mathbf{X}^{\mathbf{T}}(\%)$ & 17 & 15 & 16 \\
$\mathbf{R H}_{\mathbf{2}}(\%)$ & 4 & 8 & 3 \\
$\mathbf{H}_{\mathbf{2}} / \mathbf{C O}_{\mathbf{2}}$ & 1,7 & 2 & 1,9 \\
$\mathbf{S H}_{\mathbf{2}}(\%)$ & 68 & 81 & 75 \\
\hline
\end{tabular}




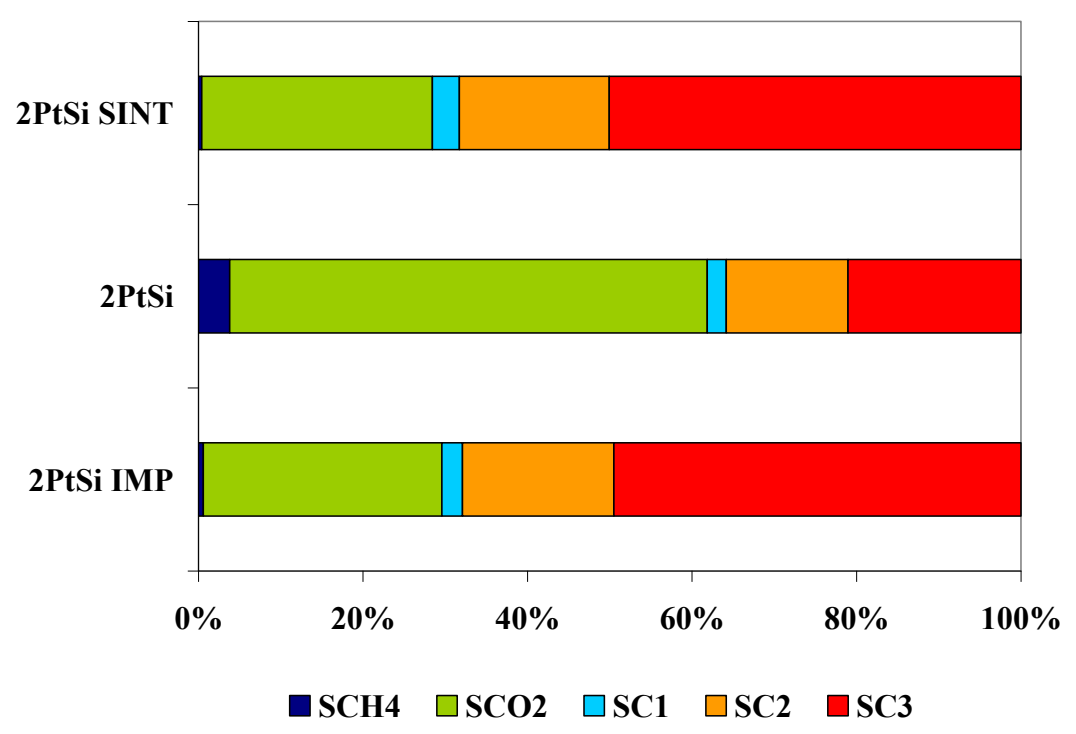

Figura IV-01. APR de glicerol con catalizadores $\mathrm{Pt} / \mathrm{SiO}_{2}$. Condiciones de reacción: 225 ${ }^{\circ} \mathrm{C}, 1$ bar $\mathrm{N}_{2}$ inicial, $2 \mathrm{~h}$ de reacción, masa catalizador: $0,5 \mathrm{~g}$, solución acuosa al 10\% p/p de glicerol, agitación $700 \mathrm{rpm}$

Los resultados muestran que los productos gaseosos son principalmente $\mathrm{H}_{2}$ y $\mathrm{CO}_{2}$ para todos los catalizadores, la relación $\mathrm{H}_{2} / \mathrm{CO}_{2}$ obtenida se encuentra en el rango entre 1,7 y 2, el contenido de $\mathrm{CO}$ es siempre inferior a $1000 \mathrm{ppm}$.

Analizando los resultados catalíticos puede verse que el catalizador con mayor dispersión metálica, 2PtSi, presenta la mayor selectividad y rendimiento a $\mathrm{H}_{2}\left(\mathrm{SH}_{2}=\right.$ $81 \%, \mathrm{RH}_{2}=8 \%$ ), el menor tamaño de partícula de este catalizador favorecería el anclaje y ruptura de los enlaces $\mathrm{C}$-C que se pone en evidencia por la $\mathrm{SCO}_{2}=58 \%$. La menor contribución de las reacciones de ruptura de los enlaces $\mathrm{C}-\mathrm{O}$ e hidrogenaciones se pone en evidencia por la $\mathrm{SC}_{3}=21 \%$.

Los catalizadores $2 \mathrm{PtSi}^{\mathrm{IMP}}$ y $2 \mathrm{PtSi}^{\mathrm{SINT}}$ poseen un tamaño de partícula similar entre sí $(\approx 5,5-6,2 \mathrm{~nm})$, y los resultados de actividad también son similares. El mayor tamaño de partícula favorecería las reacciones de ruptura de enlaces $\mathrm{C}-\mathrm{O}$ e hidrogenaciones, siendo la $\mathrm{SC}_{3} \approx 50 \%$, de esta manera se estaría evidenciando una dependencia de la reacción de reformado del glicerol con la estructura o tamaño de las partículas metálicas. 
Capítulo IV. Reformado en fase líquida de glicerol sobre catalizadores de Pt soportados

\section{IV.3.3. Resultados del APR de glicerol con catalizadores $\mathbf{P t} / \boldsymbol{\gamma}-\mathrm{Al}_{2} \mathbf{O}_{3}$}

Los resultados catalíticos obtenidos, para los catalizadores soportados en $\gamma-\mathrm{Al}_{2} \mathrm{O}_{3}$ se muestran en la Tabla IV-03 y Figura IV-02.

Tabla IV-03. APR de glicerol con catalizadores $\mathrm{Pt} / \gamma-\mathrm{Al}_{2} \mathrm{O}_{3}$. Condiciones de reacción: $225^{\circ} \mathrm{C}, 1$ bar $\mathrm{N}_{2}$ inicial, 2 h de reacción, masa catalizador: $0,5 \mathrm{~g}$, solución acuosa al $10 \%$ p/p de glicerol, agitación 700 rpm

\begin{tabular}{lcc}
\hline Catalizador & 2PtAl $^{\text {IMP }}$ & 2PtAl \\
\hline Dispersión (\%) & 54 & 71 \\
$\mathbf{X}^{\mathbf{G}}(\mathbf{\%})$ & 13 & 24 \\
$\mathbf{X}^{\mathrm{T}}(\%)$ & 23 & 38 \\
$\mathbf{S H}_{\mathbf{2}}(\mathbf{\%})$ & 61 & 88 \\
$\mathbf{H}_{\mathbf{2}} / \mathbf{C O}_{\mathbf{2}}$ & 1,6 & 1,8 \\
$\mathbf{R H}_{\mathbf{2}} \mathbf{( \% )}$ & 7 & 17 \\
\hline
\end{tabular}

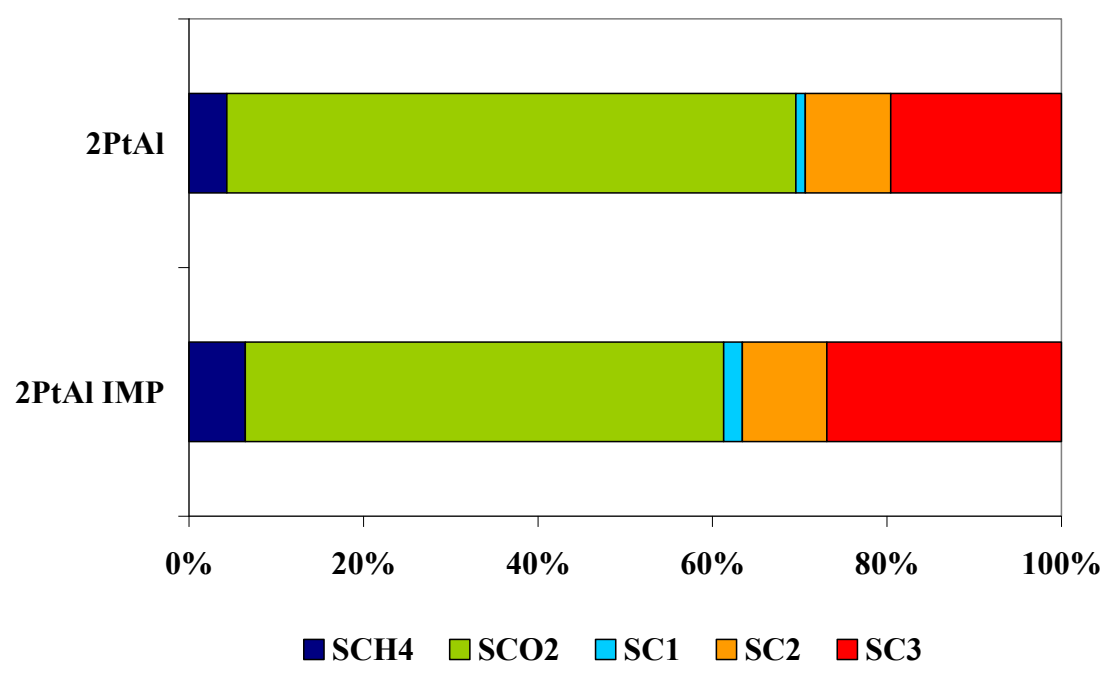

Figura IV-02. APR de glicerol con catalizadores $\mathrm{Pt} / \gamma-\mathrm{Al}_{2} \mathrm{O}_{3}$. Condiciones de reacción: $225^{\circ} \mathrm{C}, 25$ bar $\mathrm{N}_{2}, 2$ h de reacción, masa catalizador: $0,5 \mathrm{~g}$, solución al 10\% de glicerol, agitación $700 \mathrm{rpm}$

Los resultados obtenidos muestran que la relación $\mathrm{H}_{2} / \mathrm{CO}_{2}$ obtenida es similar a los catalizadores soportados sobre $\mathrm{SiO}_{2}$, en el rango entre 1,6 y 1,8 . 
Las diferencias de dispersión metálica de los catalizadores $2 \mathrm{PtAl}$ y $2 \mathrm{PtAl}^{\mathrm{IMP}}$ son menores que en los catalizadores soportados sobre $\mathrm{SiO}_{2}$, pero como ya fue indicado la mayor dispersión se obtuvo para 2PtAl (71\%).

Se puede observar que el catalizador $2 \mathrm{PtAl}$ presenta mayor actividad que $2 \mathrm{PtAl}^{\mathrm{IMP}}(24 \%$ vs 13\%, Tabla IV-03, con mayor selectividad al reformado $\mathrm{SCO}_{2} 60 \%$ vs $51 \%$ ). Además se observa una disminución en la selectividad $\mathrm{SC}_{3}$ para el catalizador más activo 2PtAl. Estos resultados nuevamente ponen en evidencia la promoción de reacciones de ruptura $\mathrm{C}-\mathrm{C}$ para el catalizador con menor tamaño de partícula. Lehnert y Claus [23] postularon que la selectividad a $\mathrm{H}_{2}$ aumenta con el tamaño de partícula de $\mathrm{Pt}$ porque favorece las reacciones de ruptura $\mathrm{C}-\mathrm{C}$ sobre ensambles superficiales de $\mathrm{Pt}$ de bajo índice. Sin embargo, Wawrzetz y col. [19] han reportado que una alta concentración relativa de bordes y esquinas sobre la superficie de pequeñas partículas de $\mathrm{Pt}$ favorecen las reacciones de ruptura de enlaces C-H y C-C. Los resultados encontrados en esta tesis están de acuerdo con lo que ha sido postulado por estos autores [19].

\section{IV.4. Efecto del soporte sobre el APR del glicerol}

\section{IV.4.1. Preparación y caracterización de catalizadores}

El rol del soporte se estudió con catalizadores de Pt con similar dispersión metálica. Para ello se analizaron los soportes de $\mathrm{SiO}_{2}, \gamma-\mathrm{Al}_{2} \mathrm{O}_{3}, \alpha-\mathrm{Al}_{2} \mathrm{O}_{3}$ y $\alpha-\mathrm{Al}_{2} \mathrm{O}_{3}$ modificada por Ce y $\mathrm{Zr}, \mathrm{Ce}_{4} \mathrm{Zr}_{1} \alpha(\mathrm{CZA})$.

Se observan que los valores de $\mathrm{S}_{\mathrm{BET}}$ varían de $8 \mathrm{~m}^{2} / \mathrm{g}$ para $\mathrm{CZA}$ a $200 \mathrm{~m}^{2} / \mathrm{g}$ para $\mathrm{SiO}_{2} \mathrm{y}$ $\gamma-\mathrm{Al}_{2} \mathrm{O}_{3}$. En la Tabla IV-04 se presentan los resultados de la descomposición catalítica de isopropanol (IPA) sobre los diferentes soportes, técnica utilizada como método indirecto para la determinacion de acidez superficial. 
Capítulo IV. Reformado en fase líquida de glicerol sobre catalizadores de Pt soportados

Tabla IV-04. Resultados de descomposición catalítica de isopropanol (IPA) de soportes

\begin{tabular}{lccccc}
\hline Soportes & $\begin{array}{c}\mathbf{S}_{\mathbf{B E T}} \\
\left(\mathbf{m}^{\mathbf{2}} / \mathbf{g}\right)\end{array}$ & $\begin{array}{c}\text { Conversión } \\
\text { de IPA (\%) } \\
(\mathbf{2 5 0} \mathbf{C})\end{array}$ & acetona & propileno & diisopropiléter \\
\hline $\mathbf{S i O}_{\mathbf{2}}$ & 200 & 10 & 93 & 7 & - \\
$\boldsymbol{\gamma}-\mathrm{Al}_{\mathbf{2}} \mathbf{O}_{\mathbf{3}}$ & 205 & 100 & - & 96 & 4 \\
$\mathbf{C e} 4 \mathbf{Z} \mathbf{1} \boldsymbol{\alpha}$ & 8 & 20 & 9 & 91 & - \\
$\boldsymbol{\alpha}-\mathrm{Al}_{\mathbf{2}} \mathbf{O}_{\mathbf{3}}$ & 10 & 3 & 3 & 97 & - \\
\hline
\end{tabular}

Como ha sido demostrado por Gervasini y col. [30], la deshidratación del isopropanol (que produce propileno y/o di-isopropiléter) es catalizada por sitios ácidos, la deshidrogenación (que produce acetona), en ausencia de sitio metálico, es catalizada por sitios ácidos y básicos a través de un mecanismo concertado sirviendo como medida de la basicidad de los materiales analizados. En la Tabla IV-04 se pueden observar los resultados de conversión del isopropanol ( $\mathrm{X}_{\mathrm{IPA}} \%$ ) determinados a $250{ }^{\circ} \mathrm{C}$.

Los resultados indican que la acidez de los soportes decrece en el orden: $\gamma-\mathrm{Al}_{2} \mathrm{O}_{3}>\alpha$ $\mathrm{Al}_{2} \mathrm{O}_{3}>\mathrm{CZA}>\mathrm{SiO}_{2}$, la selectividad a acetona para los soportes $\mathrm{CZA}$ y $\mathrm{SiO}_{2}$ fue mayor que el obtenido para los soportes $\gamma-\mathrm{Al}_{2} \mathrm{O}_{3} \mathrm{y} \alpha-\mathrm{Al}_{2} \mathrm{O}_{3}$, esto indicaría que la reacción del isopropanol se ve favorecida por la presencia de sitios fuertemente básicos. Por el contrario, la selectividad a propileno $\left(\mathrm{S}_{\text {Propileno }}\right.$ ), decrece para los soportes $\mathrm{CZA}$ y $\mathrm{SiO}_{2}$ indicando que existen menos sitios ácidos fuertes y que no existen sitios del tipo base fuerte - acido débil de Lewis.

En primer lugar, se realizará la comparación de catalizadores de Pt soportados sobre $\mathrm{SiO}_{2}$ y $\gamma-\mathrm{Al}_{2} \mathrm{O}_{3}\left(2 \mathrm{PtSi}\right.$ y $\left.2 \mathrm{PtAl}^{\mathrm{IMP}}\right)$. Estos, son soportes de similar área BET ( $\left.200 \mathrm{~m}^{2} / \mathrm{g}\right)$, pero con diferentes propiedades ácidas. Teniendo en cuenta que la $\mathrm{SiO}_{2}$ presenta alta selectividad a acetona pero baja actividad, este soporte puede ser considerado con propiedades neutras. $\mathrm{La} \gamma-\mathrm{Al}_{2} \mathrm{O}_{3}$ presenta alta actividad global lo que evidencia la gran concentración superficial de sitios activos ácidos.

Las propiedades fisicoquímicas de los catalizadores de Pt son indicadas en la Tabla IV05. 
Capítulo IV. Reformado en fase líquida de glicerol sobre catalizadores de Pt soportados

Tabla IV-05. Propiedades fisicoquimicas de los catalizadores de Pt

\begin{tabular}{|c|c|c|c|c|c|c|}
\hline \multirow{2}{*}{ Catalizador } & \multirow{2}{*}{$\begin{array}{c}\text { Soporte } \\
S_{\text {BET }}\left(\mathrm{m}^{2} / \mathrm{g}\right)\end{array}$} & \multirow{2}{*}{$\begin{array}{c}\text { Contenido de Pt } \\
(\% \mathrm{p} / \mathrm{p})\end{array}$} & \multirow{2}{*}{$\begin{array}{c}\text { Dispersión } \\
(\%)\end{array}$} & \multirow{2}{*}{$d_{v a}(n m)$} & \multicolumn{2}{|c|}{ TPR } \\
\hline & & & & & $\mathbf{L T}$ & HT \\
\hline 2PtSi & 200 & 2,0 & 60 & 2,2 & 155 & 410 \\
\hline 2PtAl ${ }^{\text {IMP }}$ & 205 & 2,0 & 54 & 2,0 & 130 & 350 \\
\hline 1PtSi & 200 & 0,93 & 60 & 2,4 & 110 & 450 \\
\hline 1PtaAl & 10 & 1,0 & 53 & 2,5 & 107 & 427 \\
\hline 1PtCZA & 8 & 1,1 & 60 & 2,1 & 134 & 391 \\
\hline
\end{tabular}

\section{IV.4.2. Resultados del APR de glicerol sobre catalizadores de Pt sobre distintos} soportes

Los ensayos catalíticos fueron realizados en las condiciones indicadas en la sección experimental del Capítulo II. Los resultados del APR del glicerol a $250{ }^{\circ} \mathrm{C}$ utilizando $\mathrm{SiO}_{2}$ y $\gamma-\mathrm{Al}_{2} \mathrm{O}_{3}(\sin \mathrm{Pt})$ mostraron niveles de conversión prácticamente nulos $(\approx 1 \%)$. Comparando estos resultados con los del test de isopropanol (Tabla IV-04), no se observa en el APR del glicerol de $\gamma-\mathrm{Al}_{2} \mathrm{O}_{3}$ el efecto por sitios ácidos que sí se puede observar en el test de isopropanol. Esto podría deberse a que en condiciones de APR la presencia de agua líquida disminuye la acidez de la $\gamma-\mathrm{Al}_{2} \mathrm{O}_{3}$.

Los resultados del reformado en fase líquida del glicerol se muestran en la Tabla IV-06 y Figura IV-03.

Tabla IV-06. Resultados del APR del glicerol sobre PtSi y PtAl. Condiciones de reacción: $250^{\circ} \mathrm{C}, 12$ bar $\mathrm{N}_{2}$ inicial, $2 \mathrm{~h}$ de reacción, masa catalizador: $0,5 \mathrm{~g}$, solución acuosa al 10\% p/p de glicerol, agitación 700 rpm

\begin{tabular}{lcc}
\hline Catalizador & 2PtSi & 2PtAl $^{\text {IMP }}$ \\
\hline Dispersión (\%) & 60 & 54 \\
\hline $\mathbf{X}^{\mathbf{G}}(\%)$ & 9 & 13 \\
$\mathbf{X}^{\mathbf{T}}(\%)$ & 15 & 23 \\
$\mathbf{R H}_{\mathbf{2}}(\%)$ & 8 & 7 \\
$\mathbf{H}_{\mathbf{2}} / \mathbf{C O}_{\mathbf{2}}$ & 2 & 1,6 \\
$\mathbf{S H}_{\mathbf{2}}(\%)$ & 81 & 61 \\
\hline
\end{tabular}




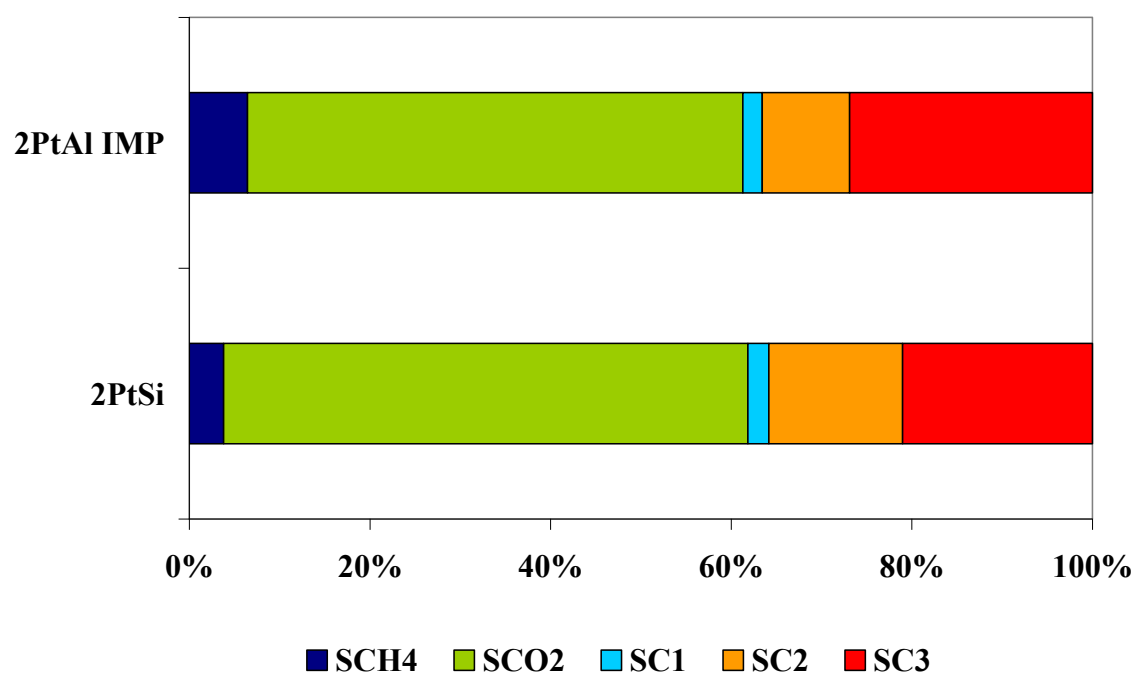

Figura IV-03. Resultados del APR del glicerol sobre PtSi y PtAl. Condiciones de reacción: $250{ }^{\circ} \mathrm{C}, 12$ bar $\mathrm{N}_{2}$ inicial, 2 h de reacción, masa catalizador: $0,5 \mathrm{~g}$, solución acuosa al 10\% p/p de glicerol, agitación 700 rpm

Es posible observar que a pesar de las notables diferencias en las propiedades ácidobase de los soportes, los catalizadores no evidencian grandes diferencias en la selectividad. Las pequeñas diferencias de selectividad que se observan en la Figura IV03 podrían deberse a los diferentes niveles de conversión.

Según el esquema de reacciones propuestos en el capítulo anterior, las reacciones de deshidratación favorecidas por la presencia de sitios ácidos superficiales conducirían a productos tales como acetol y acetona, sin embargo, el catalizador $2 \mathrm{PtAl}{ }^{\mathrm{IMP}}$ presenta un contenido similar al PtSi. Esto pone en evidencia que la acidez del soporte se neutraliza en el medio acuoso de la reacción en APR.

Por ello, posteriormente fue estudiado el efecto de un soporte con propiedades redox, que consiste de $\alpha-\mathrm{Al}_{2} \mathrm{O}_{3}$ modificada con $\mathrm{Ce}$ y $\mathrm{Zr}$. A partir de $\alpha-\mathrm{Al}_{2} \mathrm{O}_{3}$ comercial se preparó por impregnación, y de manera sucesiva (primero $\mathrm{Zr}$ y posteriormente $\mathrm{Ce}$ ), a partir de soluciones acuosas de $\mathrm{ZrO}\left(\mathrm{NO}_{3}\right)_{2} \mathrm{xH}_{2} \mathrm{O}$ (Aldrich), y $\mathrm{Ce}\left(\mathrm{NO}_{3}\right)_{3}, 6 \mathrm{H}_{2} \mathrm{O}$ (Alfa), con un contenido de óxidos de Ce y $\mathrm{Zr}$ de $5 \%$ p/p. Los detalles de la preparación se encuentran en el Capítulo II.

En un trabajo de tesis previo [31] se estudió el efecto de la composición de Ce y $\mathrm{Zr}$ sobre las propiedades redox del soporte, se determinó una ligera disminución en la superficie específica y en el volumen de poros de todos los soportes modificados por el 
agregado de $\mathrm{CeO}_{2}$ y/o $\mathrm{ZrO}_{2}$ comparados con los valores obtenidos para el soporte de referencia $\alpha-\mathrm{Al}_{2} \mathrm{O}_{3}$.

Para el soporte Ce4Zr1 $\alpha$ (CZA), por DRX (Figuras IV-04 (a) y (b)) se detectaron picos a $2 \theta=28,68^{\circ}(*) ; 47,86^{\circ}(\diamond)$ correspondientes a una estructura del tipo $\mathrm{Ce}_{\mathrm{x}} \mathrm{Zr}_{1-\mathrm{x}} \mathrm{O}_{2}$ (JCPDS 28-0271), esto indicaría la formación de una especie de óxido mixto del tipo $\mathrm{Ce}_{0,8} \mathrm{Zr}_{0,2} \mathrm{O}_{2}$ de fase cúbica tal como lo reportaron previamente Fornasiero y col. [32].

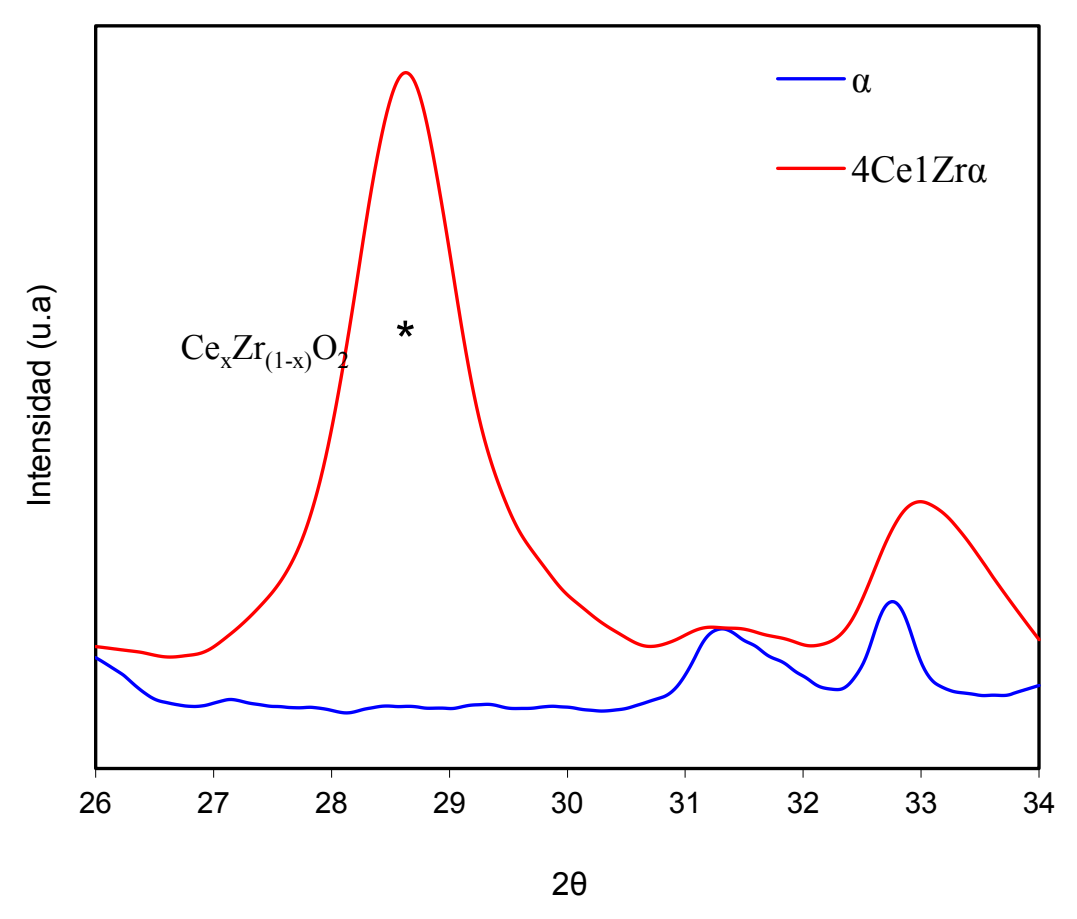

Figura IV-04(a). Difractograma de RX del soporte CZA 


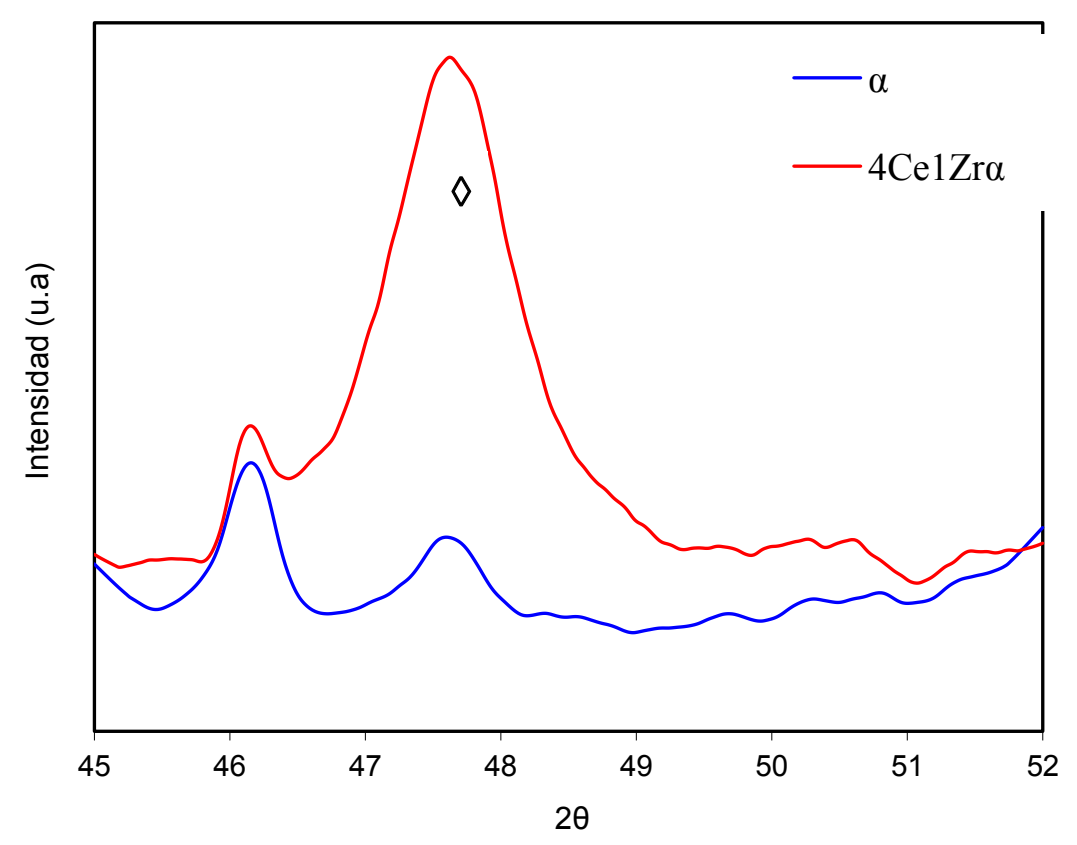

Figura IV-04(b). Difractograma de RX del soporte CZA

En la Tabla IV-07 se presentan los resultados obtenidos por XPS para el composito $\mathrm{Ce}_{4} \mathrm{Zr}_{1} \alpha$, donde se muestra la energía de enlace (BE) del O 1s, Ce $3 \mathrm{~d}_{5 / 2}, \mathrm{Zr} 3 \mathrm{~d}_{5 / 2}$ y Al 2p, y la relación de las intensidades $\mathrm{Ce} / \mathrm{Al}$ y $\mathrm{Zr} / \mathrm{Al}$. De acuerdo a estos resultados, la energía de enlace de la $\mathrm{Zr}(\mathrm{IV})$ en la matriz del soporte disminuye a $181,7 \mathrm{eV}$, debido a que la matriz rica en cerio se ve modificada por la presencia de la zirconia. Esto indica una fuerte interacción entre el cerio y la zirconia, probablemente formando una solución sólida, lo cual podría ser consecuencia de la formación del óxido mixto $\mathrm{Ce}_{0,8} \mathrm{Zr}_{0,2} \mathrm{O}_{2}$ evidenciado por DRX.

Tabla IV-07. Resultados obtenidos por XPS para el soporte CZA

\begin{tabular}{|c|c|c|c|c|}
\hline Soporte & O1s /eV & Ce $3 d_{5 / 2} / e V$ & $\mathrm{Zr} \mathrm{3d}_{5 / 2} / \mathrm{eV}$ & $\mathrm{Al} 2 \mathrm{p} / \mathrm{eV}$ \\
\hline \multirow{3}{*}{ CZA } & \multirow{3}{*}{$\begin{array}{l}531,5 \\
533,4\end{array}$} & 883,1 & \multirow{3}{*}{181,7} & \multirow{3}{*}{74,3} \\
\hline & & 887,8 & & \\
\hline & & 898,7 & & \\
\hline Soporte & & (nCe/nZr) & $(\mathrm{nCe} / \mathrm{nAl})$ & $(\mathrm{nZr} / \mathrm{nAl})$ \\
\hline \multirow{3}{*}{ CZA } & bulk & 2,86 & 0,012 & 0,004 \\
\hline & Ecuación II.19 & 2,14 & 0,083 & 0,040 \\
\hline & Ecuación II.20 & 3,20 & 0,110 & 0,034 \\
\hline
\end{tabular}


Las características estructurales y morfológicas del catalizador $\mathrm{PtCe}_{4} \mathrm{Zr}_{1} \alpha$, presentadas en la Tabla IV-05, indican que las partículas de Pt son del orden de $2 \mathrm{~nm}$. El consumo de hidrógeno determinado por TPR resultó mayor a la reducción completa Pt, lo que puede estar indicando la reducción del Ce favorecida por el Pt [33, 34].

Los resultados de la actividad en la reacción de APR del glicerol se muestran en la Tabla IV-08 y Figura IV-05.

Tabla IV-08. APR de glicerol sobre diferentes soportes. Condiciones de reacción: 250 ${ }^{\circ} \mathrm{C}, 12$ bar $\mathrm{N}_{2}$ inicial, 2 h de reacción, masa catalizador: $0,5 \mathrm{~g}$, solución acuosa al $10 \%$ $\mathrm{p} / \mathrm{p}$ de glicerol, agitación $700 \mathrm{rpm}$

\begin{tabular}{lccc}
\hline Catalizador & 1PtSi & 1PtaAl & 1PtCZA \\
\hline Dispersión (\%) & 60 & 53 & 60 \\
$\mathbf{X}^{\mathbf{G}}(\%)$ & 12 & 18 & 29 \\
$\mathbf{X}^{\mathbf{T}}(\%)$ & 29 & 43 & 60 \\
$\mathbf{R H}_{\mathbf{2}}(\%)$ & 9 & 13 & 20 \\
$\mathbf{H}_{\mathbf{2}} / \mathbf{C O}_{\mathbf{2}}$ & 2,0 & 1,7 & 1,7 \\
$\mathbf{S H}_{\mathbf{2}}(\%)$ & 78 & 71 & 81 \\
\hline
\end{tabular}

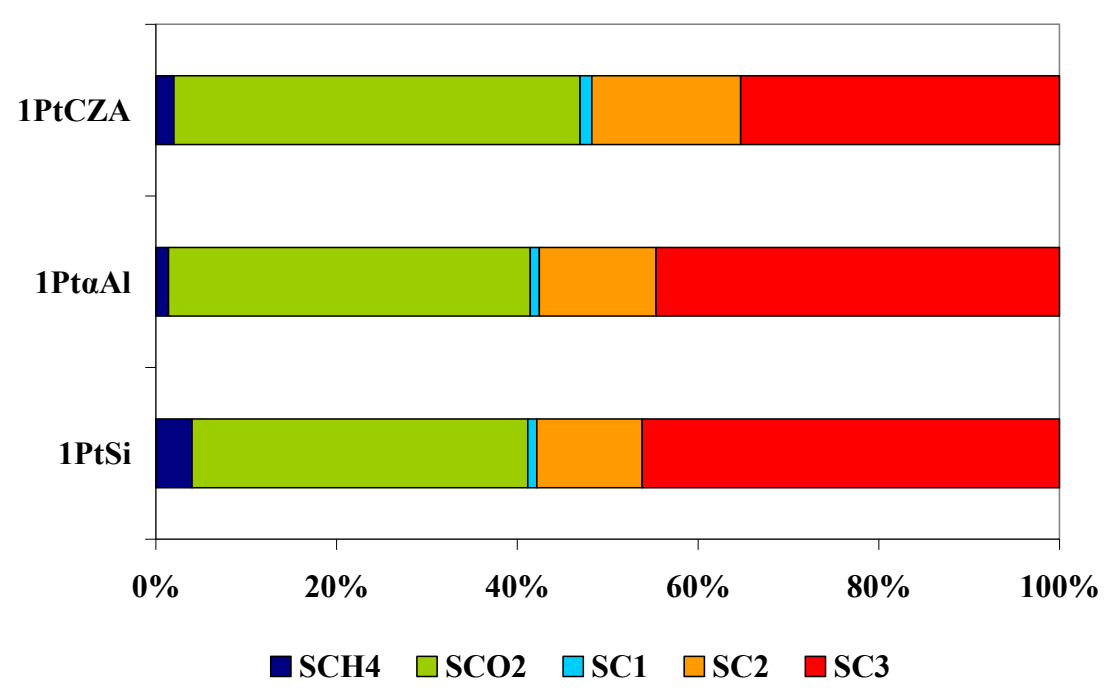

Figura IV-05. APR de glicerol sobre diferentes soportes. Condiciones de reacción: 250 ${ }^{\circ} \mathrm{C}, 12$ bar $\mathrm{N}_{2}$ inicial, 2 h de reacción, masa catalizador: $0,5 \mathrm{~g}$, solución acuosa al 10\% $\mathrm{p} / \mathrm{p}$ de glicerol, agitación $700 \mathrm{rpm}$ 


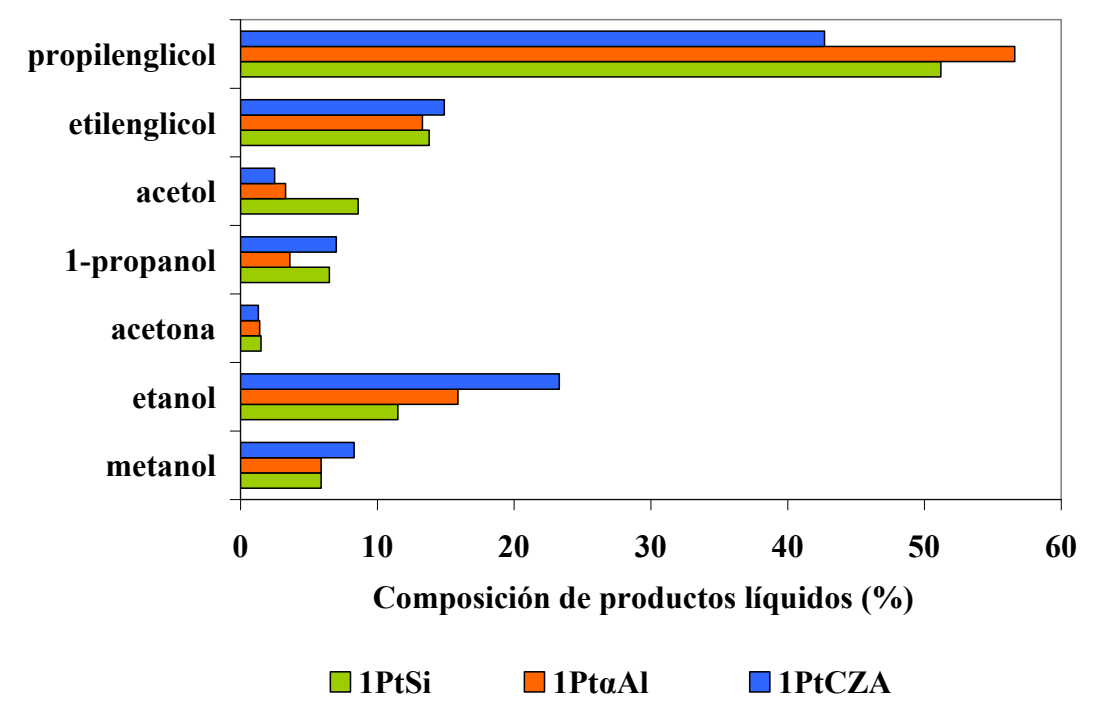

Figura IV-06. Composición molar de productos líquidos. Condiciones de reacción: 250 ${ }^{\circ} \mathrm{C}, 12$ bar $\mathrm{N}_{2}$ inicial, 2 h de reacción, masa catalizador: $0,5 \mathrm{~g}$, solución acuosa al 10\% p/p de glicerol, agitación $700 \mathrm{rpm}$

Comparando los resultados obtenidos a $250^{\circ} \mathrm{C}$, se observa que el catalizador 1PtCZA muestra la mayor actividad a productos gaseosos $\left(X^{G}=29\right)$ con la mayor selectividad al reformado $\left(\mathrm{SCO}_{2}=45\right.$ y $\left.\mathrm{SH}_{2}=81\right)$.

El comportamiento del sistema 1PtCZA podría estar asociado a las propiedades redox del soporte $\mathrm{Ce}_{4} \mathrm{Zr}_{1} \alpha$. Mientras que para los catalizadores PtSi y PtaAl la activación del agua se produce sólo sobre los sitios metálicos de Pt; en el catalizador PtCZA, el óxido mixto de $\mathrm{Ce}_{0,8} \mathrm{Zr}_{0,2} \mathrm{O}_{2}$ podría participar también además de los sitios metálicos de Pt. Como ha sido indicado en bibliografía Pt soportado en óxidos reducibles como $\mathrm{TiO}_{2}$ y $\mathrm{ZrO}_{2}$ muestran mayor actividad para la reacción de WGS [12]. En cuanto a soportes con Ce y $\mathrm{Zr}$, se ha propuesto en bibliografía que la reacción de WGS ocurre mediante un mecanismo vía formiato. En este mecanismo, se produce la formación de puentes de grupos $\mathrm{OH}$ en los sitios defectuosos de $\mathrm{Ce}^{3+}$ y la presencia de $\mathrm{Zr}^{+4}$ en interacción con $\mathrm{Ce}^{+3}$ facilita la descomposición de los formiatos [35].

La promoción de esta reacción genera un aumento considerable en la selectividad al reformado ya que como proponen varios autores $[6,36]$ la etapa controlante de la velocidad de reacción es la reacción de WGS y no las reacciones de ruptura C-C.

En el trabajo de Vignatti y col. [37], se determinó que la mayor actividad exhibida por catalizadores $\mathrm{Pt} / \mathrm{Ce}_{\mathrm{x}} \mathrm{Zr}_{1-\mathrm{x}} \mathrm{O}_{2}$ ricos en $\mathrm{Ce}$ puede ser explicada considerando que durante la reducción de esta muestra se forma una mayor concentración de grupos $\mathrm{OH}$. En 
contraste, la actividad de la reacción de WGS sobre $\mathrm{Pt} / \mathrm{Ce}_{0,25} \mathrm{Zr}_{0,75} \mathrm{O}_{2}$ es menor que la actividad sobre $\mathrm{Pt} / \mathrm{CeO}_{2}$ gracias a que la estabilidad de las especies formiato se incrementan sobre catalizadores $\mathrm{Pt} / \mathrm{Ce}_{\mathrm{x}} \mathrm{Zr}_{1-\mathrm{x}} \mathrm{O}_{2}$ ricos en $\mathrm{Zr}$, disminuyendo de esta manera la velocidad de descomposición del formiato, lo que puede limitar la velocidad de reacción en el mecanismo asociativo de la WGS.

Por otra parte, en otro trabajo de los mismos autores, se demuestra que la reacción es más rápida mediante un mecanismo bi-funcional del metal-soporte, el catalizador $\mathrm{Pt} / \mathrm{TiO}_{2}$ no solo provee los sitios activos para la adsorción del CO sino que también promueve la reducción de los iones $\mathrm{Ti}^{4+}$ a $\mathrm{Ti}^{3+}$ en la interfase metal-soporte, lo que genera sitios de vacancia de oxígeno que activan el agua y liberan hidrógeno [38].

Por lo tanto, la muy buena performance alcanzada con el catalizador 1PtCZA puede ser atribuida al efecto sinérgico entre el sitio metálico de Pt y los sitios de activación del agua de óxidos reducibles.

\section{IV.5. Estudio de la estabilidad del catalizador PtCZA}

Se estudió la estabilidad del catalizador PtCZA ya que resultó ser el más activo y selectivo al reformado del glicerol en fase líquida. Para ello se realizó la evaluación catalítica de 4 muestras de catalizador usado y se analizó el mecanismo responsable de la desactivación mediante la caracterización de las muestras post-reacción utilizando XPS, TEM y Raman.

Para estudiar la estabilidad se realizaron tres ensayos sucesivos de reacciones, donde el catalizador fue reutilizado. Las condiciones de reacción en todos los ensayos fueron de 12 bar de presión de $\mathrm{N}_{2}$ inicial, $250^{\circ} \mathrm{C}$ de temperatura y tiempo de reacción de $2 \mathrm{~h}$.

Para completar el estudio se realizó un cuarto ensayo de reacción con una muestra usada y regenerada en flujo de aire a $500^{\circ} \mathrm{C}$ durante 1 hora.

En la siguiente Tabla IV-09 y Figura IV-07 se presentan los resultados de actividad catalítica. 
Capítulo IV. Reformado en fase líquida de glicerol sobre catalizadores de Pt soportados

Tabla IV-09. Resultados de actividad catalítica en el estudio de estabilidad del catalizador 1PtCZA. Condiciones de reacción: $250{ }^{\circ} \mathrm{C}, 12$ bar $\mathrm{N}_{2}$ inicial, $2 \mathrm{~h}$ de reacción, masa catalizador: $0,5 \mathrm{~g}$, solución acuosa al $10 \% \mathrm{p} / \mathrm{p}$ de glicerol, agitación 700 rpm

\begin{tabular}{lcccc}
\hline $\begin{array}{l}\text { Ensayos de } \\
\text { actividad }\end{array}$ & $\mathbf{1}^{\mathbf{0}}$ uso & $\mathbf{2}^{\mathbf{0}}$ uso & $\mathbf{3}^{\mathbf{0}}$ uso & Regenerado \\
\hline $\mathbf{X}^{\mathbf{G}}(\mathbf{\%})$ & 29 & 24 & 23 & 31 \\
$\mathbf{X}^{\mathrm{T}}(\%)$ & 60 & 68 & 80 & 69 \\
$\mathbf{S C O}_{\mathbf{2}}(\%)$ & 45 & 35 & 27 & 40 \\
$\mathbf{S C}_{\mathbf{3}}(\%)$ & 35 & 42 & 47 & 40 \\
$\mathbf{R H}_{\mathbf{2}}(\%)$ & 20 & 18 & 17 & 17 \\
\hline
\end{tabular}

$1^{\circ}$ uso: corresponde a un test de 2 horas de reacción con catalizador fresco reducido. $2^{\circ}$ uso: corresponde a un test de 2 horas de reacción con la muestra descargada en el $1^{\circ}$ uso, lavada, secada a $120^{\circ} \mathrm{C}$ y nuevamente reducida.

$3^{\circ}$ uso: corresponde a un test de 2 horas de reacción con la muestra descargada en el $2^{\circ}$ uso, lavada, secada a $120^{\circ} \mathrm{C}$ y nuevamente reducida.

Regenerada: corresponde a un test de 2 horas de reacción con la muestra descargada en el $3^{\circ}$ uso, lavada, secada, calcinada a $500^{\circ} \mathrm{C}$ y nuevamente reducida.

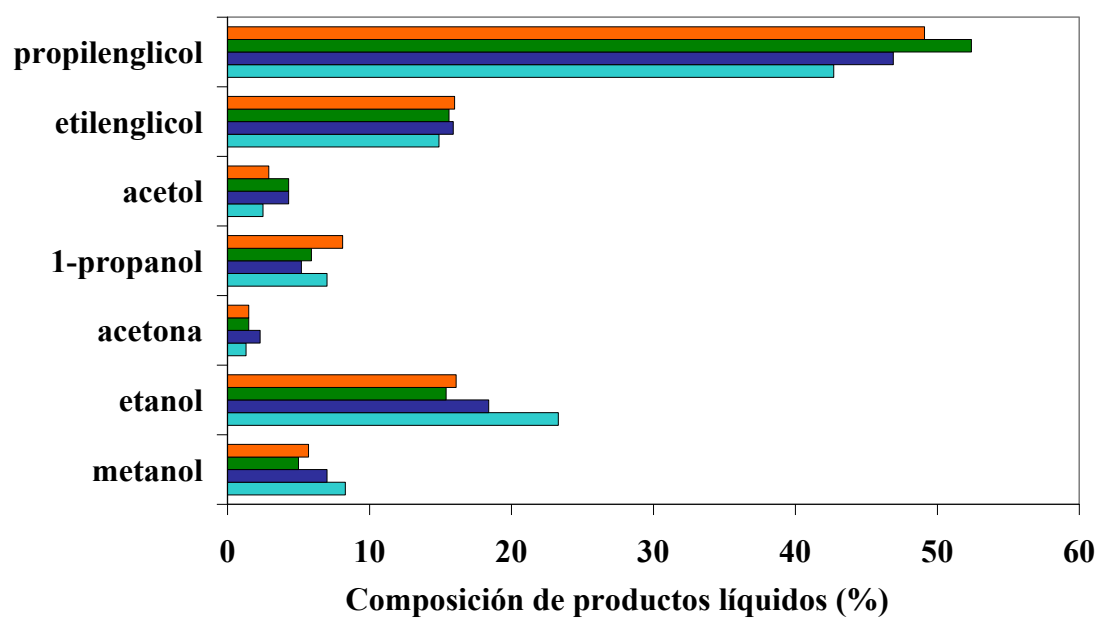

$\square$ 1er uso $\square 2$ do uso $\square$ 3er uso $\square$ 4to uso

Figura IV-07. Composición de productos líquidos en el estudio de estabilidad del catalizador 1PtCZA. Condiciones de reacción: $250^{\circ} \mathrm{C}, 12$ bar $\mathrm{N}_{2}$ inicial, $2 \mathrm{~h}$ de reacción, masa catalizador: $0,5 \mathrm{~g}$, solución acuosa al $10 \% \mathrm{p} / \mathrm{p}$ de glicerol, agitación 700 rpm 
Se puede observar que luego del primer ensayo de reacción, el catalizador muestra cierta desactivación. En el $2^{\text {do }}$ y $3^{\text {er }}$ ensayo, la conversión a productos gaseosos y la selectividad $\mathrm{SCO}_{2}$ disminuye, mientras que la selectividad a productos laterales $\mathrm{SC}_{3}$ se incrementa, conduciendo a una pérdida de rendimiento a $\mathrm{H}_{2}$. Luego de la regeneración, $4^{\text {to }}$ ensayo, se observa que la conversión a gases se recupera, pero no el rendimiento a $\mathrm{H}_{2}$ debido a la conversión a productos líquidos laterales (Tabla IV-09). Si se analiza la composición de los líquidos, se observa un incremento en la selectividad a PG. Esto resulta interesante si se considera que el PG es un producto de mayor valor agregado.

Para comprender los mecanismos de desactivación presentes en estas condiciones de reacción, los catalizadores usados fueron caracterizados mediante las técnicas TEM, Raman y XPS.

De manera de analizar el posible aumento de tamaño de partículas bajo las condiciones de reacción, se analiza el $\mathrm{d}_{\mathrm{va}}$ por la técnica TEM del catalizador 1PtCZA posreacción en función del tiempo de reacción (Tabla IV-10). El incremento del tamaño de partícula con el tiempo de reacción se observa en la Tabla $\mathbf{I V - 1 0}$, el rápido sinterizado ocurre durante los primeros minutos de reacción hasta la primera hora.

Tabla IV-10. Tamaño de partícula en función del tiempo de reacción determinado por TEM para el catalizador 1PtCZA

\begin{tabular}{cccccc}
\hline 1PtCZA & fresco & $\begin{array}{c}\text { Usado } \\
\mathbf{1 5} \text { min }\end{array}$ & $\begin{array}{c}\text { Usado } \\
\mathbf{6 0} \text { min }\end{array}$ & $\begin{array}{c}\text { Usado } \\
\mathbf{1 2 0} \text { min }\end{array}$ & $\begin{array}{c}\text { Usado } \\
\mathbf{1 4 4 0} \text { min }\end{array}$ \\
\hline $\mathrm{d}_{\mathrm{va}}(\mathrm{nm})$ & 2,1 & 3 & 3,8 & 3,8 & 3,9 \\
\hline
\end{tabular}

Por TGA/TPO no fue posible determinar cambios de peso en las muestras usadas posreacción. Se utilizó una técnica más sensible como la espectroscopia Raman. En la muestra usada en el $3^{\circ}$ ensayo consecutivo de reacción no se observó la presencia de depósitos carbonosos del tipo coque en el rango 1200 y $1700 \mathrm{~cm}^{-1}$, pero se observó una banda a $4400 \mathrm{~cm}^{-1}$ que podría ser atribuida a moléculas con grupos $-\mathrm{CH}$, aromáticos $\mathrm{y}$ aldehídos y/o grupos ciclopropanos (Figura IV-08). Esto podría indicar que debido a la quimisorción de productos laterales de reacción podría disminuir la actividad catalítica por bloqueo de sitios activos.

El análisis por espectroscopia Raman del catalizador regenerado por la calcinación en flujo de aire a $500{ }^{\circ} \mathrm{C}$ durante $1 \mathrm{~h}$, muestra que la banda a $4400 \mathrm{~cm}^{-1}$ desaparece, lo que 
estaría indicando que el tratamiento térmico permite la eliminación de los compuestos quimisorbidos.

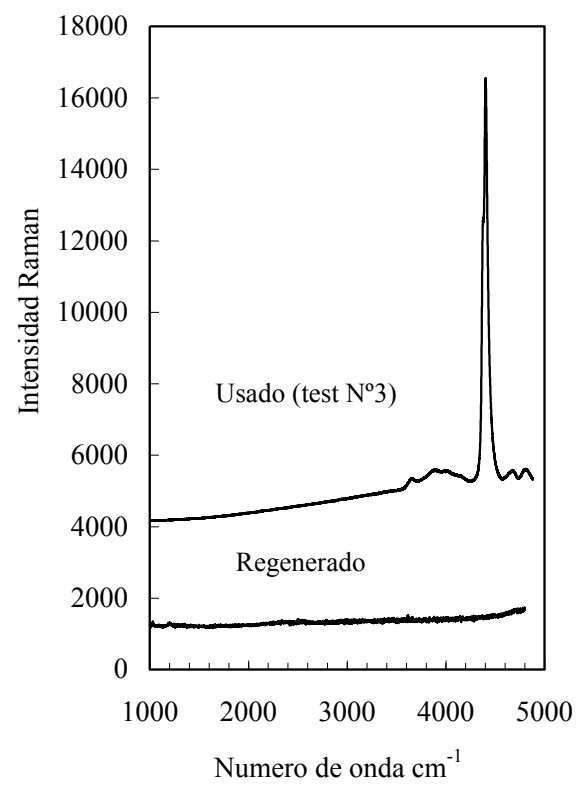

Figura IV-08. Espectro Raman de 1 PtCZA usado en Test $3^{\circ}$ y regenerado

En la Tabla IV-11 se muestran los resultados obtenidos por XPS de los catalizadores 1PtCZA fresco y regenerado, donde se muestra la energía de enlace (BE) del Pt $4 \mathrm{f}_{7 / 2}$, Ce $3 \mathrm{~d}_{5 / 2}, \mathrm{Zr} 3 \mathrm{~d}_{5 / 2}$ y Al 2p. La fuerte interacción entre Ce y $\mathrm{Zr}$ se evidencia por el descenso en el valor de $\mathrm{BE}$ del $\mathrm{Zr3d}_{5 / 2}(181,6-181,8 \mathrm{eV})$ con respecto al valor para $\mathrm{ZrO}_{2}(182,5$ eV), como fue reportado en bibliografía (Figuras IV-09 y IV-10) [39].

Para ambas muestras se observa en la región correspondiente a $\mathrm{Pt}_{4 / 2}$ un solo pico a 70,7 eV indicando la reducción completa del platino (Figuras IV-11 y IV-12).

Tabla IV-11. Caracterización por XPS, Energías de enlace $(\mathrm{eV})$ y fracción atómica superficial para el catalizador 1PtCZA

\begin{tabular}{|c|c|c|c|c|c|c|c|}
\hline & $\begin{array}{c}\operatorname{Pt} \mathbf{4 f _ { 7 / 2 }} \\
\mathrm{eV}\end{array}$ & $\begin{array}{c}\text { Ce 3d } d_{5 / 2} \\
\text { eV }\end{array}$ & $\begin{array}{c}\mathrm{Zr} \mathrm{3d_{5/2 }} \\
\mathrm{eV}\end{array}$ & $\begin{array}{c}\text { Al 2p } \\
\text { eV }\end{array}$ & $(\mathbf{P t} / \mathbf{A l})$ & $(\mathrm{Pt} / \mathrm{Zr})$ & (Pt/Ce) \\
\hline $\begin{array}{l}\text { 1PtCZA } \\
\text { fresco }\end{array}$ & 70,7 & $\begin{array}{c}881,2\left(v^{0}\right) \\
884,8\left(v^{\prime}\right) \\
915,9\left(u^{\prime \prime \prime}, 4,6 \%\right)\end{array}$ & 181,6 & 73,8 & 0,030 & 2,03 & 3,50 \\
\hline $\begin{array}{l}\text { 1PtCZA } \\
\text { regenerado }\end{array}$ & 70,7 & $\begin{array}{c}881,6\left(\mathrm{v}^{0}\right) \\
885,2\left(\mathrm{v}^{\prime}\right) \\
916,8\left(\mathrm{u}^{\prime \prime \prime}, 3 \%\right)\end{array}$ & 181,8 & 74,2 & 0,014 & 1,18 & 2,89 \\
\hline
\end{tabular}


La región del Ce $3 \mathrm{~d}$ muestra la presencia de $\mathrm{Ce}^{4+} \mathrm{y} \mathrm{Ce}^{3+}$. Para $\mathrm{Ce}^{4+}$ las bandas Ce $3 \mathrm{~d}_{5 / 2} \mathrm{y}$ Ce $3 d_{3 / 2}$ (separadas por $18,5 \mathrm{eV}$ ) son caracterizadas por tres contribuciones designadas como v, v"', $\mathrm{v}^{\prime \prime \prime}$ y u, u", $\mathrm{u}^{\prime \prime \prime}$, respectivamente [40]. Debido a que el pico u"' indica exclusivamente al $\mathrm{Ce}^{4+}$, puede usarse como medida cuantitativa de la cantidad de $\mathrm{Ce}^{4+}$, y la diferencia cuantifica el $\mathrm{Ce}^{3+}$. Como ha sido indicado en bibliografía, si todo el Ce se encuentra como $\mathrm{Ce}^{+4}$, el área integrada del pico $\mathrm{u}^{\prime \prime \prime}$ con respecto al área total del Ce $3 \mathrm{~d}$ constituye alrededor del $14 \%$ de la intensidad total [41]. Los resultados de los catalizadores (fresco y regenerado), en la Tabla IV-11 y en las Figuras IV-09 a IV-14, muestran la presencia de $\mathrm{Pt}^{0}, \mathrm{Ce}^{+3}$ y $\mathrm{Zr}^{+4}$, lo que permite explicar el rol del soporte en la reacción de water-gas-shift. Además, se observa que la relación de intensidad del Pt a los elementos del soporte ( $\mathrm{Al}, \mathrm{Zr}$ y $\mathrm{Ce}$ ) decrece en la muestra regenerada, lo que confirmaría la pérdida de platino superficial por sinterizado.

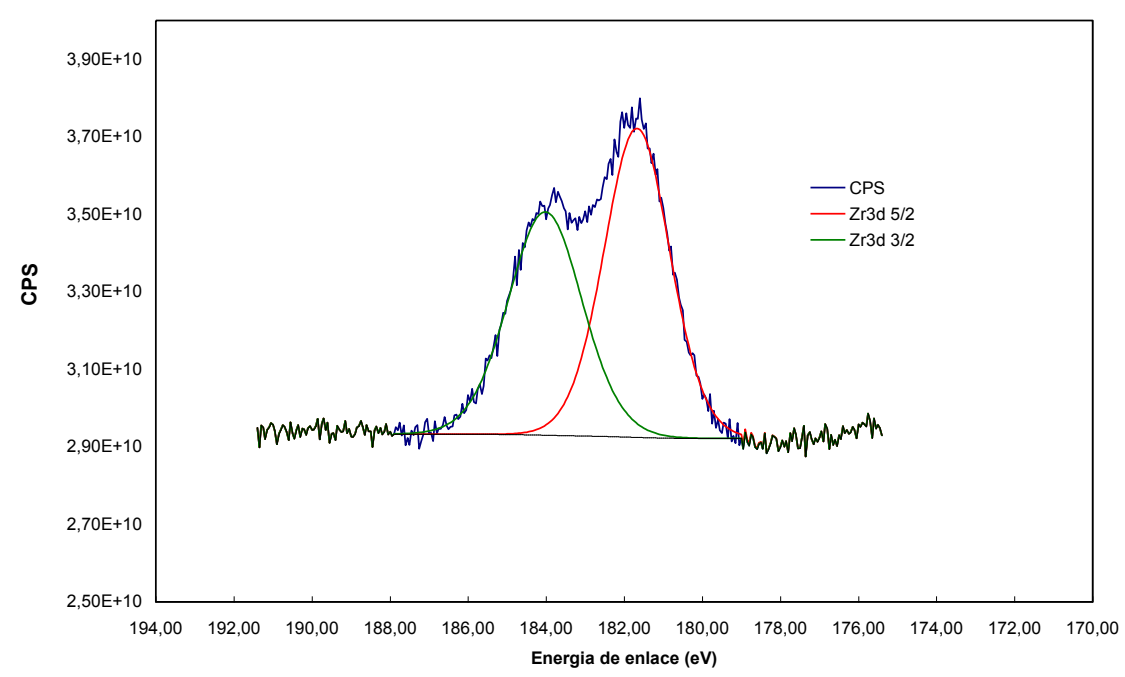

Figura IV-09. Espectro XPS para los niveles $3 d_{3 / 2}$ y $3 d_{5 / 2}$ del Zr para el catalizador 1PtCZA fresco 


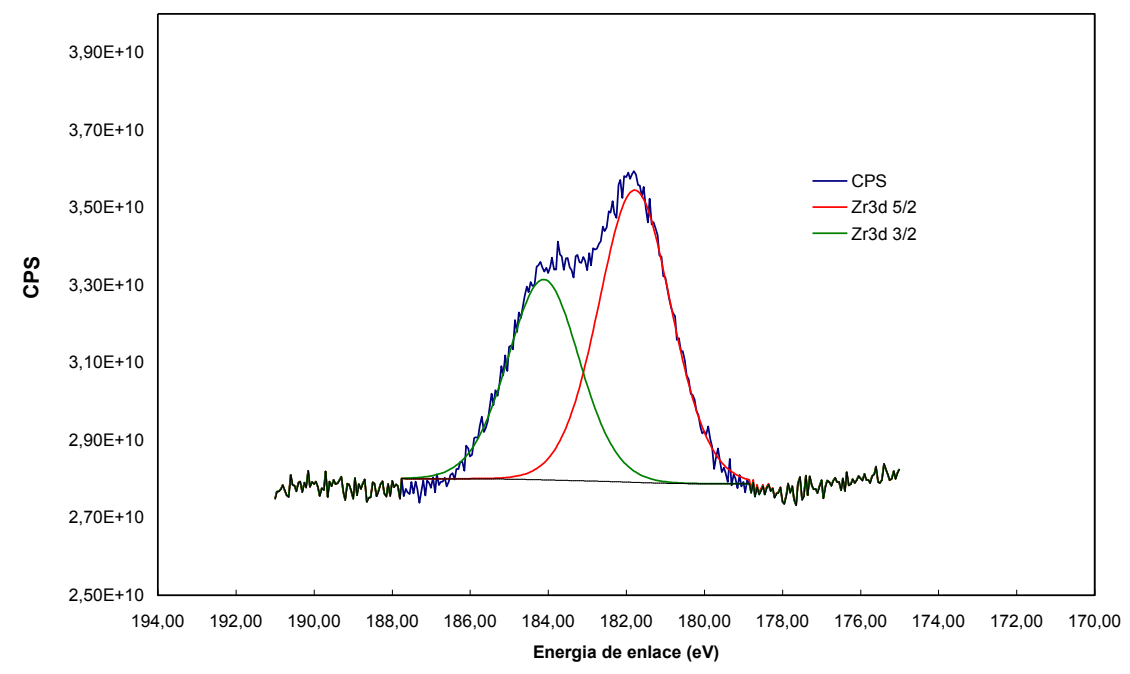

Figura IV-10. Espectro XPS para los niveles $3 d_{3 / 2}$ y $3 d_{5 / 2}$ del Zr para el catalizador 1PtCZA regenerado

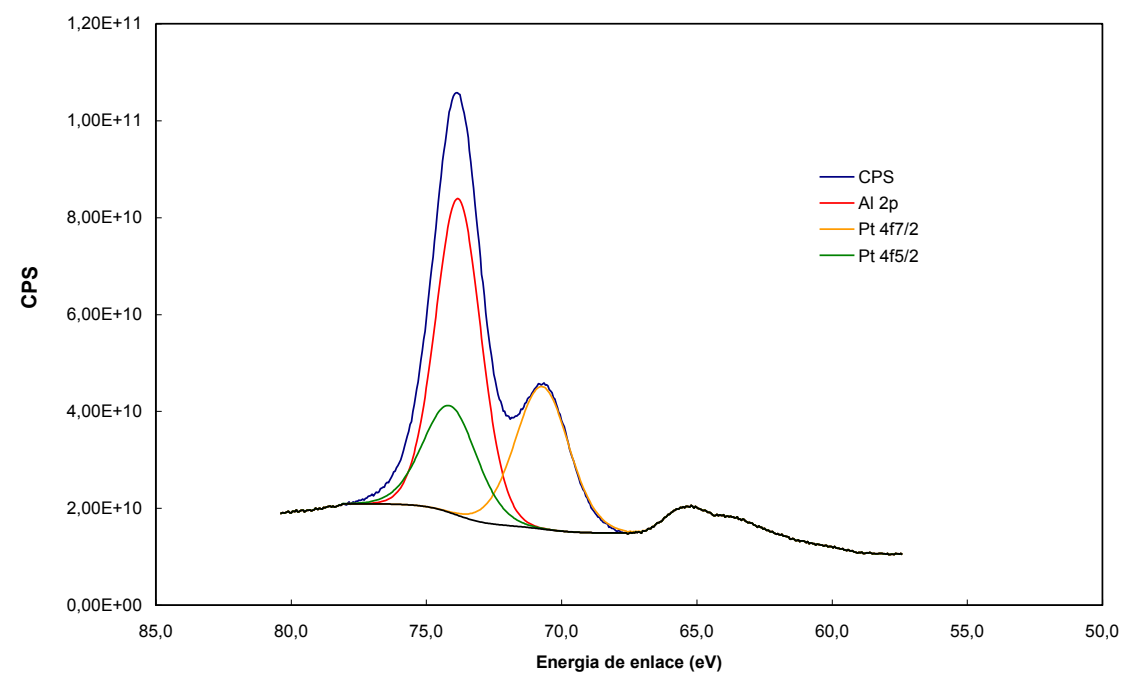

Figura IV-11. Espectro XPS para los niveles $4 \mathrm{f}_{7 / 2}$ y $4 \mathrm{f}_{5 / 2}$ del Pt y $2 \mathrm{p}$ del Al para el catalizador 1PtCZA fresco 


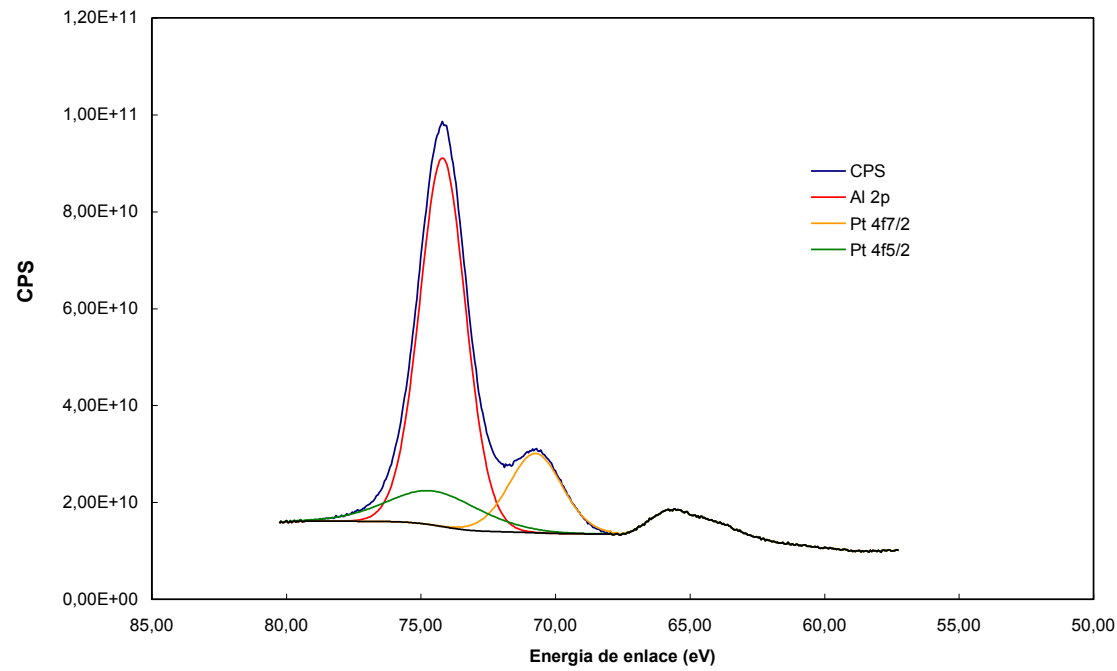

Figura IV-12. Espectro XPS para los niveles $4 \mathrm{f}_{7 / 2}$ y $4 \mathrm{f}_{5 / 2}$ del Pt y $2 p$ del Al para el catalizador 1PtCZA regenerado

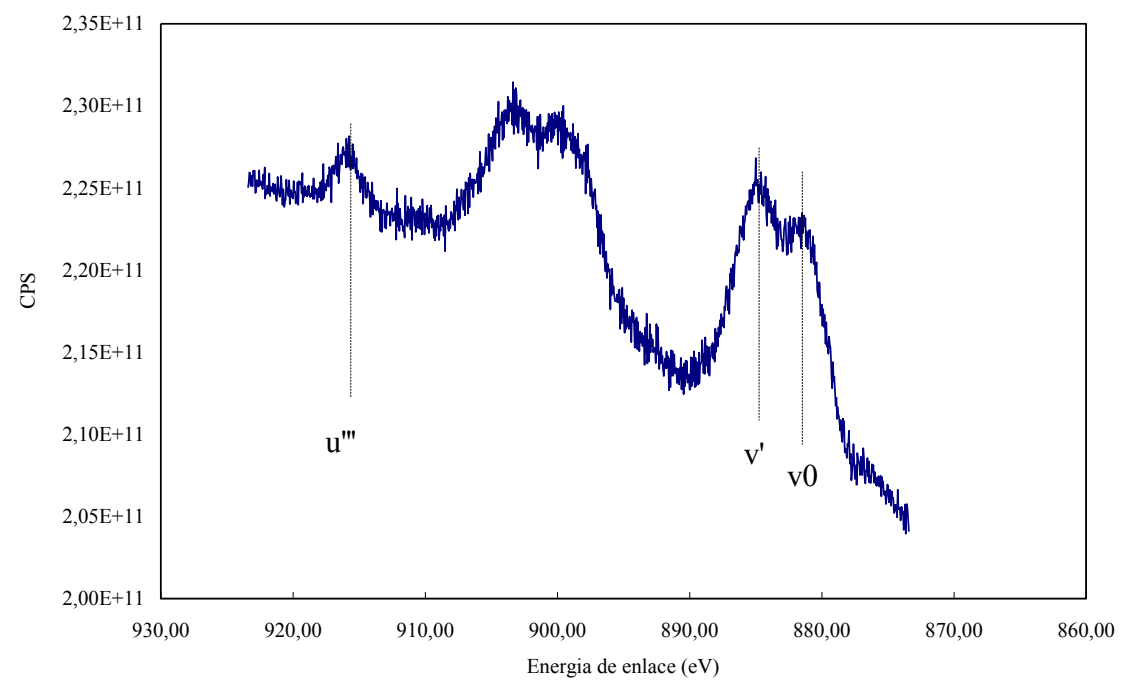

Figura IV-13. Espectro XPS para los niveles Ce $3 \mathrm{~d}_{5 / 2}$ y Ce $3 \mathrm{~d}_{3 / 2}$ del Ce para el catalizador 1PtCZA fresco $\left(\mathrm{Ce}^{+3}: \mathrm{v}^{0} \mathrm{y} \mathrm{v}^{\prime} ; \mathrm{Ce}^{+4}: \mathrm{u}^{\prime \prime \prime}\right)$ 


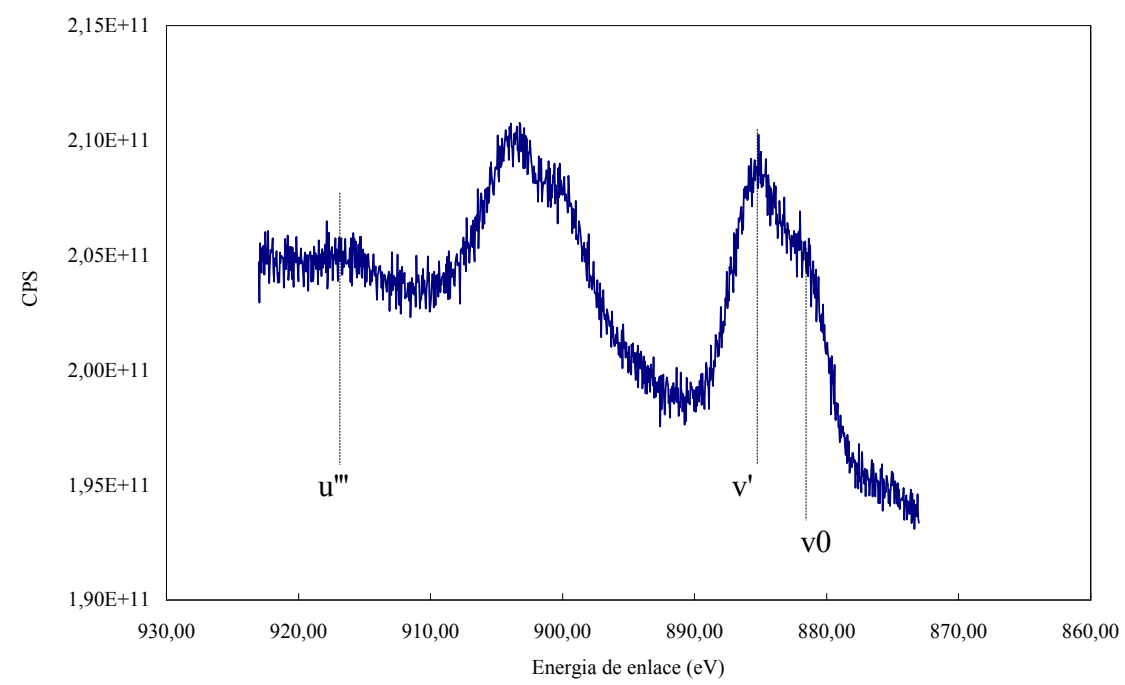

Figura IV-14. Espectro XPS para los niveles Ce $3 \mathrm{~d}_{5 / 2}$ y Ce $3 \mathrm{~d}_{3 / 2}$ del Ce para el catalizador 1PtCZA regenerado $\left(\mathrm{Ce}^{+3}: \mathrm{v}^{0} \mathrm{y} \mathrm{v}^{\prime} ; \mathrm{Ce}^{+4}: \mathrm{u}^{\prime \prime \prime}\right)$

\section{IV.6. Conclusiones del capítulo}

En este Capítulo se presentaron resultados de reformado en fase líquida de glicerol para obtener hidrógeno a partir de catalizadores de Pt utilizando soportes como $\mathrm{SiO}_{2}, \gamma$ $\mathrm{Al}_{2} \mathrm{O}_{3}, \alpha-\mathrm{Al}_{2} \mathrm{O}_{3}$ y $\alpha-\mathrm{Al}_{2} \mathrm{O}_{3}$ modificada con $\mathrm{CeO}_{2}$ y $\mathrm{ZrO}_{2}$

Se pudo determinar que el mayor efecto sobre la actividad de reformado en condiciones APR lo tiene el tamaño de partícula metálica. El menor tamaño de partícula metálica favorece el anclaje y ruptura de los enlaces $\mathrm{C}-\mathrm{C}$, por sobre los enlaces $\mathrm{C}-\mathrm{O}$ y reacciones de hidrogenación.

El efecto de acidez del soporte no se puso en evidencia en las condiciones de reacción del APR. Mientras que las propiedades redox del soporte tuvieron un rol importante en la promoción de la reacción de WGS. El catalizador 1PtCZA resultó el más activo $\left(\mathrm{X}^{\mathrm{G}}\right.$ $=29 \%)$, con la mayor selectividad al reformado $\left(\mathrm{SCO}_{2}=45 \%\right)$ y el mayor rendimiento a $\mathrm{H}_{2}\left(\mathrm{RH}_{2}=20 \%\right)$.

La presencia de átomos de $\mathrm{Pt}^{0}, \mathrm{Ce}^{+3}$ y $\mathrm{Zr}^{+4}$ confirmados por XPS, permiten explicar el rol del soporte en la reacción de WGS.

La caracterización por TEM, Raman y XPS del catalizador fresco y usado permitió determinar que la principal causa de la desactivación observada, es debida a la 
sinterización inicial que sufren las partículas de Pt y a la quimisorción de productos laterales de reacción.

El sistema 1PtCZA puede ser regenerado, recuperando la actividad de los sitios bloqueados por la quimisorción de productos laterales, pero con cierta pérdida de superficie metálica debido al sinterizado.

Es de destacar que en las condiciones APR el reactor opera con presión de hidrógeno que favorecen las reacciones de hidrogenólisis. Esto se pone en evidencia por la presencia de un importante subproducto, el PG.

En este sentido, tanto el catalizador $\mathrm{Pt} / \mathrm{Si}$ como $\mathrm{Pt} / \mathrm{CZA}$ resultaron activos para la hidrogenólisis a PG. A partir de estos resultados, en los próximos capítulos se orientará el desarrollo del catalizador para favorecer el rendimiento a propilenglicol.

\section{IV.7. Referencias}

[1] RR Soares, DA Simonetti, JA Dumesic. Angewandte Chemie Internacional Edition 45 (2006) 3982-3985

[2] MB Valenzuela, CW Jones, PK Agrawal. Energy and Fuels 20 (2006) 1744-1752

[3] E Gürbüz, E Kunkes, JA Dumesic. Applied Catalysis B: Environmental 94 (2010) 134-141

[4] DL King, L Zhang, G Xia, AM Karim, DJ Heldebrant, X Wang, T Peterson, Y Wang. Applied Catalysis B: Environmental 99 (2010) 206-213

[5] GW Huber, JW Shabaker, ST Evans, JA Dumesic. Applied Catalysis B: Environmental 62 (2006) 226-235

[6] JW Shabaker, RR Davda, GW Huber, D Cortright, JA Dumesic. Journal of Catalysis 215 (2003) 344-352

[7] RR Davda, JW Shabaker, GW Huber, D Cortright, JA Dumesic. Applied Catalysis B: Environmental 56 (2005) 171-186

[8] K Hayak, R Kramer, Z Paal. Applied Catalysis A: General 162 (1997) 1

[9] EV Benvenutti, L Franken, CC Moro. Langmuir 15 (1999) 8140

[10] H Iida, A Igarashi. Applied Catalysis A: General 298 (2006) 152-160

[11] P Panagiotopoulou, DI Kondarides. Catal. Today 112 (2006) 49

[12] JW Shabaker, GW Huber, RR Davda, RD Cortright., JA Dumesic. Catalysis Letters 88 (2003) 1-8 
Capítulo IV. Reformado en fase líquida de glicerol sobre catalizadores de Pt soportados

[13] W Turek, J Haber, A Krowiak. Applied Surface Science 252 (2005) 823

[14] N Ichikawa, S Sato, R Takahashi, T Sodesawa. Journal of Molecular Catalysis A: Chemical 256 (2006) 106

[15] JW Shabaker, GW Huber, RR Davda, D Cortright, JA Dumesic. Catalysis Letters 88 (2003) $1-8$

[16] RL Manfro, AF da Costa, NFP Ribeiro, MVM Souza. Fuel Processing Technology 92 (2011) 330-335

[17] AO Menezes, MT Rodrigues, A Zimmaro, LEP Borges, MA Fraga. Renewable Energy 36 (2011) 595-599

[18] A Iriondo, JF Cambra, VL Barrio, MB Guemez, PL Arias, MC Sanchez-Sanchez, RM Navarro, JLG Fierro. Applied Catalysis B: Environmental 106 (2011) 83-93

[19] B Wawrzetz, A Peng, A Hrabar, A Jentys, A Lemonidou, JA Lercher. Journal of Catalysis 269 (2010) 411-420

[20] B Roy, K Artyushkova, HN Pham, L Li, AK Datye, CA Leclerc. International journal of hydrogen energy 37 (2012) 18815-18826

[21] B Roy, U Martinez, K Loganathan, AK Datye, CA Leclerc. International journal of hydrogen energy 37 (2012) 8143-8153

[22] RL Manfro, AF da Costa, NFP Ribeiro, MMVM Souza. Fuel Processing Technology 92 (2011) 330-335

[23] K Lehnert, P Claus. Catalysis Communications 9 (2008) 2543-2546

[24] T Jiang, T Wang, L Maa, Y Li, Q Zhang, X Zhang. Applied Energy 90 (2012) 5157

[25] G. Wen, Y. Xu, H. Ma, Z. Xu, Z. Tian. International journal of hydrogen energy 33 (2008) 6657-6666

[26] LW Ho, CP Hwang, JF Lee, I Wang, CT Yeh. Journal of Molecular Catalysis A: Chemical 136 (1998) 293-299

[27] S Jongpatiwut, N Rattanapuchapong, T Rirksomboon, S Osuwan, DE Resasco. Catalysis Letters 122 (2008) 214-222

[28] H Lieske, G Lietz, H Spindler, J Volter. Journal of Catalysis 81 (1983) 8-16

[29] VA Mazzieri, JM Grau, JC Yori, CR Vera, CL Pieck. Applied Catalysis A: General 354 (2009) 161-168

[30] Gervasini A, Fenyvesi J, Auroux A. Catalysis Letters 43 (1997) 228

[31] F Pompeo. Tesis Doctoral, Facultad de Ingeniería, Universidad Nacional de La Plata, Argentina, (2008) 
[32] P Fornasiero, R Di Monte, GR Rao, J Kaspar, S Meriani. Journal of Catalysis 151 (1995) 168

[33] MJ Tiernan, OE Finlayson. Applied Catalysis B: Environmental 19 (1998) 23-35

[34] LF Liotta, A Longo, G Pantaleo, G Di Carlo, A Martorana, S Cimino, G Russo, G Deganello. Applied Catalysis B: Environmental 90 (2009) 470-477

[35] S Ricote, G Jacobs, M Milling, Y Ji, P Patterson, B Davis. Applied Catalysis A: General 303 (2006) 35-47

[36] Yong Guo, Muhammad Usman Azmat, Xiaohui Liu, Yanqin Wang, Guanzhong Lu. Applied Energy 92 (2012) 218-223

[37] CI Vignatti, MS Avila, CR Apesteguía, TF Garetto. Catalysis Today 171 (2011) $297-303$

[38] Ch Vignatti, MS Avila, CR Apesteguía, TF Garetto. International journal of hydrogen energy 35 (2010) 7302-7312

[39] AE Nelson, KH Schulz. Applied Surface Science 210 (2003) 206-221

[40] MV Rama Rao, T Shripathi. Journal of Electron Spectroscopy and Related Phenomena 87 (1997) 121-126

[41] JZ Shyu, K Otto, WLH Watkins, GW Graham, RK Belitz, HS Gandhi. Journal of Catalysis 114 (1988) 23-33 


\section{Capítulo V}

Hidrogenólisis de glicerol en fase líquida con catalizadores de $\mathrm{PtSn} / \mathrm{SiO}_{2}$ 
Capítulo V. Hidrogenólisis de glicerol en fase líquida con catalizadores de $\mathrm{PtSn} / \mathrm{SiO}_{2}$

\section{Capítulo V. Hidrogenólisis de glicerol en fase líquida con catalizadores de $\mathrm{PtSn} / \mathrm{SiO}_{2}$}

\section{V.1. Resumen del capítulo}

Tal como fue descrito en el capítulo anterior, es posible obtener $\mathrm{H}_{2}$ del APR de glicerol y además productos líquidos de importancia comercial. Dado que en las condiciones de reacción hemos obtenido propilenglicol (PG) como producto principal en la fase líquida (aproximadamente, 50\%), se planteó en esta tesis estudiar esta reacción para maximizar la producción de $\mathrm{PG}$.

Para ésto, focalizamos el estudio en el diseño de catalizadores que sean selectivos a la ruptura de enlaces $\mathrm{C}-\mathrm{O}$ e hidrogenaciones frente a la ruptura $\mathrm{C}-\mathrm{C}$ y establecer condiciones de reacción favorables para la producción de PG.

De este modo, en este capítulo se analiza la hidrogenólisis de glicerol utilizando catalizadores de $\mathrm{Pt}$ y $\mathrm{PtSn}$ soportados sobre $\mathrm{SiO}_{2}$ sintetizados mediante técnicas controladas de preparación derivadas de la Química Organometálica de Superficies sobre Metales (QOMS/M). Se analiza el efecto de la presión inicial de $\mathrm{H}_{2}$ y la influencia del contenido de Sn.

\section{V.2. Introducción}

El propilenglicol es un importante comoditie tradicionalmente derivado de óxidos de propileno. La dependencia con el petróleo crudo como fuente de propileno y propilenglicol ha causado una gran inestabilidad tanto en el precio como en la oferta, pero la oferta de glicerol proveniente del biodiesel, abundante y más barata, podría resolver este problema.

La hidrogenólisis del glicerol a propilenglicol ha sido previamente estudiada utilizando Pt [1,2]. Roy y col. [3] reportaron en 2010 la hidrogenólisis en fase acuosa del glicerol a 1,2-propanediol (propilenglicol), con una mezcla de catalizadores de $5 \% \mathrm{Pt} / \mathrm{Al}_{2} \mathrm{O}_{3}$ y 5 $\% \mathrm{Ru} / \mathrm{Al}_{2} \mathrm{O}_{3}$ sin agregado externo de hidrógeno. En 6 horas de reacción en modo batch a $220^{\circ} \mathrm{C}$ obtuvieron una conversión de glicerol de 50\% y una selectividad a PG de $47 \%$. 
Capítulo V. Hidrogenólisis de glicerol en fase líquida con catalizadores de $\mathrm{PtSn} / \mathrm{SiO}_{2}$

Guo y col. [4] sintetizaron catalizadores de $\mathrm{Cu}$ soportados sobre $\gamma-\mathrm{Al}_{2} \mathrm{O}_{3}$ y diferentes tipos de zeolitas: HY, 13X, HZSM-5 y Hb. La mejor performance se obtuvo con $\mathrm{Cu} / \gamma$ $\mathrm{Al}_{2} \mathrm{O}_{3}$. Los resultados experimentales junto con los estudios de caracterización por TPD y DRX revelaron que la carga de $\mathrm{Cu}$ óptima fue de 2,7 mmol de $\mathrm{Cu}$ metálico/g de $\gamma$ $\mathrm{Al}_{2} \mathrm{O}_{3}$. Este catalizador presenta una selectividad a propanodioles del $96,8 \%$ con una conversión de glicerol del $49,6 \%$ a $220{ }^{\circ} \mathrm{C}, 15$ bar de presión de $\mathrm{H}_{2}$ inicial, 10 h y una relación molar $\mathrm{Cu} / \mathrm{glicerol}=3: 100$.

Dasari y col. [5] estudiaron catalizadores de níquel, paladio, platino y cobre soportados sobre $\mathrm{C}, \mathrm{Al}_{2} \mathrm{O}_{3}$ y $\mathrm{SiO}_{2}-\mathrm{Al}_{2} \mathrm{O}_{3}$ y cromito de cobre, evaluando el efecto de la temperatura, presión de hidrógeno, contenido de agua, masa de catalizador y temperatura de reducción. A temperaturas superiores a $200{ }^{\circ} \mathrm{C}$ y presiones de hidrógeno de 14 bar, observaron una disminución en la selectividad a PG. Además con la disminución del contenido de agua en la alimentación aumentó el rendimiento de PG. Propusieron y validaron el camino de reacción a través del intermediario acetol para convertir el glicerol en PG. Este camino consiste en un primer paso con la formación del acetol, la que puede llevarse a cabo a presión atmosférica, mientras que un segundo paso requiere una cierta presión parcial de hidrógeno en el sistema. Entre todos los catalizadores estudiados el más efectivo fue el catalizador de cromito de cobre. La selectividad a PG obtenida en condiciones medias de reacción fue mayor al 73\%.

Los catalizadores bimetálicos han recibido una gran atención ya que se ha visto a través de muchos estudios que la presencia de un segundo componente puede inducir cambios significativos tanto en la actividad como en la selectividad de las reacciones catalíticas $[6,7]$. La variación en la performance del catalizador es comúnmente explicada sobre la base de efectos electrónicos y/o geométricos. Sin embargo, los factores geométricos y electrónicos generalmente no pueden ser separados como parámetros independientes.

En el trabajo de Daniel y col. [8], se determinó que los catalizadores bimetálicos de Pt$\mathrm{Re} / \mathrm{C}(5,7 \% \mathrm{p} / \mathrm{p} \mathrm{Pt}, 4,6 \% \mathrm{p} / \mathrm{p} \mathrm{Re})$ presentan mayor actividad que los catalizadores monometálicos de Pt aunque la selectividad a PG es menor. Otros sistemas bimetálicos como Pt-Ru/C (1,9\%p/p Pt, 4,7 \%p/p Ru) muestran que la selectividad mejora más que la actividad, cuando se compara con el catalizador monometálico de Ru [9].

Los catalizadores mencionados en esta breve introducción, han sido preparados por técnicas clásicas como la impregnación a humedad incipiente y por reacciones redox superficiales. Estas técnicas de preparación no aseguran un control eficiente de la fase 
Capítulo V. Hidrogenólisis de glicerol en fase líquida con catalizadores de $\mathrm{PtSn} / \mathrm{SiO}_{2}$

bimetálica. La preparación de un catalizador bimetálico a partir de la Técnica de Química Organometálica de Superficies sobre Metales (QOSM/M) es un campo de la química que estudia la reactividad de complejos organometálicos con superficies metálicas [10]. Se ha demostrado que fragmentos organometálicos pueden ser anclados por uniones covalentes sobre una superficie metálica de partículas de Platino soportado sobre sílice, lo cual provee procedimientos técnicos para preparar sistemas catalíticos de manera controlada [11].

En este capítulo se ha propuesto estudiar la reacción de hidrogenólisis de glicerol en condiciones suaves de reacción $\left(200^{\circ} \mathrm{C}\right.$ y 16 bar de $\mathrm{N}_{2}$ o $\left.\mathrm{H}_{2}\right)$ con catalizadores bimetálicos de $\mathrm{Pt} / \mathrm{Sn}$ soportados sobre $\mathrm{SiO}_{2}$ preparados a partir de las técnicas QOSM/M.

\section{V.3. Preparación y caracterización de los catalizadores bimetálicos Pt-Sn}

El catalizador monometálico $\mathrm{PtSi}(1 \%$ en peso de $\mathrm{Pt})$ se preparó por intercambio catiónico, cuyo método fue descrito en el Capítulo II, a partir de una solución de $\left[\mathrm{Pt}\left(\mathrm{NH}_{3}\right)_{4}\right]^{++}$de manera de obtener $1 \% \mathrm{p} / \mathrm{p}$ de Pt.

En esta Tesis se prepararon catalizadores bimetálicos de PtSn siguiendo el protocolo que se detalla en el Anexo I. La preparación consistió en la reacción entre el catalizador PtSi reducido y $\mathrm{SnBu}_{4}$, disuelto en n-heptano $\left(90^{\circ} \mathrm{C}\right)$ o n-decano $\left(90\right.$ y $\left.120^{\circ} \mathrm{C}\right)$, en atmósfera de $\mathrm{H}_{2}$ (Ecuación V-01). A $90^{\circ} \mathrm{C}$ se prepararon los catalizadores con 0,12 y $0,24 \% \mathrm{p} / \mathrm{p} \mathrm{Sn}$, mientras que el catalizador con $0,42 \% \mathrm{p} / \mathrm{p}$ de Sn requirió una temperatura de $120{ }^{\circ} \mathrm{C}$.

Luego de 6 horas de reacción, el sólido obtenido se lavó con varias porciones de nheptano y se secó en $\operatorname{Ar}$ a $90^{\circ} \mathrm{C}$.

$$
\begin{array}{ll}
\mathrm{Pt} / \mathrm{SiO}_{2}+y \mathrm{SnBu}_{4}+x y / 2 \mathrm{H}_{2} \rightarrow \mathrm{Pt}\left(\mathrm{SnBu} u_{4-x}\right)_{y} / \mathrm{SiO}_{2}+x y \mathrm{BuH} & \text { Ecuación V-01 } \\
\mathrm{Pt}\left(\mathrm{SnBu}_{4-x}\right)_{y} / \mathrm{SiO}_{2}+(4-x) y / 2 \mathrm{H}_{2} \rightarrow \mathrm{PtSn}_{y} / \mathrm{SiO}_{2}+(4-x) y \mathrm{BuH} & \text { Ecuación V-02 }
\end{array}
$$

Luego de esta primera etapa de reacción, se realizó la activación de la fase organobimetálica soportada $\left.\mathrm{Pt}(\mathrm{SnBu})_{4-\mathrm{x}}\right)_{\mathrm{y}} / \mathrm{SiO}_{2}$ en $\mathrm{H}_{2}$ a $500^{\circ} \mathrm{C}$ durante 2 h (Ecuación V- 
Capítulo V. Hidrogenólisis de glicerol en fase líquida con catalizadores de $\mathrm{PtSn} / \mathrm{SiO}_{2}$

02). La variación de la concentración de $\mathrm{SnBu}_{4}$ y la de los gases desprendidos en la reacción (principalmente butano) fue analizada por CG/FID y TCD. El contenido de Pt y Sn en los catalizadores se determinó por Absorción Atómica (AA) y estuvo en concordancia con los valores calculados a partir del balance de materia.

En la Tabla V-01 se muestra la denominación y composición de los sistemas bimetálicos. Debido a que todos los catalizadores tienen $1 \% \mathrm{Pt}$, se eliminó el 1 en la denominación. Por lo tanto, el catalizador "PtSi" corresponde al catalizador "1PtSi" mostrado en el capítulo IV.

Tabla V-01. Cantidad de Sn fijado a diferentes temperaturas y relación atómica $\mathrm{Sn} / \mathrm{Pt}$

\begin{tabular}{lccc}
\hline Catalizador & Temperatura $\left({ }^{\mathbf{O}} \mathbf{C}\right)$ & Sn $(\% \mathbf{p} / \mathbf{p})$ & Sn $/ \mathbf{P t}$ \\
\hline PtSi & - & 0 & 0 \\
PtSn0.2 & 90 & 0,12 & 0,2 \\
PtSn0.4 & 90 & 0,24 & 0,4 \\
PtSn0.7 & 120 & 0,42 & 0,7 \\
\hline
\end{tabular}

Estos catalizadores fueron caracterizados por adsorción atómica, reducción a temperatura programada (TPR), quimisorción de hidrogeno y $\mathrm{CO}$, espectroscopia fotoelectrónica de rayos X (XPS) y microscopía electrónica de transmisión (TEM).

En las Figuras V-01 a, b, c y d) se observan los histogramas de la distribución de tamaño de partícula de los catalizadores, donde es posible notar en todas las muestras una distribución estrecha de tamaños de partículas entre 1,5 y 3,5 nm. 


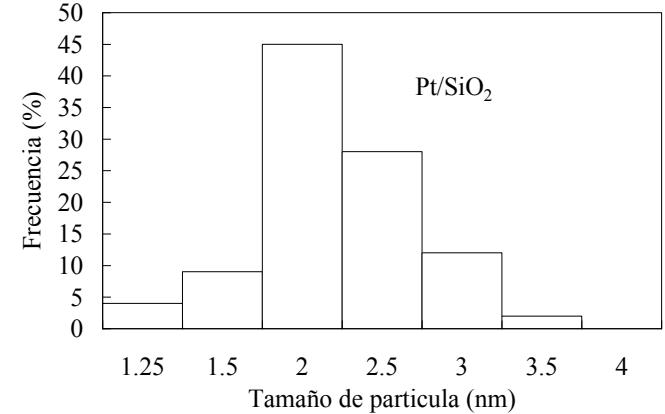

a)

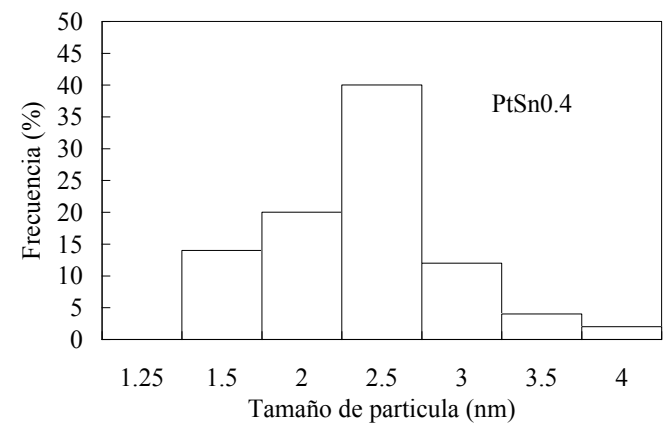

c)

Figura V-01. Distribución de tamaños de partículas determinadas por TEM de los

catalizadores: a) $\mathrm{Pt} / \mathrm{SiO}_{2}$, b) PtSn0.2, c) PtSn0.4 y d) PtSn0.7

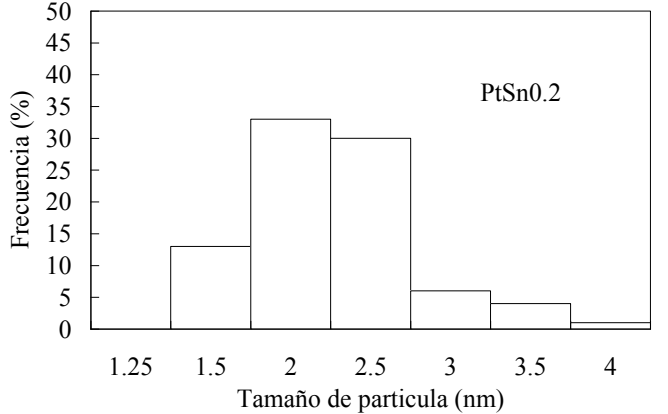

b)

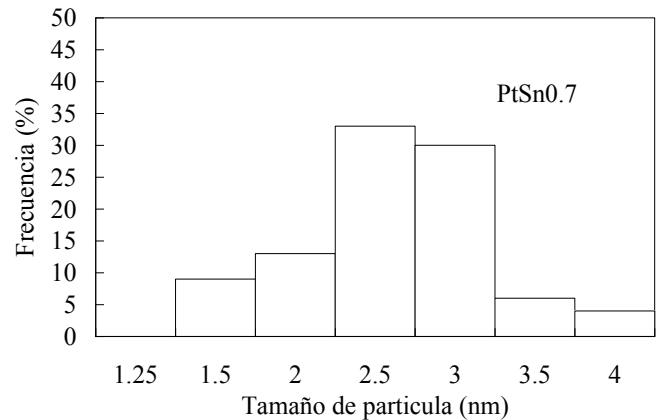

d)

En la Tabla V-02 se puede observar que la adición de una pequeña cantidad de $\operatorname{Sn}(0,12$ $\%$ p/p Sn, muestra PtSn0.2) produce una fuerte disminución en el valor de quimisorción de $\mathrm{H}_{2}$ de 0,64 a 0,27. Para el catalizador con 0,42 \% p/p Sn, muestra PtSn0.7, que corresponde a una relación $\mathrm{Sn} / \mathrm{Pt}=0,7$, el valor de $\mathrm{H} / \mathrm{Pt}$ disminuye a 0,20. $\mathrm{La}$ quimisorción de $\mathrm{CO}$ muestra la misma tendencia que la quimisorción de hidrógeno.

Tabla V-02. Caracterización de los catalizadores. Diámetro medio de partícula determinado por TEM y quimisorción de $\mathrm{H}_{2}$ y $\mathrm{CO}(\mathrm{H} / \mathrm{Pt}$ y $\mathrm{CO} / \mathrm{Pt})$

\begin{tabular}{lccc}
\hline Catalizador & H/Pt & CO/Pt & $\begin{array}{c}\text { dva } \\
\text { (nm) }\end{array}$ \\
\hline PtSi & 0,60 & 0,56 & 2,4 \\
PtSn0.2 & 0,27 & 0,29 & 2,7 \\
PtSn0.4 & 0,26 & 0,27 & 2,7 \\
PtSn0.7 & 0,20 & 0,25 & 2,9 \\
\hline
\end{tabular}


Además, los resultados por TEM muestran claramente que la adición de Sn no produce cambios significativos en el tamaño medio de partícula, ya que todas las muestras presentan un tamaño medio comprendido en el rango de 2,4 a 2,9 nm.

Estos resultados podrían estar indicando que la fuerte disminución en la quimisorción de $\mathrm{H}_{2}$ y $\mathrm{CO}$ no es consecuencia de la sinterización de Pt. Cortright y Dumesic [12] determinaron diferencias en los calores de adsorción del $\mathrm{H}_{2}$ y $\mathrm{CO}$ para $\mathrm{Pt}$ y $\mathrm{PtSn}$, lo que podría indicar que la disminución en la quimisorción se debe a efectos electrónicos y no solamente a efectos geométricos.

Los resultados de TPR mostraron dos picos de consumo de hidrógeno en la región de los $100-150{ }^{\circ} \mathrm{C}$ y $400-500{ }^{\circ} \mathrm{C}$ (Figura V-02). Con la adición de Sn (PtSn0.4 y PtSn0.7) existe un incremento en el consumo de hidrógeno, correspondiente al pico de baja temperatura $\left(\mathrm{T}<150^{\circ} \mathrm{C}\right)$, indicando una fuerte interacción entre el $\mathrm{Pt}$ y el $\mathrm{Sn}$. Los perfiles de TPR no muestran ningún pico en la zona correspondiente a la reducción de óxidos de $\mathrm{Sn}$ másico, los que ocurren a temperaturas mayores de $630^{\circ} \mathrm{C}$.

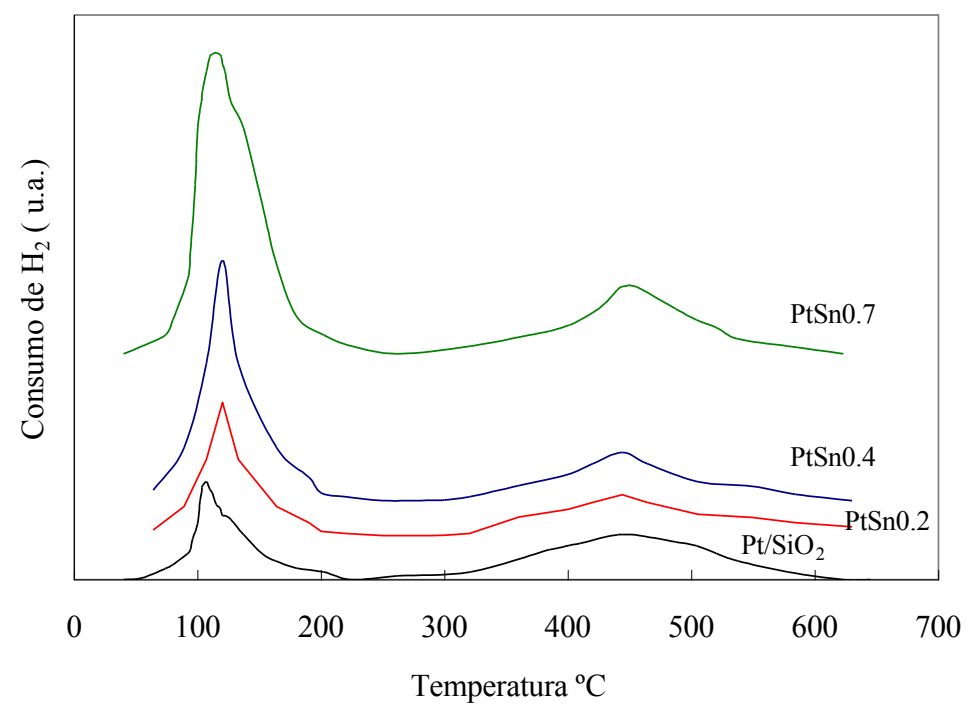

Figura V-02. Resultados de Reducción a temperatura programada (TPR)

En lo que respecta al análisis XPS, se muestran en la Tabla V-03 los valores de las energías de enlace $(\mathrm{BE})$ de los niveles $\mathrm{Pt} 4 \mathrm{f}_{7 / 2}$ y $\mathrm{Sn} 3 \mathrm{~d}_{5 / 2}$, referidos a las energías de enlace del C1s de $285 \mathrm{eV}$. Para todos los catalizadores estudiados (pre-tratados en $\mathrm{H}_{2}$ a 
Capítulo V. Hidrogenólisis de glicerol en fase líquida con catalizadores de $\mathrm{PtSn} / \mathrm{SiO}_{2}$

$500{ }^{\circ} \mathrm{C}$ ) aparece en la región correspondiente a $\mathrm{Pt} 4 \mathrm{f}_{7 / 2}$ a $71,6 \mathrm{eV}$, un pico indicando la reducción completa del Pt.

Tabla V-03. Caracterización por XPS. Energías de enlace $(\mathrm{eV})$ y fracción atómica de $\mathrm{Sn}(\mathrm{II}, \mathrm{IV}) / \mathrm{Sn}$ total para los catalizadores estudiados

\begin{tabular}{|c|c|c|c|c|c|}
\hline \multirow[b]{2}{*}{ Catalizador } & \multirow[b]{2}{*}{$\mathbf{S n} / \mathbf{P t}$} & \multicolumn{3}{|c|}{ Energía de enlace (eV) } & \multirow[b]{2}{*}{$\begin{array}{c}\operatorname{Sn}(I I, I V) / \\
(\operatorname{Sn}(I I, I V)+\operatorname{Sn}(0))\end{array}$} \\
\hline & & $\begin{array}{c}\mathbf{P t} \\
4_{f 7 / 2}\end{array}$ & $\begin{array}{l}\text { Sn (0) } \\
3_{d 5 / 2}\end{array}$ & $\begin{array}{c}\text { Sn (II, IV) } \\
3_{d 5 / 2}\end{array}$ & \\
\hline PtSi & 0 & 71,6 & --- & --- & --- \\
\hline PtSn0.2 & 0,2 & 71,1 & 484,4 & 486,5 & 0,30 \\
\hline PtSn0.4 & 0,4 & 71,1 & 484,4 & 486,5 & 0,33 \\
\hline PtSn0.7 & 0,7 & 70,6 & 484,6 & 487,1 & 0,36 \\
\hline
\end{tabular}

En la región de XPS del Sn $3_{d 5 / 2}$, ambos estados de oxidación $\operatorname{Sn}(\mathrm{II}, \mathrm{IV})$ y $\operatorname{Sn}(0)$ se encuentran a 486,5 y 484,4 eV, respectivamente. La deconvolución del espectro nos permite obtener la contribución de estas especies en cada muestra, como se indica en la misma tabla.

En los tres sistemas modificados con Sn, se observó un cambio en la BE del Pt hacia valores más bajos, con una disminución de $0,5-1 \mathrm{eV}$ con respecto al PtSi. Este cambio puede ser interpretado como una transferencia electrónica del Sn al Pt. Esto corrobora la hipótesis de los efectos electrónicos inducidos por el Sn que fueron propuestos en la explicación de la disminución en la quimisorción de $\mathrm{H}_{2}$ y CO.

El Sn iónico (Sn(II,IV)) probablemente se obtiene por la migración a la interfase metalsoporte, donde se presentaría como $\mathrm{SnOx}$. El $\mathrm{Sn}(0)$ podría formar aleaciones PtSn superficiales. La fracción de $\operatorname{Sn}(0)$ decrece levemente de 70 a $64 \%$ a medida que la relación $\mathrm{Sn} / \mathrm{Pt}$ se incrementa de 0,2 a 0,70 .

\section{V.4. Resultados catalíticos en la hidrogenólisis del glicerol}

Para realizar los ensayos de hidrogenólisis de glicerol se seleccionaron condiciones de presión y temperatura que beneficien esta reacción frente al reformado. Se estudió la 
Capítulo V. Hidrogenólisis de glicerol en fase líquida con catalizadores de $\mathrm{PtSn} / \mathrm{SiO}_{2}$

reacción a temperaturas bajas, entre 200 y $225^{\circ} \mathrm{C}$ y 4 bar de presión inicial de $\mathrm{N}_{2}$ o de $\mathrm{H}_{2}$ puro. A $200{ }^{\circ} \mathrm{C}$ la presión autogenerada en el reactor fue de 16 bar.

En la Tabla V-04 se muestran los resultados de la hidrogenólisis del glicerol sobre los diferentes catalizadores estudiados. El catalizador de $\mathrm{PtSi}$ a $200^{\circ} \mathrm{C}$ presentó una actividad catalítica muy baja de aproximadamente $1 \%$ de conversión de glicerol. A partir de $225^{\circ} \mathrm{C}$, el catalizador PtSi comienza a favorecer las reacciones indeseables de ruptura de enlaces $\mathrm{C}-\mathrm{C}$.

Tabla V-04. Resultados de la hidrogenólisis del glicerol. Condiciones de reacción: 200 ${ }^{\circ} \mathrm{C}, 4$ bar de presión inicial, 2 horas de reacción, masa catalizador: $0,3 \mathrm{~g}$, solución acuosa al 10\% p/p de glicerol. Condiciones de reacción *: $225^{\circ} \mathrm{C}, 4$ bar de presión inicial, 2 horas de reacción, masa catalizador: $0,5 \mathrm{~g}$, solución acuosa al 10\% p/p de glicerol

\begin{tabular}{|c|c|c|c|c|c|c|c|c|c|}
\hline \multirow{2}{*}{ Catalizador } & \multicolumn{3}{|c|}{ PtSi } & \multicolumn{2}{|c|}{ PtSn0.2 } & \multicolumn{2}{|c|}{ PtSn0.4 } & \multirow{2}{*}{$\begin{array}{c}\text { PtSn0.7 } \\
\mathrm{N}_{2}\end{array}$} & \multirow{2}{*}{$\begin{array}{c}\text { PtSn1.4 } \\
\mathrm{N}_{2}\end{array}$} \\
\hline & $\mathbf{N}_{2}$ & $\mathbf{N}_{2}{ }^{*}$ & $\mathbf{H}_{2}$ & $\mathbf{N}_{2}$ & $\mathbf{H}_{2}$ & $\mathbf{N}_{2}$ & $\mathbf{H}_{2}$ & & \\
\hline$X^{L}(\%)$ & 1 & 3 & 0,6 & 54 & 16 & 49 & 6 & 35 & 0 \\
\hline Smetanol (\%) & 6 & 15 & 11 & 1 & 1 & 1 & 1 & 1 & --- \\
\hline Setanol (\%) & 11 & 7 & 10 & 2 & 2 & 1 & 1 & 1 & --- \\
\hline S1-propanol (\%) & 1 & 1 & --- & 2 & 2 & 1 & 1 & 0 & --- \\
\hline Sacetol (\%) & 32 & 16 & 23 & 25 & 3 & 27 & 5 & 32 & --- \\
\hline Setilenglicol (\%) & --- & 19 & --- & 11 & 8 & 7 & 10 & 4 & --- \\
\hline Spropilenglicol (\%) & 50 & 42 & 56 & 59 & 84 & 63 & 82 & 62 & --- \\
\hline RPG (\%) & 0,4 & 4,8 & 0,3 & 32 & 13 & 31 & 12 & 22 & --- \\
\hline
\end{tabular}

Donde:

$$
\text { RPG }(\%)=\frac{\text { Moles producidos de propilenglicol }}{\text { Moles iniciales de glicerol }} \times 100
$$

Ecuación V-01

Los catalizadores de PtSn muestran un marcado incremento en la actividad con respecto al catalizador PtSi. En todos los ensayos se determinaron como productos principales: propilenglicol, acetol, etilenglicol, metanol, etanol y 1-propanol.

Las reacciones que pueden estar presentes involucran deshidrogenaciones iniciales, rupturas de enlaces $\mathrm{C}$-C y de enlaces $\mathrm{C}-\mathrm{O}$. El principal intermediario de reacción podría ser el acetol, que proviene de una primera etapa de deshidrogenación y posterior ruptura 
C-O. El acetol en presencia de $\mathrm{H}_{2}$ puede hidrogenarse para dar propilenglicol. Los alcoholes como metanol, etanol y etilenglicol se producirían debido a reacciones de deshidrogenación seguidas por rupturas C-C.

El esquema de la reacción principal se presenta a continuación:

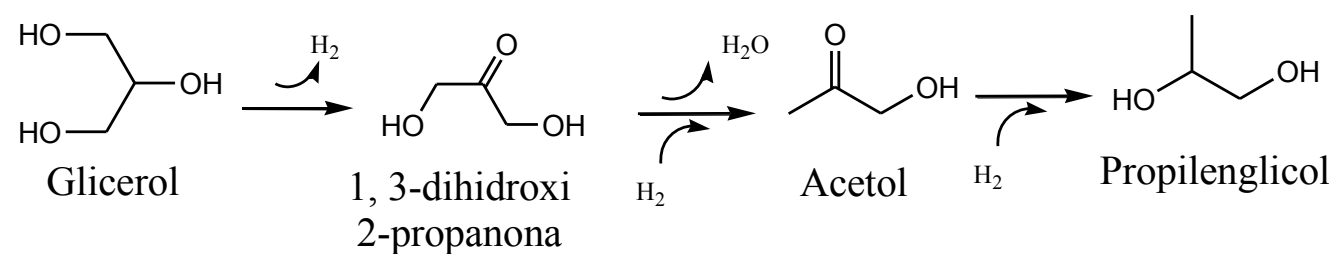

Esquema V-01. Esquema de la reacción principal de la hidrogenólisis del glicerol

\section{V.4.1. Ensayos bajo presión de $\mathrm{N}_{2}$}

Para los ensayos bajo presión inicial de $\mathrm{N}_{2}$, el catalizador PtSn0.2 mostró un $54 \%$ de conversión de glicerol con un 59\% de selectividad a propilenglicol (PG), conduciendo al mayor rendimiento a PG (32\%) (Tabla V-04).

Cuando la relación $\mathrm{Sn} / \mathrm{Pt}$ se incrementa a 0,4 , la actividad fue similar, con una conversión de glicerol del 49\% y una selectividad a PG del 63\%.

Para una relación $\mathrm{Sn} / \mathrm{Pt}$ igual a 0,7, la actividad disminuye con una conversión de glicerol de $35 \%$ y una caída del rendimiento a PG a 22\%.

Cuando la relación de $\mathrm{Sn} / \mathrm{Pt}$ varía de 0,2 a 0,7, la disminución en la actividad es similar a la reducción de sitios superficiales de $\mathrm{Pt}$ determinado por quimisorción de $\mathrm{H}_{2}$.

En los sistemas bimetálicos es aceptado que un número de sitios adyacentes o ensambles de varios átomos se requiere para la reacción de hidrogenólisis [13]. Los catalizadores bimetálicos de PtSn podrían tener este tipo de sitios adyacentes entre el $\mathrm{Pt}$ y el Sn, sobre todo para las muestras con relaciones de $\mathrm{Sn} / \mathrm{Pt}$ entre 0,2 y 0,7.

Como se observa por XPS, el Sn, además de encontrarse como $\operatorname{Sn}(0)$, presenta una importante contribución de estaño iónico (Sn II, IV), lo que podría favorecer la polarización de los enlaces $\mathrm{C}-\mathrm{OH}$. Los átomos de carbono polarizados positivamente son unidos a un átomo de Pt cuya densidad electrónica resulta incrementada por la adición de Sn. Por otro lado, el átomo de oxígeno del grupo C-OH es unido al estaño iónico $\mathrm{Sn}^{+\mathrm{n}}$ que actúa como un "sitio ácido de Lewis". Esto produce un debilitamiento del enlace C-OH, permitiendo el anclaje y ruptura del enlace C-O para obtener acetol, que sería el precursor del PG. Además, el sistema bimetálico PtSn preserva la capacidad 
de quimisorber y disociar el $\mathrm{H}_{2}$ para convertir el acetol a PG. Este mecanismo podría explicar que incluso cuando la producción de hidrógeno es baja, puede ocurrir la reacción de hidrogenólisis.

Otros autores [2] sugieren que los sitios ácidos del soporte y los sitios de Pt están involucrados en la deshidratación de glicerol a acetol, y posteriormente la hidrogenación se produce gracias a la disponibilidad de $\mathrm{H}_{2}$ obtenido del glicerol. Del mismo modo, Roy y col. [3] explican la menor actividad del $\mathrm{Ru}$ debido a su baja actividad para el reformado y por lo tanto, existe insuficiente cantidad de hidrógeno generado in situ para convertir el glicerol remanente a PG.

Finalmente, para $\mathrm{PtSn}$ con $1 \% \mathrm{Sn}$ (relación $\mathrm{Sn} / \mathrm{Pt}=1,4$ ), el catalizador fue inactivo en la reacción de hidrogenólisis. Esto evidencia la necesidad de usar métodos de preparación controlados para los catalizadores bimetálicos, de manera de alcanzar bajas relaciones $\mathrm{Sn} / \mathrm{Pt}$ con fuerte interacción entre $\mathrm{Pt}-\mathrm{Sn}$ y la presencia de estaño iónico ( $\mathrm{Sn}$ (II, IV)) de manera de promover los anclajes y rupturas de enlaces $\mathrm{C}-\mathrm{O}$ frente a los de los enlaces C-C.

\section{V.4.2. Ensayos bajo presión de $\mathrm{H}_{2}$}

La presencia de $\mathrm{H}_{2}$ podría inhibir el primer paso de deshidrogenación del glicerol y ésto podría explicar la menor actividad y la mayor selectividad a PG comparado con los resultados con presión inicial de $\mathrm{N}_{2}$.

El catalizador PtSn0.2 presenta una selectividad a PG del $84 \%$, pero la actividad cae a $16 \%$ de conversión de glicerol (Tabla V-04).

Roy y col. [3] reportaron que para la obtención de $\mathrm{PG}$ resulta mejor la generación de $\mathrm{H}_{2}$ in situ que la adición externa de $\mathrm{H}_{2}$. Encontraron que a 41 bar de $\mathrm{H}_{2}$ la selectividad a $\mathrm{PG}$ fue de $32 \%$ comparado con un $47 \%$ en el ensayo sin agregado de $\mathrm{H}_{2}$.

\section{V.5. Conclusiones parciales del capítulo}

En este capítulo se demostró que la adición de Sn (entre 0,12 y 0,4\%) a partir de la Química Organometálica de Superficies sobre un catalizador de PtSi, afecta fuertemente la actividad y selectividad en la hidrogenólisis del glicerol para obtener propilenglicol. 
Capítulo V. Hidrogenólisis de glicerol en fase líquida con catalizadores de $\mathrm{PtSn} / \mathrm{SiO}_{2}$

El mayor rendimiento es obtenido con el catalizador PtSn0.2. Para mayores contenidos de Sn, el descenso en la actividad se relaciona con la reducción de sitios de Pt accesibles.

La presencia de Sn iónico actuando como un sitio ácido de Lewis y el Pt con mayor densidad electrónica, conducen a un sitio favorable para la adsorción del C-OH y subsiguiente ruptura C-O, que es el paso inicial en la producción de propilenglicol.

\section{V.6. Referencias}

[1] D’Hondt E, Vyver SVd, Sels BF, Jacobs PA. Chemical Communications (2008) $6011-6012$

[2] Gandarias I, Arias PL, Requies J, Güemez MB, Fierro JLG. Applied Catalysis B: Environmental 97 (2010) 248-256

[3] Roy D, Subramaniam B, Chaudhari RV. Catalysis Today 156 (2010) 31-37

[4] L Guo, J Zhou, J Mao, X Guo, S Zhang. Applied Catalysis A: General 367 (2009) 93-98

[5] MA Dasari, P-P Kiatsimkul, WR Sutterlin, GJ Suppes. Applied Catalysis A: General 281 (2005) 225-231

[6] V. Ponec. Applied Catalysis A: General 222 (2001) 31-45

[7] Bernard Coq, Francois Figueras. Chemistry Reviews 178-180 (1998) 1753-1783

[8] Daniel OM, DeLaRiva A, Kunkes EL, Datye AK, Dumesic JA, Davis RJ. ChemCatChem 2 (2010) 1107-1114

[9] Maris EP, Ketchie WC, Murayama M, Davis RJ. Journal of Catalysis 251 (2007) $281-294$

[10] Chupin C, Candy JP, Basset JM. Catalysis Today 79 (2003) 15-19

[11] Santori GF, Casella ML, Ferretti OA. Journal of Molecular Catalysis A: Chemical 186 (2002) 223-239

[12] Cortright RD, Dumesic JA. Applied Catalysis A: General 129 (1995) 101-115

[13] Asedegbega-Nieto E, Bachiller-Baez B, Guerrero-Ruız A, Rodrıguez-Ramos I. Applied Catalysis A: General 303(2006) 88-95 
Capítulo VI

Hidrogenólisis de glicerol en fase liquida con un catalizador de PtNi/CZA 


\section{Capítulo VI: Hidrogenólisis de glicerol en fase líquida con un catalizador de PtNi/ PtNi/CZA}

\section{VI.1. Resumen del capítulo}

En el capítulo anterior se ha presentado el efecto de un promotor metálico como el Sn, que en una concentración muy baja del $0,12 \%$ es capaz de mejorar las propiedades catalíticas del Pt en la hidrogenólisis del glicerol.

El sistema Pt/CZA presentó buena actividad a productos gaseosos como el hidrógeno y a productos líquidos como el propilenglicol. Con el objetivo de mejorar la selectividad a propilenglicol se utilizó otra estrategia en el diseño del catalizador que consistió en estudiar el efecto de una fase bimetálica PtNi. El catalizador bimetálico se preparó por técnicas convencionales de impregnación y se utilizaron catalizadores monometálicos de Pt y Ni como referencia.

Además, se realizó la caracterización estructural por Espectroscopia de Absorción de Rayos X Extendida de Estructura Fina (EXAFS), TEM, DRX y XPS de los catalizadores frescos y usados para correlacionar la estructura con la performance catalítica y estabilidad frente a diferentes ciclos de reacción.

\section{VI.2. Introducción}

Tal como se ha descripto en el capítulo anterior, un catalizador efectivo para obtener propilenglicol a partir de glicerol deber ser activo para las reacciones de ruptura C-O. En este sentido diferentes sistemas bimetálicos han sido estudiados. King y col. [1] estudiaron catalizadores de $\mathrm{Pt}-\mathrm{Re} / \mathrm{C}$ y reportaron que diferentes especies coexisten en la fase activa: una aleación Pt-Re y especies ReOx. La aleación Pt-Re conduce a un incremento en la velocidad de deshidrogenación y decarbonilación, mientras que las especies $\mathrm{ReOx}$ acídicas promueven la deshidratación conduciendo a productos líquidos (propilenglicol, ácidos y alcoholes) y alcanos. Zhang y col. [2] encontraron que en catalizadores de $\mathrm{Pt}-\mathrm{Re} / \mathrm{C}$ las condiciones hidrotérmicas de la reacción causan la oxidación de las especies $\mathrm{Pt}-\mathrm{Re}$ lo que genera acidez superficial y favorece las 
reacciones de ruptura $\mathrm{C}-\mathrm{O}$ sobre las $\mathrm{C}-\mathrm{C}$, produciendo mayor selectividad a productos líquidos y alcanos y menor selectividad a hidrógeno.

Iriondo y col. [3] estudiaron sistemas bimetálicos PtNi soportados sobre $\gamma-\mathrm{Al}_{2} \mathrm{O}_{3}$ y $\mathrm{La}_{2} \mathrm{O}_{3}-\gamma-\mathrm{Al}_{2} \mathrm{O}_{3}$ en el APR de glicerol. La presencia de $\mathrm{La}_{2} \mathrm{O}_{3}$ mejora el comportamiento catalítico hacia productos gaseosos livianos. La mayor actividad del catalizador PtNi puede estar asociado a la formación de una aleación Pt-Ni y al fenómeno de "spillover". Doukkali y col. [4] estudiaron el APR de glicerol con catalizadores de Pt y Ni- $\gamma$ $\mathrm{Al}_{2} \mathrm{O}_{3}$. Estos catalizadores preparados por el método sol-gel son intrínsecamente más activos que los preparados por impregnación. La mayor actividad puede ser explicada debido a las mejores propiedades obtenidas por el método sol-gel, respecto al área superficial, tamaño de partícula de Pt y Ni y un efecto sinérgico entre ambos metales.

\section{VI.3. Preparación de catalizadores}

Se utilizó el Pt/CZA ( $1 \% \mathrm{p} / \mathrm{p})$, preparado por impregnación con $\mathrm{H}_{2} \mathrm{PtCl}_{6}$, como catalizador base.

Se preparó un catalizador de Ni/CZA (5 \% p/p) por impregnación con una solución acuosa de $\mathrm{Ni}\left(\mathrm{NO}_{3}\right)_{3} \cdot 6 \mathrm{H}_{2} \mathrm{O}$ (Aldrich), tal como se detalla en la sección experimental.

El catalizador bimetálico $\mathrm{PtNi} / \mathrm{CZA}$ fue preparado por impregnación del catalizador $\mathrm{Ni} / \mathrm{CZA}$ con una solución de $\mathrm{H}_{2} \mathrm{PtCl}_{6}$ de tal manera de obtener $1 \% \mathrm{p} / \mathrm{p}$ de $\mathrm{Pt}$ en el catalizador. Los catalizadores $\mathrm{Pt} / \mathrm{CZA}$ y $\mathrm{PtNi} / \mathrm{CZA}$ fueron reducidos a $500^{\circ} \mathrm{C}$ durante 1 hora en flujo de $\mathrm{H}_{2}$ puro $(30 \mathrm{~mL} / \mathrm{min})$. El catalizador $\mathrm{Ni} / \mathrm{CZA}$ fue reducido a $750{ }^{\circ} \mathrm{C}$ durante 2 horas en flujo de $\mathrm{H}_{2}$ puro $(30 \mathrm{~mL} / \mathrm{min})$.

\section{VI.4. Resultados de Caracterización de Catalizadores}

Se realizaron análisis por DRX de todos los catalizadores reducidos que se muestran en la Figura VI-01. 


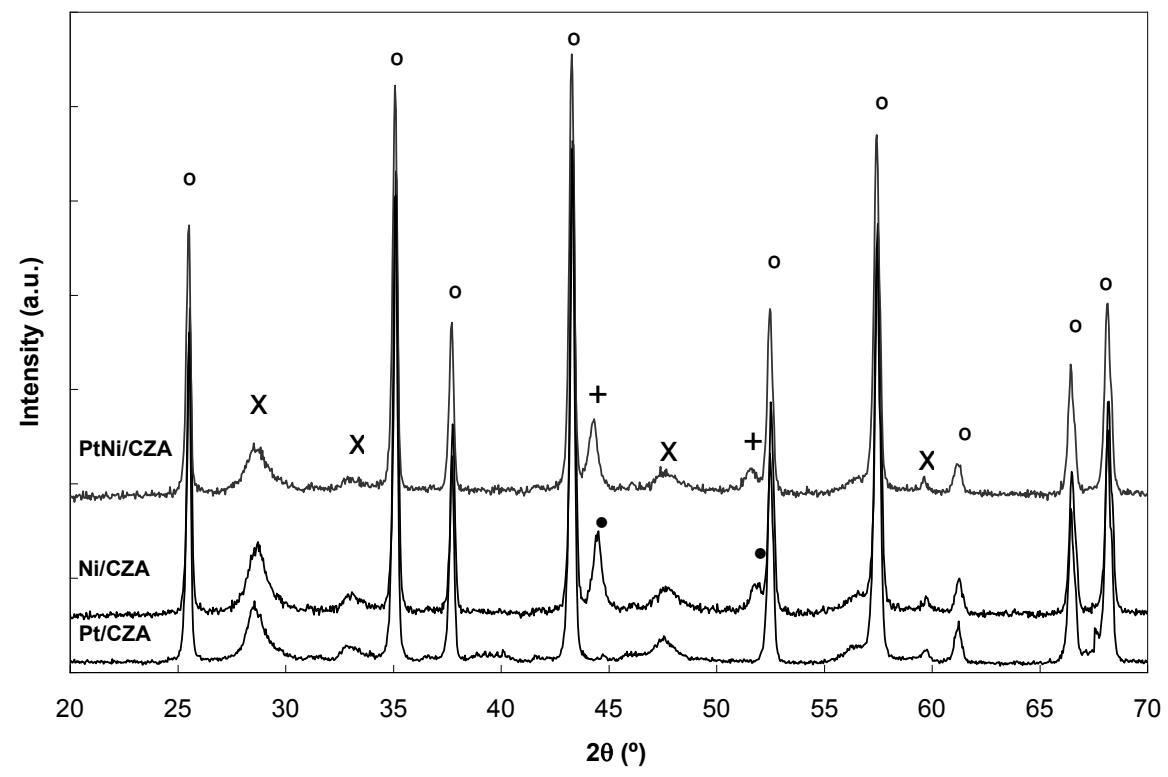

Figura VI-01. Resultados de análisis por DRX de los catalizadores reducidos Ni/CZA, Pt/CZA y PtNi/CZA: (o) $\alpha-\mathrm{Al}_{2} \mathrm{O}_{3}$, (x) $\mathrm{Ce}_{0.8} \mathrm{Zr}_{0.2} \mathrm{O}_{2},(\bullet) \mathrm{Ni},(+) \mathrm{PtNi}$

Todos los difractogramas DRX presentan un pico principal a $2 \theta=28,68^{\circ}$ que corresponde a la fase cúbica de la solución sólida de composición $\mathrm{Ce}_{0.8} \mathrm{Zr}_{0.2} \mathrm{O}_{2}$ [5]. Para el catalizador $\mathrm{Ni} / \mathrm{CZA}$, el pico principal del Ni metálico se observa a $2 \theta=44,5^{\circ}$ y $51,7^{\circ}$, con un parámetro de red $\mathrm{a}=3,5253 \AA$. El tamaño medio de cristal estimado utilizando la relación de Scherrer es 17,7 nm.

Para el catalizador monometálico Pt/CZA la señal de difracción fue muy similar a la del soporte (Figura IV-04 del Capítulo IV), no pudiendo observarse picos correspondientes al Pt. Este resultado sugiere que las partículas de Pt metálico son muy pequeñas para ser detectadas por esta técnica [6].

Para el catalizador PtNi/CZA se observa que el parámetro de red obtenido para Ni fue $\mathrm{a}=3,5361 \AA$, lo que muestra un pequeño desplazamiento con respecto a la del catalizador Ni/ZCA $(a=3,5253 \AA)$. Esta pequeña variación se puede deber a la formación de una aleación o una solución sólida de átomos de Pt en la estructura de Ni. Por esta razón, se utilizó una técnica más específica, como el EXAFS, de manera de determinar la presencia de una aleación entre el Ni y el Pt en el catalizador bimetálico.

Los ensayos de caracterización por TEM permitieron obtener la distribución de tamaños de partícula, y el diámetro medio $\mathrm{d}_{\mathrm{va}}$ de partículas. En la Figura VI-02 y en el Anexo III se muestran las imágenes TEM del soporte y de los catalizadores reducidos. 
Capítulo VI. Hidrogenólisis de glicerol en fase líquida con un catalizador de PtNi/CZA
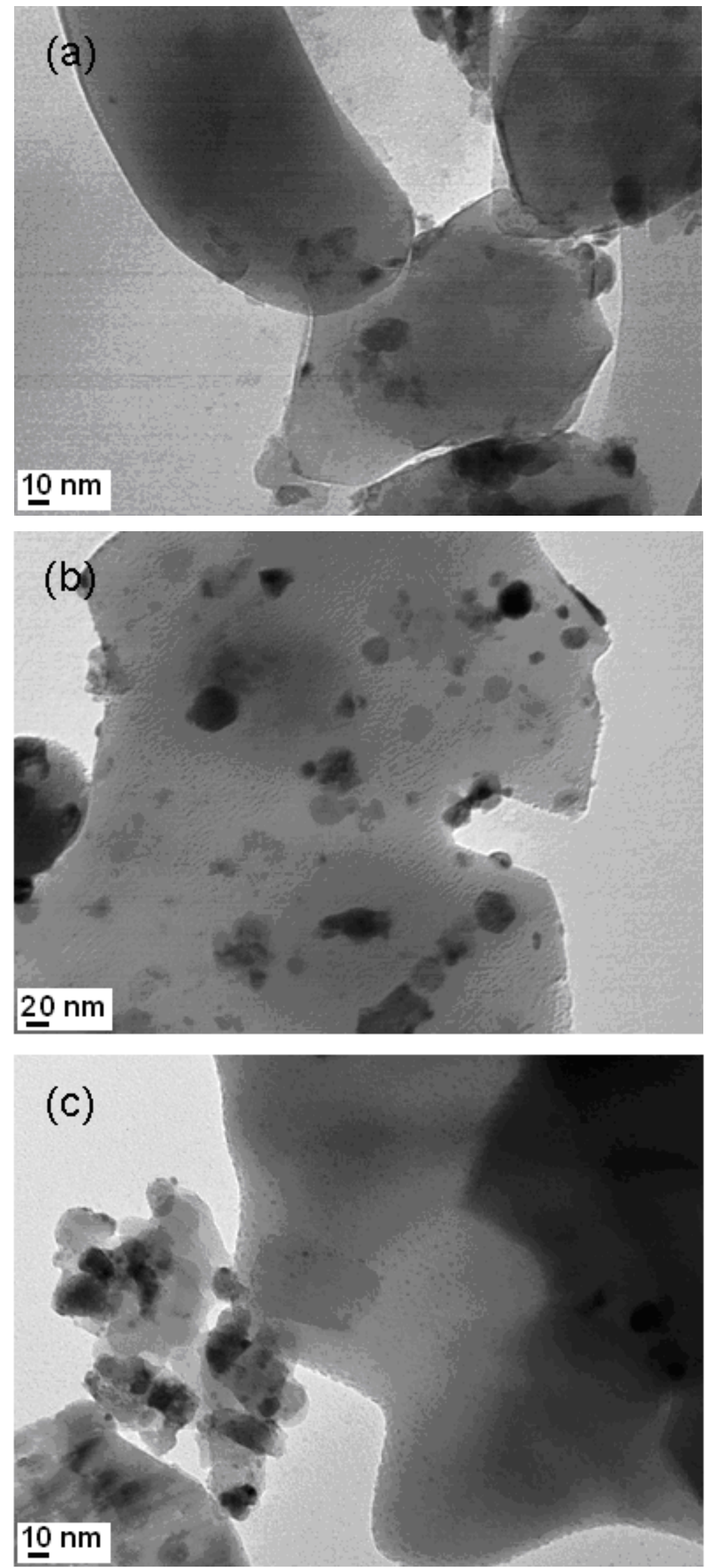


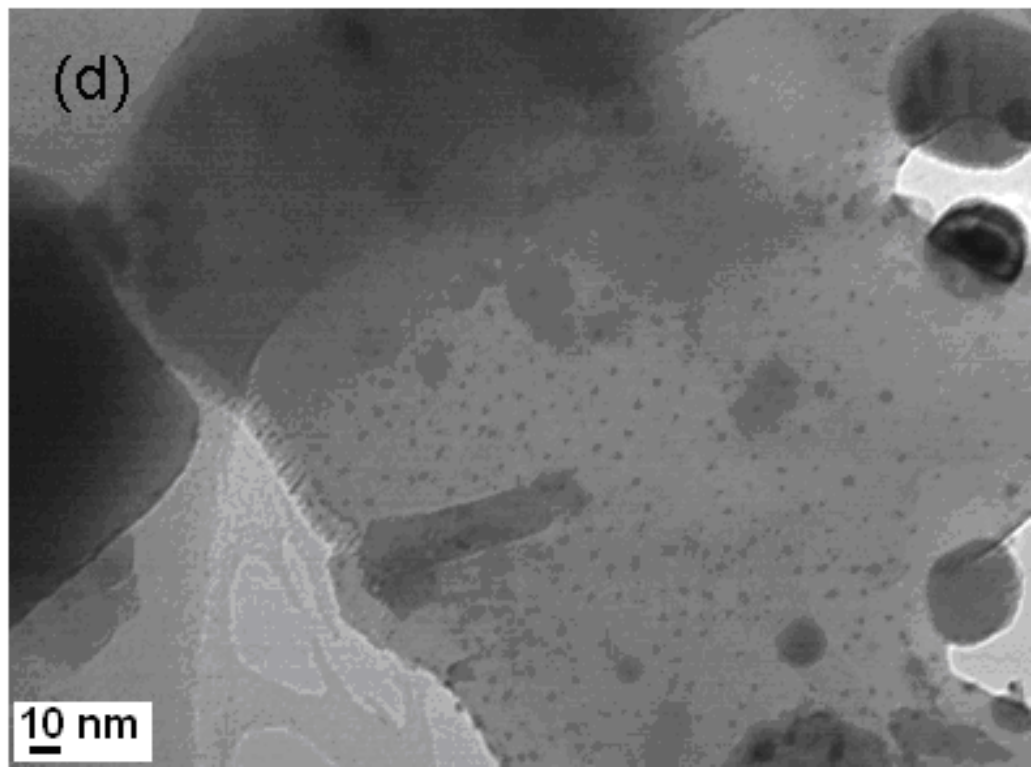

Figura VI-02. Micrografías TEM: (a) CZA, (b) Ni/CZA, (c) Pt/CZA, y (d) PtNi/CZA

Los resultados de TEM del soporte de $\alpha-\mathrm{Al}_{2} \mathrm{O}_{3}$ modificada con Ce y $\mathrm{Zr}(\mathrm{CZA})$ muestran la presencia de partículas del composito de $\mathrm{Ce}_{0.8} \mathrm{Zr}_{0.2} \mathrm{O}_{2}$ de 8 a $20 \mathrm{~nm}$ (Figura VI02(a)). Si bien en la muestra Ni/CZA no es posible distinguir claramente entre las partículas de $\mathrm{Ni}$ y las partículas del composito $\mathrm{Ce}_{0.8} \mathrm{Zr}_{0.2} \mathrm{O}_{2}$ (Figura VI-02(b)), se observa un mayor número de partículas en el rango de 16 a $28 \mathrm{~nm}$. Esto está de acuerdo con la estimación del tamaño de cristalitos de Ni de $17,7 \mathrm{~nm}$ realizada a partir de los resultados de DRX.

En los catalizadores Pt/CZA y PtNi/CZA (Figura VI-02(c)-(d)) se detecta un gran número de partículas pequeñas con tamaños de entre 1 y $2 \mathrm{~nm}$.

Los catalizadores fueron caracterizados por EXAFS. En la Figura VI-03 se muestra la transformada de Fourier (pesada en $k^{3}$ ) (FT) de la señal EXAFS de los catalizadores $\mathrm{Ni} / \mathrm{CZA}, \mathrm{Pt} / \mathrm{CZA}, \mathrm{y} \mathrm{PtNi} / \mathrm{CZA}$ en el borde $\mathrm{K}$ del $\mathrm{Ni}$ y $\mathrm{L}_{3}$ del $\mathrm{Pt}$ comparados al correspondiente a una lámina metálica ("foil"). De los resultados obtenidos en el borde $\mathrm{K}$ del Ni, se puede observar que las tres FT del espectro EXAFS (A, B, y C) son similares entre sí. Se puede observar la misma similitud cuando se compara Pt/CZA (E) con la lámina de Pt (D). Esto indica que ambos átomos se encuentran en estado metálico formando partículas pequeñas. En contraste, el catalizador PtNi/CZA (F) muestra una diferente FT en el borde L3 del Pt con dos picos a 2,2 y 2,6 $\AA$ aproximadamente (sin corrección de fase) indicando que los átomos de Pt están inmersos en una estructura más compleja que en el catalizador monometálico. 

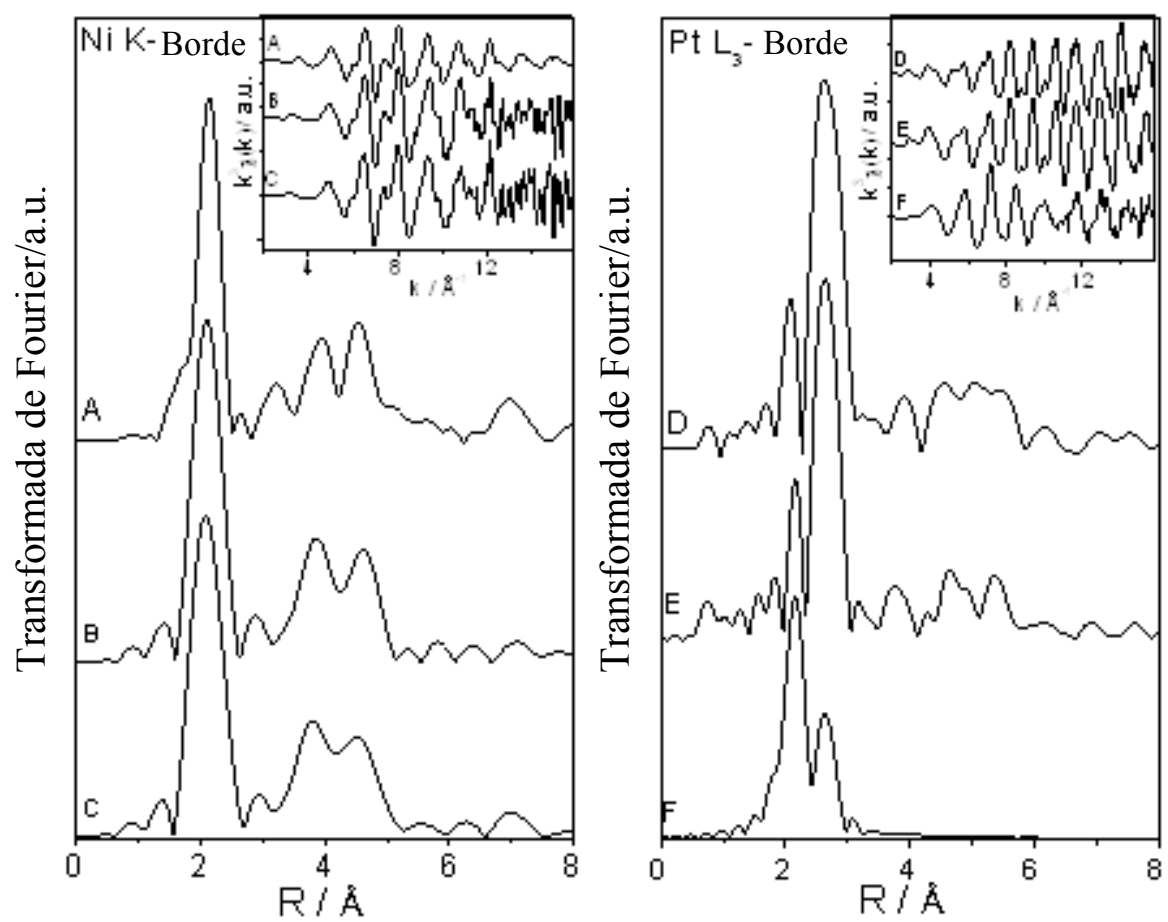

Figura VI-03. Transformada de Fourier (pesada en $k^{3}$ ) de la señal EXAFS de los catalizadores: Ni/CZA(B), Pt/CZA(E) y PtNi/CZA (C y F) junto con las láminas metálicas correspondientes (A y D). Borde K-Ni (izq.) y L3-Pt (der)

Para poder analizar cuantitativamente estos datos, los picos principales fueron aislados y ajustados utilizando los procedimientos estándares. Los estándares teóricos fueron generados con el programa FEFF [7]. En el ajuste, las distancias de enlaces, número de coordinación (NC), el factor de Debye-Waller y el parámetro E0 para cada par atómico podían variar de forma independiente. El valor del factor de atenuación $\mathrm{S}_{0}{ }^{2}=0,79$ para $\mathrm{Ni} \mathrm{y}_{0}{ }^{2}=0,93$ para $\mathrm{Pt}$ se obtuvo a partir de una lámina de $\mathrm{Ni}$ y una lámina de $\mathrm{Pt}$, respectivamente, y se mantuvo fija para todas las muestras.

Los ajustes y los parámetros estructurales obtenidos se muestran en la Figura VI-04 y la Tabla VI-01. Los espectros EXAFS en el borde $\mathrm{K}$ del Ni de Ni/CZA y PtNi/CZA fueron ajustados utilizando una sola esfera de coordinación Ni-Ni. En ambos catalizadores se observa un descenso en el número de coordinación promedio $\mathrm{Ni}-\mathrm{Ni}$ $\left(\mathrm{N}_{\mathrm{Ni}-\mathrm{Ni}} \sim 7 \pm 1\right)$ respecto del $\mathrm{Ni}$ másico $\left(\mathrm{N}_{\mathrm{Ni}-\mathrm{Ni}} \sim 12\right)$. Con un número de coordinación 7 es de esperar partículas metálicas de 1 a $2 \mathrm{~nm}$, sin embargo los resultados de TEM y DRX mostraban la presencia de partículas del orden de $17 \mathrm{~nm}$. Esto podría ser indicativo que 
Capítulo VI. Hidrogenólisis de glicerol en fase líquida con un catalizador de PtNi/CZA

la forma de la partícula de Ni no es esférica sino que adoptaría una estructura plana deformada.

Tabla VI-01. Resultados obtenidos a partir de los ajustes EXAFS para los diferentes catalizadores reducidos. NC: Número de coordinación promedio, R: distancia intraatómica, $\sigma^{2}$ : Factor de Debye-Waller

\begin{tabular}{lcccccc}
\hline Muestra & Par & NC & $\mathbf{R} / \AA$ & $\Delta \mathbf{E} / \mathbf{e V}$ & $\sigma^{2} / \AA^{\mathbf{2}}$ & r-factor \\
\hline Ni/CZA & Ni-Ni & $7,1 \pm 1$ & $2,47 \pm 0.01$ & $-3,0 \pm 0,7$ & $0,004 \pm 0,001$ & 0,003 \\
Pt/CZA & Pt-Pt & $7,2 \pm 0.4$ & $2,76 \pm 0.01$ & $1,0 \pm 0,3$ & $0,0053 \pm 0,0002$ & 0,003 \\
& Ni-Ni & $7,0 \pm 1$ & $2,48 \pm 0.01$ & $-4 \pm 2$ & $0,004 \pm 0,001$ & 0,005 \\
PtNi/CZA & Pt-Ni & $3,4 \pm 0.6$ & $2,55 \pm 0.01$ & $2 \pm 1$ & $0,006 \pm 0,001$ & 0,005 \\
& Pt-Pt & $3,8 \pm 0.9$ & $2,71 \pm 0.01$ & $3 \pm 1$ & $0,004 \pm 0,001$ & 0,005 \\
\hline
\end{tabular}

El catalizador Pt/CZA fue ajustado con una sola esfera de coordinación Pt-Pt. La existencia de átomos de Pt solamente en la vecindad del absorbedor es indicativo de que el Pt se encuentra en la forma metálica. No obstante, el número de coordinación promedio de la esfera de $\mathrm{Pt}-\mathrm{Pt}$ es de 7,2 \pm ,4, menor al valor de 12, que es el número de coordinación para el Pt másico. En este caso, y considerando los resultados TEM, es posible asumir que el bajo valor del número de coordinación se debe al tamaño de las partículas de Pt. Esta disminución respecto al másico indica la formación de partículas metálicas muy pequeñas y bien dispersas sobre el soporte. Asumiendo partículas esféricas, la estimación del tamaño medio de partícula puede realizarse mediante una correlación con el número de coordinación promedio $\mathrm{N}_{\mathrm{Pt}-\mathrm{Pt}}$, lo que resulta en un tamaño de $2 \mathrm{~nm}$ en concordancia con los resultados encontrados por TEM [8].

El espectro FT de la señal de EXAFS en el borde L3 del Pt correspondiente a la muestra de catalizador PtNi/CZA fue ajustado en la región entre los 1,5 y $3 \AA$ usando dos esferas de coordinación alrededor del Pt (una formada por átomos de Ni y otra formada por átomos de $\mathrm{Pt}$ ). 


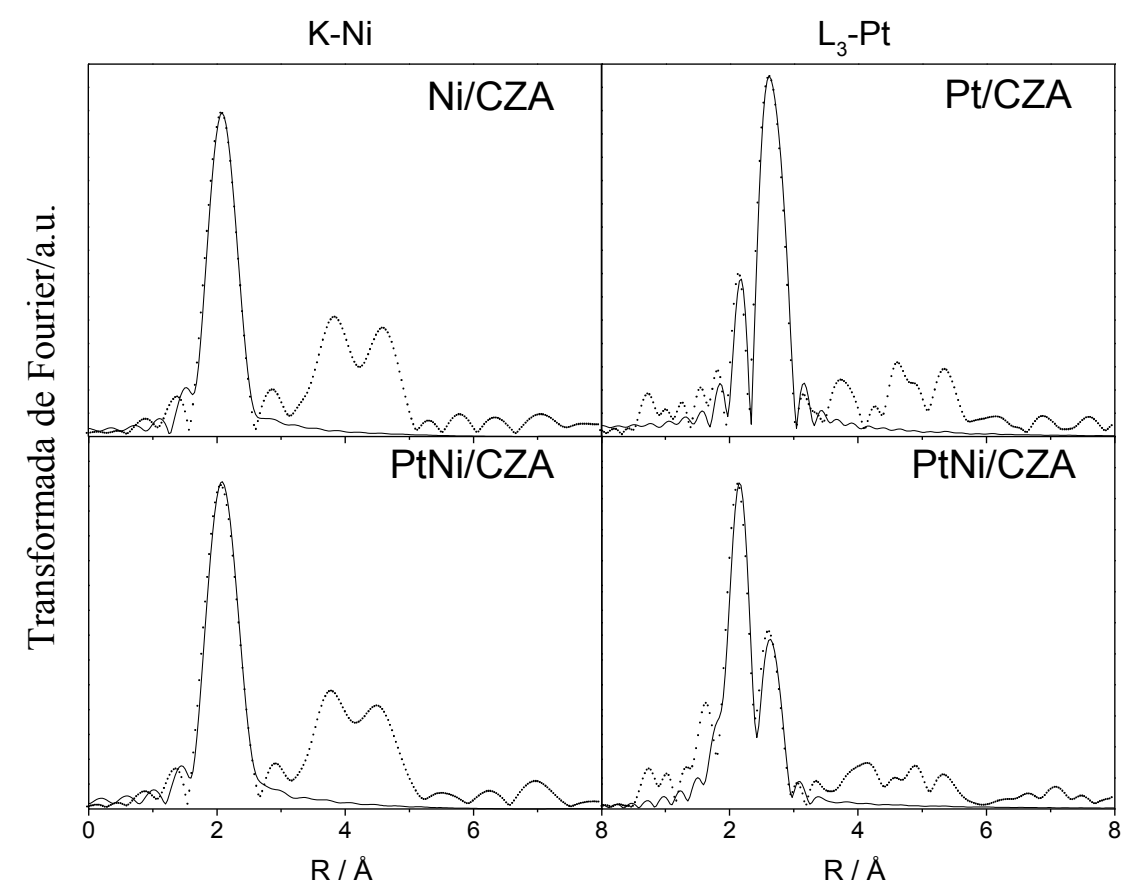

Figura VI-04. Transformada de Fourier (puntos) y ajuste EXAFS (líneas) para los catalizadores monometálicos y bimetálicos

Los resultados de los ajustes se muestran en la Tabla VI-01 y la Figura VI-04. Ambas esferas de coordinación poseen número de coordinación similar $\left(\mathrm{N}_{\mathrm{Pt}-\mathrm{Ni}} 3,4 \pm 0,6\right.$ y $\mathrm{N}_{\mathrm{Pt}-\mathrm{Pt}}$ $3,8 \pm 0,9)$ totalizando el mismo número de primeros vecinos que en $\mathrm{Pt} / \mathrm{CZA}\left(\mathrm{N}_{\mathrm{Pt}-\mathrm{Pt}}\right.$ 7,2 $\pm 0,4)$. Esto demuestra que el Pt también se encuentra bien disperso en el catalizador bimetálico. La presencia de la esfera de coordinación $\mathrm{Pt}-\mathrm{Ni}$ es una indicación de la interacción entre los dos metales debida a la formación de una aleación $\mathrm{Ni}-\mathrm{Pt}$ en la muestra. Como el método de preparación del catalizador $\mathrm{PtNi} / \mathrm{CZA}$ se realiza adicionando Pt sobre el catalizador Ni/CZA, se espera que la aleación Pt-Ni se forme en la superficie de las partículas de Ni. Además, como la cantidad de níquel es mayor a la cantidad de $\mathrm{Pt}$ (la relación atómica $\mathrm{Ni} / \mathrm{Pt}=16,5$ ), no todo el Ni puede formar aleación, y por lo tanto la mayor parte de los átomos de Ni estarán formando partículas planas monometálicas de $\mathrm{Ni}$.

Por EXAFS es difícil extraer información estructural directa a partir de los números de coordinación, sin conocer la proporción exacta de cada fase diferente presente en la muestra. Sin embargo, es posible extraer alguna conclusión comparando la relación de los diferentes números de coordinación y las distancias de enlace con las del material 
másico [9]. Para este propósito, se comparan los resultados con diferentes aleaciones $\mathrm{Ni}-\mathrm{Pt}$ de manera de estimar la aleación formada en el catalizador PtNi/CZA.

Considerando la relación atómica de $\mathrm{Ni} / \mathrm{Pt}$ en el catalizador, se puede esperar una aleación rica en $\mathrm{Ni}$. Sin embargo, también son posibles aleaciones mixtas o desordenadas, por lo que el análisis no se restringe solo a aleaciones ricas en Ni. En particular, se eligieron las aleaciones $\mathrm{Pt}_{3} \mathrm{Ni}, \mathrm{PtNi}$, y $\mathrm{PtNi}_{3}$ para el análisis de EXAFS $[10,11]$. En la aleación $\mathrm{Pt}_{3} \mathrm{Ni}$, la distancia atómica $\mathrm{Pt}-\mathrm{Ni}$ es de $2,713 \AA$, la cual es mayor que aquella obtenida para nuestros catalizadores $(2,55 \AA)$, presentando una diferencia de $0,163 \AA$ A. Aunque es de esperar una contracción de las distancias de enlace debido a la pequeña dimensión de las partículas, se ha demostrado que esta contracción puede ser de hasta $0,1 \AA$ para clusters de Pt subnanométricos a temperatura ambiente [12-15]. Sin embargo, la diferencia de $0,163 \AA$ nos permite descartar la presencia de aleación $\mathrm{Pt}_{3} \mathrm{Ni}$.

Las distancias del enlace $\mathrm{Pt}-\mathrm{Ni}$ en las otras dos aleaciones ( $\mathrm{PtNi}$ y $\mathrm{PtNi}_{3}$ ) son menores (2,662 y 2,578 $\AA$, respectivamente) y mayores que los valores obtenidos experimentalmente, pero dentro del rango de contracción esperado. Sin embargo, el valor de la distancia del enlace $\mathrm{Pt}-\mathrm{Ni}(2,55 \AA)$ es muy similar al valor de 2,578 $\AA$, indicando que la aleación con estructura: $\mathrm{PtNi}_{3}$ es la más probable en el catalizador $\mathrm{PtNi} / \mathrm{CZA}$.

En el catalizador PtNi/CZA, el número de coordinación de $\mathrm{N}_{\mathrm{Pt}-\mathrm{Pt}}(3,8 \pm 0,9)$ puede estar indicando que hay una proporción no aleada de Pt. De estos resultados se concluye que los átomos de Pt se encuentran presentes en dos fases diferentes: en una aleación $\mathrm{PtNi}_{3}$ en la superficie de las partículas de Ni y en forma no aleada y metálica. Los números de coordinación obtenidos podrían ser un promedio de los $\mathrm{N}_{\mathrm{Pt}-\mathrm{Ni}}$ y $\mathrm{N}_{\mathrm{Pt}-\mathrm{Pt}}$ de ambas fases, ponderado por la proporción de cada fase en la muestra [16]. Como la media de los números de coordinación $\mathrm{N}_{\mathrm{Pt}-\mathrm{Pt}}(3,8 \pm 0,9)$ y $\mathrm{N}_{\mathrm{Pt}-\mathrm{Ni}}(3,4 \pm 0,6)$ son similares $\mathrm{y}$ asumiendo que el tamaño de partícula es similar para el Pt aleado y no aleado, podemos concluir que la proporción de cada fase es de aproximadamente 50\%.

\section{VI.5. Resultados catalíticos}

En la Tabla VI-02 se muestran los resultados de actividad en diferentes condiciones de reacción. En condiciones favorables al reformado del glicerol, $250^{\circ} \mathrm{C}$ y 12 bar de $\mathrm{N}_{2}$ 
Capítulo VI. Hidrogenólisis de glicerol en fase líquida con un catalizador de PtNi/CZA

inicial, se observa la mayor producción de gases. Los productos gaseosos principales fueron $\mathrm{H}_{2}$ y $\mathrm{CO}_{2}$ (Figura VI-05).

Tabla VI-02. Resultados de actividad catalítica. Condiciones de reacción: solución acuosa al $10 \% \mathrm{p} / \mathrm{p}$ de glicerol, $500 \mathrm{mg}$ masa de catalizador, $2 \mathrm{~h}$ de tiempo de reacción

\begin{tabular}{|c|c|c|c|c|c|c|c|c|c|}
\hline Catalizador & $\mathrm{Ni} / \mathrm{CZA}$ & $\mathrm{Pt} / \mathrm{CZA}$ & $\mathrm{PtNi} / \mathrm{CZA}$ & $\mathrm{Ni} / \mathrm{CZA}$ & $\mathrm{Pt} / \mathrm{CZA}$ & PtNi/CZA & $\mathrm{Ni} / \mathrm{CZA}$ & $\mathrm{Pt} / \mathrm{CZA}$ & PtNi/CZA \\
\hline $\mathrm{T}\left({ }^{\circ} \mathrm{C}\right)$ & 250 & 250 & 250 & 200 & 200 & 200 & 220 & 220 & 220 \\
\hline $\mathrm{PN}_{2}$ (atm) & 12 & 12 & 12 & 12 & 12 & 12 & --- & --- & --- \\
\hline $\mathrm{PH}_{2}$ (atm) & --- & --- & --- & --- & --- & --- & 20 & 20 & 20 \\
\hline $\mathrm{X}^{\mathrm{T}}(\%)$ & 17 & 60 & 100 & $<5$ & 9 & 15 & 13 & 6 & 32 \\
\hline$X^{L}(\%)$ & 13 & 31 & 61 & $<5$ & 5 & 12 & 12 & 5,5 & 28 \\
\hline $\mathrm{SCO}_{2}(\%)$ & 28,4 & 45 & 35,2 & n.d. & 41,5 & 19 & 1,1 & 0,1 & 8 \\
\hline $\mathrm{SCH}_{4}(\%)$ & 5 & 2,6 & 9,4 & n.d. & 3,4 & 1 & 7 & 8 & 5,7 \\
\hline Smetanol (\%) & 2,2 & 1,6 & 2,2 & n.d. & 1,5 & 0,0 & 0,3 & 0,5 & 0,4 \\
\hline Setanol (\%) & 5,7 & 8,6 & 30,2 & n.d. & 4,9 & 4,4 & 2,9 & 2,9 & 1,9 \\
\hline Setilenglicol (\%) & 7 & 6,3 & 1,6 & n.d. & 7,2 & 6,8 & 10,5 & 9,5 & 17 \\
\hline Sacetona (\%) & 1,2 & 1 & 0,1 & n.d. & 0,3 & 0,0 & 1,2 & 0,0 & 1,5 \\
\hline Spropanol (\%) & 0,6 & 4,5 & 8,2 & n.d. & 0,6 & 0,0 & 0,0 & 0,4 & 0,7 \\
\hline Sacetol (\%) & 21,8 & 2,6 & 0,2 & n.d. & 6 & 7,2 & 1,9 & 2,9 & 0,2 \\
\hline Spropilenglicol (\%) & 26,6 & 25,1 & 9,7 & n.d. & 33,4 & 61,4 & 73,1 & 73 & 63,6 \\
\hline RPG (\%) & 4,5 & 15 & 9.7 & n.d. & 3 & 9,2 & 9,5 & 4,4 & 20,3 \\
\hline
\end{tabular}

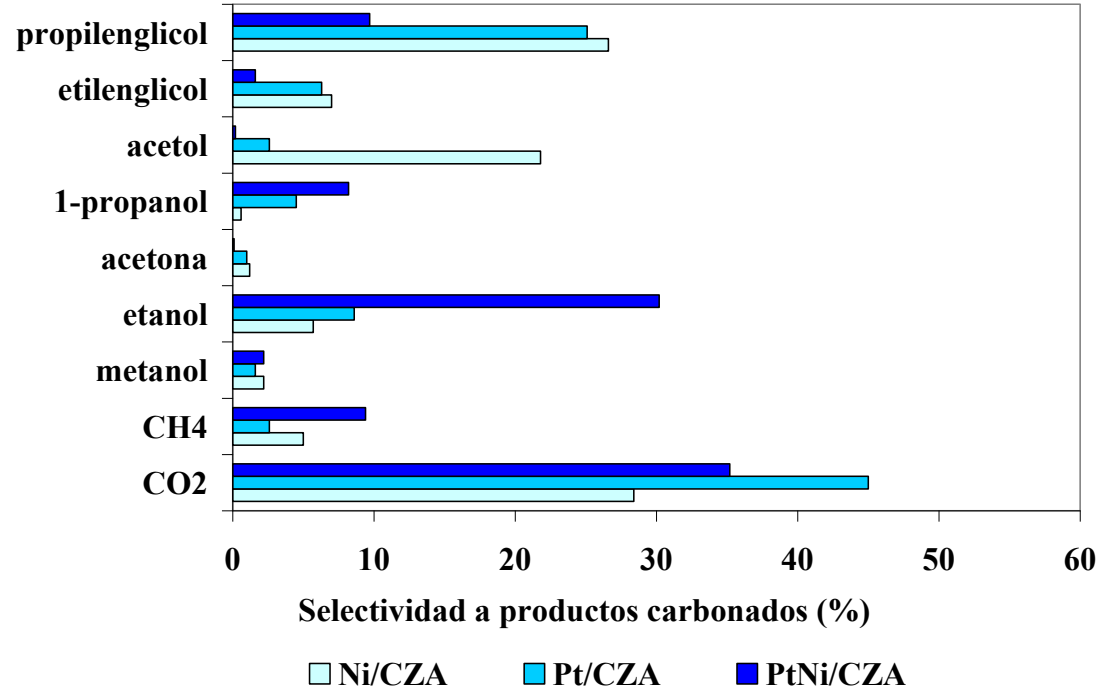

Figura VI-05. Resultados de actividad catalítica a $250{ }^{\circ} \mathrm{C}$ y 12 bar de $\mathrm{N}_{2}$ inicial

En condiciones favorables a la hidrogenólisis del glicerol, $200^{\circ} \mathrm{C}$ y 12 bar de $\mathrm{N}_{2}$, se reducen las reacciones de ruptura $\mathrm{C}-\mathrm{C}$ y los productos principales se encuentran en la fase líquida (Figura VI-06). 


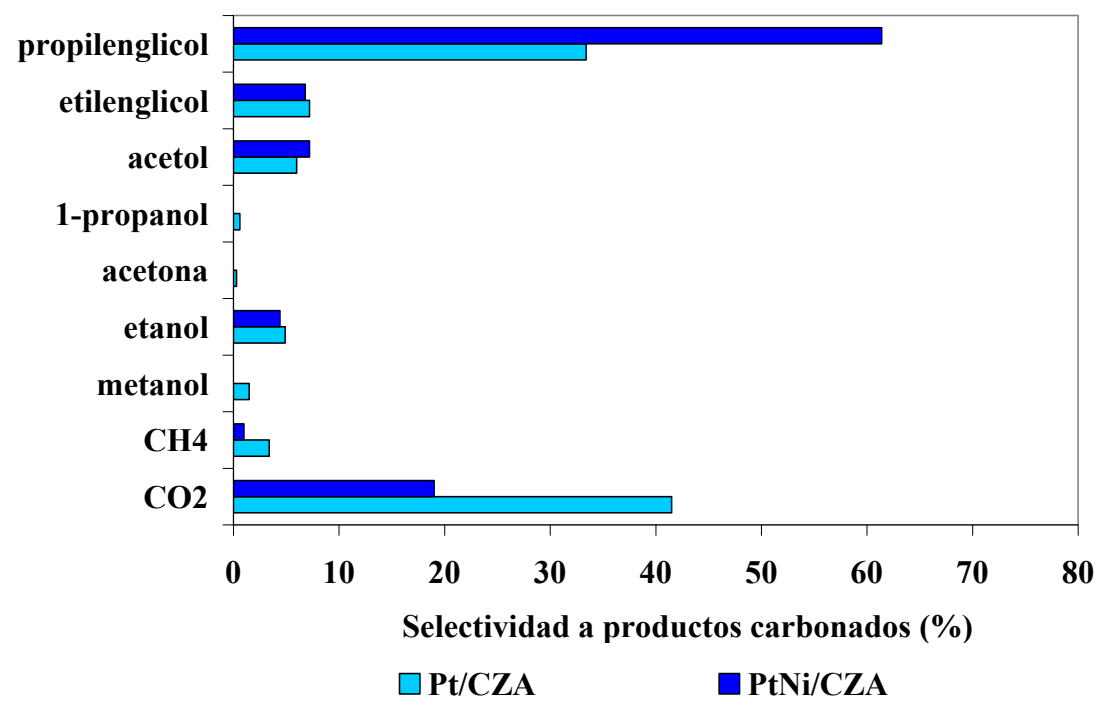

Figura VI-06. Resultados de actividad catalítica a $200{ }^{\circ} \mathrm{C}$ y 12 bar de $\mathrm{N}_{2}$ inicial

El catalizador Ni/CZA tiene muy baja conversión de glicerol en ambas condiciones $\left(\mathrm{X}^{\mathrm{T}}\right.$ $=17 \%$ y $<5 \%$, a 250 y $200^{\circ} \mathrm{C}$ respectivamente) en comparación con $\mathrm{Pt} / \mathrm{CZA}$ y $\mathrm{PtNi} / \mathrm{CZA}$.

El catalizador Pt/CZA presenta la mayor selectividad a la reacción de reformado a 200 y $250{ }^{\circ} \mathrm{C}$. Este resultado era esperable dado que se ha demostrado que el pequeño tamaño de partícula y la alta dispersión metálica del Pt favorecen las reacciones de ruptura de enlaces C-C para producir gases, como se ha visto en el Capítulo IV.

El catalizador bimetálico PtNi/CZA presenta la mayor conversión de glicerol a productos líquidos, pero además a $200{ }^{\circ} \mathrm{C}$ se observa alta Spropilenglicol $(61,4 \%)$. Para minimizar las reacciones de ruptura $\mathrm{C}-\mathrm{C}$ y promover la hidrogenólisis, se realizaron ensayos de reacción a $220^{\circ} \mathrm{C}$ y 20 atm de $\mathrm{H}_{2}$ (Tabla VI-02 y Figura VI-07). 


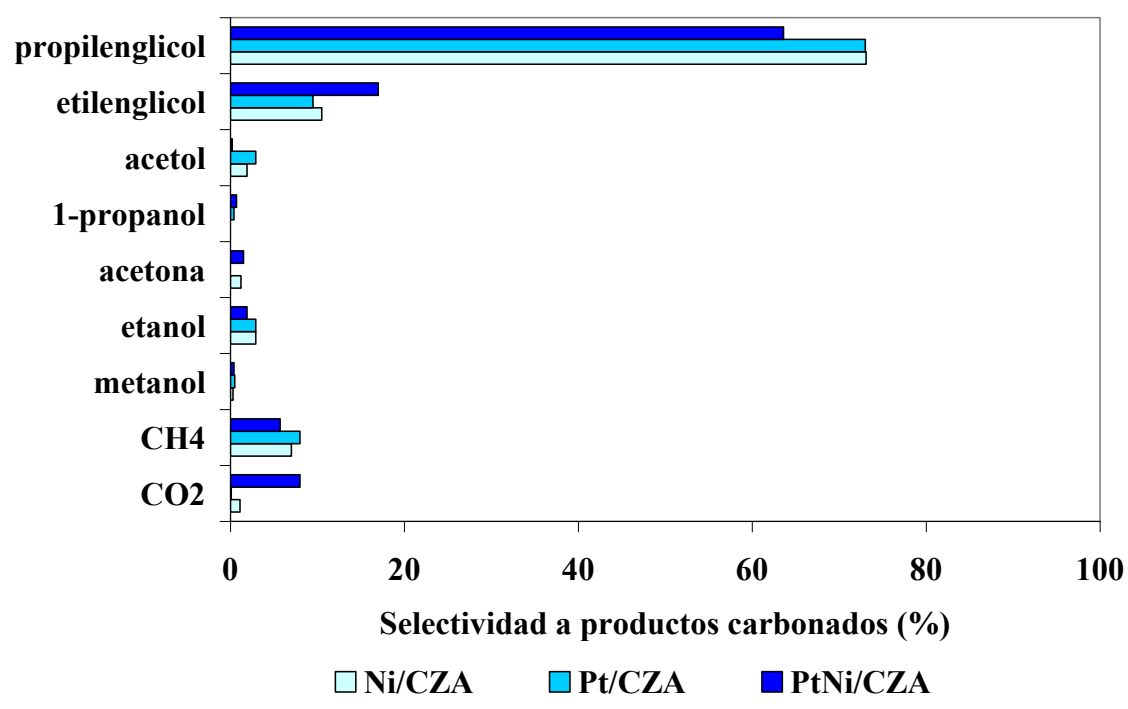

Figura VI-07. Resultados de actividad catalítica a $220{ }^{\circ} \mathrm{C}$ y 20 bar de $\mathrm{H}_{2}$ inicial

Los resultados de PtNi/CZA confirman que este catalizador promueve la formación de glicoles por hidrogenólisis de glicerol, con $32 \%$ de conversión y $80,6 \%$ de selectividad a glicoles (Spropilenglicol+Setilenglicol). Esto indicaría que las reacciones de ruptura de enlaces $\mathrm{C}-\mathrm{O}$ son favorecidas, lo que puede relacionarse con la formación de la nueva fase activa, como la aleación $\mathrm{PtNi}_{3}$ encontrada por EXAFS en el catalizador bimetálico. Estos resultados fueron comparados con los reportados por Iriondo y col. [6] y Doukkali y col. [4]. Los primeros autores [6] estudiaron el APR del glicerol en un reactor de flujo contínuo a $240{ }^{\circ} \mathrm{C}$ y 40 bar de presión; y encontraron una conversión del glicerol de $44 \%$ y una selectividad a propilenglicol de $45 \%$ para catalizadores $\mathrm{PtNi} / \gamma-\mathrm{Al}_{2} \mathrm{O}_{3}$. Estos resultados fueron mejores que los obtenidos con $\mathrm{Pt} / \gamma-\mathrm{Al}_{2} \mathrm{O}_{3}$ y lo atribuyeron a un efecto sinérgico entre Pt y Ni. Doukkali y col. [4] reportan que el catalizador de Pt promueve la producción a productos gaseosos con una mayor selectividad a $\mathrm{H}_{2}$; el catalizador de Ni es más selectivo a la formación de alcanos, y el catalizador PtNi presenta un comportamiento intermedio: moderada selectividad a $\mathrm{H}_{2}$ y a alcanos gracias al efecto cooperativo entre los dos metales.

\section{VI.6. Análisis de la estabilidad}

Debido a las severas condiciones hidrotérmicas presentes en esta reacción, es necesario evaluar la estabilidad del catalizador. Para esto, el catalizador PtNi/CZA fue utilizado en 
3 ciclos consecutivos de reacción. Cada ciclo incluye la reducción del catalizador durante 2 horas en flujo de $\mathrm{H}_{2}$, la reacción durante 2 horas a $250{ }^{\circ} \mathrm{C}$, la regeneración en flujo de aire a $500{ }^{\circ} \mathrm{C}$ durante 2 horas, y la reducción posterior en flujo de $\mathrm{H}_{2}$ a $500{ }^{\circ} \mathrm{C}$ durante 2 horas. Se eligió la temperatura de reacción de $250^{\circ} \mathrm{C}$ debido a que es la condición más severa para el sinterizado de la partícula metálica.

En la Tabla VI-03 se observan los cambios en la conversión y selectividad a través de los tres ciclos de reacción estudiados. El catalizador PtNi/CZA presenta muy pocos cambios en la conversión y selectividad $(<15 \%)$ luego del tercer ciclo, lo que indica una muy buena estabilidad de este catalizador.

Tabla VI-03. Estabilidad del catalizador PtNi/CZA. Condiciones de reacción: $250^{\circ} \mathrm{C}$, 12 bar de $\mathrm{N}_{2}$ inicial, $2 \mathrm{~h}$ de tiempo de reacción, 0,5 g de masa de catalizador, solución acuosa al $10 \% \mathrm{p} / \mathrm{p}$ de glicerol

\begin{tabular}{|c|c|c|c|}
\hline PtNi/CZA & 1er ciclo & 2 do ciclo & 3 er ciclo \\
\hline$X^{G}(\%)$ & 39 & 37 & 34 \\
\hline$X^{L}(\%)$ & 61 & 63 & 53 \\
\hline $\mathbf{X}^{\mathrm{T}}(\%)$ & 100 & 100 & 87 \\
\hline $\mathrm{SCO}+\mathrm{SCO}_{2}+\mathrm{SCH}_{4}+$ Setano & 44 & 45 & 44,5 \\
\hline \multicolumn{4}{|l|}{ Productos liquidos } \\
\hline $\mathbf{S C}_{1}$ & 2 & 1,5 & 1,6 \\
\hline $\mathrm{SC}_{2}$ & 32,1 & 16,8 & 14,8 \\
\hline $\mathrm{SC}_{3}$ & 21,9 & 36,7 & 39,1 \\
\hline
\end{tabular}




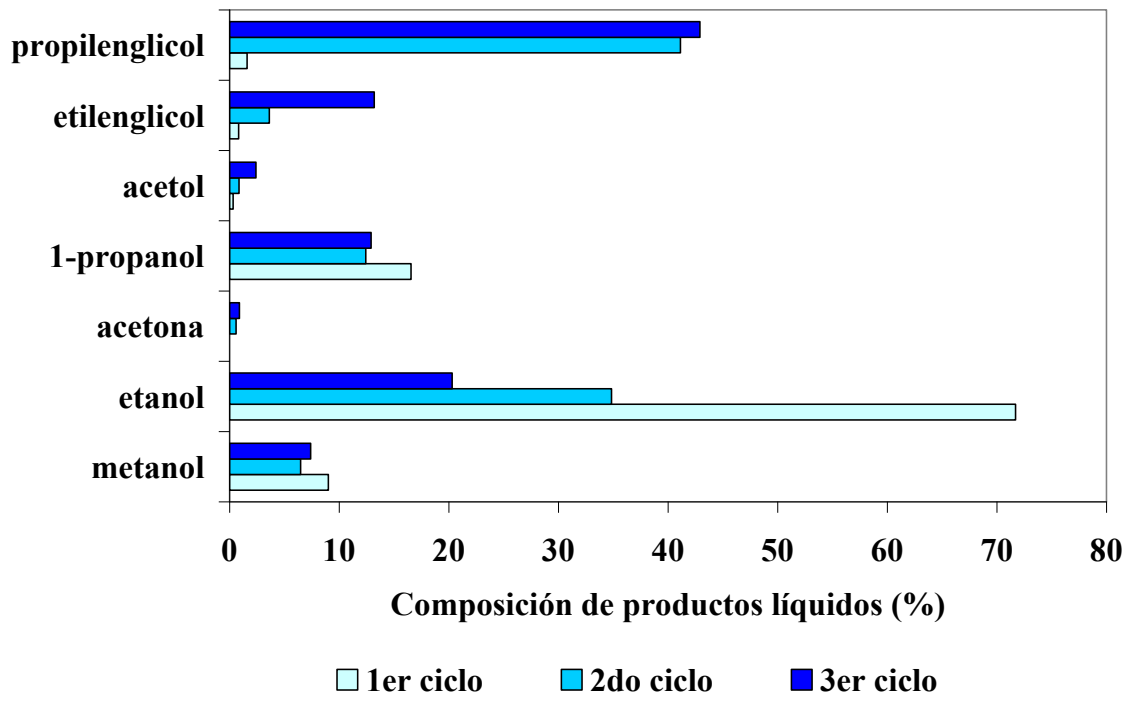

Figura VI-08. Composición molar de productos líquidos en cada ciclo. Condiciones de reacción: $250{ }^{\circ} \mathrm{C}, 12$ bar de $\mathrm{N}_{2}$ inicial, 2 h de tiempo de reacción, $0,5 \mathrm{~g}$ de masa de catalizador, solución acuosa al $10 \%$ p/p de glicerol

La Figura VI-09 muestra la transformada de Fourier (pesada en k3) de la señal de EXAFS del catalizador bimetálico PtNi/CZA en el borde $\mathrm{K}$ del Ni y el borde $\mathrm{L} 3$ del Pt luego de 1 hora, 2 horas y 3 ciclos de reacción. Los ajustes y los parámetros estructurales obtenidos se muestran en la Figura VI-10 y en la Tabla VI-04. 

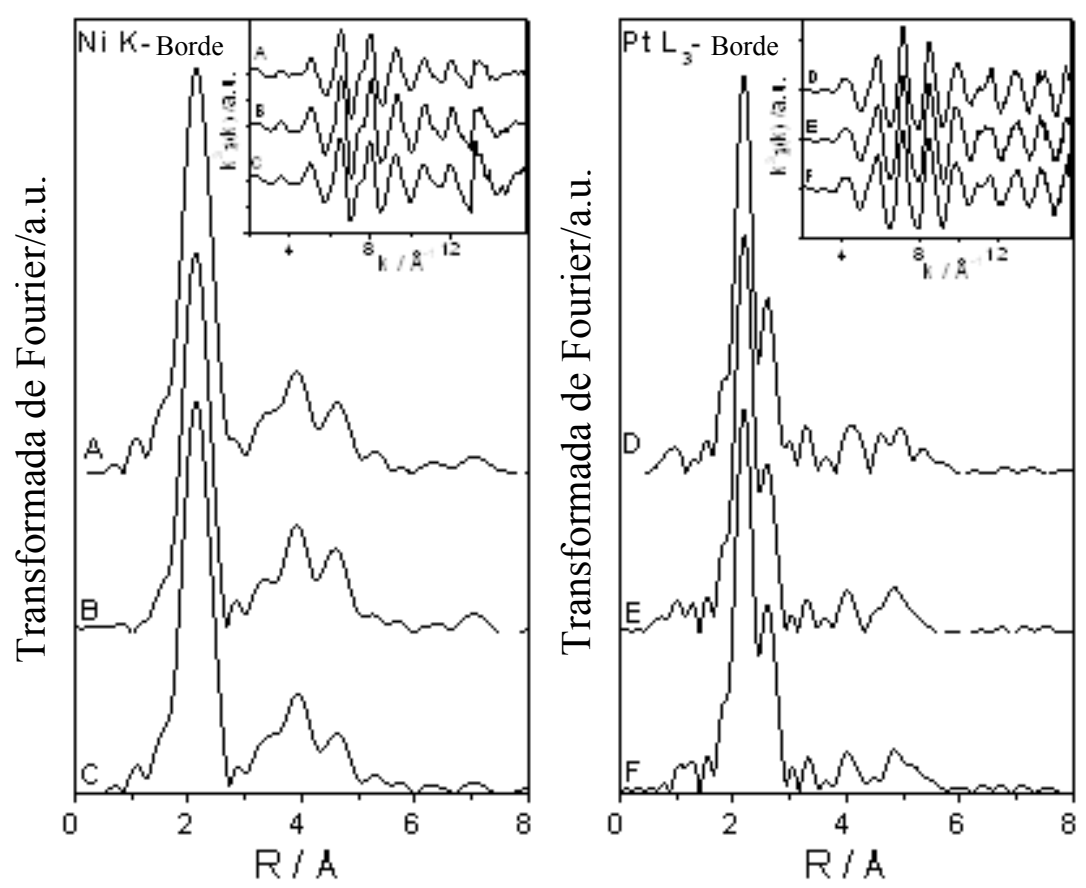

Figura VI-09. Transformada de Fourier (pesada en $k^{3}$ ) de la señal EXAFS para el catalizador bimetálico PtNi/CZA luego de 1 hora de uso (A and D), 2 horas de uso (B and $\mathrm{E}$ ) y tres ciclos (C and F). Borde K-Ni (izq.) y L3-Pt (der) 


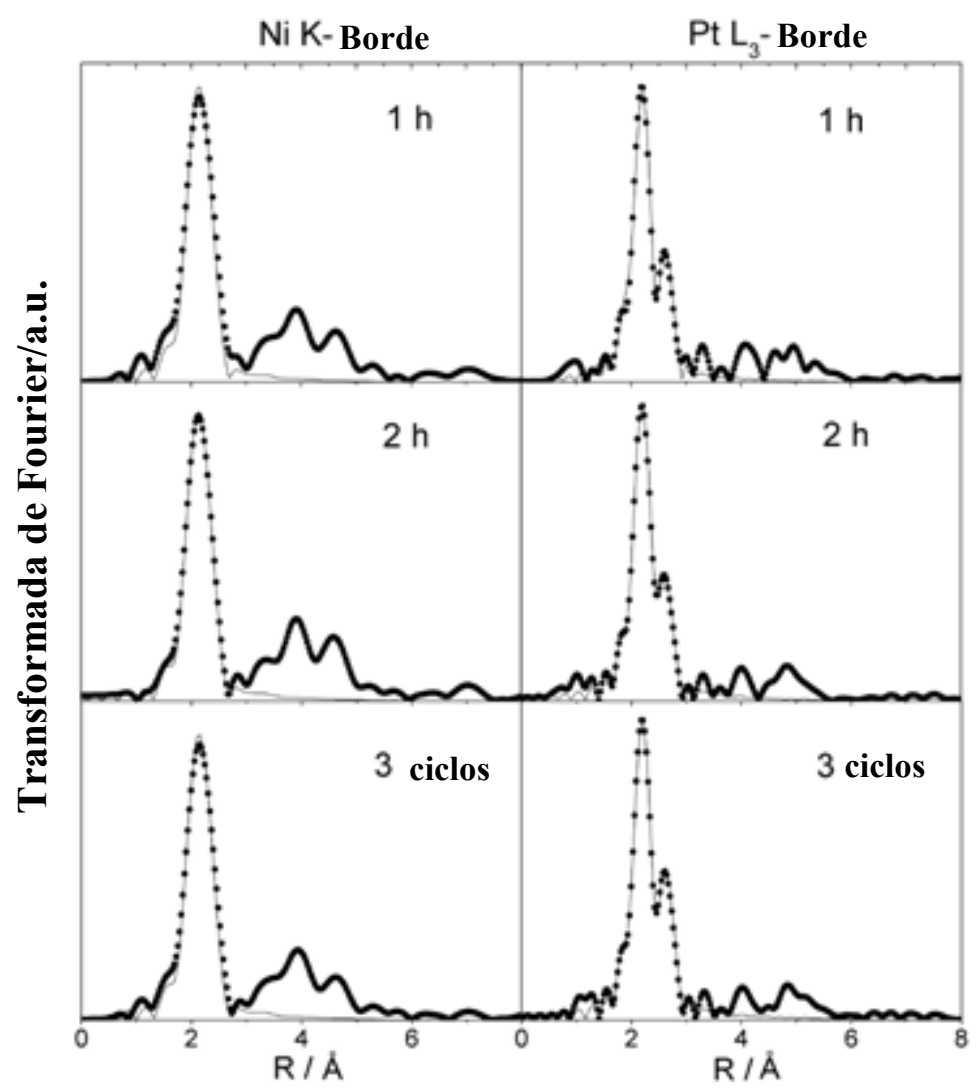

Figura VI-10. Transformada de Fourier (puntos) y ajuste EXAFS (líneas) para el catalizador PtNi/CZA usado luego de 1 hora, 2 horas de reacción y luego de tres ciclos

Al analizar los resultados de EXAFS de las muestras usadas se observan pequeños cambios en el número de coordinación promedio cuando se comparan con los obtenidos para el catalizador fresco $\mathrm{PtNi} / \mathrm{CZA}$.

Los resultados del borde $\mathrm{K}$ del $\mathrm{Ni}$ muestran un incremento en el número de coordinación de Ni-Ni. Para el borde L3 del Pt, el número de coordinación total para el $\mathrm{Pt}\left(\mathrm{N}_{\mathrm{Pt}-\mathrm{Ni}}+\mathrm{N}_{\mathrm{Pt}-\mathrm{Pt}}\right)$ es mayor que el encontrado para el catalizador fresco. En particular, se observa un incremento en el valor observado de $\mathrm{N}_{\mathrm{Pt}-\mathrm{Ni}} \mathrm{y}$ una disminución del valor de $\mathrm{N}_{\mathrm{Pt}-\mathrm{Pt}}$. Estos resultados muestran que existe un crecimiento de la fase aleada a expensas de la fase de Pt metálico segregado. 
Capítulo VI. Hidrogenólisis de glicerol en fase líquida con un catalizador de PtNi/CZA

Tabla VI-04. Resultados obtenidos a partir de los ajustes EXAFS para los catalizadores bimetálicos PtNi/ZCA fresco y usados. NC: Número de coordinación promedio, R: distancia interatómica, $\sigma^{2}$ : Factor de Debye-Waller

\begin{tabular}{lcccccc}
\hline Muestra & Par & $\mathbf{N C}$ & $\mathbf{R} / \AA$ & $\Delta \mathbf{E} / \mathbf{e V}$ & $\sigma^{2} / \AA^{2}$ & r-factor \\
\hline PtNi/CZA & $\mathrm{Ni}-\mathrm{Ni}$ & $7,0 \pm 1$ & $2,48 \pm 0,01$ & $-4 \pm 2$ & $0,004 \pm 0,001$ & 0,005 \\
fresco & $\mathrm{Pt}-\mathrm{Ni}$ & $3,4 \pm 0.6$ & $2,55 \pm 0,01$ & $2 \pm 1$ & $0,006 \pm 0,001$ & 0,005 \\
& $\mathrm{Pt}-\mathrm{Pt}$ & $3,8 \pm 0.9$ & $2,71 \pm 0,01$ & $3 \pm 1$ & $0,004 \pm 0,001$ & 0,005 \\
& $\mathrm{Ni}-\mathrm{Ni}$ & $8,6 \pm 1.6$ & $2,51 \pm 0,01$ & $-4 \pm 1$ & $0,008 \pm 0,001$ & 0,002 \\
PtNi/CZA & $\mathrm{Pt}-\mathrm{Ni}$ & $6,5 \pm 0.8$ & $2,56 \pm 0,01$ & $2 \pm 1$ & $0,0069 \pm 0,0008$ & 0,002 \\
usado 1 hora & $\mathrm{Pt}-\mathrm{Pt}$ & $2,7 \pm 0.9$ & $2,71 \pm 0,01$ & $3 \pm 2$ & $0,004 \pm 0,001$ & 0,002 \\
& $\mathrm{Ni}-\mathrm{Ni}$ & $9,4 \pm 0.9$ & $2,50 \pm 0,01$ & $-4 \pm 1$ & $0,0076 \pm 0,0008$ & 0,001 \\
& $\mathrm{Pt}-\mathrm{Ni}$ & $6,5 \pm 0.5$ & $2,56 \pm 0,01$ & $3 \pm 1$ & $0,0064 \pm 0,0004$ & 0,002 \\
PtNi/CZA & $\mathrm{Pt}-\mathrm{Pt}$ & $2,1 \pm 0.5$ & $2,70 \pm 0,01$ & $3 \pm 2$ & $0,004 \pm 0,001$ & 0,002 \\
usado 2 horas & $\mathrm{Ni}-\mathrm{Ni}$ & $8,5 \pm 1$ & $2,51 \pm 0,01$ & $-4 \pm 1$ & $0,008 \pm 0,001$ & 0,002 \\
& $\mathrm{Pt}-\mathrm{Ni}$ & $6,4 \pm 0.5$ & $2,57 \pm 0,01$ & $3 \pm 1$ & $0,0070 \pm 0,0005$ & 0,002 \\
PtNi/CZA & $\mathrm{Pt}-\mathrm{Pt}$ & $2,8 \pm 0.6$ & $2,71 \pm 0,01$ & $3 \pm 1$ & $0,0046 \pm 0,0006$ & 0,002 \\
usado 3 ciclos & & & & &
\end{tabular}

A pesar de las variaciones observadas en el número de coordinación de las muestras usadas, las distancias de enlaces $\mathrm{Pt}-\mathrm{Pt}$ y $\mathrm{Pt}-\mathrm{Ni}$ permanecen inalteradas en comparación con los catalizadores frescos. De esta manera, cuando comparamos el catalizador fresco con los catalizadores usados (1 hora, 2 horas y 3 ciclos de reacción) se puede concluir que el medio de reacción favorece la formación de la aleación $\mathrm{PtNi}_{3}$.

Para las muestras usadas, el número de coordinación promedio $\mathrm{N}_{\mathrm{Pt}-\mathrm{Pt}}$ es de 2,7 $\pm 0,9 \mathrm{y}$ $\mathrm{N}_{\mathrm{Pt}-\mathrm{Ni}}$ de 6,5 $\pm 0,8$, y asumiendo que el tamaño de partícula es similar para el Pt no aleado y el Pt aleado, entonces se puede concluir que el $70 \%$ de los átomos de Pt, aproximadamente, estaría formando aleación, mientras que el otro $30 \%$ podría estar formando nanopartículas no aleadas.

En la Tabla VI-05 se muestran los resultados obtenidos por XPS para el catalizador $\mathrm{PtNi} / \mathrm{CZA}$ fresco y usado luego de $1 \mathrm{~h}$. En esta tabla se muestran las energías de enlace (BE) de los orbitales Pt 4f $\mathrm{f}_{7 / 2}$, Ni $2 \mathrm{p}_{3 / 2}$, Ce $3 \mathrm{~d}_{5 / 2}, \mathrm{Zr} 3 \mathrm{~d}_{5 / 2}$, y Al $2 \mathrm{p}$. Los espectros XPS se muestran en el Anexo III. 
Capítulo VI. Hidrogenólisis de glicerol en fase líquida con un catalizador de PtNi/CZA

Tabla VI-05. Caracterización por XPS. Energías de enlace $(\mathrm{eV})$ y relaciones atómicas superficiales para los catalizadores $\mathrm{PtNi} / \mathrm{CZA}$ fresco y usado

\begin{tabular}{|c|c|c|}
\hline Catalizador & PtNi/CZA fresco & $\begin{array}{c}\text { PtNi/CZA } \\
\text { usado luego de 1hora } \\
\text { de reacción* }\end{array}$ \\
\hline $\operatorname{Pt} 4 f_{7 / 2} \quad(e V)$ & 70,9 & 70,9 \\
\hline $\mathrm{Ni} 2 \mathbf{p}_{3 / 2}(\mathrm{eV})$ & $\begin{array}{c}851,8\left(\mathrm{Ni}^{0}, 73 \%\right) \\
855,3\left(\mathrm{Ni}^{+2}, 27 \%\right)\end{array}$ & $\begin{array}{c}851,8\left(\mathrm{Ni}^{0}, 75 \%\right) \\
855,2\left(\mathrm{Ni}^{+2}, 25 \%\right)\end{array}$ \\
\hline $\operatorname{Ce~} 3 d_{5 / 2}(e V)$ & $\begin{array}{c}881,2\left(\mathrm{v}^{0}\right) \\
885,0\left(\mathrm{v}^{\prime}\right) \\
916,2\left(\mathrm{u}^{\prime \prime \prime}, 2 \%\right)\end{array}$ & $\begin{array}{c}881,1\left(\mathrm{v}^{0}\right) \\
885,3\left(\mathrm{v}^{\prime}\right) \\
916,6\left(\mathrm{u}^{\prime \prime \prime}, 3 \%\right)\end{array}$ \\
\hline $\operatorname{Zr} 3 d_{5 / 2}(e V)$ & 181,7 & 181,6 \\
\hline Al 2p (eV) & 73,9 & 73,9 \\
\hline $\begin{array}{l}\text { Ni/Pt } \\
\text { (bulk) }\end{array}$ & $\begin{array}{l}0,436 \\
(16,6)\end{array}$ & 0,8890 \\
\hline $\begin{array}{l}\mathrm{Ni} /(\mathrm{Al}+\mathrm{Ce}+\mathrm{Zr}) \\
\text { (bulk) }\end{array}$ & $\begin{array}{c}0,0089 \\
(0,0450)\end{array}$ & 0,0095 \\
\hline $\begin{array}{l}\mathrm{Pt} /(\mathrm{Al}+\mathrm{Ce}+\mathrm{Zr}) \\
\text { (bulk) }\end{array}$ & $\begin{array}{c}0,0204 \\
(0,0027)\end{array}$ & 0,0107 \\
\hline
\end{tabular}

* luego de la reacción fue secado, calcinado y reducido en flujo de $\mathrm{H}_{2} / \mathrm{Ar}$ in situ

Como ya se indicó para este soporte en el Capítulo IV, la aparición de una fuerte interacción entre el cerio y la zirconio se evidencia en la disminución del valor de $\mathrm{BE}$ del $\mathrm{Zr} 3 \mathrm{~d}_{5 / 2}(181,6-181,8 \mathrm{eV})$ con respecto al valor para $\mathrm{ZrO}_{2}$ de $182,5 \mathrm{eV}$ que se reporta en bibliografía [17]. La región de Ce 3d muestra la presencia de los estados de oxidación $\mathrm{Ce}^{4+} \mathrm{y} \mathrm{Ce}^{3+}$. Debido a que el pico $\mathrm{u}^{\prime \prime \prime}$ indica exclusivamente $\mathrm{Ce}^{4+}$, puede usarse como medida cuantitativa de la cantidad $\mathrm{de} \mathrm{Ce}^{4+}$, y la diferencia cuantifica el $\mathrm{Ce}^{3+}$. Como ha sido indicado en bibliografía, si todo el Ce se encuentra como $\mathrm{Ce}^{+4}$, el área integrada del pico $\mathrm{u}^{\prime \prime \prime}$ con respecto al área total del Ce $3 \mathrm{~d}$ constituye alrededor del $14 \%$ de la intensidad total [18].

Para el catalizador PtNi/CZA en la región correspondiente al $\mathrm{Pt} 4 \mathrm{f}_{7 / 2}$ a $70,9 \mathrm{eV}$, aparece un pico indicando la completa reducción del platino. El espectro de $\mathrm{Ni} 2 \mathrm{p}_{3 / 2}$ consiste en $\mathrm{Ni}^{0}$ y $\mathrm{Ni}^{2+}$, dado que el proceso de reducción llevado a cabo (en la cámara de 
pretratamiento del equipo de XPS a $400{ }^{\circ} \mathrm{C}$ en flujo de $\mathrm{H}_{2} 5 \% / \mathrm{Ar}$ ) no resulta en una reducción completa del níquel.

Las relaciones atómicas superficiales determinadas por XPS muestran una marcada disminución de los átomos de Pt en la superficie en la muestra usada respecto de la muestra fresca, (de 0,0107 a 0,0204, respectivamente). Las micrografías TEM (Anexo III) del catalizador usado luego de $1 \mathrm{~h}$ de reacción de PtNi/CZA corrobora este resultado de XPS, ya que se nota la disminución en la cantidad de partículas de Pt menores a $2 \mathrm{~nm}$.

Esta disminución puede ser debido a una difusión de los átomos de Pt hacia el núcleo de las partículas de Ni dando como consecuencia mayor cantidad de aleación, lo cual es compatible con el incremento observado del número de coordinación $\mathrm{N}_{\mathrm{Pt}-\mathrm{Ni}}$ en todas las muestras usadas.

Si se comparan las muestras usadas, se observa que todos los números de coordinación promedios permanecen inalterados Tabla VI-03, lo que estaría indicando que los cambios ocurren principalmente en las primeras horas de reacción del primer ciclo (Figuras VI-09 y VI-10). Estos resultados explicarían la estabilidad catalítica evidenciada en los resultados de la Tabla VI-03.

Los resultados EXAFS confirman la presencia de la aleación $\mathrm{PtNi}_{3}$ en la superficie de las partículas de $\mathrm{Ni}$, las cuales conferirían estabilidad al catalizador $\mathrm{PtNi} / \mathrm{CZA}$ en la reacción en fase liquida del glicerol. Los cambios se producen al inicio de la reacción para luego alcanzar un estado estable debido a que posteriormente los cambios estructurales son menores.

\section{VI.7. Conclusiones del capítulo}

En este capítulo se estudiaron catalizadores de $\mathrm{Pt}$ y $\mathrm{Ni}$ soportados sobre $\alpha-\mathrm{Al}_{2} \mathrm{O}_{3}$ modificado con $\mathrm{CeO}_{2}$ y $\mathrm{ZrO}_{2}$ en la conversión catalítica en fase líquida del glicerol. Se ha realizado la caracterización por EXAFS, XPS y DRX con el objetivo de identificar la estructura de las fases metálicas en el catalizador PtNi/CZA.

El catalizador monometálico $\mathrm{Ni} / \mathrm{CZA}$ presentó baja actividad, a diferencia del catalizador Pt/CZA el cual mostró buena actividad para el reformado del glicerol, $\left(\mathrm{SCO}_{2}: 45 \%\right)$. El catalizador bimetálico PtNi/CZA presentó la mayor actividad para la 
hidrogenólisis del glicerol al promover la formación de hidrocarburos líquidos oxigenados, principalmente acetol, etilenglicol y 1,2-propilenglicol.

Se determinó por EXAFS que en el catalizador bimetálico PtNi/CZA, se encuentran presentes tres fases: el Ni se encuentra principalmente como nanopartículas metálicas, al menos el 50\% de los átomos de Pt se encuentran formando nanopartículas de aleación $\mathrm{PtNi}_{3}$ sobre la superficie de las partículas de Ni más grandes y el 50\% restante de los átomos de $\mathrm{Pt}$ permanecen sin alear con una alta dispersión formando pequeñas nanopartículas.

Teniendo en cuenta los resultados catalíticos, la mayor actividad que presentó el catalizador $\mathrm{PtNi} / \mathrm{CZA}$ se le asignó a la presencia de aleación $\mathrm{PtNi}_{3}$ que resultó en una fase más activa que el Pt y el Ni en sitios separados. La mayor estabilidad encontrada para el catalizador PtNi/CZA puede ser asociada a la presencia de estas nanopartículas de aleación $\mathrm{PtNi}_{3}$ con baja movilidad. El catalizador alcanzó un estado estable durante las primeras horas de reacción, para luego presentar un pequeño aumento en los tamaños de partícula así también como un incremento en la cantidad de aleación presente. Esta fase metálica $\mathrm{PtNi}_{3}$ se mantiene luego de tres ciclos completos de reacción acompañado de niveles de conversión y selectividad estables.

\section{VI.8. Referencias}

[1] King D, Zhang L, Xia G, Karim A, Heldebrant D, Wang X, Peterson T, Wang Y. Applied Catalysis B: Environmental 99 (2010) 206-213

[2] Zhang L, Karim AM, Engelhard MH, Wei Z, King DL, Wang Y. Journal of Catalysis 287 (2012) 37-43

[3] Iriondo A, Cambra JF, Barrio VL, Guemez MB, Arias PL, Sanchez-Sanchez MC, Navarro RM, Fierro JL. Applied Catalysis B: Environmental 106 (2011) 83-93

[4] Doukkali ME, Iriondo A, Arias PL, Requies J, Gandarías I, Jalowiecki-Duhamel L, Dumeignil F. Applied Catalysis B: Environmental 125 (2012) 516-529

[5] Pompeo F; Gazzoli D; Nichio N N. Materials Letters 63 (2009) 477-479

[6] A Iriondo, J Cambra, V Barrio, M Guemez, P Arias, M Sanchez-Sanchez. Applied Catalysis B: Environmental 106 (2011) 83-93

[7] Wijnen PWJG, Van Zon FBM, Koningsberger DC. Journal of Catalysis 114 (1988) $463-468$ 
[8] Frenkel AI, Hills CW, Nuzzo RGA. The Journal of Physical Chemistry B 105 (2001) 12689-12703

[9] Frenkel AI, Yevick A, Cooper C, Vasic R.. Annual Review of Analytical Chemistry 4 (2011) 23-39

[10] Leroux C, Cadeville MC, Pierron-Bohnes V, Inden G, Hinz F. Journal of Physics F: Metal Physics18 (1988) 2033-2051

[11] Okamoto H. Journal of Phase Equilibria and Diffusion 31 (2010) 322

[12] Wijnen PWJG, Van Zon FBM, Koningsberger DC. Journal of Catalysis 114 (1988) $463-468$

[13] Kang JH, Menard LD, Nuzzo RG, Frenkel AI. Journal of the American Chemical Society 128 (2006) 12068-12069

[14] Bus E, Miller JT, Kropf AJ, Prins R, van Bokhoven JA. Physical Chemistry Chemical Physics 8 (2006) 3248-3258

[15] Lei Y, Jelic J, Nitsche L, Meyer R, Miller J. Topics in Catalysis 54 (2011) 334-348

[16] Frenkel AZ. Kristallografiya 222 (2007) 605-611

[17] Nelson A, Schulz K. Applied Surface Science 210 (2003) 206-221

[18] Shyu J, Otto K, Watkins W, Graham G, Belitz R, Gandhi HJ. Catalysis 114 (1988) $23-33$ 


\section{Capítulo VII}

\section{Conclusiones y perspectivas}




\section{Capítulo VII. Conclusiones y perspectivas}

\section{VII.1. Conclusiones generales}

En los últimos años ha crecido notablemente el interés y las contribuciones científicas dirigidas a la producción de hidrógeno y productos de alto valor a partir de materias primas provenientes de biomasa. Sin embargo, aún no se ha alcanzado el nivel de conocimiento que permita una aplicación tecnológica industrial, lo que indica que hay que continuar profundizando los estudios en esta temática.

La conversión de biomasa requiere de varias etapas. Primero resultan necesarias etapas de extracción y obtención de una corriente acuosa de hidrocarburos oxigenados o carbohidratos a partir del recurso de biomasa. Posteriormente esta corriente constituirá la alimentación para las reacciones catalíticas. El procesamiento de materias primas provenientes de biomasa implica además un desafío en el área de desarrollo de catalizadores debido a la alta funcionalidad que poseen estas moléculas, sumado al mayor contenido de impurezas presentes en estas materias primas. Esta alta funcionalidad le proporciona baja volatilidad, alta reactividad y usualmente pueden ser procesados con tecnologías en fase líquida.

En este trabajo de Tesis se han estudiado reacciones en fase líquida para la obtención de hidrógeno y biopropilenglicol a partir del glicerol, poniendo especial énfasis en el desarrollo de catalizadores metálicos soportados.

Del estudio de la reactividad de diferentes alcoholes frente a un catalizador de Pt, se determinó que el metanol y etanol son alcoholes muy poco reactivos en condiciones del APR a temperaturas entre 200 y $250^{\circ} \mathrm{C}$; mientras que el etilenglicol, acetol y propilenglicol tienen mayor reactividad y resulta similar entre ellos. En el APR del etilenglicol se observó la mayor selectividad a las reacciones de ruptura C-C y en consecuencia la mayor selectividad al reformado $\left(\mathrm{SCO}_{2}=85 \%\right)$. Estos resultados nos permiten concluir que la ruta para la producción de $\mathrm{H}_{2} \mathrm{y} \mathrm{CO}_{2}$ en el APR del glicerol es vía la obtención de etilenglicol como producto intermediario. El acetol es un producto lateral derivado de reacciones de ruptura $\mathrm{C}-\mathrm{O}$ y principal producto intermediario para la obtención de propilenglicol. 


\section{Capítulo VII. Conclusiones y perspectivas}

De esta manera se observa que el proceso de reformado presenta una clara competencia entre los caminos de producción de $\mathrm{H}_{2} \mathrm{y} \mathrm{CO}_{2} \mathrm{y}$ los caminos laterales para formar productos líquidos.

A partir de este estudio del APR de glicerol para obtener hidrógeno, utilizando catalizadores de Pt soportados, se determinó que el mayor efecto sobre la actividad lo tiene el tamaño de partícula metálica. El menor tamaño de la partícula metálica favorece el anclaje y ruptura de los enlaces $\mathrm{C}-\mathrm{C}$, por sobre los enlaces $\mathrm{C}-\mathrm{O}$ y reacciones de hidrogenación.

El efecto de la acidez del soporte no se puso en evidencia en las condiciones de reacción APR. Mientras que las propiedades redox del soporte tuvieron un rol importante en la promoción de la reacción de WGS. El catalizador $\mathrm{Pt} / \mathrm{CZA}$ resultó el más activo $\left(\mathrm{X}^{\mathrm{G}}=\right.$ $29 \%$ ), con la mayor selectividad al reformado $\left(\mathrm{SCO}_{2}=45 \%\right)$ y el mayor rendimiento a $\mathrm{H}_{2}$ (Rendimiento $\mathrm{H}_{2}=20 \%$ ). La presencia de átomos de $\mathrm{Pt}^{0}, \mathrm{Ce}^{+3} \mathrm{y} \mathrm{Zr}^{+4}$ confirmados por XPS, permiten explicar el rol del soporte en la reacción de WGS.

La caracterización por TEM, Raman y XPS del catalizador Pt/CZA fresco y usado permitió determinar que la principal causa de la desactivación observada es la sinterización inicial que sufren las partículas de Pt y la quimisorción de productos laterales de reacción. El catalizador $\mathrm{Pt} / \mathrm{CZA}$ puede ser regenerado, recuperando la actividad de los sitios bloqueados por la quimisorción de productos laterales pero con cierta pérdida de superficie metálica debido al sinterizado.

Es de destacar que en las condiciones APR el reactor opera con presión de hidrógeno que favorece las reacciones de hidrogenólisis. Esto se evidencia por la presencia de propilenglicol como subproducto mayoritario, el cual resulta de gran interés comercial. En este sentido, tanto el catalizador PtSi como Pt/CZA resultaron activos para la hidrogenólisis del glicerol.

Para maximizar la producción de propilenglicol, esta Tesis planteó el diseño de catalizadores que sean selectivos a la ruptura de enlaces $\mathrm{C}-\mathrm{O}$ e hidrogenaciones frente a la ruptura C-C. El estudio de catalizadores de Pt modificados por Sn permitió demostrar que la adición de $\operatorname{Sn}$ (entre 0,12 y $0,4 \%$ ) empleando una técnica de preparación controlada derivada de la Química Organometálica de Superficies sobre un catalizador de PtSi, mejora fuertemente la actividad y selectividad en la hidrogenólisis del glicerol para obtener propilenglicol.

El mayor rendimiento fue obtenido con el catalizador PtSn0.2. Para mayores contenidos de $\mathrm{Sn}$, el descenso en la actividad se relacionó con la reducción de sitios de Pt 


\section{Capítulo VII. Conclusiones y perspectivas}

accesibles. La presencia de Sn iónico actuando como un sitio ácido de Lewis y el Pt con mayor densidad electrónica, conducen a un sitio favorable para la adsorción del C-OH y subsiguiente ruptura C-O, que es el paso inicial en la producción de propilenglicol.

Finalmente se estudiaron catalizadores bimetálicos de Pt y Ni soportados sobre $\alpha-\mathrm{Al}_{2} \mathrm{O}_{3}$ modificada con $\mathrm{CeO}_{2}$ y $\mathrm{ZrO}_{2}$ en la conversión catalítica del glicerol en fase líquida. El catalizador bimetálico PtNi/CZA presentó mayor actividad para la hidrogenólisis del glicerol ya que promueve la formación de acetol y propilenglicol. Se determinó por EXAFS que en este catalizador bimetálico $\mathrm{PtNi} / \mathrm{CZA}$, se encuentran presentes tres fases: Ni principalmente como nanopartículas metálicas, Pt que se encuentra formando nanopartículas de aleación $\mathrm{PtNi}_{3}$ sobre la superficie de las partículas de $\mathrm{Ni}$ más grandes y Pt que permanece sin alear, con una alta dispersión y formando pequeñas nanopartículas. Teniendo en cuenta los resultados catalíticos, la mayor actividad que presenta el catalizador $\mathrm{PtNi} / \mathrm{CZA}$ se asignó a la presencia de aleación $\mathrm{PtNi}_{3}$ que resultó en una fase más activa que Pt y Ni en sitios separados. Se demostró a través de Raman que las muestras usadas no presentan depósitos carbonosos y por TEM se observó un crecimiento de la partícula metálica durante la primera hora de reacción. La mayor estabilidad encontrada para el catalizador $\mathrm{PtNi} / \mathrm{CZA}$ pudo ser asociada a la presencia de estas nanopartículas de $\mathrm{PtNi}_{3}$ con baja movilidad. Esta fase metálica permaneció inalterable luego de tres ciclos completos de reacción acompañado de niveles de conversión y selectividad estables.

\section{VII.2. Perspectivas}

La selección del soporte es un desafío para reacciones en fase acuosa, de modo de evitar sus transformaciones y en consecuencia el sinterizado de la fase metálica. Hay que destacar las severas condiciones hidrotérmicas que esta reacción impone a los catalizadores sumergidos en agua caliente y con elevadas presiones. En esta dirección, se propone como perspectiva el estudio de catalizadores metálicos soportados en un material más estable: un soporte composito de $\mathrm{SiO}_{2}-\mathrm{C}$, preparado a partir de la cogelificación de una resina fenólica y silicato de etilo prehidrolizado (TEOS). Este soporte presenta una estrecha distribución de tamaño de poro en la región meso-porosa y la presencia de $\mathrm{SiO}_{2}$ en la red carbonosa los estabilizaría, propiedades que podrían 
aprovecharse para el procesamiento de biomasa en condiciones de fase líquida a presión.

Respecto de la naturaleza del metal, $\mathrm{Ni}$ y $\mathrm{Cu}$ presentan mayor capacidad para la ruptura $\mathrm{C}-\mathrm{O}$ que el $\mathrm{Pt}$, por lo que resultarían interesantes considerando su menor costo para estudiar la producción de Propilenglicol.

Pensando en una aplicación tecnológica, también se debería investigar el efecto de altas concentraciones de glicerol, considerando que el glicerol crudo obtenido del proceso de biodiesel tiene una concentración próxima al 80\%.

Por último, es necesario considerar que la presencia de impurezas habituales en las materias primas provenientes de biomasa pueden provocar desactivación en los catalizadores empleados. El glicerol crudo contiene 5\% de sales (Cloruros y Sulfatos) y $3 \%$ de MONG (materia orgánica no glicerol). Estas impurezas podrían ser venenos para los catalizadores metálicos y deberían ser estudiados. 
Anexo I

Protocolo operativo de la preparación de catalizadores bimetálicos PtSn 
Anexo I. Protocolo operativo de la preparación de catalizadores bimetálicos PtSn

\begin{abstract}
AI.1. Preparación de $\mathrm{PtSn} / \mathrm{SiO}_{2}$ por reacción entre $\mathrm{SnBu}_{4}$ y el catalizador monometálico $\mathrm{Pt} / \mathrm{SiO}_{2}$ en estado reducido
\end{abstract}

Para la preparación de los catalizadores $\mathrm{PtSn} / \mathrm{SiO}_{2}$ se utilizó el equipo que se muestra en la Figura AI-01.

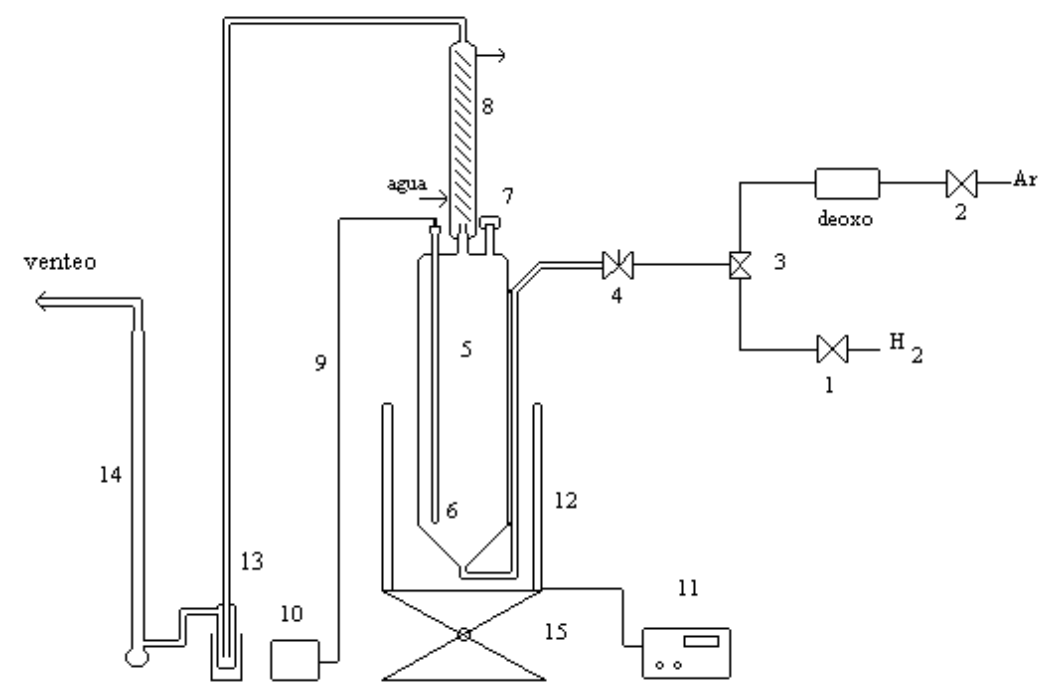

Figura AI-01. Esquema del equipo de preparación de los catalizadores bimetálicos

Referencias:

1- Válvula ON-OFF de línea de $\mathrm{H}_{2}$

2- Válvula ON-OFF de línea de Ar

3- Válvula de tres vías

4- Válvula aguja

5- Reactor

6- Vaina para termocupla

7- Inyección y toma de muestra de reactivos

8- Refrigerante

9- Termocupla

10- Indicador de temperatura

11- Controlador de temperatura 
12- Horno calefactor

13- Trampa de retención de gases

14- Caudalímetro de burbuja

15- Mesa criquet

El sistema consta de un reactor de vidrio, un horno calefactor con control de temperatura y entrada de gases $\left(\mathrm{H}_{2} \mathrm{o} \mathrm{Ar}\right)$ para mantener en todo momento el sistema en atmósfera controlada. El reactor además está provisto de un refrigerante para evitar la evaporación del solvente y mantener el reflujo del mismo durante la reacción y una trampa de n-heptano a una temperatura de $\left(-78^{\circ} \mathrm{C}\right)$ para la recolección de los gases desprendidos durante la preparación.

\section{Modo operatorio:}

\section{AI.1.1. Reducción del catalizador monometálico}

El catalizador $\mathrm{Pt} / \mathrm{SiO}_{2}$ obtenido luego de las etapas de intercambio, lavado y secado, Se cargó en el reactor y se hizo pasar Ar para barrer el $\mathrm{O}_{2}$ del sistema durante 30 minutos. Luego se hizo circular $\mathrm{H}_{2}$ para comenzar la etapa de reducción con una velocidad de calentamiento de $10^{\circ} \mathrm{C}$ por minuto hasta $500^{\circ} \mathrm{C}$. Luego de 2 horas se enfrió hasta temperatura ambiente, siempre en atmósfera de $\mathrm{H}_{2}$.

\section{AI.1.2. Reacción entre $\mathrm{SnBu}_{4}$ y Pt/SiO}

El solvente utilizado en esta reacción fue n-heptano cuando la temperatura de la reacción fue $90^{\circ} \mathrm{C}$ y n-decano cuando fue $120^{\circ} \mathrm{C}$ y $150^{\circ} \mathrm{C}$. El solvente utilizado se desoxigenó haciendo burbujear Ar y se agregó zeolita 4A para deshidratarlo. Luego, se cargaron $20 \mathrm{~mL}$ de solvente en el reactor y se mantuvo en esta condición durante 30 min. Posteriormente se agregóal reactor la cantidad deseada de $\mathrm{SnBu}_{4}$ y tetradecano como patrón interno a temperatura ambiente y siempre en atmósfera de $\mathrm{H}_{2}$ y se dejó reaccionar durante 6 horas, controlando el progreso de la reacción cromatograficamente. Una vez finalizada la reacción, se extrajo con jeringa el resto de solución de $\mathrm{SnBu}_{4} \mathrm{y}$ tetradecano en solvente y se lavó el catalizador con porciones de solvente durante 30 minutos. Además se tomaron muestras del solvente contenido en la trampa para retener 
$\mathrm{BuH}$, las que se analizaron cromatográficamente con el fin de determinar la cantidad de $\mathrm{BuH}$ desprendido durante la reacción. La última etapa fue el secado en atmósfera de Ar durante $5 \mathrm{~h}$ a $90^{\circ} \mathrm{C}$.

El cálculo de la concentración de $\mathrm{SnBu}_{4}$ a agregar surge de la siguiente ecuación:

$\mathrm{SnBu}_{4}\left[\mathrm{mLg}^{-1}\right.$ cat. $]=\left[\left(\operatorname{Rel} \frac{\mathrm{Sn}}{\mathrm{M}}\right) \times\left(\frac{\mathrm{gM}}{\mathrm{PMM}}\right) \times\left(\frac{118,7}{0,35}\right) \times\left(\frac{1}{\rho}\right)\right]$

Ecuación AI-01

Donde:

$\mathrm{SnBu}_{4}\left[\mathrm{mLg}^{-1}\right.$ cat. $]$ volumen de $\mathrm{SnBu}_{4}$ por gramo de catalizador.

$\left(\operatorname{Rel} \frac{\mathrm{Sn}}{\mathrm{M}}\right)$ relación atómica $\mathrm{Sn} / \mathrm{M}$ etaldeseada

$\left(\frac{\mathrm{gM}}{\mathrm{PMM}}\right)$ relación entreel contenido de metal en un gra mo de catalizador y el peso molecular del metal de base

$\left(\frac{118,7}{0,35}\right)$ pesomolecular del Sn dividido la cantidad de $\mathrm{Sn}$ como $\mathrm{SnBu}_{4}$

$\left(\frac{1}{\rho}\right)$ inversa de la densidad del $\mathrm{SnBu}_{4}$ en $\left[\mathrm{mLg}^{-1}\right]$

En la Tabla AI-01 se presentan la concentración agregada de $\mathrm{SnBu}_{4}$ y la relación $\mathrm{Sn} / \mathrm{Pt}$ alcanzada en el catalizador.

\section{AI.1.3. Activación de las fases organometálicas $\mathrm{Pt}\left(\mathrm{SnBu}_{\mathrm{x}}\right)_{\mathrm{y}} / \mathrm{SiO}_{2}$}

Luego de la etapa de reacción entre $\mathrm{Pt} / \mathrm{SiO}_{2}$ y $\mathrm{SnBu}_{4}$ y del secado, las muestras $\mathrm{Pt}\left(\mathrm{SnBu}_{\mathrm{x}}\right)_{\mathrm{y}} / \mathrm{SiO}_{2}$ se sometieron a un proceso de reducción en $\mathrm{H}_{2}$ a $500^{\circ} \mathrm{C}$ durante $2 \mathrm{~h}$, con el fin de eliminar los grupos orgánicos ligados a la fase metálica. Estos catalizadores conteniendo la relación $\mathrm{Sn} / \mathrm{Pt}$ indicada en la Tabla AI-01, se designaron en forma general como: PtSn-BM. 
Anexo I. Protocolo operativo de la preparación de catalizadores bimetálicos PtSn

Tabla AI-01. Concentración de $\mathrm{SnBu}_{4}$ agregada a cada catalizador y relación $\mathrm{Sn} / \mathrm{Pt}$ obtenida

\begin{tabular}{cccc}
\hline Catalizador & $\begin{array}{c}\text { Concentración } \\
\text { agregada de } \mathbf{S n B u}_{\mathbf{4}} \\
\left(\mathbf{m m o l ~ L}^{\mathbf{- 1}}\right)\end{array}$ & $\begin{array}{c}\text { Relación Sn/Pt } \\
\text { en el catalizador } \\
\text { final }\end{array}$ & \% de Sn fijado \\
\hline $\mathrm{PtSn} 0.2$ & $0,47^{\mathrm{a}}$ & 0,20 & 0,12 \\
$\mathrm{PtSn} 0.4$ & $1,83^{\mathrm{a}}$ & 0,40 & 0,24 \\
$\mathrm{PtSn} 0.7$ & $1,82^{\mathrm{b}}$ & 0,70 & 0,48 \\
\hline $\mathrm{PtSn} 1.4$ & $3,64^{\mathrm{c}}$ & 1,40 & 0,84 \\
\hline
\end{tabular}

${ }^{\mathrm{a}}$ Se realizó a $90^{\circ} \mathrm{C} .{ }^{\mathrm{b}}$ Se realizó a $120^{\circ} \mathrm{C}$. ${ }^{\mathrm{c}}$ Se realizó a $150^{\circ} \mathrm{C}$

\section{AI.2. Determinación de la concentración de $\mathrm{SnBu}_{4}$ y gases desprendidos durante la reacción}

\section{AI.2.1. Condiciones operativas y calibración del sistema cromatográfico para la determinación de la concentración de $\mathrm{SnBu}_{4}$}

Se utilizó un cromatógrafo Varian CX 3400 provisto de una columna de 10\% OV-101 sobre Chromosorb P-AW 80/100 de $50 \mathrm{~cm}$ de longitud y de 1/8" de O.D., equipado con un FID como detector. Como gas carrier se utilizó $\mathrm{N}_{2}$ con una presión de 0,5 bar. Para el detector FID se utilizó una presión $\mathrm{H}_{2}$ de 0,9 bar y una presión de aire de 1,5 bar. La temperatura de la columna fue de $120^{\circ} \mathrm{C}$.

Para la determinación cuantitativa de $\mathrm{SnBu}_{4}$ se utilizó tetradecano como patrón interno. Se prepararon diferentes soluciones patrones de $\mathrm{SnBu}_{4}$ y tetradecano en n-heptano. Se inyectaron $10 \mu \mathrm{l}$ de cada patrón y se registró el área de cada pico mediante un integrador. La Figura AI-02, nos muestra la relación de áreas (Área $\mathrm{SnBu}_{4} / \mathrm{Area}_{\mathrm{C}}$ $_{14}$ vs. la relación porcentual ( $\left.\% \mathrm{SnBu}_{4} / \% \mathrm{C}_{14}\right)$. 


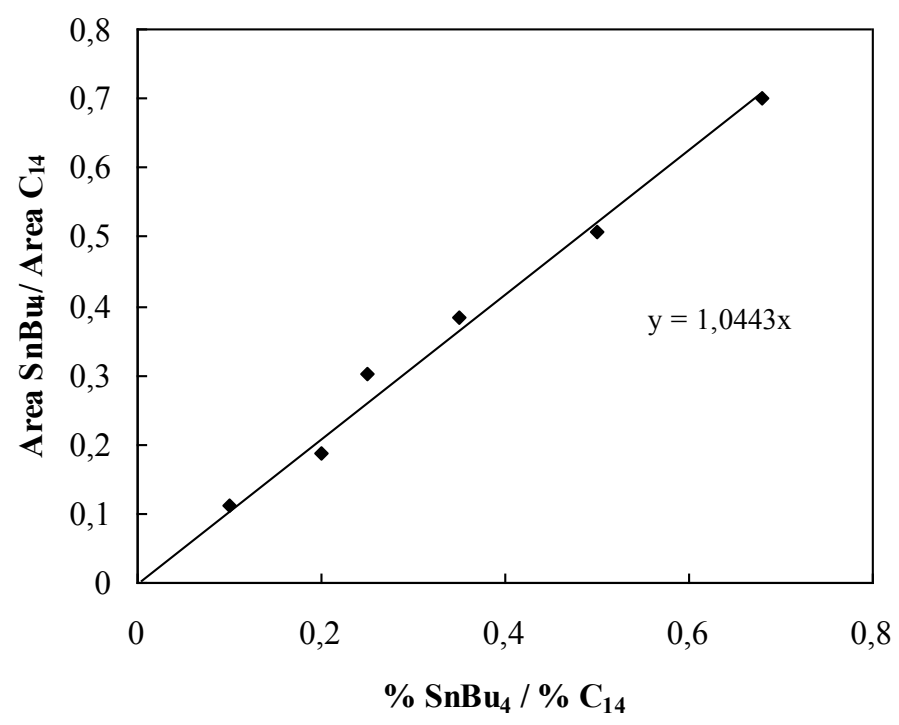

Figura AI-02. Curva de calibración de $\mathrm{SnBu}_{4}$ utilizando tetradecano $\left(\mathrm{C}_{14}\right)$ como patrón interno

\section{AI.2.1.2. Cálculo del consumo de $\mathrm{SnBu}_{4}$ y de la cantidad de $\mathrm{Sn}$ fijado en el catalizador}

La concentración de $\mathrm{SnBu}_{4}$ se siguió durante el transcurso de la reacción, para lo cual se tomaron muestras de reacción a diferentes tiempos. Se inyectaron $10 \mu \mathrm{L}$ de cada muestra en el cromatógrafo determinándose de esta manera, la relación de áreas cromatográficas:

$\frac{\text { Area } \mathrm{SnBu}_{4}}{\text { Area } \mathrm{C}_{14}}$

\section{Ecuación AI-02}

Con la relación de áreas y el valor de la pendiente de la curva de calibración se determinó la relación porcentual:

$\frac{[\% \mathrm{v} / \mathrm{v}] \mathrm{SnBu}_{4}}{[\% \mathrm{v} / \mathrm{v}] \mathrm{C}_{14}}$

Ecuación AI-03

Luego conociendo el $\left[\begin{array}{ll}\% & \mathrm{v} / \mathrm{v}]\end{array}\right.$ de $\mathrm{C}_{14}$ agregado en la mezcla, se determinó la concentración de $\mathrm{SnBu}_{4}$, de acuerdo a la siguiente expresión: 
Conc de $\mathrm{SnBu}_{4}\left[\mathrm{mmol} \mathrm{L}^{-1}\right]=\left(\frac{[\% \mathrm{v} / \mathrm{v}] \mathrm{SnBu}_{4} \times 10^{4} \times \rho}{346,7}\right)$

donde: $\rho$ es la densidad de $\mathrm{SnBu}_{4}$ igual a $1,057\left[\mathrm{~g} \mathrm{~mL}^{-1}\right], 346,7\left[\mathrm{~g}\left(\mathrm{~g} \mathrm{~mol}^{-1}\right.\right.$ ] es el peso molecular de $\mathrm{SnBu}_{4}$ y $10^{4}$ es un factor corrector de unidades.

Por otra parte la concentración inicial de $\mathrm{SnBu}_{4}$ en la mezcla de reacción, se calculó a partir de la siguiente expresión:

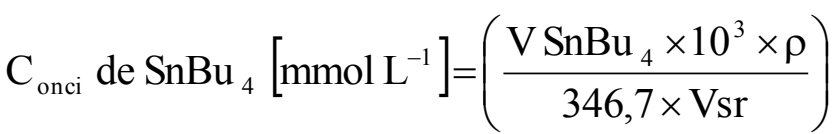

Ecuación AI-05

donde: $\mathrm{V} \mathrm{SnBu}_{4}$ es el volumen de $\mathrm{SnBu}_{4}$ agregado en $[\mu \mathrm{L}]$, Vsr es el volumen de solvente en el reactor en $[\mathrm{mL}], 10^{3}$ es un factor corrector de unidades.

El consumo de $\mathrm{SnBu}_{4}$ en $\left[\mathrm{mmol} \mathrm{L}^{-1}\right]$ se determinó de acuerdo a:

Consumo de $\mathrm{SnBu}_{4}=\mathrm{C}_{\text {onci }}-\mathrm{C}_{\text {oncf }}$

Ecuación AI-06

donde: $\mathrm{C}_{\text {oncf }}$ corresponde a la concentración final de $\mathrm{SnBu}_{4}$, determinada de acuerdo a la expresión (Ecuación AI-04)

La cantidad de estaño fijada en el catalizador se calculó a partir de:

$[\% \mathrm{p} / \mathrm{p}]$ Sn fijado $=\left(\frac{\text { Consumo de } \mathrm{SnBu}_{4} \times \mathrm{Vsr} \times 118,7}{10^{4} \times \text { mcat }}\right)$

Ecuación AI-07

donde: Consumo de $\mathrm{SnBu}_{4}$ corresponde al valor calculado con la expresión (Ecuación AI-06), Vsr es el volumen de solvente definido anteriormente, 118,7 [g (gmol) $\left.{ }^{-1}\right]$ es el peso molecular del Sn, y mcat es la masa de catalizador expresada en [g].

La relación porcentual entre el estaño fijado y el metal de base se calculó como:

$\left(\frac{\% \mathrm{Sn}}{\% \mathrm{Pt}}\right)=\left(\frac{[\% \mathrm{p} / \mathrm{p}] \mathrm{Sn} \text { fijado }}{[\% \mathrm{p} / \mathrm{p}] \mathrm{Pt}}\right)$

Ecuación AI-08

Luego la relación atómica $\mathrm{Sn} / \mathrm{Pt}$ se calculó de acuerdo a: 


$$
\left(\frac{\mathrm{Sn}}{\mathrm{Pt}}\right)=\left(\frac{(\% \mathrm{Sn} / \% \mathrm{Pt})}{(195 / 118,7)}\right)
$$

\section{AI.2.2. Condiciones operativas y calibración del sistema cromatográfico para la determinación de la concentración de butano}

Se empleó el mismo cromatógrafo que el utilizado para el seguimiento de $\mathrm{SnBu}_{4}$. Como gas carrier se utilizó $\mathrm{N}_{2}$ con una presión de 0,2 bar. Para el detector FID se trabajó a una presión de $\mathrm{H}_{2}$ de 0,9 bar y una presión de aire de 1,5 bar. La temperatura de la columna fue de $40^{\circ} \mathrm{C}$.

Para la determinación cuantitativa de butano se calibró el equipo inyectando distintas cantidades de gas butano. Se registra el área de cada pico mediante un integrador. El siguiente gráfico (Figura AI-03) nos muestra el número de cuentas vs. volumen de gas butano.

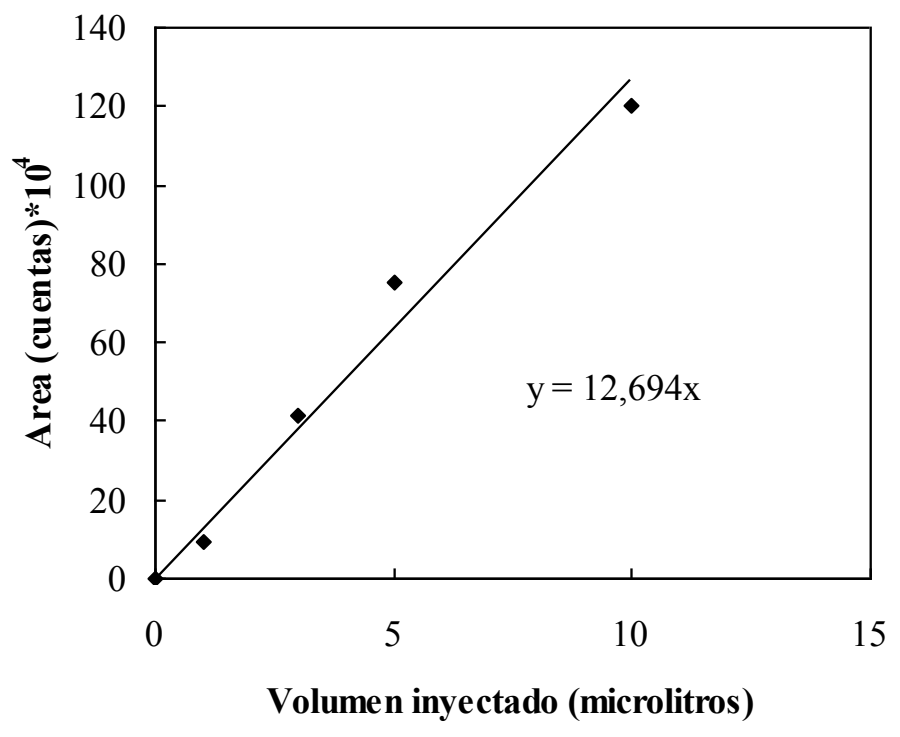

Figura AI-03. Calibración del gas butano

\section{AI.2.2.1. Cálculo de la cantidad de BuH desprendidos durante la reacción}

La concentración de $\mathrm{BuH}$ desprendidos durante la reacción se siguió cromatográficamente, para lo cual se tomaron muestras del solvente contenido en la 
trampa para retener $\mathrm{BuH}$, al finalizar la reacción. Se inyectaron $1 \mu \mathrm{L}$ de cada muestra en el cromatógrafo determinándose de esta manera el área cromatográfica correspondiente a BuH.

Los moles de $\mathrm{BuH}$ inyectados, expresados como [moles $\mu \mathrm{L}^{-1}$, se calcularon de acuerdo a:

Moles de $\mathrm{BuH}$ inyectados $=\left(\frac{\text { Area } \mathrm{BuH} \times 10^{-3}}{\text { pend } \times 22414 \times \text { Vin }}\right)$

Ecuación AI-10

donde: Área $\mathrm{BuH}$ es el área cromatográfica [cuentas], pend es el valor de la pendiente de la curva de calibración [cuentas $\mu \mathrm{L}^{-1}$ ], 22414 es el volumen molar [ $\mathrm{mL} \mathrm{mol}^{-1}$ ] y Vin es el volumen de inyección $[\mu \mathrm{L}]$.

Los moles de $\mathrm{BuH}$ disueltos en la trampa se obtuvieron a partir de:

Moles de $\mathrm{BuH}$ disueltos $=\left(\right.$ Moles de $\mathrm{BuH}$ inyectados $\left.\times \mathrm{Vst} \times 10^{3}\right)$

donde: Vst es el volumen de solvente en la trampa para retener BuH expresado en [mL].

Por otra parte el consumo de $\mathrm{SnBu}_{4}$ en la reacción se calculó de acuerdo a la expresión (Ecuación AI-05). De esta manera se determinaron los moles de BuH desprendidos por mol de $\mathrm{SnBu}_{4}$ que reaccionó de acuerdo a:

$\left(\frac{\text { Moles de } \mathrm{BuH}}{{\text { Moles de } \mathrm{SnBu}_{4}}_{\text {onsumo de } \mathrm{SnBu}_{4} \times \mathrm{Vsr} \times 10^{-6}}}\right)=\left(\frac{\text { Moles de } \mathrm{BuH} \text { disueltos }}{\text { Consum }}\right.$

donde: Vsr es el volumen de solvente en el reactor en [mL]. 
Anexo II

Calibraciones cromatográficas 


\section{Anexo II. Calibraciones cromatográficas}

\section{AII.1. Análisis de productos gaseosos de reacción}

\section{AII.1.1. Descripción de equipos y condiciones utilizadas}

La salida y entrada al reactor se analizó por cromatografía gaseosa.

Los productos gaseosos de la reacción se identificaron y cuantificaron por cromatografía gaseosa con detector de conductividad térmica (CG/TCD).

El equipo utilizado fue un cromatógrafo HP equipado con un detector de conductividad térmica (TCD) y una columna Hayesep D 100-120 de 10 m de longitud y un diámetro de 1/8 “. El integrador utilizado fue un Spectra-Physics SP4290.

Los productos detectados fueron $\mathrm{H}_{2}, \mathrm{~N}_{2}, \mathrm{CH}_{4}, \mathrm{CO}$ y $\mathrm{CO}_{2}$.

\section{Condiciones operativas del cromatógrafo TCD}

Gas portador (Carrier): Argón

Presión de Cabeza de columna: 1,8 bar

Temperatura inicial de columna: $28^{\circ} \mathrm{C}$

Tiempo inicial: $9 \mathrm{~min}$

Rampa: $40^{\circ} \mathrm{C} \min$

Temperatura final de columna: $180^{\circ} \mathrm{C}$

Tiempos de elusión: $\mathrm{H}_{2}(5 \mathrm{~min}), \mathrm{N}_{2}(7 \mathrm{~min}), \mathrm{CO}(8 \mathrm{~min}), \mathrm{CH}_{4}(14 \mathrm{~min})$ y $\mathrm{CO}_{2}(17 \mathrm{~min})$

Para la cuantificación de los componentes se utilizó el método de normalización de área con factores de respuesta, para lo cual se asume que todos los componentes salen y se detectan. Y la ventaja es que es insensible a la cantidad exacta de muestra inyectada.

\section{AII.1.2. Calibración de componentes gaseosos a detectar}

Los factores de respuesta se obtienen realizando la calibración de los todos los componentes a detectar, para la cual se inyectan volúmenes conocidos de un componente y luego se grafica la señal del detector (área de integración de pico: 
cuentas) vs. cantidad inyectada de cada componente. El factor de respuesta en unidades de moles de $\mathrm{X} /$ cuentas es la relación que existe entre ambos.

A continuación se muestran las gráficas de calibración (Figura AII-01 a 05) y los factores de respuesta obtenidos (Tabla AII-01).

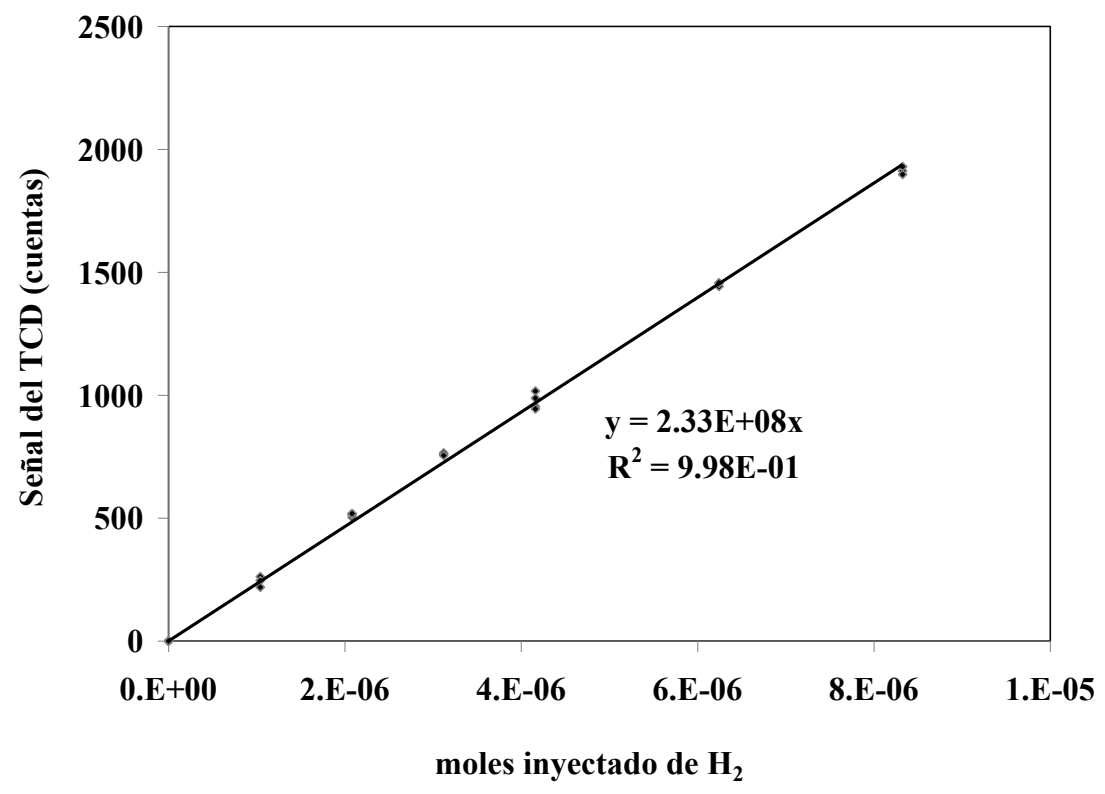

Figura AII-01. Curva de calibración para TCD del $\mathrm{H}_{2}$

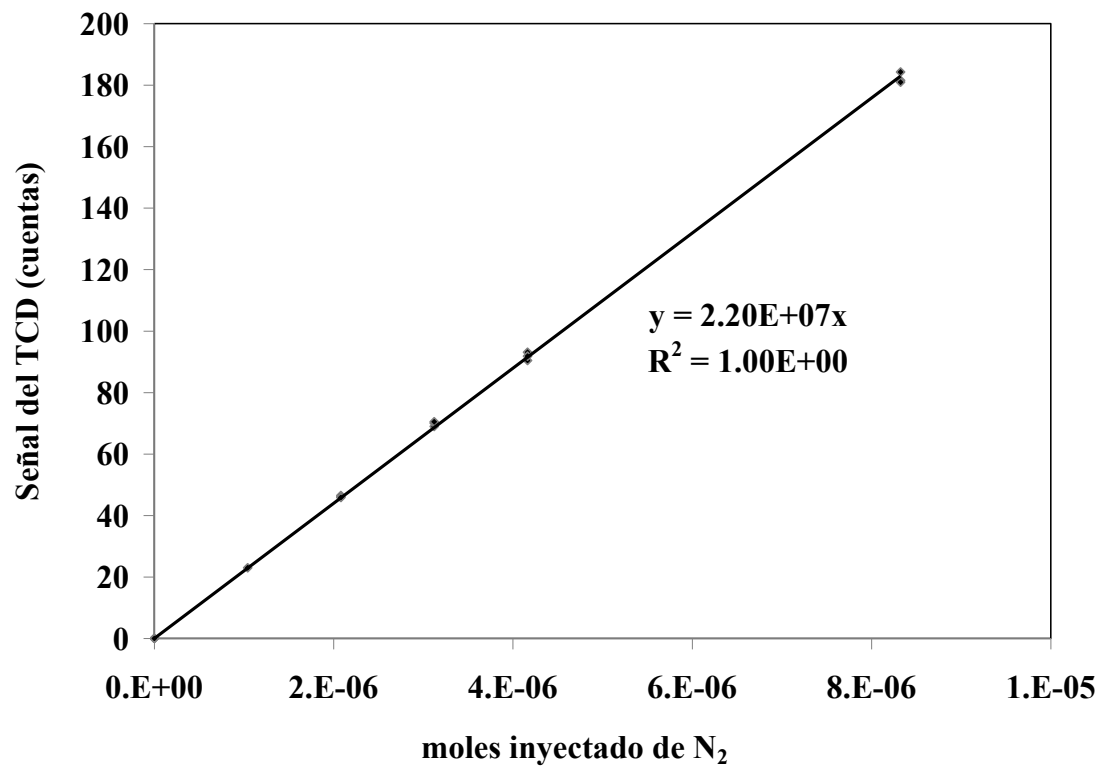

Figura AII-02. Curva de calibración para TCD del $\mathrm{N}_{2}$ 


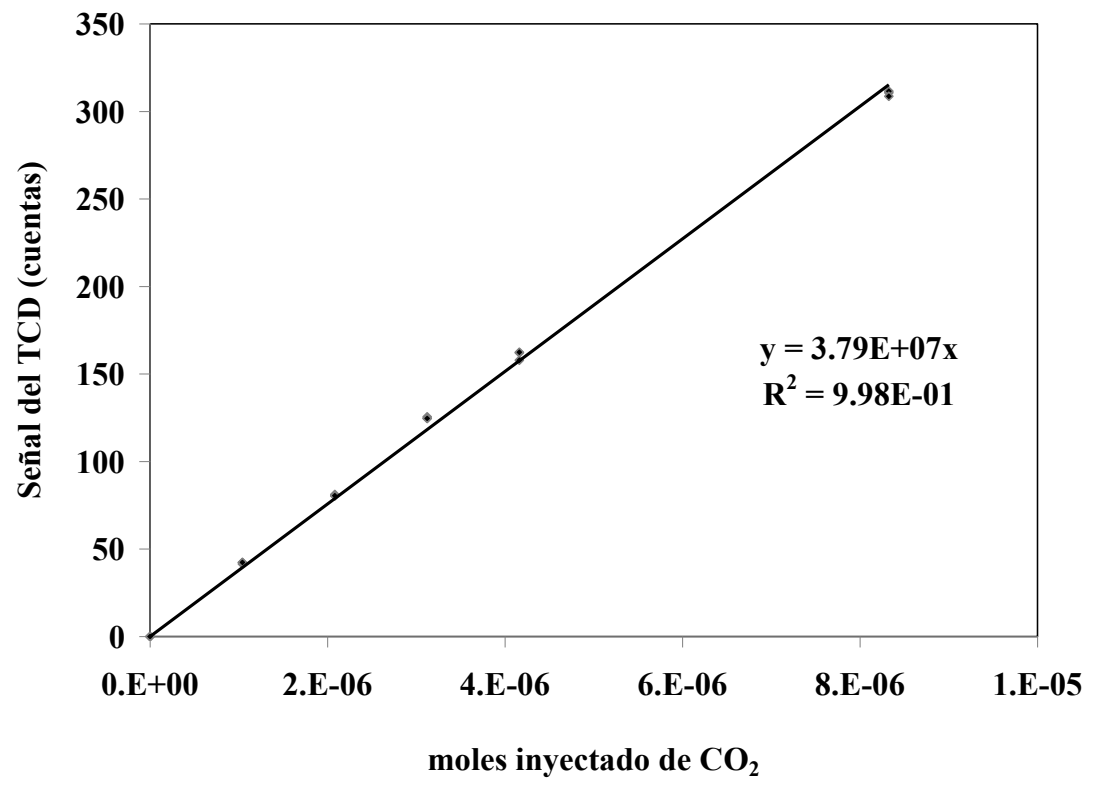

Figura AII-03. Curva de calibración para TCD del $\mathrm{CO}_{2}$

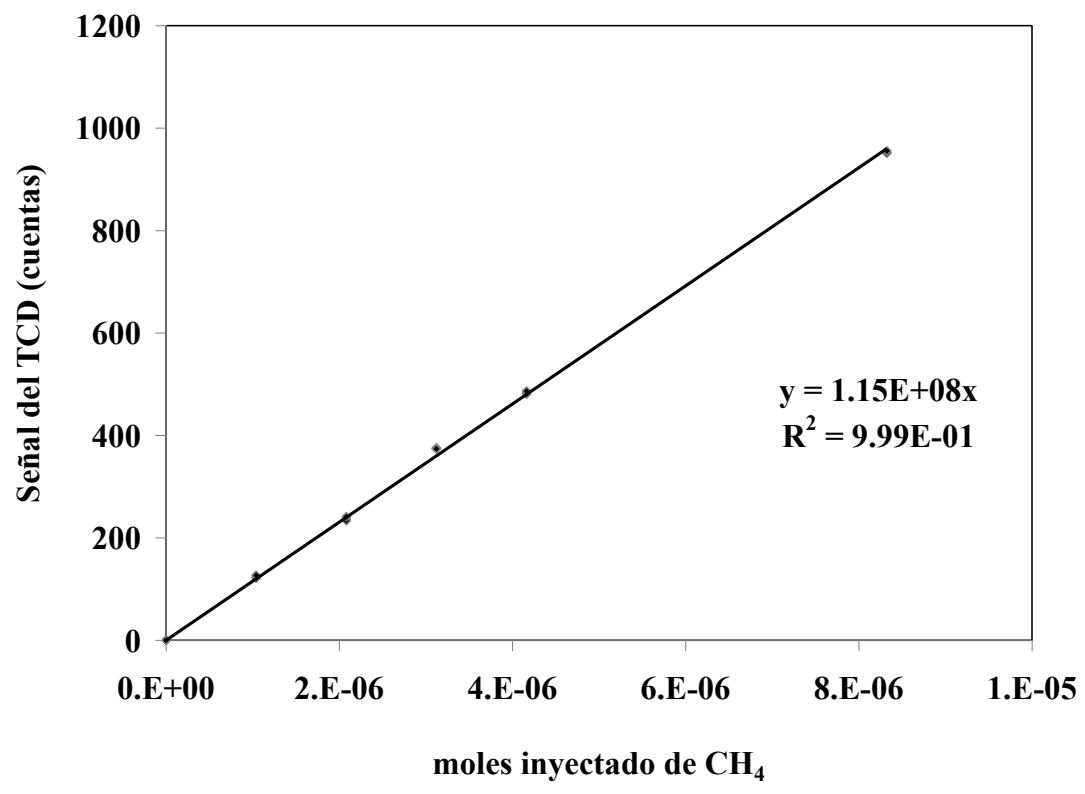

Figura AII-04. Curva de calibración para TCD del $\mathrm{CH}_{4}$ 


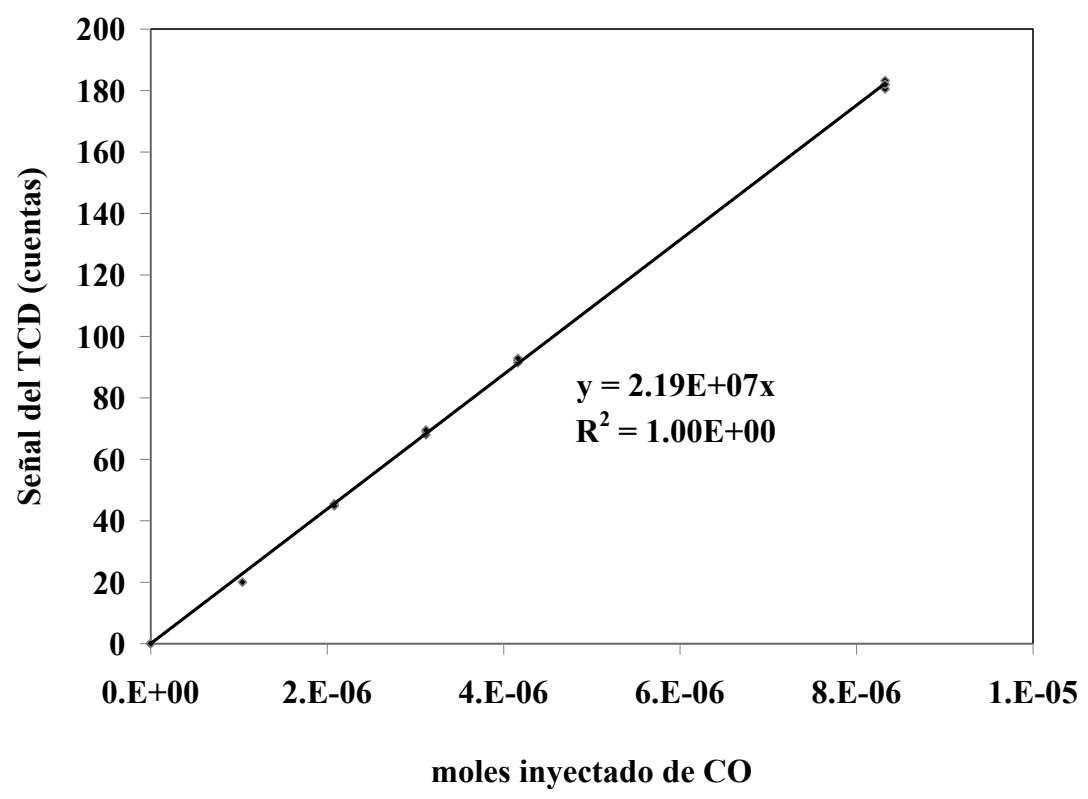

Figura AII-05. Curva de calibración para TCD del CO

Tabla AII-01. Factores de respuesta de productos gaseosos

\begin{tabular}{lcc}
\hline Molécula & $\mathbf{P M}$ & $\mathbf{f}_{\mathbf{i}}$ \\
\hline $\mathrm{H}_{2}$ & 2 & $4,29 \mathrm{E}-09$ \\
$\mathrm{~N}_{2}$ & 14 & $4,54 \mathrm{E}-08$ \\
$\mathrm{CO}_{2}$ & 44 & $2,64 \mathrm{E}-08$ \\
$\mathrm{CH}_{4}$ & 16 & $8,69 \mathrm{E}-09$ \\
$\mathrm{CO}$ & 28 & $4,57 \mathrm{E}-08$ \\
\hline
\end{tabular}

\section{AII.2. Análisis de productos líquidos}

\section{AII.2.1. Determinación de productos líquidos}

El análisis de los productos líquidos se realiza mediante espectrometría de masas. El cromatógrafo utilizado es CG/MS, Shimadzu GCMS-QP5050A. Para la separación de los distintos productos se utiliza una columna capilar 19091S-001 HP PONA 50m, $0,2 \mathrm{~mm}, 0,5 \mathrm{um}$.

Los productos identificados en los test catalíticos en la fase líquida postreacción fueron:

Metanol, Etanol, Acetona, 1-propanol, Acetol, Etilenglicol, Propilenglicol y Glicerol. 


\section{AII.2.2. Cuantificación de subproductos líquidos de reacción en CG/FID}

La cuantificación de los productos líquidos se realizó mediante cromatografía gaseosa con detector FID.

El cromatógrafo gaseoso equipado con un detector de ionización de llama (FID) utilizado es modelo Chrompack CP-9001. Este se encuentra conectado a un bus modulador de comunicaciones Shimazu CBM-102 y software procesador e integrador de datos cromatográficos, modelo CLASS GC-10 C, marca Shimadzu. Para la separación de los distintos productos se utilizó una columna 19091S-001 HP PONA $50 \mathrm{~m}, 0,2 \mathrm{~mm}, 0,5 \mu \mathrm{m}$.

\section{Condiciones operativas del cromatógrafo FID}

- Gas portador (carrier): Hidrógeno

- Presión de cabeza de Columna: 1,7 bar

- Caudal de Make Up: Nitrógeno, $30 \mathrm{~mL} / \mathrm{min}$

- Caudal de $\mathrm{H}_{2}: 30 \mathrm{~mL} / \mathrm{min}$

- Caudal de Aire: $200 \mathrm{~mL} / \mathrm{min}$

- Caudal de Venteo: $30 \mathrm{~mL} / \mathrm{min}$

- Temperatura de Inyección: $150^{\circ} \mathrm{C}$

- Temperatura del Detector: $300^{\circ} \mathrm{C}$

- Temperatura inicial: $50^{\circ} \mathrm{C}$

- Tiempo inicial: 1 minuto

- Rampa: $10^{\circ} \mathrm{C} / \mathrm{min}$

- Temperatura Final: $150{ }^{\circ} \mathrm{C}$

- Tiempo Final: 14 minutos

- Volumen de Inyección: 0,2 $\mu 1$ 


\section{Calculo de factores de respuesta}

Para el cálculo de los factores de respuesta de los productos cuantificados por cromatografía gaseosa con detector FID, se utilizó el método de cálculo propuesto por Scanlon y Willis [1].

Este método se aplica a detectores de ionización de llama y se basa en el número efectivo de carbonos que posee una molécula de hidrocarburos. Este número efectivo de carbonos desvía del número real de acuerdo a los átomos a los que están unidos los carbonos de una molécula. A continuación se muestra la tabla para el cálculo del número efectivo de carbonos (NEC) para una molécula.

Tabla AII-02. Número efectivo de carbonos (NEC) para una molécula

\begin{tabular}{ccc}
\hline Átomo & tipo & $\begin{array}{c}\text { NEC } \\
\text { (número efectivo de carbono) }\end{array}$ \\
\hline $\mathrm{C}$ & alifático & 1 \\
$\mathrm{C}$ & aromático & 1 \\
$\mathrm{C}$ & olefínico & 0.95 \\
$\mathrm{C}$ & acetilénico & 1.3 \\
$\mathrm{C}$ & carbonilo & 0 \\
$\mathrm{C}$ & nitrilo & 0.3 \\
$\mathrm{O}$ & éter & -1 \\
$\mathrm{O}$ & Alcohol 1rio & -0.6 \\
$\mathrm{O}$ & Alcohol 2rio & -0.75 \\
$\mathrm{O}$ & Alcohol 3rio y ésteres & -0.25 \\
$\mathrm{Cl}$ & 2 o más en un C alifático & $-0.12($ solo uno) \\
$\mathrm{Cl}$ & en un olefínico & 0.05 \\
$\mathrm{~N}$ & aminas & Igual para alcoholes \\
\hline
\end{tabular}

Luego el factor de respuesta relativo a un compuesto se calcula como:

$f_{i}=\frac{\left(N E F_{P a t r o ́ n}\right) *\left(P M_{i}\right)}{\left(N E F_{i}\right) *\left(P M_{P a t r o ́ n}\right)}$

Ecuación AII-01

Los factores de respuesta de los subproductos líquidos por FID son: 
Tabla AII-04. Factores de respuesta de productos líquidos

\begin{tabular}{lccc}
\hline Molécula & NEC & PM & $\mathbf{f}_{\mathbf{i}}$ \\
\hline metanol & 0,4 & 32 & 0,91 \\
etanol & 1,4 & 46 & 0,38 \\
acetona & 3 & 58 & 0,22 \\
1-propanol & 2,4 & 60 & 0,29 \\
2-propanol & 2,4 & 60 & 0,29 \\
acetol & 2,4 & 74 & 0,35 \\
etilenglicol & 0,8 & 62 & 0,88 \\
propilenglicol & 1,65 & 76 & 0,53 \\
glicerol (patrón) & 1,05 & 92 & 1 \\
\hline
\end{tabular}

\section{AII.3. Bibliografía}

[1] James T. Scanlon y Donald E. Willis. Journal of Chromatographic Science 23 (8) (1985) 333-340 
Anexo III

Resultados TEM y XPS 


\section{Anexo III. Resultados TEM y XPS}

\section{AIII.1. Resultados TEM}

Micrografías y distribución de tamaños de partícula del soporte CZA y de los catalizadores Ni/CZA, Pt/CZA, PtNi/CZA y PtNi/CZA usado 1 hora.

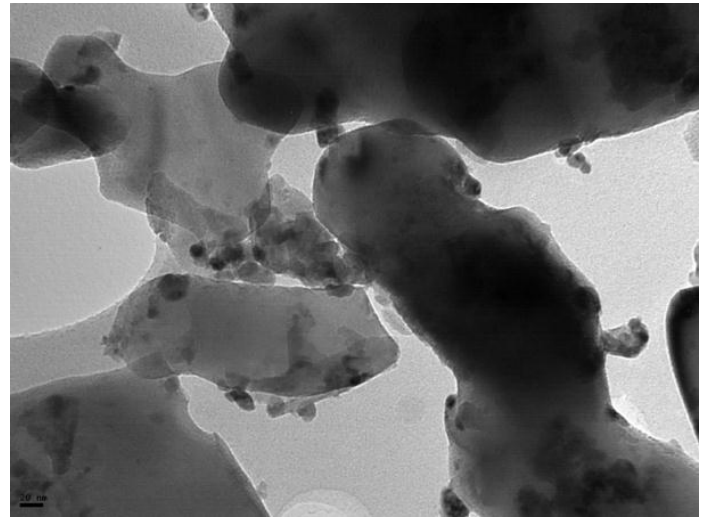

(a)

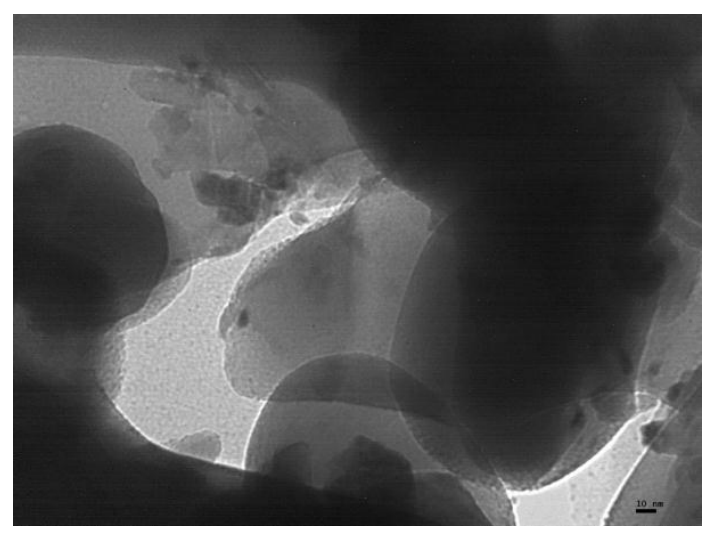

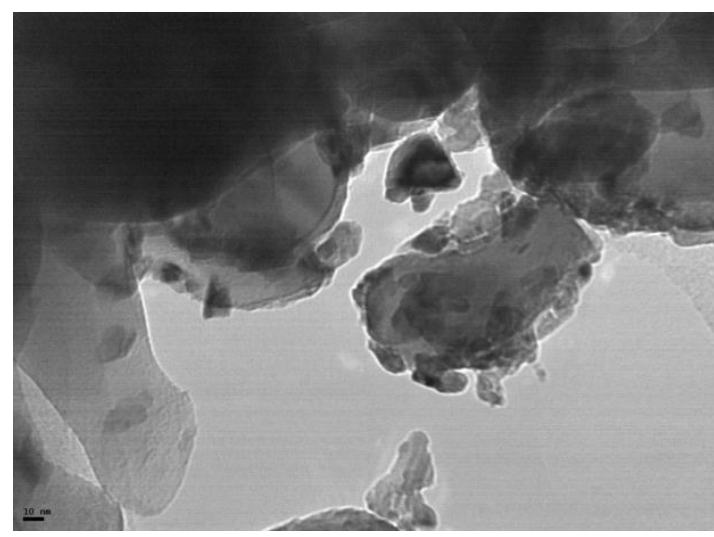

(b)

(c)

Figura AIII-1. Micrografías TEM del soporte CZA (a, b y c) 


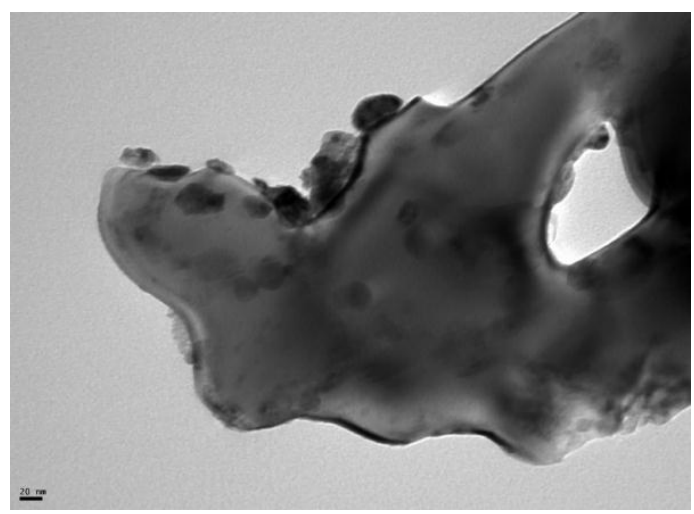

(a)

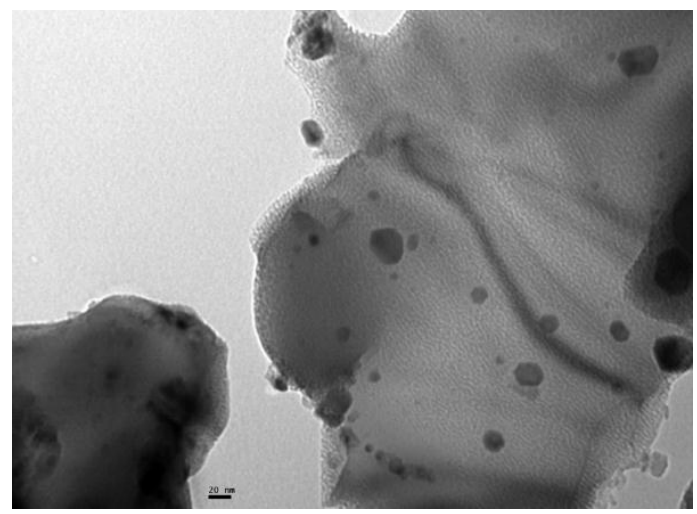

(c)

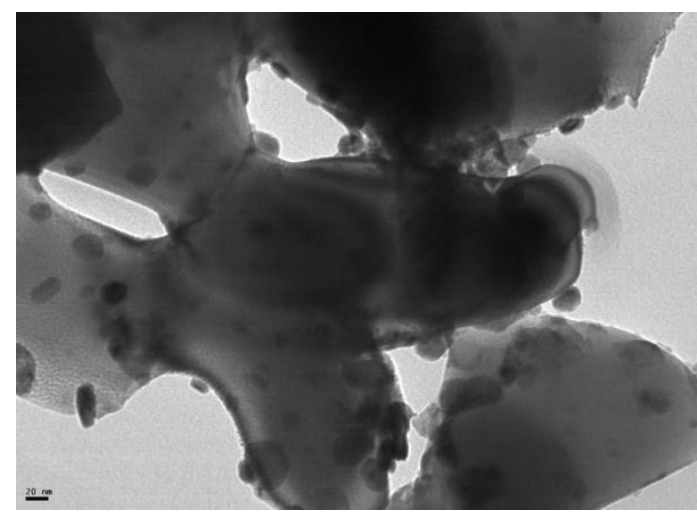

(b)

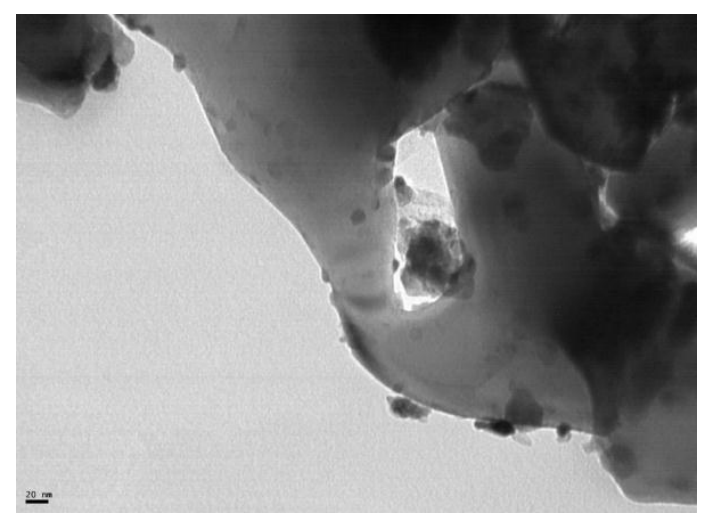

(d)

Figura AIII-2. Micrografias TEM del catalizador Ni/CZA (a, b, c y d) 


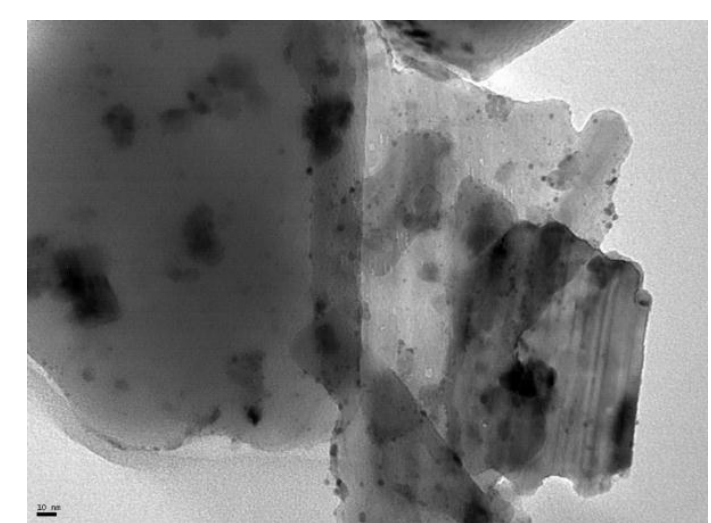

(a)

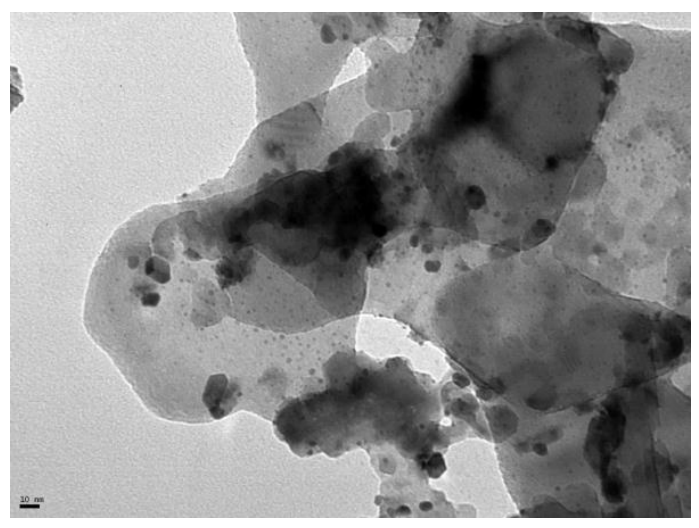

(c)

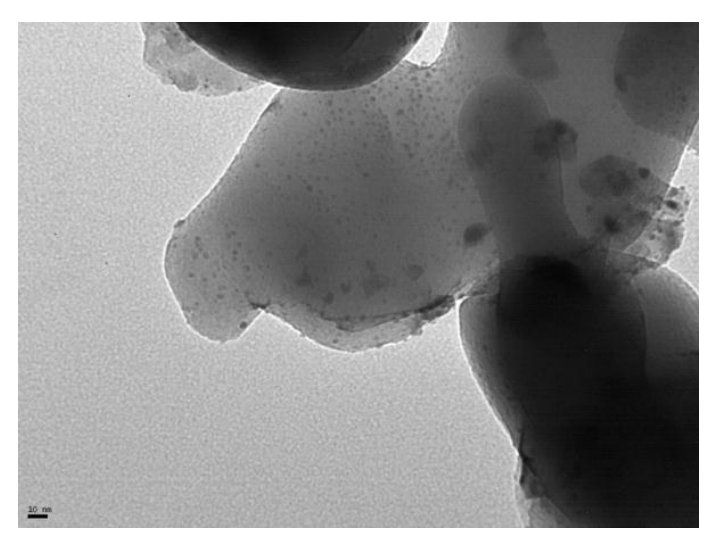

(b)

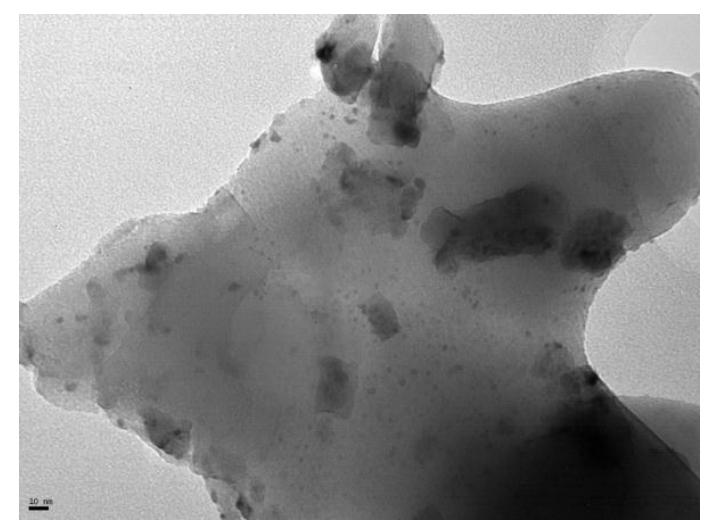

(d)

Figura AIII-3. Micrografias TEM del catalizador Pt/CZA (a, b, c y d) 


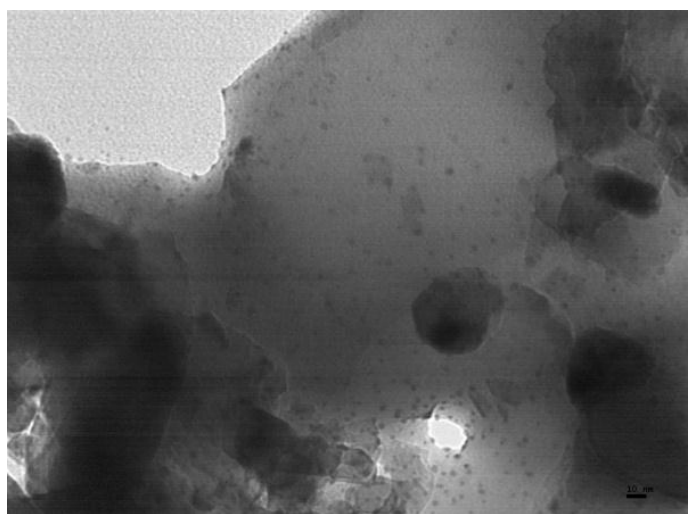

(a)

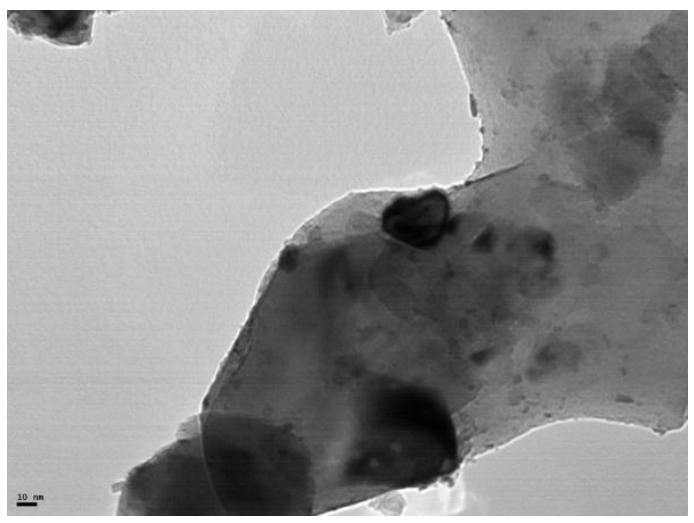

(c)

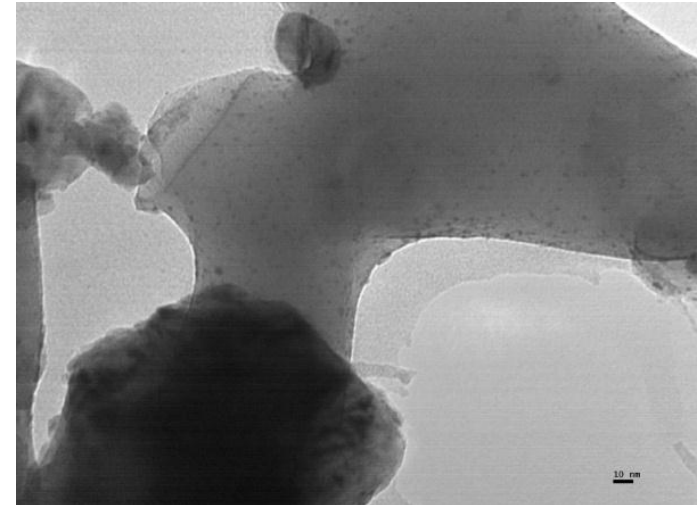

(b)

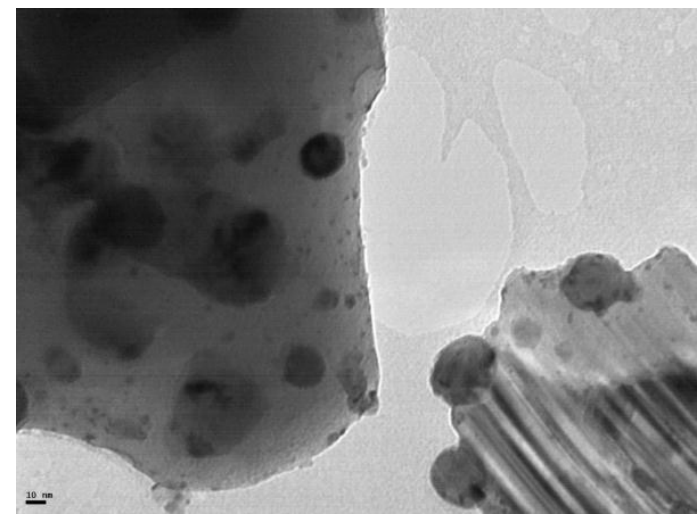

(d)

Figura AIII-4. Micrografias TEM del catalizador PtNi/CZA (a, b, c y d) 


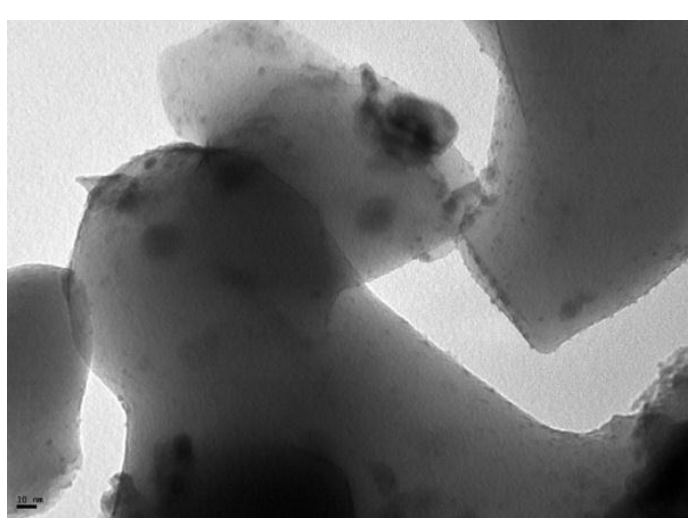

(a)

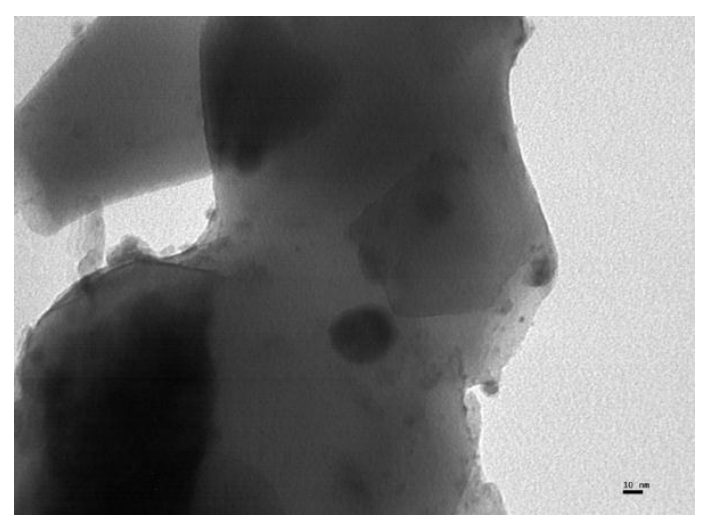

(c)

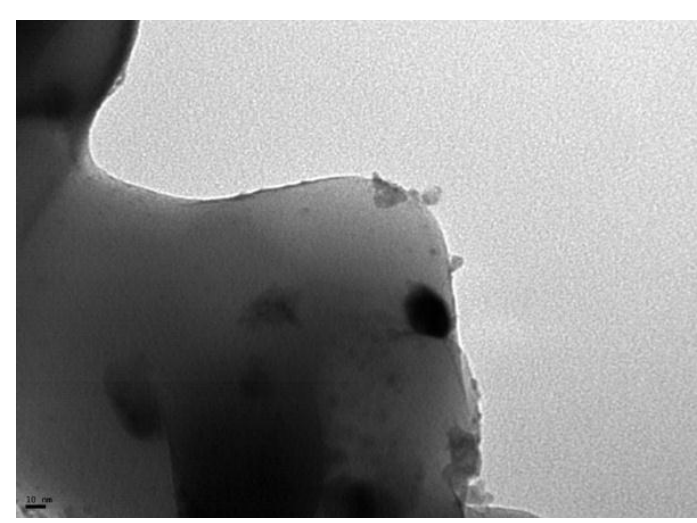

(b)

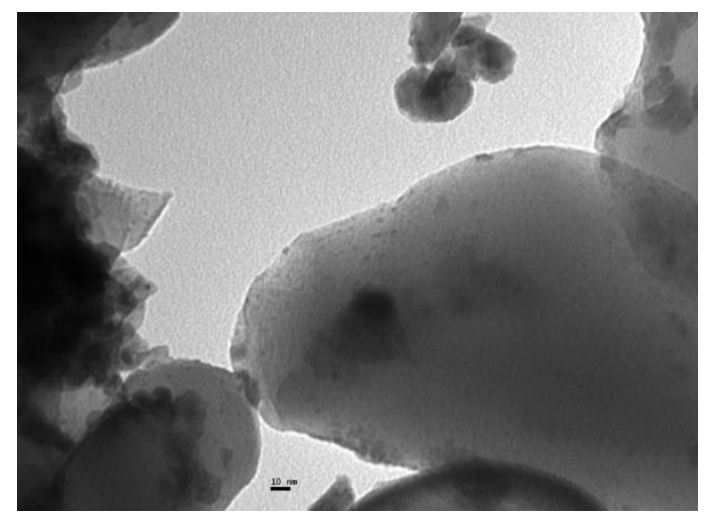

(d)

Figura AIII-5. Micrografias TEM del catalizador PtNi/CZA usado 1 hora (a, b, c y d)

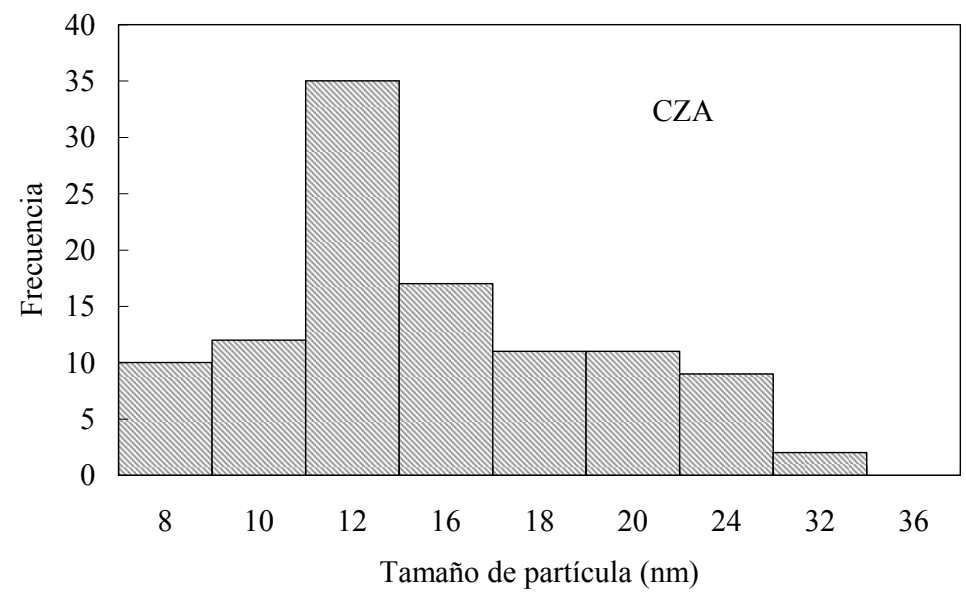

Figura AIII-6. Distribución de tamaños de partícula de Ni para el soporte CZA 


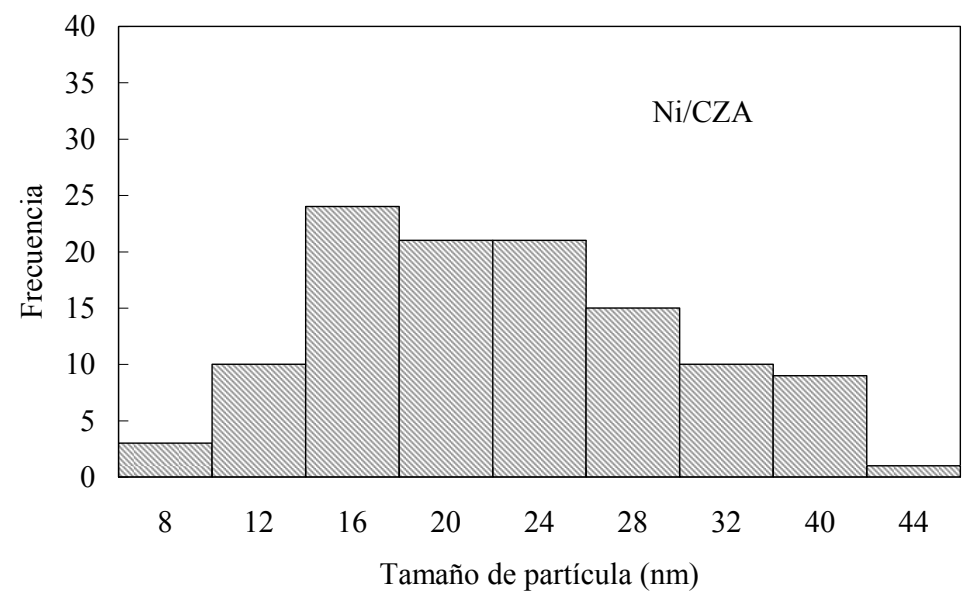

Figura AIII-7. Distribución de tamaños de partícula de Pt para el catalizador Ni/CZA

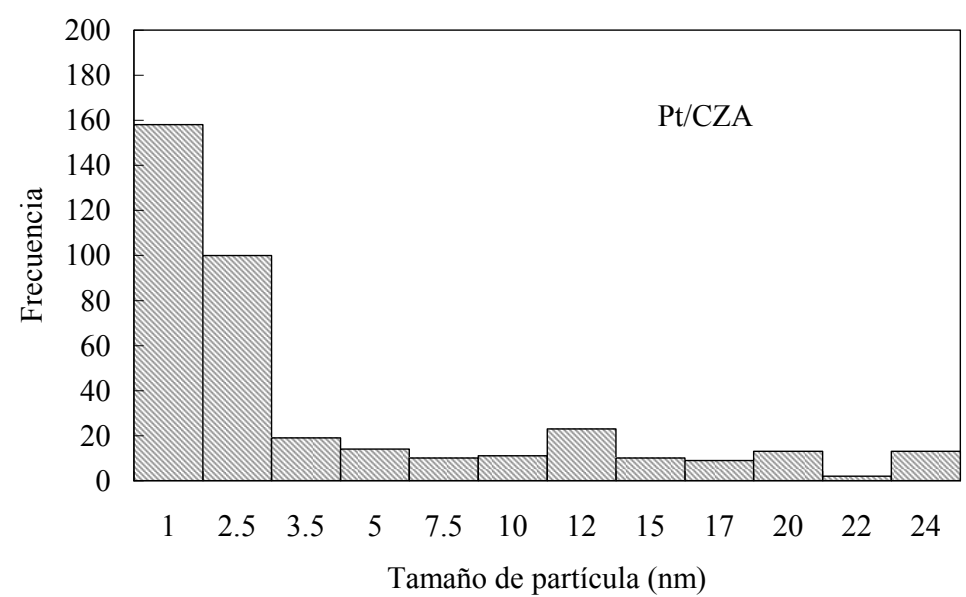

Figura AIII-8. Distribución de tamaños de partícula para el catalizador Pt/CZA

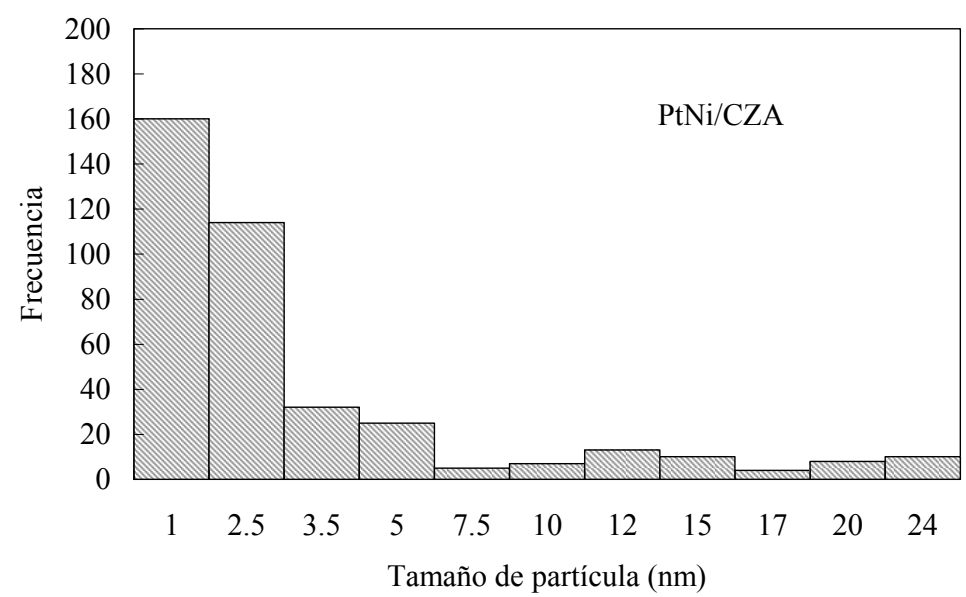

Figura AIII-9. Distribución de tamaños de partícula para el catalizador PtNi/CZA 


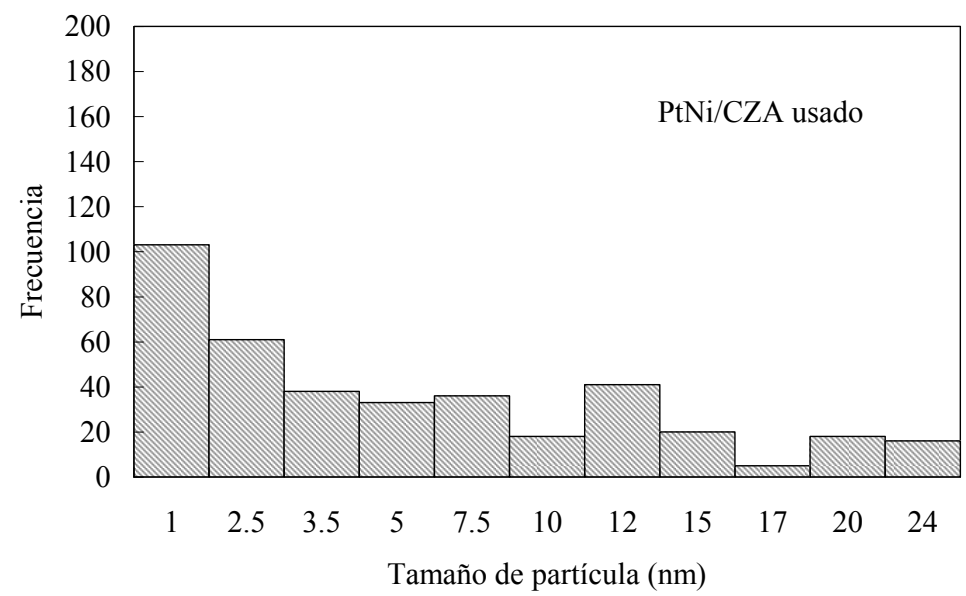

Figura AIII-10. Distribución de tamaños de partícula para el catalizador PtNi/CZA luego de 1 hora de reacción

\section{AIII.2. Espectros XPS}

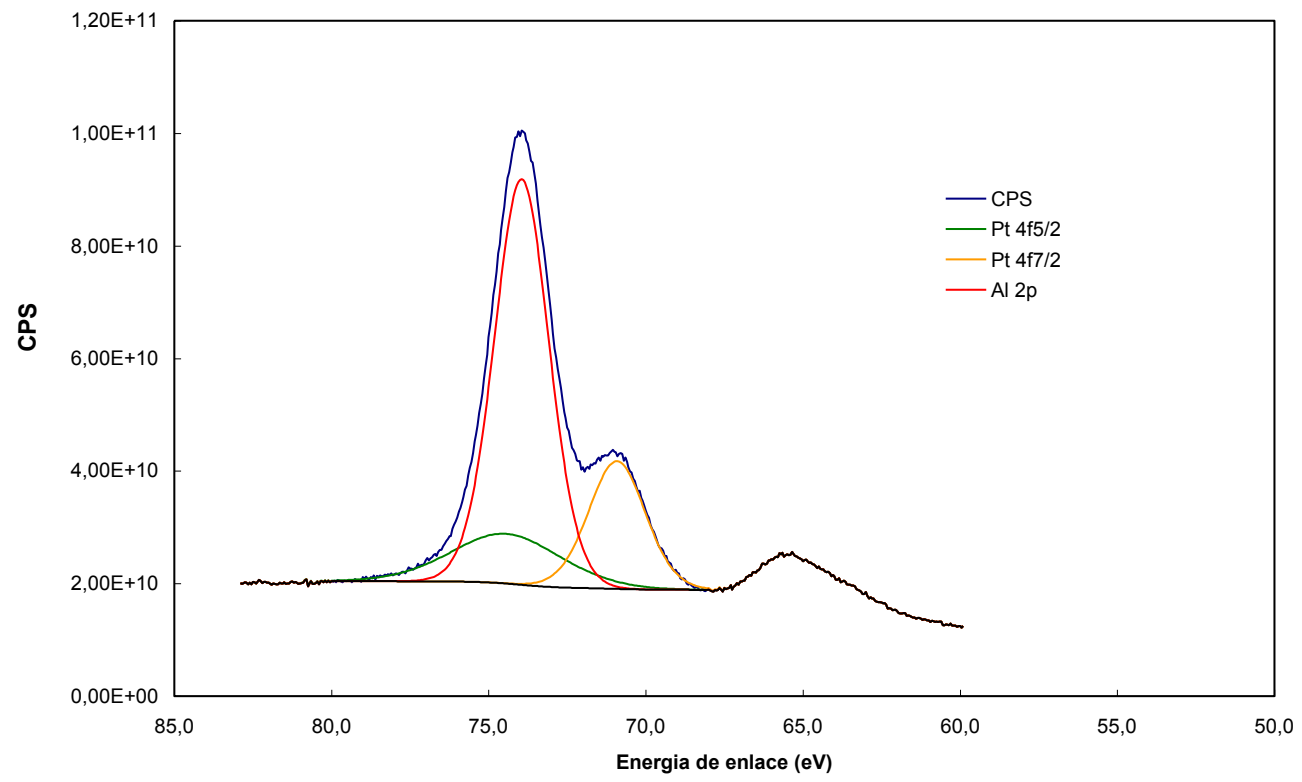

Figura AIII-11. Espectro XPS para los niveles $4 \mathrm{f}_{7 / 2}$ y $4 \mathrm{f}_{5 / 2}$ del Pt y $2 \mathrm{p}$ del Al para el catalizador PtNi/CZA fresco reducido 


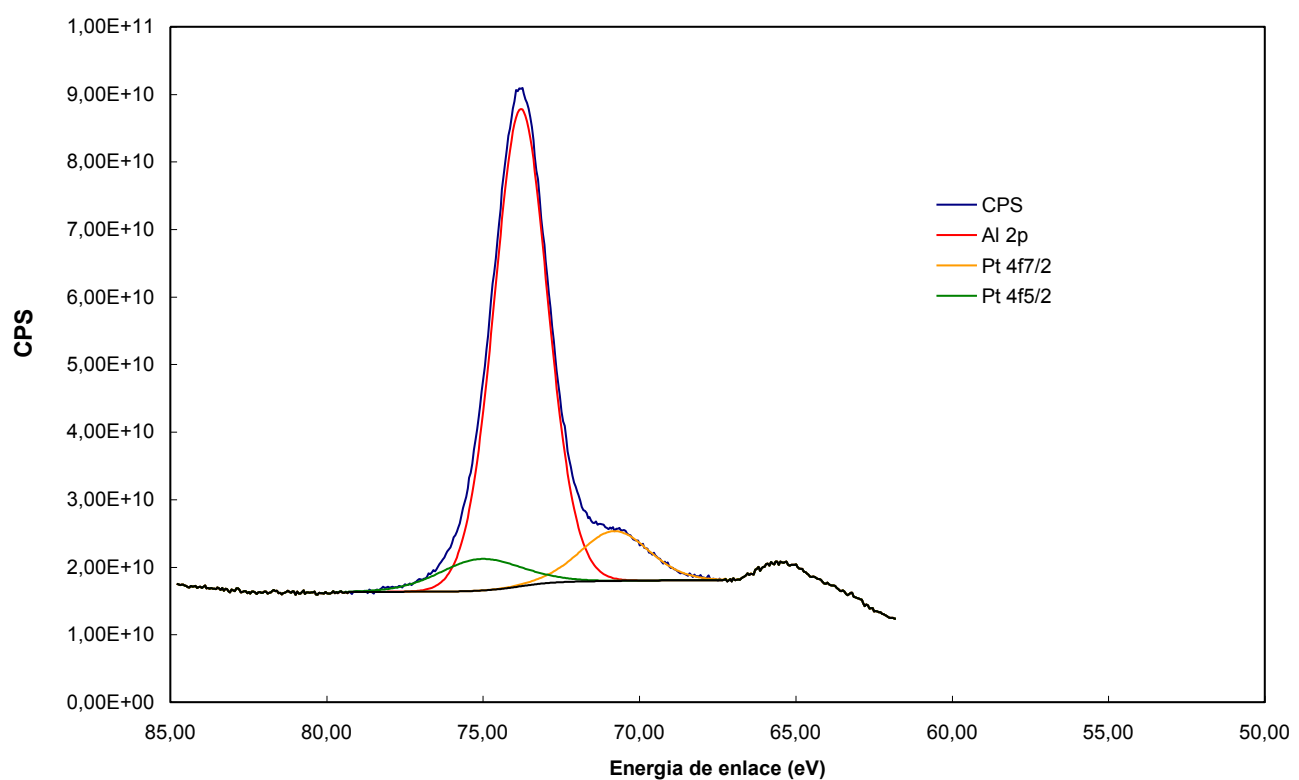

Figura AIII-12. Espectro XPS para los niveles $4 \mathrm{f}_{7 / 2}$ y $4 \mathrm{f}_{5 / 2}$ del Pt y $2 p$ del Al para el catalizador $\mathrm{PtNi} / \mathrm{CZA}$ usado 1 hora

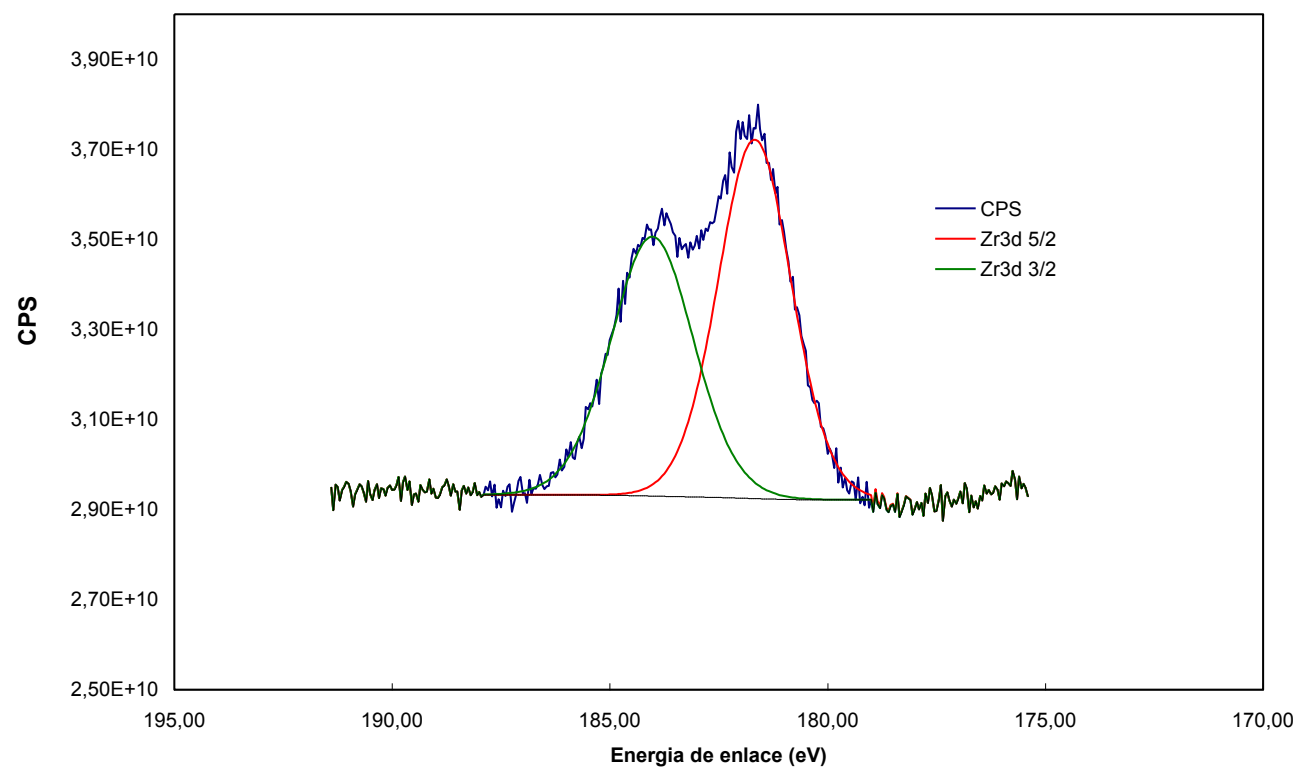

Figura AIII-13. Espectro XPS para los niveles $3 d_{3 / 2}$ y $3 d_{5 / 2}$ del $\mathrm{Zr}$ para el catalizador $\mathrm{PtNi} / \mathrm{CZA}$ fresco 


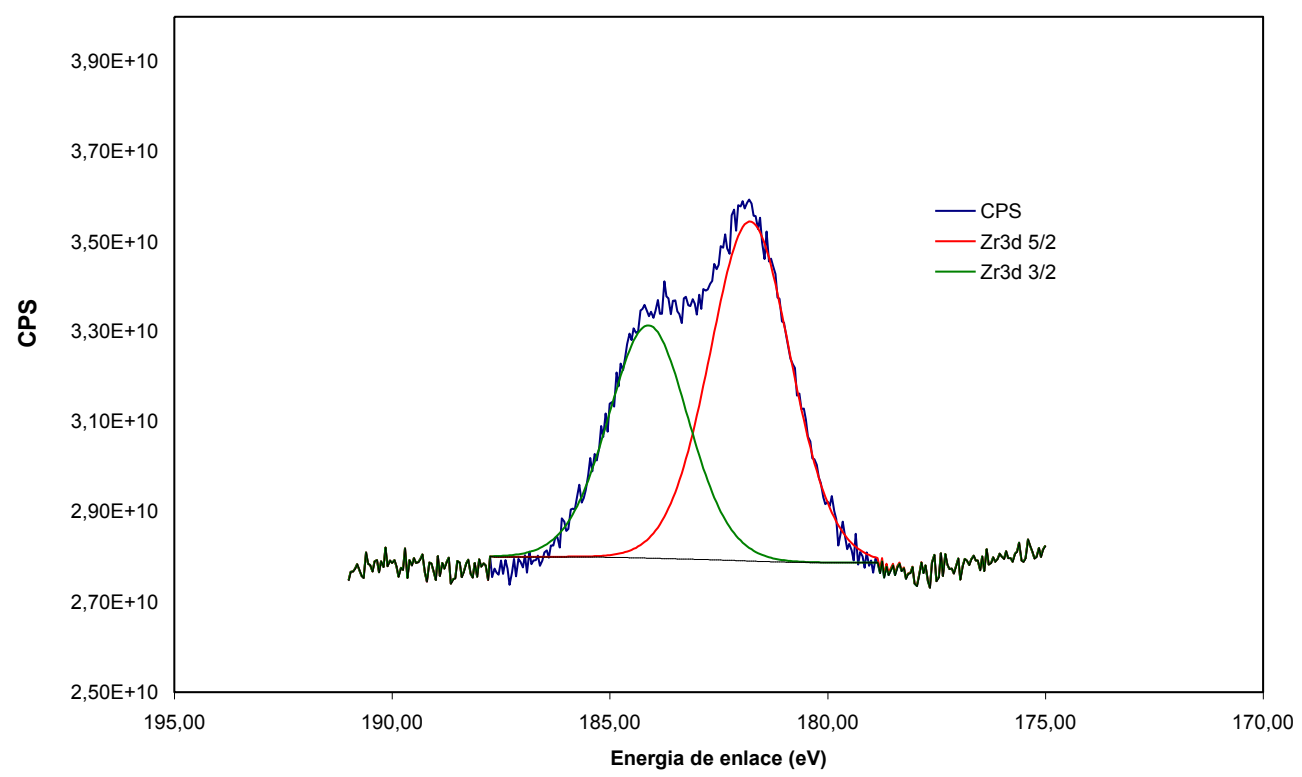

Figura AIII-14. Espectro XPS para los niveles $3 d_{3 / 2}$ y $3 d_{5 / 2}$ del Zr para el catalizador $\mathrm{PtNi} / \mathrm{CZA}$ usado 1 hora

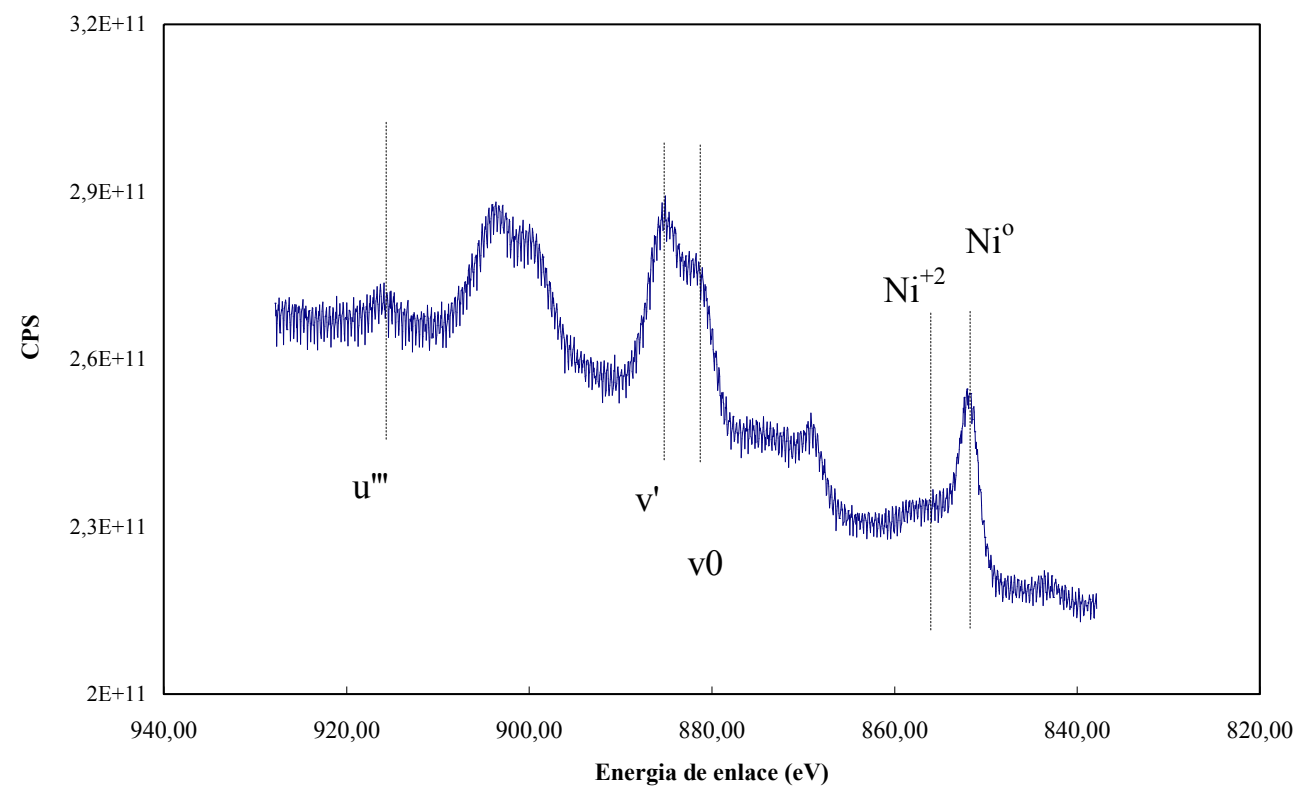

Figura AIII-15. Espectro XPS para los niveles Ce $3 d_{5 / 2}$ y Ce $3 d_{3 / 2}$ del Ce y para Ni $2 p_{3 / 2}$ para el catalizador PtNi/CZA fresco $\left(\mathrm{Ce}^{+3}: \mathrm{v}^{0} \mathrm{y} \mathrm{v}^{\prime} ; \mathrm{Ce}^{+4}: \mathrm{u}^{\prime \prime}{ }^{\prime}\right)$ 


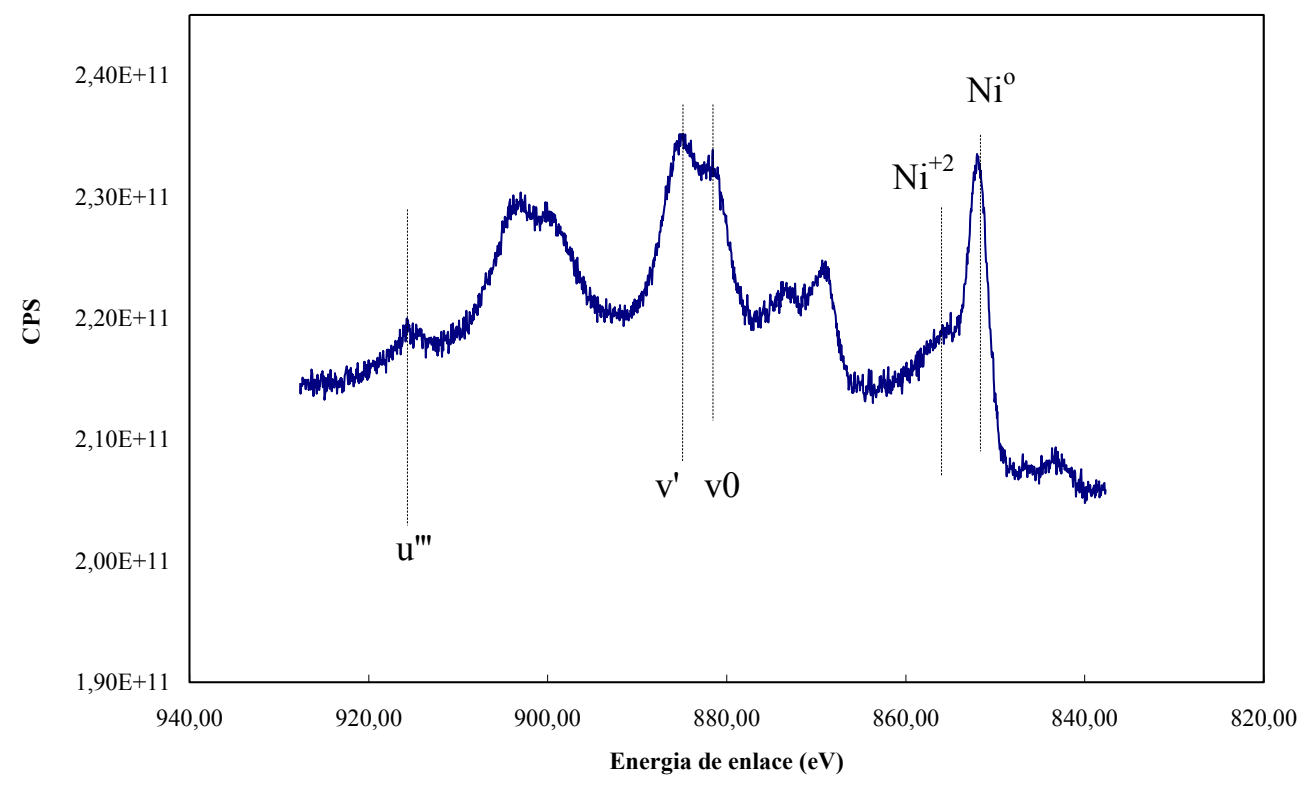

Figura AIII-16. Espectro XPS para los niveles Ce $3 \mathrm{~d}_{5 / 2}$ y Ce $3 \mathrm{~d}_{3 / 2}$ del Ce y para $\mathrm{Ni}$ $2 p_{3 / 2}$ para el catalizador PtNi/CZA usado 1 hora $\left(\mathrm{Ce}^{+3}: \mathrm{v}^{0} \mathrm{y} \mathrm{v}^{\prime} ; \mathrm{Ce}^{+4}: \mathrm{u}^{\prime \prime \prime}\right)$ 